\title{
HIGH-PERFORMANCE LIQUID CHROMATOGRAPHIC ENANTIOSEPARATION OF UNNATURAL $\beta$-AMINO ACIDS ON CHIRAL STATIONARY PHASES
}

László Sipos

Ph.D. Thesis

Szeged

2013 


\title{
HIGH-PERFORMANCE LIQUID CHROMATOGRAPHIC ENANTIOSEPARATION OF UNNATURAL $\beta$-AMINO ACIDS ON CHIRAL STATIONARY PHASES
}

\author{
László Sipos
}

Ph.D. Thesis

Supervisors:

Prof. Ferenc Fülöp, Ph.D., D.Sc.

Prof. Antal Péter, Ph.D., D.Sc.

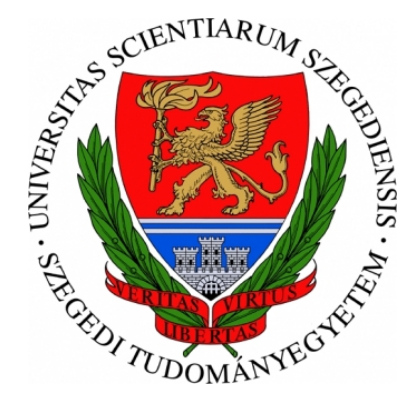

Institute of Pharmaceutical Chemistry, University of Szeged 2013 


\section{CONTENTS}

\section{Abbreviations and symbols}

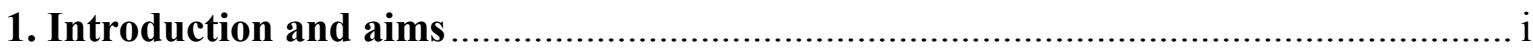

1.1. The history of liquid chromatography ............................................................. i

1.2. The biological importance of $\beta$-amino acids ........................................................ i

1.3. The significance of chirality ................................................................................ ii

1.4. Aims of this work ............................................................................................. iv

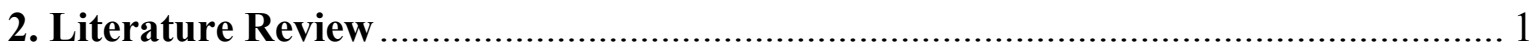

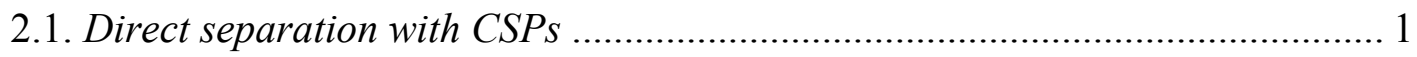

2.1.1. Protein-based CSPs ................................................................ 2

2.1.2. Donor-acceptor (Pirkle-type or brush-type) CSPs .......................... 2

2.1.3. Polymer-based CSPs .................................................................. 2

2.1.4. Macrocyclic antibiotic-based CSPs ................................................ 3

2.1.5. Cavity-type CSPs ....................................................................... 7

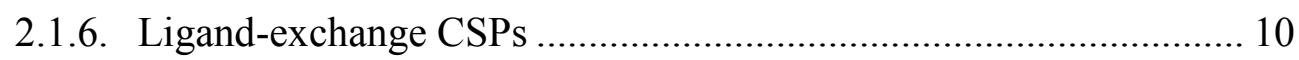

2.1.7. Molecular imprinted CSPs ........................................................ 11

2.2. Chemical and biological importance of monoterpene-based and isoxazolinefused 2-aminocyclopentanecarboxilic acids .................................................. 12

2.3. Thermodynamic principles of temperature dependence ................................... 12

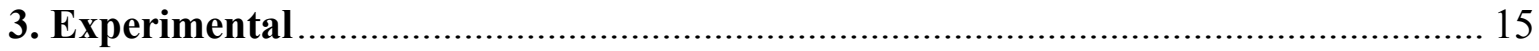

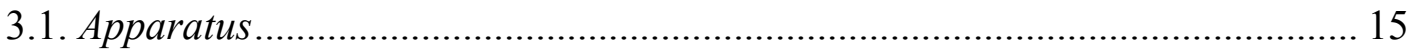

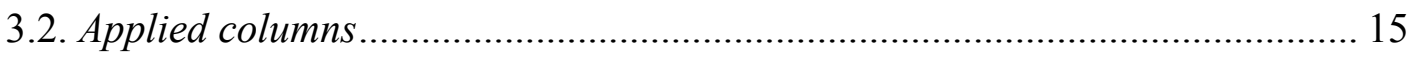

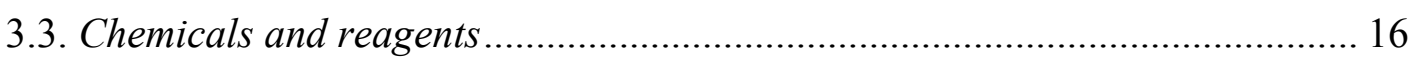

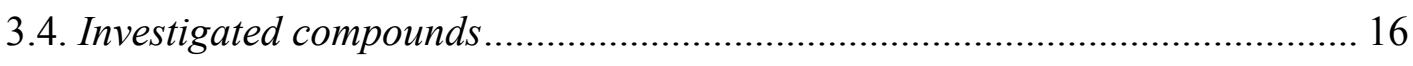

3.4.1. Monoterpene-based $\beta$-amino acids ............................................. 16

3.4.2. Isoxazoline-fused 2-aminocyclopentanecarboxylic acids................. 17

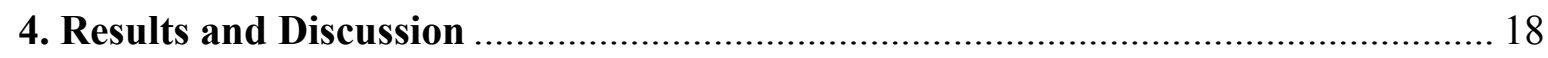

4.1. Separation of monoterpene-based $\beta$-amino acids on macrocyclic glycopeptide-

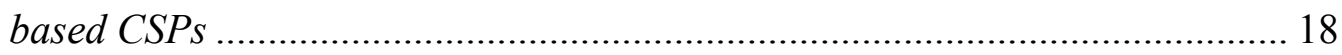

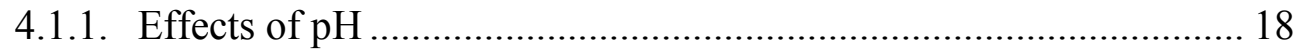

4.1.2. Effects of $\mathrm{MeOH}$ as alcohol modifier ............................................ 19

4.1.3. Influence of the structures of the compounds ................................ 22

4.1.4. Effects of temperature on the chromatographic parameters ........... 22 
4.2 Enantioseparation of isoxazoline-fused 2-aminocyclopentanecarboxylic acid analogues on macrocyclic antibiotic-based CSPS.

4.2.1. Effects of the nature of the mobile phase........................................ 27

4.2.2. Effects of the structures of the molecules ...................................... 31

4.2.3. Separation of four enantiomers of isoxazoline-fused cispentacin

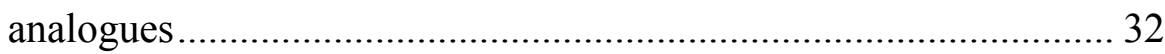

4.2.4. Effects of temperature on chiral recognition.................................. 32

4.3. Separation of isoxazoline-fused cispentacin stereoisomers on chiral crown

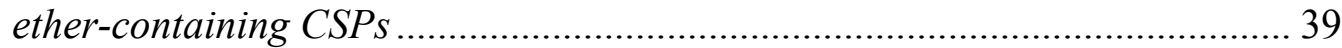

4.3.1. Effects of the nature and content of the alcoholic modifier ............ 39

4.3.2. Effects of the nature and content of the acidic modifier ................. 42

4.3.3. Effects of the structures of the analytes on chiral recognition ......... 44

4.3.4. Enantioseparation of four enantiomers of isoxazoline-fused

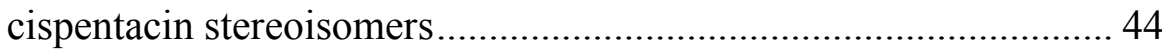

4.4. Comparison of macrocyclic antibiotic- and crown ether-based CSPs............ 45

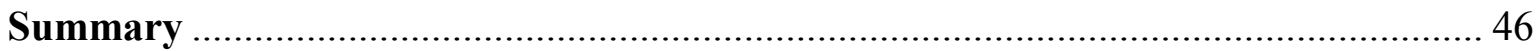

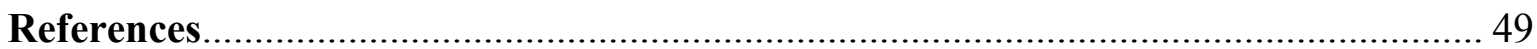

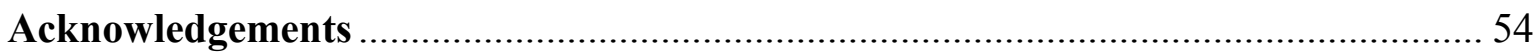

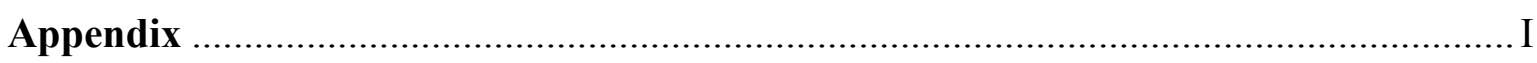




\section{Abbreviations and symbols}

$\begin{array}{ll}(v / v) & \text { volume to volume ratio } \\ \mathrm{AcOH} & \text { glacial acetic acid } \\ \mathrm{CD} & \text { cyclodextrin } \\ \mathrm{CF} & \text { cyclofructane }\end{array}$

Crown 1-3 (+)-(18-crown-6)-2,3,11,12-tetracarboxylic acid-based chiral stationary phase CSP chiral stationary phase

Et ethyl-

EtOH ethanol

$\mathrm{H}_{2} \mathrm{O} \quad$ Milli-Q water

$\mathrm{H}_{2} \mathrm{SO}_{4} \quad$ sulfuric acid

$\mathrm{H}_{3} \mathrm{PO}_{4} \quad$ phosphoric acid

$\mathrm{HClO}_{4} \quad$ perchloric acid

$\mathrm{HCOOH}$ methanoic acid

HILIC hydrophilic interaction chromatography

HPLC high-performance liquid chromatography

IPA 2-propanol

$\mathrm{Me} \quad$ methyl-

$\mathrm{MeOH}$ methanol

MIP molecular imprinted polymer

MIT molecular imprinted technology

$\mathrm{NaOH} \quad$ sodium hydroxide

NP normal-phase

$\mathrm{Ph} \quad$ phenyl-

PI polar-ionic

PO polar-organic

Pr propyl-

$\mathrm{PrOH}$ 1-propanol

$\mathrm{R} \quad$ ristocetin A-containing Chirobiotic ${ }^{\mathrm{TM}} \mathrm{R}$ column

RP reversed-phase

$\mathrm{T} \quad$ teicoplanin-containing Chirobiotic ${ }^{\mathrm{TM}} \mathrm{T}$ column

T2 teicoplanin-containing Chirobiotic ${ }^{\mathrm{TM}} \mathrm{T} 2$ column

TAG teicoplanin aglycone-containing Chirobiotic ${ }^{\mathrm{TM}}$ TAG column

TEA triethylamine

TEAA triethylammonium acetate

TFA trifluoracetic acid

V vancomycin-containing Chirobiotic ${ }^{\mathrm{TM}} \mathrm{V}$ column

VAG vancomycin aglycone-containing Chirobiotic ${ }^{\mathrm{TM}}$ VAG column

$k^{\prime} \quad$ retention factor; defined as $\left(t_{R^{-}} t_{0}\right) / t_{0} ; t_{R}$, retention time; $t_{0}$, column dead-time

$\alpha \quad$ separation factor; defined as $k_{2}^{\prime} / k_{1}^{\prime} ; 1$ : first- and 2: second-eluting peak

$R_{S} \quad$ resolution; defined as $2\left(t_{R 2}-t_{R 1}\right) /\left(w_{1}+w_{2}\right) ; w$, peak width measured on the baseline 


\section{INTRODUCTION AND AIMS}

Chromatography has been defined as follows:

Chromatography is a separation process that is achieved by distributing the components of a mixture between two phases: a mobile phase and a stationary phase.

\subsection{The history of liquid chromatography}

The process of liquid chromatography was discovered in the 1890s by the Russian botanist $T$ swett, who used it to separate and isolate various plant pigments. This was in fact liquid-solid chromatography, which was the first type of chromatography [1]. The coloured bands he produced on the adsorbent bed evoked the term chromatography for this type of separation.

In 1913, Tswett's experiment was repeated by Willstatter and Stoll, but they used an aggressive adsorbent, and consequently the chlorophylls were decomposed [2].

Martin and Synge achieved a variant of liquid-liquid chromatography in the late 1930s and early 1940s. Some acetyl amino acids were separated on silica gel and in 1941 their work was published [3]. In that publication, they offered a suitable gas instead of the liquid mobile phase, to accelerate the transfer between the mobile and stationary phases, when the separation may be more effective. With this suggestion, the basis of gas chromatography was created. Also in that paper, Martin and Synge recommended the application of high pressures and small particles in liquid chromatography in order to reach a better separation. This was the beginning of the development of high-performance liquid chromatography (HPLC).

Nowadays, HPLC (like other chromatographic techniques) is an extremely versatile technique with which to separate chemical materials (or enantiomers in chiral chemistry) and also to purify medical agents, for example, from impurities.

\subsection{The biological importance of $\beta$-amino acids}

$\beta$-Amino acids occur in greater diversity than $\alpha$-amino acids, and have therefore received increased research attention. Because of their unique biological, neurological and pharmaceutical activities, unnatural amino acids are utilized as building blocks, molecular scaffolds, conformational constraints, or pharmacologically active products [4,5]. $\beta$-Amino acids are key components of numerous bioactive molecules, such as peptides, alkaloids or 
$\beta$-lactam antibiotics. They are used as precursors for antibiotics [6] and building blocks in cryptophycins $[7,8]$. They are known to be receptor antagonists, enzyme inhibitors and also components of naturally occurring compounds, e.g. taxol, one of the most active antitumour agents, which contains phenylisoserine as its side-chain. They exhibit hypoglycaemic and antiketogenic activities in rats [9].

They represent a nearly infinite array of diverse structural elements for the development of new leads in peptidic and non-peptidic compounds, and $\beta$-amino acids are therefore also target compounds in the preparation of peptidomimetics. Novel short-chain peptide ligand mimetics with both enhanced biological activity and proteolytic resistance are drug candidates in today's R\&D pipelines of pharmaceutical companies. Optimized and fine-tuned analogues of peptidic substrates, effectors or inhibitors are also excellent analytical tools for the investigation of signal transduction pathways or gene regulation [10-12].

In the past few years, interest in $\beta$-peptides and $\beta$-amino acid-containing oligomers has increased in medical chemistry, because they display marked biological activity and extreme biological stability [13]. An important aspect of biologically active peptides is their ability to fold into compact helices and turn and pleated sheet conformations in solution [14-17]. An understanding of the biologically active conformations of peptide hormones is an important goal in modern biology. A cyclic $\beta$-tetrapeptide was recently synthetized with biological activity similar to that of somatostatin, an important endogenous neurotransmitter and inhibitor of hormone secretion [18]. Systematic replacement of an $\alpha$-amino acid by a $\beta$-amino acid residue resulted in a hybrid oligopeptide which binds to major histocompatibility complex proteins, while exhibiting increased stability towards proteolysis [19-21].

\subsection{The significance of chirality}

If an organic molecule has an asymmetric centre and all four ligands of the carbon atom are different from each other, then the molecule is asymmetrically chiral. A molecule may also demonstrate axial, planar or inherent chirality. If these molecules are superimposed on their mirror image and their physicochemical properties (melting point, boiling point, density, solubility, etc.) are equal, they are called enantiomers. They can rotate plane-polarized light (+/-) by equal amounts but in opposite directions, so they are optically active molecules. A mixture composed of equal proportions of them is termed a 
racemic mixture or racemate and exhibits zero net rotation of plane-polarized light. If molecules have two or more chiral centres, they do not have a mirror image and their physical and chemical properties are different; they are termed diastereomers.

The interest in chirality and chiral effects increased in the past decade, due to demands of biology, medicine, the pharmaceutical and food industries etc. [22]

In nature, most substances with biological and pharmacological effects are chiral, e.g. amino acids, sugars, proteins and nucleic acids. In living systems, pharmaceutical molecules react with asymmetric biological macromolecules in the course of physical and chemical processes. This chiral environment can discriminate the enantiomers because the biological properties of the enantiomers, such as protein transport and binding, their stability in the environment and the kinetics of their metabolism, are different [23-25].

One of the enantiomers is often the more active stereoisomer for a given action (eutomer), while the other, less active one (distomer) may either contribute side-effects, display toxicity or act as an antagonist [26-28].

Naturally, there are some opposite cases, such as the example of two enantiomers of Ibuprofen, whose spectra of activity and effect are equal, but the rates of uptake in the organism may be different [29].

An unfortunate example of the latter situation was the case of Thalidomide [30]. In the 1960s, racemic Thalidomide was given to pregnant women to inhibit nausea. While the $R$ isomer was a eutomer and was well applicable against nausea, the $S$ isomer was teratogenic, which caused defects in the embryos. It was later discovered, that the $R$ enantiomer racemizes in living systems to from the $S$ isomer. Thalidomide was therefore banned.

Consequently, discrimination of the enantiomers of medical agents is currently a very important task. Either stereoselective synthesis or chromatographic enantioseparation are applied. In a valid case, use of a racemate is allowed by the US Food and Drug Administration (FDA), but a full scale of clinical and toxicological investigations of the two enantiomers and the racemate is required [31,32]. However, the manufacture of chirally pure compounds is generally cheaper for the pharmaceutical firms. 


\subsection{Aims of this work}

The primary aim of this work was to investigate the chiral separation of two types of $\beta$-amino acids on two different chiral stationary phases (CSPs), macrocyclic glycopeptides and crown ether-based CSPs.

1. The enantioseparation of monoterpene-based $\beta$-amino acids was investigated on macrocyclic glycopeptide-based CSPs such as teicoplanin, ristocetin A and vancomycin-based columns. The influence of the $\mathrm{pH}$, the mobile phase composition, the structures of the molecules, the sugar moieties of the selectors and temperature on the chiral recognition was examined.

2. The enantioseparation of isoxazoline-fused 2-aminocyclopentanecarboxylic acid analogues on macrocyclic antibiotic-based CSPs was studied, with the aim of developing new chromatographic methods for their chiral separation. For this purpose, the method was optimized by changing the chromatographic conditions $(\mathrm{pH}$, mobile phase composition, temperature, etc.).

3. For the enantioseparation of isoxazoline-fused 2-aminocyclopentanecarboxylic acid analogues new types of crown ether-based selectors were used. With variation of the chromatographic conditions, the goal was to determine the main interactions which contribute to chiral recognition. The effects of the nature of the spacer used for the immobilization of the selector was also studied.

4. The separation efficiencies of the two types of CSPs were compared on the basis of the chromatographic data obtained for isoxazoline-fused 2aminocyclopentanecarboxylic acid analogues.

In all measurements, the chromatographic parameters (retention factors, selectivity factors and resolutions) were determined; in the case of the temperature dependence, the thermodynamic parameters were collected. 


\section{LITERATURE REVIEW}

The physical and chemical properties of enantiomers are equal, and their discrimination in the past was therefore too difficult. For the discrimination of enantiomers, a chiral environment is required. Chiral separation is achieved with two methods in chromatography.

The first is indirect separation, which is based on the formation of diastereomeric derivatives through use of a chiral derivatizing agent. The diastereomers formed can be separated on achiral stationary phases because their physico-chemical properties are different.

The easiest way to achieve enantioseparation is direct separation, which involves two methods: either the addition of a chiral mobile phase additive and separation of the enantiomers on an achiral stationary phase or the more elegant and convenient application of CSPs, where the chiral selector is adsorbed or chemically bonded to a silica support.

In this study, the direct method was used with the application of CSPs.

\subsection{Direct separation with CSPS}

The three-point contact model is the most reliable model which has sufficient requirements to satisfy the chiral recognition (Fig. 1). It was suggested by Dalgliesh [33], who discussed that three interactions have to predominate between the analyte and the CSP. Pirkle and Pochapsky complemented this theory in that one of them has to be stereoselective [34]. This model can still be used also today for most of the chiral separation principles.

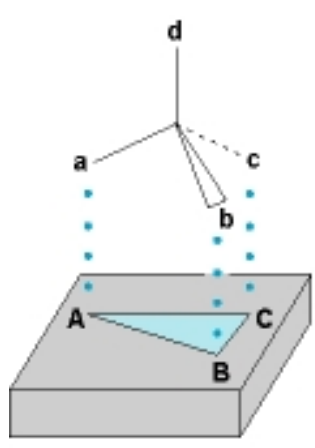

(a)

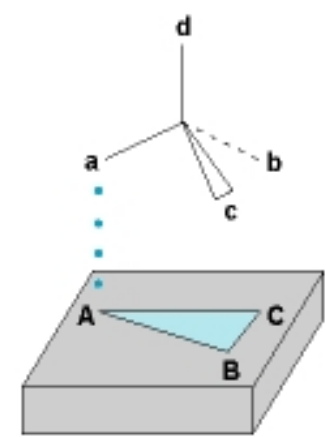

(b)

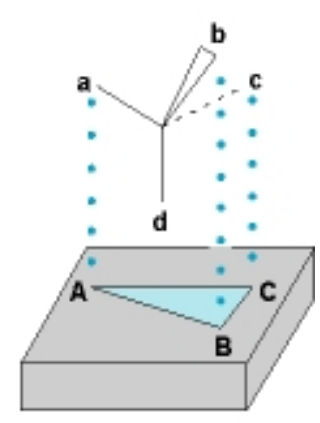

(c)

Figure 1. Explanation of the three-point model 
The preparation of chiral columns was a significant milestone in the 1980s. Since that period, a large number of various types of CSPs have been created, which are grouped according to the type of their selectors as follows: protein-based, Pirkle- or brush-type, polymer-based, macrocyclic glycopeptide-based, cavity-type, ligand-exchange and molecular imprinted CSPs.

\subsubsection{Protein-based CSPS}

In these stationary phases, natural proteins are bonded to a silica support. Bovine serum albumin was initially applied as CSP for the enantioseparation of $\alpha$-amino acids by Stewart et al. in 1973 [35]. Protein-based CSPs have a large number of chiral centres and interact strongly with small compounds through the dipole-dipole, H-bonding and hydrophobic interactions. The ionic strength and naturally the $\mathrm{pH}$, the concentration and nature of the organic modifier are known to influence the retention and resolution.

There are various protein groups in protein-based CSPs, such as albumins, glycoproteins and enzymes. In the past few decades, there have been many publications involving all types of protein-based CSPs [36].

\subsubsection{Donor-acceptor (Pirkle-type or brush-type) CSPS}

These CSPs contain neutral synthetic chiral low molecular mass selectors. William H. Pirkle was the pioneer in the development of brush-type CSPs at the end of the 1970s [37]. They are known to be able to activate donor-acceptor interactions (face-to-face or face-to-edge $\pi$ - $\pi$ interactions and H-bonding) and dipole-dipole stacking in normal-phase (NP) mode. An aromatic ring ensures the $\pi-\pi$ interactions, and acidic and basic sites may participate in intermolecular H-bonding interactions.

The $\pi$-acidic and $\pi$-basic-type Pirkle CSPs are well applicable for the separation of alcohols, thiols, aromatic acids and their derivatives [38-41].

\subsubsection{Polymer-based CSPS}

The selectors of these CSPs are mainly cellulose or amylose. The cellulose-based CSPs have a rigid, linear form, whereas amylose is helical. The interactions evolving between the CSP and the analyte are H-bonding, $\pi-\pi$ and dipole-dipole interactions. The hydroxy groups on three carbon atoms of the saccharide ring can be modified by ester or carbamate formation. 
The first racemate resolution was reported in 1951, by Kotake et al. [42]. They resolved amino acids on polysaccharide-containing papers. Hesse and Hagel considered microcrystalline cellulose triacetate as a polymeric selector in 1976 [43]. Okamoto et al. attempted to enhance the enantioselectivity by coating a macroporous aminopropylsilica gel with microcrystalline cellulose triacetate [44,45], and recognized that the enantioselectivity can also increase if the hydroxy group, of the polysaccharide are substituted. Coated polysaccharide CSPs had some disadvantages. Some solvents (i.e. $\mathrm{CH}_{2} \mathrm{Cl}_{2}$, EtOAc, THF, dioxane, etc.) are incompatible with polysaccharides because they are physically adsorbed on silica, so these solvents swell and/or dissolve the CSP in NP mode. In 1987, Okamoto et al. covalently bonded a polysaccharide to aminopropylsilica gel, which was the first immobilized polysaccharide-based CSP [46].

Modified polysaccharide-based CSPs were recently used to separate various types of compounds, such as aromatic ring-containing racemic compounds [47], acidic drugs [48], neutral pharmaceuticals [49], aminonaphthol analogues [50,51] and $\beta$-lactam derivatives [52].

\subsubsection{Macrocyclic antibiotic-based CSPS}

The study of antibiotics started in 1928, when the antibacterial action of penicillin was discovered by A. Fleming. In 1953, the first macrocylic antibiotic, vancomycin, was isolated by E. Kornfeld from a soil sample [53]. Vancomycin was also extracted from Amycolatopsis orientalis [54]. This was the beginning of the discovery of more than 100 macrocyclic antibiotics. They exert biological activity to block the synthesis of the cell wall of Gram(+) bacteria, but they have no effect on Gram(-) bacteria [55]. All of them contain an aglycone unit (which forms a characteristic basket shape) and some sugar moieties (except for the aglycone derivaties). Their molecular masses are in the range 1100-2100 Da.

These natural molecules were introduced as CSPs by Armstrong in 1994. This was one of the most significant turning-points in chromatography. Armstrong recognized that the several chiral centres and interactive points of macrocyclic antibiotics may be suitable for interaction with a variety of different compounds [56].

These macromolecules were divided into four subclasses: ansamycins, glycopeptides, polypeptides and aminoglycosides. As regards chromatography, the most significant is the subclass of glycopeptides. Since 1994, hundreds of publications have 
appeared on the applications of glycopeptides: vancomycin, teicoplanin, ristocetin A, avoparcin and their aglycone derivaties.

They contain numerous funcional groups, and therefore all kinds of interactions can occuer, such as hydrophobic, $\pi-\pi$, dipole-dipole interactions, H-bonding, steric repulsion and ionic or charge-to-charge interactions. Macrocyclic glycopeptides can be used in NP, reversed-phase (RP), polar-organic (PO) and also polar-ionic (PI) mode.

Vancomycin (Fig. 2) was the first discovered glycopeptide. It is produced by Streptomyces orientalis and Amycolatopsis orientalis. Vancomycin has 18 stereogenic centres. It has two major parts. The aglycone basket is produced from three macrocyclic parts containing five aromatic rings. It may be hypothesized that this portion is involved in hydrophobic and $\pi$ - $\pi$ interactions.

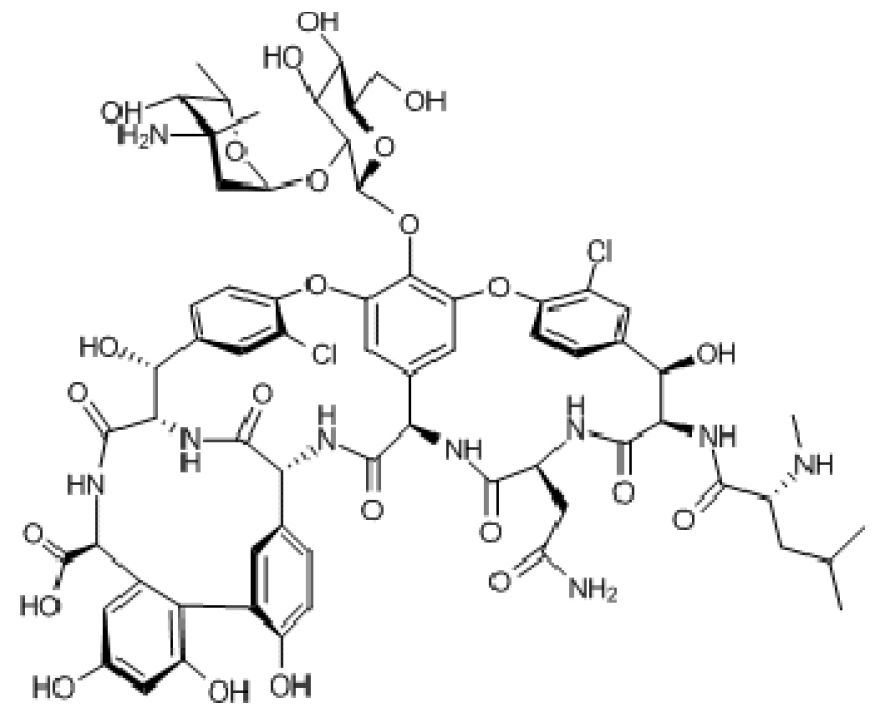

Figure 2. The structure of vancomycin

Two of the aromatic rings have chlorine substituents, which have a $\pi$-acidic character and play a part in the formation of H-bonds. The nine hydroxy groups also contribute the formation of H-bonds. There are also primary, and secondary amino and carboxylic acid groups, which are responsible for ionic interactions. The aglycone portion bears two sugar moieties, which may be responsible for steric effects [57].

Vancomycin aglycone is a derivative of vancomycin which lacks the disaccharide units (Fig. 3). The lack of sugar units in some cases increases the enantioselectivity and resolution [58]. 


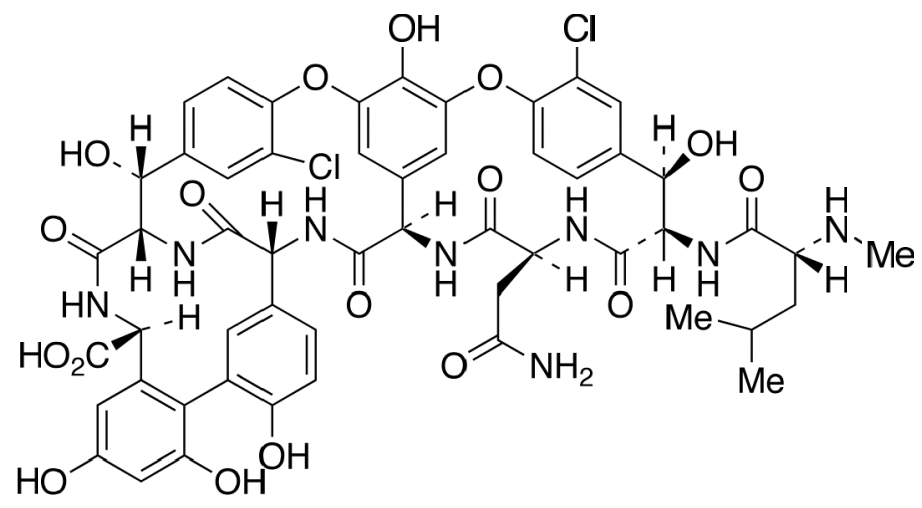

Figure 3. Vancomycin aglyone

Teicoplanin, produced by Actinoplanes teicomyceticus, is active against anaerobic and aerobic Gram(+) bacteria [59]. It has an aglycone including four macrocyclic rings, three sugar units and a hydrocarbon chain.

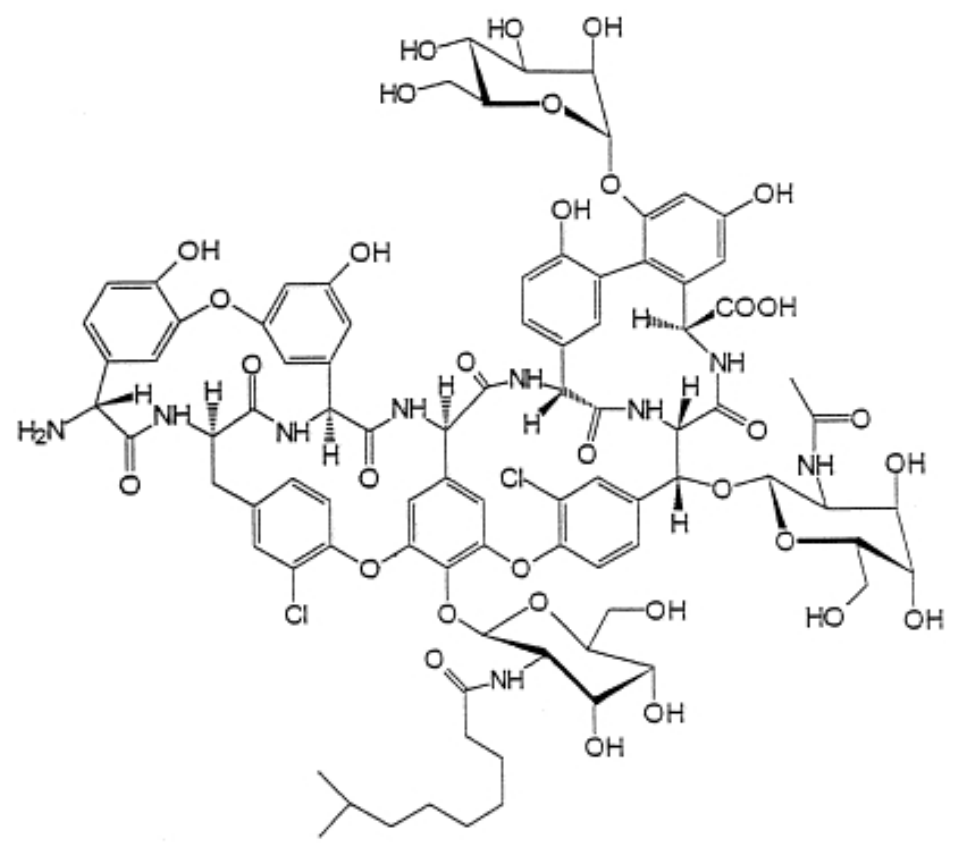

Figure 4. Stucture of teicoplanin $\mathrm{A}_{2}-2$

Natural teicoplanin consists of five derivatives, which differ only in the length of the hydrocarbon chain. The main component of the teicoplanin complex is $\mathrm{A}_{2}-2$ (Fig. 4), with 23 stereogenic centres.

The macrocyclic rings contain seven aromatic rings, which able to form $\pi-\pi$ interactions with the analyte. Two of them are chloro-substituted and four of them contain ionizable phenolic moeties. The aglycone basket consists of primary amino $\left(\mathrm{pK}_{\mathrm{a}}=9.2\right)$ and carboxylic acid $\left(\mathrm{pK}_{\mathrm{a}}=2.5\right)$ groups. These two groups are the basis of ionic interactions, which is characteristic of all of the CSPs. The three carbohydrate units are D-mannose, D- 
$\mathrm{N}$-acetylglucosamine and D- $N$-acylglucosamine. The teicoplanin CSP is more surfaceactive than other glycopeptides, because of the hydrophobicity of D-N-acylglucosamine, caused by a hydrocarbon chain [60].

The first publications on the use of teicoplanin as a CSP appeared in 1995 [61]. In the past few years, mostly teicoplanin-containing CSPs have been applied. They are able to separate amino acids and their derivatives [62-64], peptides [65,66], mandelic and lactic acid derivatives, non-steroidal anti-inflammatory drugs and $N$-blocked amino acids [67], indole-based amino analogues [68], $\beta$-blocker drugs [69], amino alcohols [70], etc.

Teicoplanin aglycone was synthetized from native teicoplanin (Fig. 5). It contains the same heptapeptide backbone as teicoplanin, but it lacks the sugar units. Berthod et al. recognized that the carbohydrate units are not necessary for the enantioresolution of common $\alpha$-amino acids [71]. The cleft near the ureido terminal of the aglycone basket is an important part of the receptor site for amino acid recognition. Amino acids have easier access to this site on the aglycone, which produces much higher enantioselectivity and resolution factors for these compounds relative to those achieved on a Chirobiotic $\mathrm{T}$ column. However, Péter et al. have published mainly opposite results as concerns $\beta^{3}$ homoamino acids [64].

The phenolic and alcoholic hydroxy groups are protected by these carbohydrate moieties blocking the formation of possible interactions. However, further interactions may occure with the sample molecules through the alcoholic, ether and amide groups and the nonyl chain of the sugar unit.

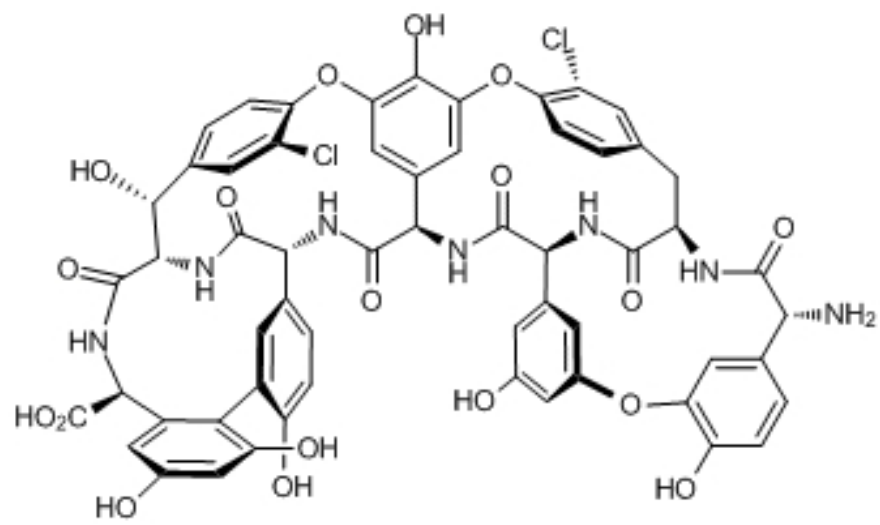

Figure 5. Structure of teicoplanin aglycone 
In the past decade numerous publications have reported that in many cases teicoplanin aglycone is more efficient in enantiorecognition than the sugar-containing teicoplanin [72-74].

The most polar macrocyclic glycopeptide is ristocetin A (Fig. 6) with 21 hydroxy groups. It is produced by Proactinomyces fructiferi and Nocardia lurida [75]. It is an important molecule in biochemistry. Ristocetin A selectively bonds to the D-Ala-D-Ala sequence to influence cell wall synthesis [76]. It has 38 stereogenic centres, seven aromatic rings and six sugar moieties. Two of the latter are D-mannose, one D-glucose, one Lristosamine, one L-rhamnose and one D-arabinose. Its aglycone contains four macrocyclic rings, two amino groups and a carboxymethyl group, and it therefore interacts weakly with cationic compounds.

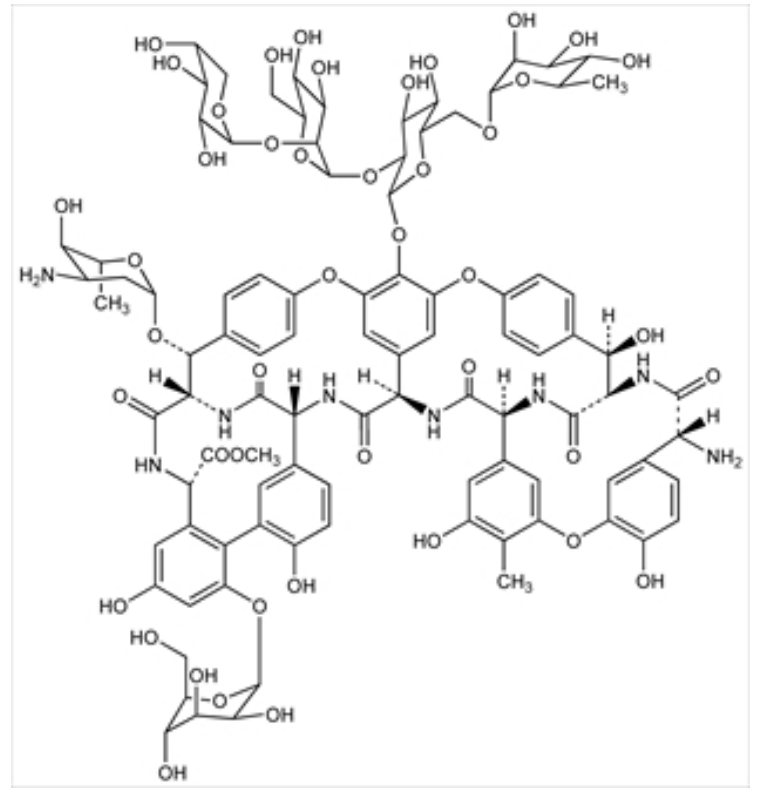

Figure 6. Structure of ristocetin A

Ristocetin A acts well as a selector to separate the enantiomers of $\alpha$-amino acid and their derivatives with free carboxylic acid moeties in capillary electrophoresis [77], $\mathrm{N}$ blocked amino acids [78], some synthetic amino acid analogues [79,80], peptides [80,81] and hydroxyl group-containing $\beta$-amino acids [74].

\subsubsection{Cavity-type CSPS}

Within cavity type-CSPs, three different groups are discriminated: cyclodextrin (CD)-based, crown ether-containing and cyclofructan (CF)-based CSPs. 
CD-based CSPs were introduced by Armstrong and DeMond [82]. Three types of CDs are well known in chromatography: $\alpha-, \beta$ - and $\gamma$-CDs with six, seven and eight glucose moieties connected via an $\alpha$-1,4-linkage to the silica surface. The CDs inside the cavity are hydrophobic due to the carbon backbone of the sugar units, while the upper and lower ones are hydrophilic due to the hydroxy-groups. They can be used in NP, RP, PO or PI mode.

CD is one of the most popular selectors in chiral separation. These CSPs have proved useful for the resolution of coumarin derivatives [83], flavonones and flavonone glycosides by nano-liquid chromatography [84], $\beta$-lactams [85], chiral drugs [86] and unnatural $\beta$-amino acids [87].

Chiral crown ether-containing CSPs are another group of the cavity types. Crown ethers were introduced by Pedersen in 1967 [88]. Cram and Sogah immobilized bis-(1,19binaphthyl)-22-crown-6 on silica gel by preparing the first crown ether-based CSP in 1979, and the separations of various amino acids were investigated on it [89]. In 1987, 1,19binaphthyl-20-crown-6 was coated on octadecylsilica gel by Shinbo et al., who used this material as CSP to separate D,L-amino acids [90,91]. The importance of crown ether-based CSPs was increased when (+)-(18-crown-6)-2,3,11,12-tetracarboxylic acid was covalently bonded to silica gel by Macchida [92].

Sawada et al. demonstrated the importance of the ether bond in the crown ether ring with the FAB/MS technique. They replaced two ether bonds with two aromatic rings, but this was not effective for chiral recognition [93].

After Machida [92], (+)-(18-crown-6)-2,3,11,12-tetracarboxylic acid was covalently bonded to a modified aminopropylsilica support (Fig. 7) by Hyun et. al. [94]. With this crown ether, quinolone antibiotic enantiomers (primary and secondary amine compounds) were resolved by Behr et al. [95].

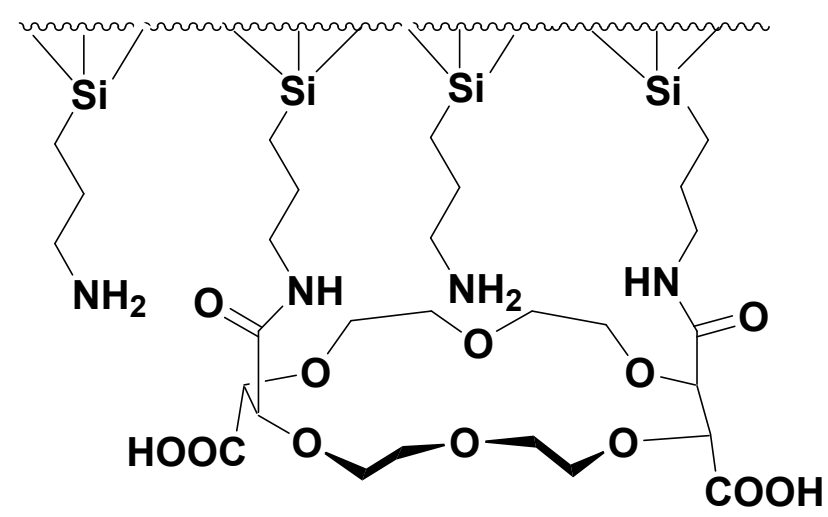

Figure 7. (+)-(18-Crown-6)-2,3,11,12-tetracarboxylic acid bound to silica gel (Crown 1) 
Later, the separations of racemic natural and unnatural $\alpha$-amino acids, $\alpha$-amino esters and amides were reported by Hyun et al. [96]. The separation of amino acids was successful, except in the case of proline, whereby it was concluded that the lack of a primary amino group is impedes the formation of an ammonium ion-crown ether complex.

With this type of selector, one of the most essential interactions is the formation of an ammonium ion-crown ether complex between the selector and the protonated primary amine analyte (Fig. 8 ). Therefore, an acidic modifier should be added to the mobile phase to protonate the primary amino group of the analyte. Besides these interactions, Hbonding, dipole-dipole, hydrophobic, steric, etc. interactions similarly mean advantages.
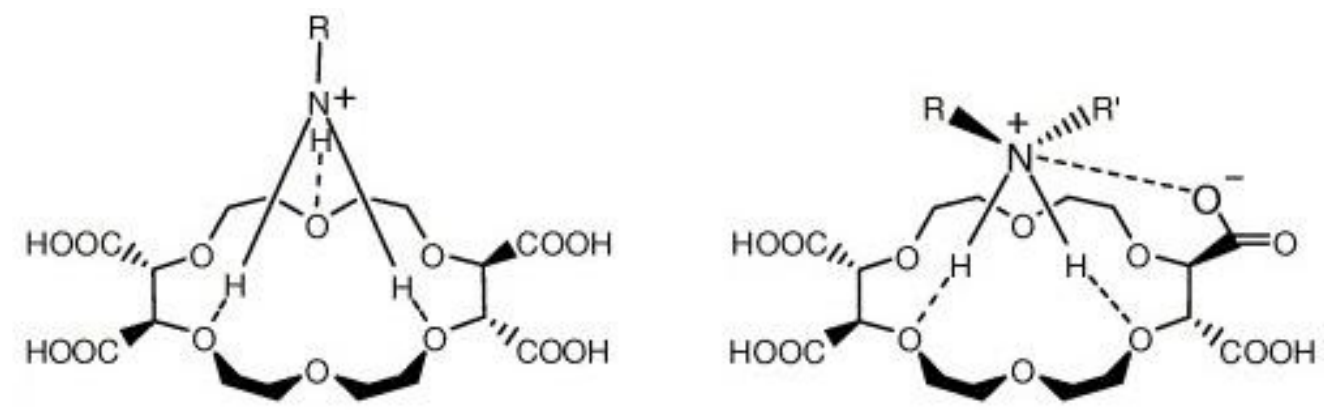

Figure 8. Presumed structures of crown ether-ammonium ion complex

Lee et al. [97] reported that the high enantioselectivity of this type of CSP for $\alpha$ amino acids was due to the H-bonding between one carboxylic acid in the CSP and a carbonyl group oxygen in the amino acids.

In 2001, Hyun et al. modified the previously synthetized (+)-(18-crown-6)2,3,11,12-tetracarboxylic acid-containing CSP, but there was not a major change in chiral recognition (Fig. 9) [98].

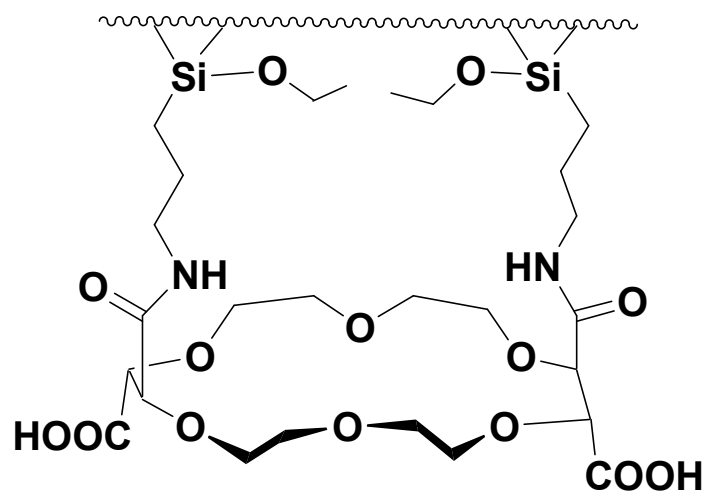

Figure 9. The modified crown ether-containing selector (Crown 2)

The properties of the spacer were investigated by Hyun [99]. The (+)-(18-crown-6)2,3,11,12-tetracarboxylic acid was covalently bonded to the silica surface through an 
aminoundecyl group (Fig. 10). With this more apolar and more flexible selector, the resolution increased in the case of less hydrophilic $\beta$-amino acids, amines and amino alcohols, but not in the case of $\alpha$-amino acids.

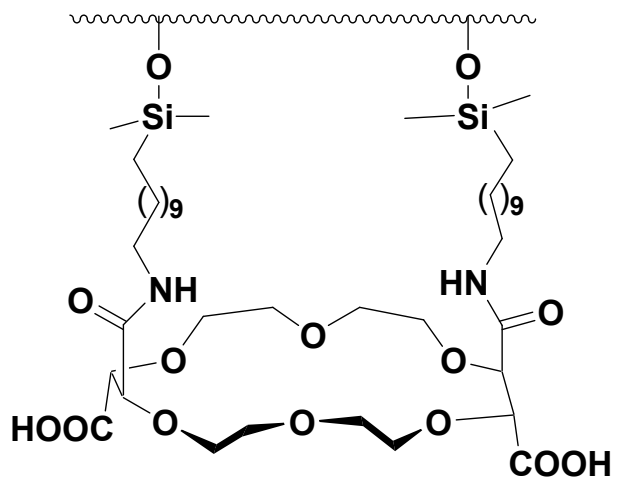

Figure 10. The selector bonded to silica gel through an aminoundecyl chain (Crown 3)

Recently, many publications have appeared on the synthesis of 1,1'-binaphthyl unit-containing and phenolic pseudo crown ether CSPs. With these, primary and secondary amino compounds $[100,101]$, enantiomers of fluoroquinolones including gemifloxacin (a chemotherapeutic reagent for various infections) [102], some $\alpha$ - and $\beta$-amino acids [103105], di- and tripeptides [106], amino alcohols [107] and chiral drugs with free primary amino groups [108] were resolved.

CF-based stationary phases are a new class of cavity-type CSPs. The CFs that contain six, seven or eight $\beta$-(2,1)-linked D-fructofuranose moieties are named CF6, CF7 and CF8. These sugar units contain four stereogenic centres and three hydroxyl groups, and the central core has the same structure as in crown ethers. The first CF-based stationary phases containing six D-fructofuranose units (CF6) were introduced by Armstrong in 2009 [109]. Isopropyl carbamate-functionalized CF6 was able to separate enantiomers of Betti base analogues [110], amino acids, amino acid amides, esters and alcohols [111], and nucleic acids and nucleosides in HILIC mode by Qui et al. [112].

\subsubsection{Ligand-exchange CSPS}

Ligand-exchange chromatography was developed in the early 1970s by Davankov and Rogozhin [113] and proved effective in the separation of amino acids. This was the first enantioselective liquid chromatographic technique. Proline as selector was immobilized onto a polystyrene surface, in combination with $\mathrm{Cu}(\mathrm{II})$ ions in the mobile phase. The principle of ligand exchange is complex formation with a metal ion [Cu(II), 
$\mathrm{Zn}(\mathrm{II})$ or $\mathrm{Ni}(\mathrm{II})]$ between the analyte enantiomers to be resolved (containing electrondonating functional groups such as hydroxy, amino, amido, thio, carboxyl, etc.) and the chiral selector. Ligand-exchange CSPs have been employed to separate proline [114] and cysteine derivatives [115] and also amino alcohols [116,117].

Hyun et al. [117,118] prepared new ligand-exchange CSPs based on $(S)-N, N$ carboxymethyl undecyl leucinol monosodium salt and on $(R)-N, N$-carboxymethyl undecyl phenylglycinol monosodium salt selectors. In the resolution of $\beta$-amino acids, the latter was always much better than the former in terms of both the separation factor $(\alpha)$ and resolution $\left(R_{S}\right)$. The chromatographic behaviour depended on the $\mathrm{Cu}(\mathrm{II})$ concentration and the content of the organic modifier.

\subsubsection{Molecular imprinted CSPS}

These stationary phases are of template type, which ensures high enantioselectivity. Through molecular imprinting technology (MIT), the target molecule is copolymerized, and the template is removed from the polymer by solute extraction, resulting in the exact polymerized shape of the enantiomers. One of the pioneers of MIT was Mosbach [119121], and Wulff investigated antibodies [122]. Among others, $(S)$-ipuprofen- [123] and (S)propranolol-based [124] molecular imprinted polymers (MIP) were prepared by Haginaka et al. Alanine and serine were separated on L-alanine- and L-serine-based MIPs [125]. Zhang et al. used one of the most important host molecules, CDs, to prepare MIPs [126]. Moreover, Silva et al. [127] applied supercritical $\mathrm{CO}_{2}$ technology to prepare MIPs to separate tryptophan enantiomers.

In summary, a survey of the literature on the CSPs from the aspect of the enantioseparation of protein and unusual amino acids reveals that only few of them can be taken into consideration. The most popular and useful CSPs for the separation of amino acids and their analogues are macrocyclic antibiotic- and crown ether-based phases. However, the latter can be used only for amino acids containing primary amino groups. Applications of CD-type CSPs generally need derivatization with a derivatizing agent containing an aromatic group with $\pi$-acidic or $\pi$-basic character. The same holds for the application of Pirkle-type and polysaccharide-based phases. 


\subsection{Chemical and biological importance of monoterpene-based and} isoxazoline-fused 2-aminocyclopentanecarboxylic acids

Naturally occurring $\beta$-amino acid cispentacin, icofungipen and oryzoxymycin are bioactive compounds with antibacterial and antifungal properties. Icofungipen disturbs the biosynthesis of protein in Candida albicans.

Enantiomerically pure $\alpha$-pinene, $\delta$-pinene and 3 -carene can be transformed into $\beta$ amino acid derivatives, which are excellent building blocks for the synthesis of monoterpene-fused saturated 1,3-heterocycles. Apopinane-based $\beta$-amino acids were used as building blocks in the construction of stable H12 foldameric helices and in Ugi fourcentre three-component reactions.

Amino acids containing an isoxazoline moiety have revealed anti-influenza activities and antifungal properties. Several isoxazole carboxylic acids, such as conformationally constrained aspartate and glutamate analogues, have been reported as enzyme inhibitors or agents possessing neuroprotective activities. Isoxazoline-fused amino acids have served as important precursors for the synthesis of novel multisubstituted cyclopentene derivatives with antiviral activities.

\subsection{Thermodynamic principles of temperature dependence}

Enthalpy, a measure of the total energy of a thermodynamic system, is defined as:

$$
H=U+p V
$$

where

$$
\begin{aligned}
& U=\text { internal energy } \\
& p=\text { pressure } \\
& V=\text { volume }
\end{aligned}
$$

In classical thermodynamics, entropy is defined by the second law of thermodynamics, which states that the entropy of an isolated system always increases or remains constant. Thus, entropy is also a measure of the tendency of a process:

$$
d S \geq 0
$$

Enthalpy $(H)$ and entropy $(S)$ can describe a state where both reactants and products are in standard state, called standard reaction enthalpy / reaction entropy. 
The position of equilibrium depends on the temperature and pressure in the system. In thermodynamics, Gibbs free energy $(G)$ is a thermodynamic potential that measures the useful or process-initiating work obtainable from a thermodynamic system at a constant temperature and pressure. It is defined as:

$$
G=H-T S
$$

The standard Gibbs free energy of equilibrium formation is

$$
\Delta_{r} G=\Delta_{r} G^{\circ}+R T \ln Q_{r}
$$

where

$$
\begin{aligned}
& R=\text { gas constant } \\
& T=\text { absolute temperature } \\
& Q_{r}=\text { reaction quotient }
\end{aligned}
$$

At equilibrium, $\Delta_{r} G=0$ and $Q_{r}=K$, and therefore the equation is modified:

$$
\Delta_{r} G^{\circ}=-R T \ln K
$$

where: $\quad K=$ equilibrium constant

This Gibbs-Helmholz formula [Eq. (6)] is rearranged to $\ln K$ differentiated with respect to $T$ and substituted into Equation (4) to give a van't Hoff type equation:

$$
\frac{d \ln K}{d T}=\frac{\Delta H^{\circ}}{R T^{2}}
$$

A rearranged form of Eq. (7) is used to investigate the effects of temperature in chromatography:

$$
\frac{d \ln K}{d(1 / T)}=-\frac{\Delta H^{\circ}}{R}
$$

If $\ln K$ is plotted vs. $1 / T$, we obtain the right-hand side as slope, and $\Delta H^{\circ}$ can be determined. From Eq. (4), the standard Gibbs free energy is described as follows:

$$
\Delta G^{\circ}=\Delta H^{\circ}-T \Delta S^{\circ}
$$

where

$$
\begin{aligned}
& \Delta H^{\circ}=\text { standard change of enthalpy } \\
& \Delta S^{\circ}=\text { standard change of entropy }
\end{aligned}
$$


In chromatography, one of the most important data is the retention factor $\left(k^{\prime}\right)$, which is a measure of the stochiometric mass distribution of the analyte between the mobile and stationary phases. The relationship between $k^{\prime}$ and $K$ is:

$$
k^{\prime}=\frac{K}{\beta} \quad \beta=\frac{V_{M}}{V_{S}} \quad \text { where: } \quad \beta \text { is the phase ratio }
$$

With the previous equation, Eq. (6) is modified as

$$
\Delta G^{\circ}=-R T \ln k^{\prime} \beta
$$

The previous equation is rearranged to express $k$, to give the equation used in chromatography:

$$
\ln k^{\prime}=-\frac{\Delta H^{\circ}}{R T}+\frac{\Delta S^{\circ}}{R}+\ln \phi
$$

Eq. (12) shows that a plot of $\ln k^{\prime}$ vs. $1 / T$ has a slope of $-\Delta H^{\circ} / R$ and an intercept of $\Delta S^{\circ} / R+\ln \phi$ if $\Delta H^{\circ}$ is invariant with temperature $(\ln \phi$ is the inverse of the phase ratio; if $\ln \phi$ is not known, the value of the intercept multiplied by $R$ is dinoted $\Delta S^{\circ *}$ in chromatography).

In chiral chromatography, the difference the changes of standard free energy of the two enantiomers is used for determinations:

$$
\Delta G_{2}^{\circ}-\Delta G_{1}^{\circ}=\Delta\left(\Delta G^{\circ}\right)
$$

A combine Eq. (6) and (13) gives

$$
-\Delta\left(\Delta G^{\circ}\right)=R T \ln \frac{k_{2}{ }^{\prime}}{k_{1}{ }^{\prime}}
$$

As $\alpha=k_{2}{ }^{\prime} / k_{1}{ }^{\prime}$ :

$$
\ln \alpha=-\frac{\Delta\left(\Delta H^{\circ}\right)}{R T}+\frac{\Delta\left(\Delta S^{\circ}\right)}{R}
$$

From this, it can be determined whether the separation is an enthalpy-driven or an entropy-driven process. In the first case, increasing temperature lowers the enantioselectivity and enantioseparation. In an entropy-driven process, increasing temperature increases the enantioselectivity. 


\section{EXPERIMENTAL}

\subsection{Apparatus}

Our measurements were carried out with three HPLC systems.

System I: An M-600 low-pressure gradient pump, equipped with an M-2996 photodiodearray detector and a Millenium ${ }^{32} 3.2$ Chromatography Manager data system (all Waters Chromatography, Milford, MA, USA).

System II: A 1525 binary pump, a 2487 dual-channel absorbance detector, a 717 plus autosampler and Empower 2 data manager software (all Waters Chromatography, Milford, MA, USA).

System III: An L-6000 pump (Hitachi Ltd., Tokio, Japan), an SPD-6AV UV-VIS detector (Shimadzu Corporation, Japan) and Borwin data software (Merck, Darmstadt, Germany).

All of the HPLC systems were equipped with a Rheodyne 7125 injector with a 20$\mu \mathrm{L}$ loop (Rheodyne, Cotati, CA, USA).

A Thermo Orion $420 \mathrm{pH}$-meter was employed for $\mathrm{pH}$ measurements.

The columns were thermostated in a water bath with thermostat and a coolingheating thermostat. The accuracy of temperature adjustment was $\pm 0.1^{\circ} \mathrm{C}$.

The chromatographic system was conditioned by passing the eluent through the column until a stable baseline signal and reproducible retention factors were obtained for the subsequent injections. This procedure was always followed when a new mobile phase or temperature was chosen.

\subsection{Applied columns}

Crown ether-based CSPs: (+)-(18-crown-6)-2,3,11,12-tetracarboxylic acid-based CSPs, $150 \times 4.6 \mathrm{~mm}$ I.D., $5 \mu \mathrm{m}$ particle size.

Macrocyclic glycopeptide-based CSPs: teicoplanin-containing Chirobiotic $\mathrm{T}$ and T2, teicoplanin aglycone-containing Chirobiotic TAG, vancomycin-containing Chirobiotic $\mathrm{V}$, vancomycin aglycone-containing Chirobiotic VAG and ristocetin A-containing Chirobiotic R, $250 \times 4.6 \mathrm{~mm}$ I.D., $5 \mu \mathrm{m}$ particle size. 


\subsection{Chemicals and reagents}

The applied methanol $(\mathrm{MeOH})$, ethanol (EtOH), propan-1-ol ( $\mathrm{PrOH})$ and propan-2ol (IPA) of HPLC grade were purchased from Merck (Darmstadt, Germany). Glacial acetic acid $(\mathrm{AcOH})$ was from Scharlau Chemie S. A. (Barcelona, Spain). Triethylamine (TEA), trifluoracetic acid (TFA), phosphoric acid $\left(\mathrm{H}_{3} \mathrm{PO}_{4}\right)$, perchloric acid $\left(\mathrm{HClO}_{4}\right)$, sulfuric acid $\left(\mathrm{H}_{2} \mathrm{SO}_{4}\right)$ and sodium hydroxide, of analytical reagent grade were from Merck. Milli-Q water was further purified by filtering it on a $0.45 \mu \mathrm{m}$ filter, type HV, Millipore (Molsheim, France). 0.1\% Triethylammonium acetate (TEAA) buffer was prepared by dissolving $750 \mu \mathrm{L}$ of TEA in $750 \mathrm{~mL}$ of water, and adjusting the $\mathrm{pH}$ with $\mathrm{AcOH}$ to 4.1.

Mobile phases were prepared by mixing the indicated volumes of solvents. Stock solutions of analytes $\left(1 \mathrm{mg} \mathrm{mL} \mathrm{mL}^{-1}\right)$ were prepared by dissolution in the starting mobile phase.

\subsection{Investigated compounds}

\subsubsection{Monoterpene-based $\beta$-amino acids}

The investigated monoterpene-based $\beta$-amino acids were prepared [128-131] at the Institute of Pharmaceutical Chemistry in Szeged (Fig. 11). Their IUPAC names are presented in the Appendix.

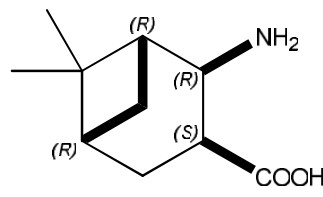

1a

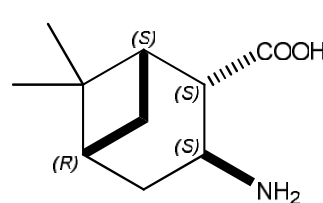

3a

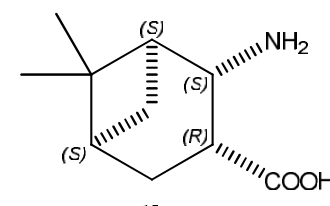

$1 b$

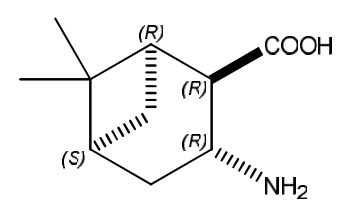

3b

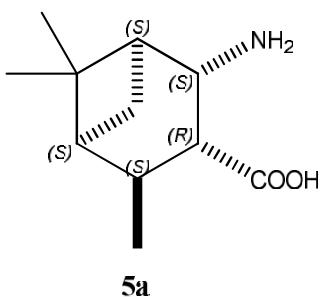

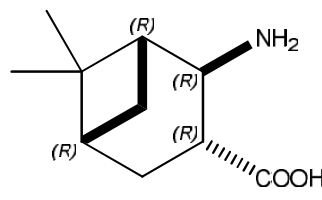

$2 \mathfrak{a}$

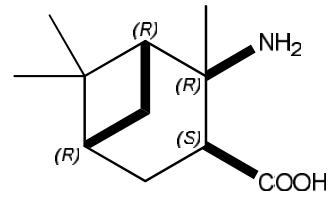

$4 a$

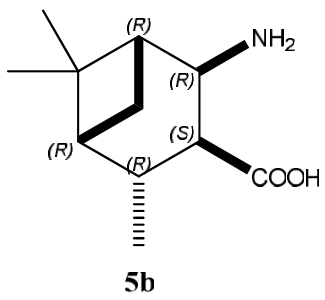

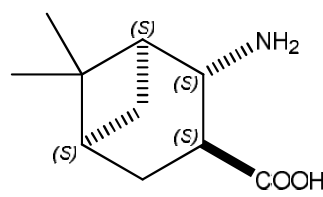

2b

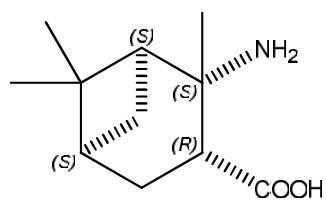

$4 b$

Figure 11. Structures of monoterpene-based $\beta$-amino acids 


\subsubsection{Isoxazoline-fused 2-aminocyclopentanecarboxylic acids}

These compounds (Fig. 12) were prepared [132,133] at the Institute of Pharmaceutical Chemistry in Szeged. Their IUPAC names are presented in the Appendix.

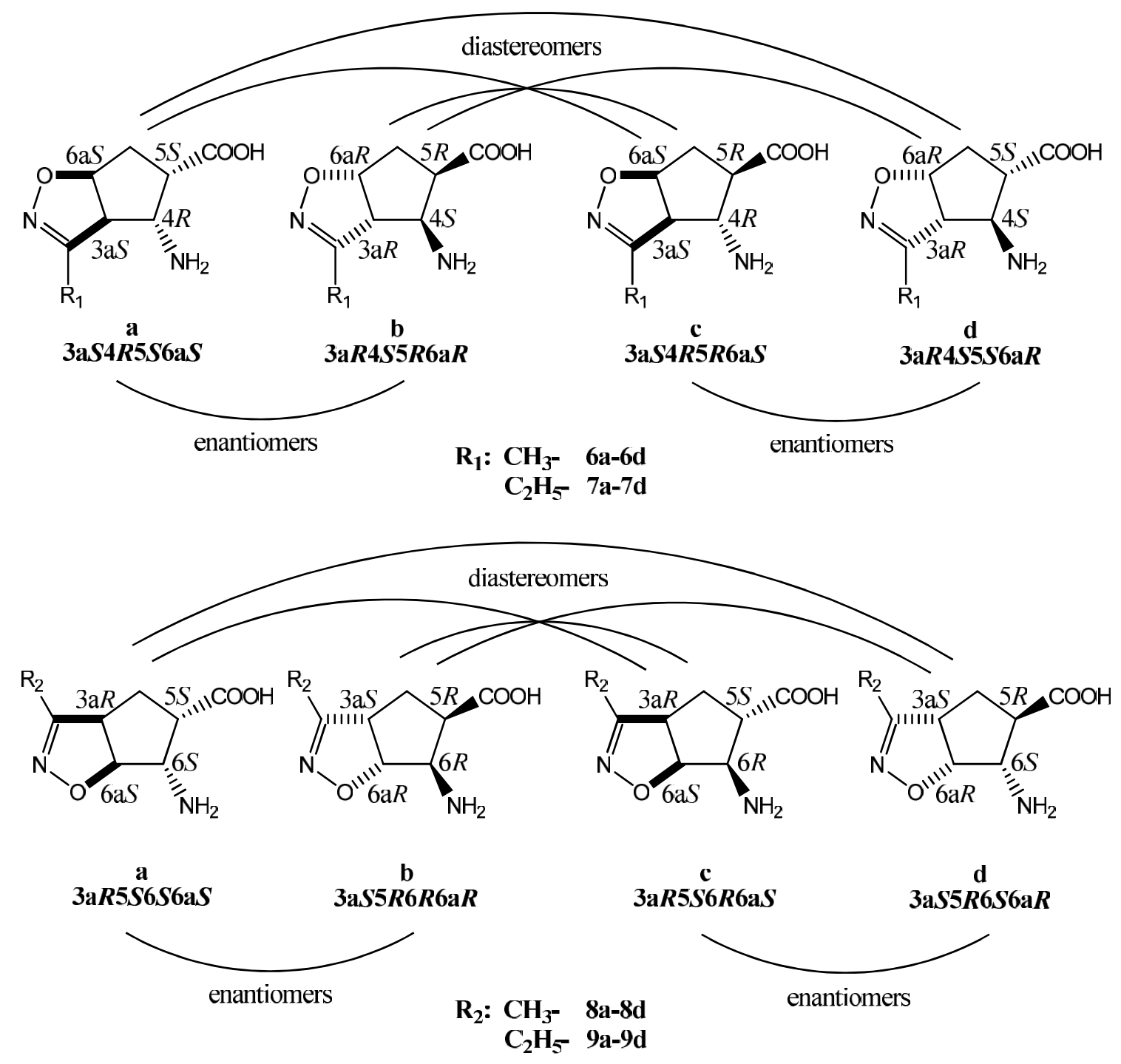

Figure 12. Structures of isoxazoline-fused 2-aminocyclopentanecarboxylic acid analogues 


\section{RESULTS AND DISCUSSION}

\subsection{Separation of monoterpene-based $\beta$-amino acids on macrocyclic glycopeptide-based CSPS}

These compounds possess a monoterpene-based skeleton. Analogues $\mathbf{4}$ and $\mathbf{5}$ bear one methyl group on position 2 or 4 . In the case of analogue 3 , the locations of the carboxyl and amino group are opposite. These differences result in different steric effects and influence the hydrophobicity, bulkiness and rigidity of the molecules, depending on how their atoms are linked and how capable they are of different interactions with the selector.

\subsubsection{Effects of $p H$}

First of all, the effects of $\mathrm{pH}$ on the separation were investigated in the acidic $\mathrm{pH}$ range from 6.50 to 4.00 in the $0.1 \%$ aqueous TEAA/MeOH $=60 / 40(v / v)$ eluent system on analyte 4 (Fig. 13). With increasing pH, the retention factors decreased on Chirobiotic T, while the selectivity increased slightly and the resolution considerably. Similar results were obtained by Armstrong et al. [60] on a teicoplanin CSP for analytes with free carboxylic acid groups. The $\mathrm{pH}$ that produced the highest $\alpha$ also yielded the best resolution. The discontinuities in $k^{\prime}, \alpha$ and $R_{S}$ at low $\mathrm{pH}$ are most probably due to the protonation on the teicoplanin CSP and analyte. Protonation of teicoplanin either directly affects the coulombic or dipolar interactions between the analyte and CSP, or indirectly influences the separation by changing the conformation of the selector.

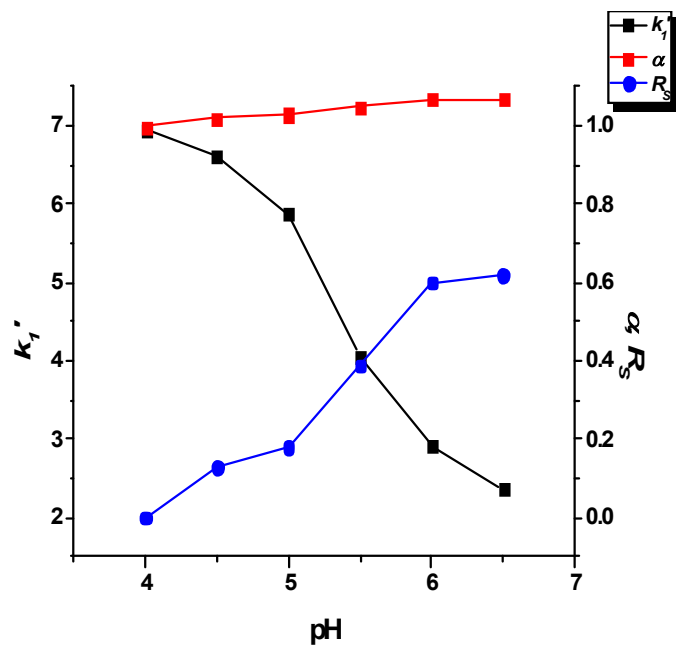

Figure 13. Influence of the $\mathrm{pH}$ on the chromatographic parameters for analyte 4.

Chromatographic conditions: column, Chirobiotic T; mobile phase, $0.1 \%$ TEAA ( $\mathrm{pH}=$ $4.1) / \mathrm{MeOH}=60 / 40(v / v)$; flow rate, $0.5 \mathrm{~mL} \mathrm{~min}^{-1}$; detection, $210 \mathrm{~nm}$ 


\subsubsection{Effects of $\mathrm{MeOH}$ as alcohol modifier}

All the compounds were evaluated with different mobile phases, the eluent composition being varied between 0.1\% TEAA $(\mathrm{pH}=4.1) / \mathrm{MeOH}=98 / 2,90 / 10,80 / 20$, $60 / 40,40 / 60,20 / 80,10 / 90,0 / 100(v / v)$ and $\mathrm{MeOH} / \mathrm{AcOH} / \mathrm{TEA}=100 / 0.1 / 0.1(v / v / v)$

(Table 1). For comparison purposes and to simplify the presentation, Table 1 lists only the chromatographic results obtained at some mobile phase compositions. With the same mobile phase composition, the retention factors were lower on the teicoplanin CSPs (T and T2) than on the aglycone CSP (TAG) (except for analyte 3 in some cases). The native teicoplanin phase (Chirobiotic T) exhibited intermediate $k$ ' values. Similar trends, with higher $k^{\prime}$ values on the teicoplanin aglycone-containing CSP than on native teicoplanin, were observed by D'Acquarica et al. [134], Berthod et al. [135] and Péter et al. $[62,136,137]$ for unusual $\alpha$-amino acids and cyclic $\beta$-amino acids. Comparison of the $\mathrm{T}$ and $\mathrm{T} 2$ columns revealed that the retention factors on Chirobiotic $\mathrm{T}$ were somewhat larger (except for analytes 2 and 3 at 100\% MeOH) (Table 1). Slightly higher $k$ ' values on Chirobiotic T2 than on Chirobiotic T were observed by Péter et al. [137] for $\beta^{3}$ homoamino acids.

The effects of the $\mathrm{MeOH}$ content of the mobile phase were investigated on all macrocyclic glycopeptide-based columns, but on the Chirobiotic V, VAG and R columns the values of selectivity $(\alpha)$ and resolution $\left(R_{S}\right)$ were very low. The best resolution $\left(R_{S}=\right.$ 1.00) was achieved on Chirobiotic $\mathrm{R}$ for analyte 4 in the $0.1 \%$ TEAA $(\mathrm{pH}=4.1) / \mathrm{MeOH}=$ 10/90 $(v / v)$ mobile phase. As concerns the Chirobiotic V and VAG columns, the $k$ ' values on VAG were larger in all cases than those on $\mathrm{V}$, similarly as for the $\mathrm{T}$ and TAG columns.

For the dependence of the chromatographic data on the $\mathrm{MeOH}$ concentration in the mobile phase, in most cases a U-shaped retention curve was observed for all analytes (the only exception was analyte 3 on the Chirobiotic T and T2 columns). At higher water content, the retention factor increased with increasing water content, which was probably due to enhanced hydrophobic interactions between the analyte and the CSP in the waterrich mobile phases (Table 1). In the RP mode, one of the most important interactions between the analyte and the CSP is the hydrophobic interaction inside the basket of the glycopeptide. Here, an increase in $k^{\prime}$ at high water content was observed for all analogues (Table 1). When the $\mathrm{MeOH}$ content of the mobile phase exceeded $\sim 50 \%$, the retention factor increased (an exception was analyte 3 on the Chirobiotic T and T2 columns). 
Table 1. Chromatographic data, retention factor of first-eluted enantiomer $\left(k_{l}{ }^{\prime}\right)$, separation factor $(\alpha)$, resolution $\left(R_{S}\right)$ and configuration of the first-eluted enantiomer of monoterpenebased 2-aminocarboxylic acids on different macrocyclic glycopeptide-based columns

\begin{tabular}{|c|c|c|c|c|c|c|}
\hline Analyte & Column & $\begin{array}{c}\text { Mobile phase } \\
\text { TEAA/MeOH } \\
(v / v), \text { a } \\
\text { MeOH/AcOH/TEA } \\
(v / v / v), \text { b }\end{array}$ & $k_{1}$, & $\alpha$ & $\boldsymbol{R}_{S}$ & $\begin{array}{c}\text { Configuration } \\
\text { of the first- } \\
\text { eluted } \\
\text { enantiomer }\end{array}$ \\
\hline \multirow{15}{*}{1} & \multirow{5}{*}{$\mathrm{T}$} & $90 / 10, \mathbf{a}$ & 3.48 & 1.14 & 1.27 & \multirow{15}{*}{$1 R, 2 R, 3 S, 5 R$} \\
\hline & & $40 / 60, \mathbf{a}$ & 1.98 & 1.08 & 0.72 & \\
\hline & & $10 / 90, \mathbf{a}$ & 2.65 & 1.15 & 1.74 & \\
\hline & & $0 / 100, \mathbf{a}$ & 4.18 & 1.19 & 1.85 & \\
\hline & & $100 / 0.1 / 0.1, \mathbf{b}$ & 3.05 & 1.24 & 1.57 & \\
\hline & \multirow{5}{*}{$\mathrm{T} 2$} & $90 / 10, \mathbf{a}$ & 3.21 & 1.00 & 0.00 & \\
\hline & & $40 / 60, \mathbf{a}$ & 1.59 & 1.12 & 1.24 & \\
\hline & & $10 / 90, \mathbf{a}$ & 2.00 & 1.16 & 1.40 & \\
\hline & & $0 / 100, \mathbf{a}$ & 2.67 & 1.19 & 1.17 & \\
\hline & & $100 / 0.1 / 0.1, \mathbf{b}$ & 2.01 & 1.00 & 0.00 & \\
\hline & \multirow{5}{*}{ TAG } & $90 / 10, \mathbf{a}$ & 6.92 & 1.00 & 0.00 & \\
\hline & & $40 / 60, \mathbf{a}$ & 3.74 & 1.15 & 1.79 & \\
\hline & & $10 / 90, \mathbf{a}$ & 4.89 & 1.22 & 1.63 & \\
\hline & & $0 / 100, \mathbf{a}$ & 6.61 & 1.23 & 1.13 & \\
\hline & & $100 / 0.1 / 0.1, \mathbf{b}$ & 3.88 & 1.00 & 0.00 & \\
\hline \multirow{15}{*}{2} & \multirow{5}{*}{$\mathrm{T}$} & $90 / 10, \mathbf{a}$ & 3.28 & 1.00 & 0.00 & \multirow{4}{*}{$1 R, 2 R, 3 R, 5 R$} \\
\hline & & $40 / 60, \mathbf{a}$ & 2.30 & 1.04 & 0.39 & \\
\hline & & $10 / 90, \mathbf{a}$ & 3.65 & 1.06 & 0.80 & \\
\hline & & $0 / 100, \mathbf{a}$ & 4.73 & 1.08 & 0.90 & \\
\hline & & $100 / 0.1 / 0.1, \mathbf{b}$ & 3.39 & 1.08 & 0.56 & $1 S, 2 S, 3 S, 5 S$ \\
\hline & \multirow{5}{*}{$\mathrm{T} 2$} & $90 / 10, \mathbf{a}$ & 3.13 & 1.18 & 1.35 & \multirow{4}{*}{$1 R, 2 R, 3 R, 5 R$} \\
\hline & & $40 / 60, \mathbf{a}$ & 2.23 & 1.03 & 0.27 & \\
\hline & & $10 / 90, \mathbf{a}$ & 3.35 & 1.05 & 0.51 & \\
\hline & & $0 / 100, \mathbf{a}$ & 5.98 & 1.06 & 0.60 & \\
\hline & & $100 / 0.1 / 0.1, \mathbf{b}$ & 2.32 & 1.09 & 0.42 & $1 S, 2 S, 3 S, 5 S$ \\
\hline & \multirow{5}{*}{ TAG } & $90 / 10, \mathbf{a}$ & 7.63 & 1.19 & 1.06 & \multirow{4}{*}{$1 R, 2 R, 3 R, 5 R$} \\
\hline & & $40 / 60, \mathbf{a}$ & 4.88 & 1.00 & 0.00 & \\
\hline & & $10 / 90, \mathbf{a}$ & 7.05 & 1.00 & 0.00 & \\
\hline & & $0 / 100, \mathbf{a}$ & 8.96 & 1.02 & 1.53 & \\
\hline & & $100 / 0.1 / 0.1, \mathbf{b}$ & 4.09 & 1.00 & 0.00 & $1 S, 2 S, 3 S, 5 S$ \\
\hline \multirow{10}{*}{3} & \multirow{5}{*}{$\mathrm{T}$} & $90 / 10, \mathbf{a}$ & 11.95 & 1.00 & 0.00 & \multirow{10}{*}{$1 R, 2 R, 3 R, 5 S$} \\
\hline & & $40 / 60, \mathbf{a}$ & 7.49 & 1.00 & 0.00 & \\
\hline & & $10 / 90, \mathbf{a}$ & 3.68 & 1.15 & 1.34 & \\
\hline & & $0 / 100, \mathbf{a}$ & 1.30 & 1.48 & 3.49 & \\
\hline & & $100 / 0.1 / 0.1, \mathbf{b}$ & 3.17 & 1.32 & 2.67 & \\
\hline & \multirow{5}{*}{$\mathrm{T} 2$} & $90 / 10, \mathbf{a}$ & 10.11 & 1.00 & 0.00 & \\
\hline & & $40 / 60, \mathbf{a}$ & 2.43 & 1.12 & 0.62 & \\
\hline & & $10 / 90, \mathbf{a}$ & 2.00 & 1.22 & 1.22 & \\
\hline & & $0 / 100, \mathbf{a}$ & 1.80 & 1.29 & 1.97 & \\
\hline & & $100 / 0.1 / 0.1, \mathbf{b}$ & 2.84 & 1.09 & 0.95 & \\
\hline
\end{tabular}


Table 1 (continued)

\begin{tabular}{|c|c|c|c|c|c|c|}
\hline Analyte & Column & $\begin{array}{c}\text { Mobile phase } \\
\text { TEAA/MeOH } \\
(v / v), \mathbf{a} \\
\text { MeOH/AcOH/TEA } \\
(v / v / v), \mathrm{b}\end{array}$ & $k_{1}$, & $\alpha$ & $\boldsymbol{R}_{S}$ & $\begin{array}{c}\text { Configuration } \\
\text { of the first- } \\
\text { eluted } \\
\text { enantiomer }\end{array}$ \\
\hline \multirow{5}{*}{3} & \multirow{5}{*}{ TAG } & $90 / 10, \mathbf{a}$ & 11.90 & 1.07 & 0.81 & \multirow{5}{*}{$1 R, 2 R, 3 R, 5 S$} \\
\hline & & $40 / 60, \mathbf{a}$ & 5.96 & 1.08 & 0.35 & \\
\hline & & $10 / 90, \mathbf{a}$ & 4.75 & 1.29 & 1.83 & \\
\hline & & $0 / 100, \mathbf{a}$ & 4.84 & 1.32 & 2.76 & \\
\hline & & $100 / 0.1 / 0.1, \mathbf{b}$ & 3.13 & 1.35 & 1.97 & \\
\hline \multirow{15}{*}{4} & \multirow{5}{*}{$\mathrm{T}$} & $90 / 10, \mathbf{a}$ & 3.28 & 1.34 & 2.95 & \multirow{15}{*}{$1 S, 2 S, 3 R, 5 S$} \\
\hline & & $40 / 60, \mathbf{a}$ & 1.79 & 1.08 & 0.66 & \\
\hline & & $10 / 90, \mathbf{a}$ & 2.17 & 1.15 & 1.32 & \\
\hline & & $0 / 100, \mathbf{a}$ & 3.29 & 1.22 & 1.38 & \\
\hline & & $100 / 0.1 / 0.1, \mathbf{b}$ & 2.07 & 1.30 & 2.31 & \\
\hline & \multirow{10}{*}{ TAG } & $90 / 10, \mathbf{a}$ & 3.22 & 1.20 & 1.78 & \\
\hline & & $40 / 60, \mathbf{a}$ & 1.40 & 1.12 & 1.07 & \\
\hline & & $10 / 90, \mathbf{a}$ & 1.52 & 1.27 & 1.78 & \\
\hline & & $0 / 100, \mathbf{a}$ & 1.90 & 1.45 & 1.92 & \\
\hline & & $100 / 0.1 / 0.1, \mathbf{b}$ & 1.25 & 1.65 & 2.11 & \\
\hline & & $90 / 10, \mathbf{a}$ & 9.68 & 1.06 & 0.48 & \\
\hline & & $40 / 60, \mathbf{a}$ & 3.86 & 1.17 & 1.68 & \\
\hline & & $10 / 90, \mathbf{a}$ & 3.25 & 1.25 & 1.80 & \\
\hline & & $0 / 100, \mathbf{a}$ & 4.63 & 1.30 & 1.83 & \\
\hline & & $100 / 0.1 / 0.1, \mathbf{b}$ & 2.69 & 1.49 & 3.27 & \\
\hline \multirow{15}{*}{5} & \multirow{5}{*}{$\mathrm{T}$} & $90 / 10, \mathbf{a}$ & 4.40 & 1.00 & 0.00 & \multirow{15}{*}{$1 R, 2 R, 3 S, 4 R, 5 R$} \\
\hline & & $40 / 60, \mathbf{a}$ & 1.91 & 1.00 & 0.00 & \\
\hline & & $10 / 90, \mathbf{a}$ & 2.44 & 1.05 & 0.67 & \\
\hline & & $0 / 100, \mathbf{a}$ & 3.69 & 1.09 & 0.81 & \\
\hline & & $100 / 0.1 / 0.1, \mathbf{b}$ & 2.51 & 1.12 & 1.78 & \\
\hline & \multirow{5}{*}{$\mathrm{T} 2$} & $90 / 10, \mathbf{a}$ & 4.38 & 1.12 & 0.89 & \\
\hline & & $40 / 60, \mathbf{a}$ & 1.59 & 1.08 & 0.74 & \\
\hline & & $10 / 90, \mathbf{a}$ & 1.90 & 1.10 & 0.86 & \\
\hline & & $0 / 100, \mathbf{a}$ & 2.24 & 1.14 & 0.90 & \\
\hline & & $100 / 0.1 / 0.1, \mathbf{b}$ & 1.54 & 1.17 & 0.75 & \\
\hline & \multirow{5}{*}{ TAG } & $90 / 10, \mathbf{a}$ & 10.93 & 1.07 & 0.66 & \\
\hline & & $40 / 60, \mathbf{a}$ & 4.49 & 1.09 & 0.81 & \\
\hline & & $10 / 90, \mathbf{a}$ & 3.86 & 1.11 & 1.09 & \\
\hline & & $0 / 100, \mathbf{a}$ & 5.34 & 1.16 & 1.11 & \\
\hline & & $100 / 0.1 / 0.1, \mathbf{b}$ & 2.88 & 1.25 & 1.36 & \\
\hline
\end{tabular}

Chromatographic conditions: columns, T, Chirobiotic T, T2, Chirobiotic T2, TAG, Chirobiotic TAG; mobile phase, a, $0.1 \%$ TEAA $(\mathrm{pH}=4.1) / \mathrm{MeOH}(v / v), \quad \mathbf{b}$, $\mathrm{MeOH} / \mathrm{AcOH} / \mathrm{TEA}(v / v / v)$; temperature, ambient; flow rate, $0.5 \mathrm{~mL} \mathrm{~min}^{-1}$; detection, 210 $\mathrm{nm}$

This suggests that the separation may be controlled rather by the hydrophilic interaction chromatography (HILIC) than by the RP mechanism at high MeOH content. The existence of HILIC may relate to the change in solvation of the stationary phase and the strength of 
polarity. Besides the stationary phase, the water layer is thinned by increasing alcohol content, and therefore the polar unit of the analyte interacts more strongly with the selector and the retention is increased.

For analyte $\mathbf{3}$ on Chirobiotic T and T2, a continuous increase in $k^{\prime}$ was observed with increasing water content. This different behaviour of analyte 3 may be due to the different positions of the carboxyl and amino groups, resulting in a difference in the steric interaction with the selectors containing carbohydrate units (Chirobiotic T and T2).

As regards the effect of a change of $\mathrm{MeOH}$ content on the changes in the separation factors $(\alpha)$ and resolution $\left(R_{S}\right)$, no general rules could be observed.

Application of the $\mathrm{MeOH} / \mathrm{AcOH} / \mathrm{TEA}=100 / 0.1 / 0.1(v / v / v)$ mobile phase system generally resulted in lower retention than on the application of $100 \% \mathrm{MeOH}$ (except for analyte $\mathbf{3}$ on Chirobiotic T and T2). However, for analytes 4 and 5, despite the lower $k$ ' values, higher $\alpha$ and $R_{S}$ values were obtained, indicating that the chiral discrimination improved in the PI mode when the carboxyl and amino groups were in positions 2 and 3, respectively, or methyl substitution resulted in a highly constrained analogue (Table $\mathbf{1}$ ).

\subsubsection{Influence of the structures of the compounds}

The structures of the compounds affected the chiral recognition. In the RP mode in water-rich mobile phases, analyte 3 exhibited large $k_{l}$ ' values, which were not accompanied by high resolution. At high water content, the non-specific hydrophobic interaction resulted in high retention without chiral recognition. The $\alpha$ value reached its maximum at high $\mathrm{MeOH}$ content. Molecules 4 and 5 containing a methyl group are sterically constrained, resulting in most cases in higher $\alpha$ (and $R_{S}$ ) values as compared with analytes $\mathbf{1}$ and 2. Interestingly, it seems that the position of the methyl group on the cycloalkane skeleton (position 2 or 4 ) produced a considerable effect on $\alpha$ and $R_{S}$; the more constrained analyte $\mathbf{4}$ gave higher $\alpha$ and $R_{S}$ values than those of analyte 5 .

Baseline resolution was achieved in all cases, as shown in selected chromatograms in the Appendix.

\subsubsection{Effects of temperature on the chromatographic parameters}

In order to investigate the effects of temperature on the chromatographic parameters, a variable-temperature study was carried out over the temperature range 10-40 ${ }^{\circ} \mathrm{C}$ (in 5 or $10{ }^{\circ} \mathrm{C}$ increments) on Chirobiotic $\mathrm{T}$ and TAG columns. Experimental data for 
the mobile phase $0.1 \%$ TEAA $(\mathrm{pH}=4.1) / \mathrm{MeOH}=10 / 90(\mathrm{v} / \mathrm{v})$ are listed in Table 2. A comparison of the retention factors in Table 2 reveals that all of the recorded values decreased with increasing temperature (similar tendencies were measured at other mobile phase compositions). It is evident that an increase in separation temperature lowers the separation factor, $\alpha$. However, for analyte 3 on the T column, $\alpha$ (and also $R_{S}$ ) increased with increasing temperature (Table 2). Increasing temperature may improve the peak symmetry and efficiency, and therefore the resolution may also improve.

Since the effect of temperature on the separation was complex, an extensive study relating to the thermodynamics of the enantiomer separation was carried out. In order to calculate the thermodynamic parameters and to acquire information towards an understanding of the enantiomeric retention, the selectivity and the mechanism on these CSPs, van't Hoff plots were constructed [Eq. (12)].

Table 2. Retention factor of first-eluting enantiomer $\left(k^{\prime}\right)$, separation factor $(\alpha)$ and resolution $\left(R_{s}\right)$ of enantiomers of monoterpene-based 2-aminocarboxylic acids $\mathbf{1 - 5}$ as a function of temperature

\begin{tabular}{|c|c|c|c|c|c|c|c|}
\hline \multirow{2}{*}{ Analyte } & \multirow{2}{*}{ Columns } & \multirow{2}{*}{$\begin{array}{c}\boldsymbol{k}_{1}^{\prime}, \alpha, \alpha \\
\boldsymbol{R}_{S}\end{array}$} & \multicolumn{5}{|c|}{ Temperature $\left({ }^{\circ} \mathbf{C}\right)$} \\
\hline & & & 10 & 15 & 20 & 30 & 40 \\
\hline \multirow{6}{*}{1} & \multirow{3}{*}{$\mathrm{T}$} & $k_{1}^{\prime}$ & 4.49 & 4.18 & 4.05 & 3.58 & 3.21 \\
\hline & & $\alpha$ & 1.13 & 1.12 & 1.12 & 1.11 & 1.10 \\
\hline & & $R_{S}$ & 1.66 & 1.64 & 1.51 & 1.59 & 1.62 \\
\hline & \multirow{3}{*}{ TAG } & $k_{1}^{\prime}$ & 6.79 & 6.29 & 5.81 & 5.09 & 4.63 \\
\hline & & $\alpha$ & 1.17 & 1.16 & 1.15 & 1.14 & 1.12 \\
\hline & & $R_{S}$ & 1.46 & 1.48 & 1.66 & 1.71 & 1.88 \\
\hline \multirow{6}{*}{2} & \multirow{3}{*}{$\mathrm{T}$} & $k_{l}^{\prime}$ & 5.84 & 5.54 & 5.31 & 4.97 & 4.63 \\
\hline & & $\alpha$ & 1.04 & 1.03 & 1.03 & 1.02 & 1.01 \\
\hline & & $R_{S}$ & 0.53 & 0.50 & 0.39 & 0.38 & 0.46 \\
\hline & \multirow{3}{*}{$\mathrm{TAG}$} & $k_{l}^{\prime}$ & 10.66 & 9.96 & 9.65 & 8.68 & 8.12 \\
\hline & & $\alpha$ & 1.00 & 1.00 & 1.00 & 1.00 & 1.00 \\
\hline & & $R_{S}$ & 0.00 & 0.00 & 0.00 & 0.00 & 0.00 \\
\hline \multirow{6}{*}{3} & \multirow{3}{*}{$\mathrm{T}$} & $k_{l}^{\prime}$ & 7.30 & 6.26 & 5.66 & 4.76 & 4.05 \\
\hline & & $\alpha$ & 1.09 & 1.11 & 1.12 & 1.14 & 1.17 \\
\hline & & $R_{S}$ & 0.70 & 0.81 & 0.85 & 1.07 & 1.09 \\
\hline & \multirow{3}{*}{ TAG } & $k_{l}^{\prime}$ & 13.37 & 10.21 & 8.09 & 6.18 & 4.08 \\
\hline & & $\alpha$ & 1.20 & 1.17 & 1.13 & 1.09 & 1.04 \\
\hline & & $R_{S}$ & 1.97 & 1.33 & 1.04 & 0.75 & 0.33 \\
\hline
\end{tabular}


Table 2 (continued)

\begin{tabular}{|c|c|c|c|c|c|c|c|}
\hline \multirow{2}{*}{ Analyte } & \multirow{2}{*}{ Columns } & \multirow{2}{*}{$\begin{array}{c}\boldsymbol{k}_{1}, \alpha \\
\quad \boldsymbol{R}_{S}\end{array}$} & \multicolumn{5}{|c|}{ Temperature $\left({ }^{\circ} \mathbf{C}\right)$} \\
\hline & & & 10 & 15 & 20 & 30 & 40 \\
\hline \multirow{6}{*}{4} & \multirow{3}{*}{$\mathrm{T}$} & $k_{1}^{\prime}$ & 3.74 & 3.51 & 3.35 & 3.06 & 2.73 \\
\hline & & $\alpha$ & 1.13 & 1.12 & 1.11 & 1.10 & 1.09 \\
\hline & & $R_{S}$ & 1.27 & 1.28 & 1.30 & 1.32 & 1.35 \\
\hline & \multirow{3}{*}{ TAG } & $k_{1}^{\prime}$ & 5.18 & 4.86 & 4.48 & 4.13 & 3.75 \\
\hline & & $\alpha$ & 1.20 & 1.19 & 1.18 & 1.17 & 1.16 \\
\hline & & $R_{S}$ & 1.47 & 1.74 & 1.84 & 1.95 & 2.09 \\
\hline \multirow{6}{*}{5} & \multirow{3}{*}{$\mathrm{T}$} & $k_{1}^{\prime}$ & 4.29 & 4.02 & 3.77 & 3.43 & 3.08 \\
\hline & & $\alpha$ & 1.05 & 1.05 & 1.04 & 1.04 & 1.03 \\
\hline & & $R_{S}$ & 0.72 & 0.67 & 0.61 & 0.48 & 0.38 \\
\hline & \multirow{3}{*}{ TAG } & $k_{1}^{\prime}$ & 6.23 & 5.82 & 5.64 & 4.89 & 4.37 \\
\hline & & $\alpha$ & 1.12 & 1.11 & 1.10 & 1.09 & 1.07 \\
\hline & & $R_{S}$ & 1.24 & 1.25 & 1.30 & 1.29 & 1.22 \\
\hline
\end{tabular}

Chromatographic conditions: column, T, Chirobiotic T, TAG, Chirobiotic TAG; mobile phase, $0.1 \%$ TEAA $(\mathrm{pH}=4.1) / \mathrm{MeOH}=10 / 90(v / v)$; temperature, ambient; flow rate, 0.5 $\mathrm{mL} \min ^{-1}$; detection, $210 \mathrm{~nm}$

The $\Delta H^{\circ}$ and $\Delta S^{\circ *}$ values calculated from the slopes and intercepts of the plot of Eq. (12) for the enantiomers on both columns were negative (Table 3). Further, $\Delta H^{\circ}$ and $\Delta S^{\circ}$ for the first-eluting enantiomer were always less negative than those for the secondeluting enantiomer (analyte $\mathbf{2}$ was not separated on the Chirobiotic TAG column). Since the second-eluting enantiomers have more negative $\Delta S^{\circ *}$ values, they probably have fewer degrees of freedom on the CSP, i.e. they are held at more points or are less able to move or rotate. It is widely accepted that both enantiomers show the same non-specific interactions and the more strongly retained one is subjected to additional stereospecific interactions with chiral centres. It was also observed that $\Delta H^{\circ}{ }_{1}$ and $\Delta H^{\circ}{ }_{2}$ and in parallel $\Delta S^{\circ} *_{1}$ and $\Delta S^{\circ} *_{2}$ for the native teicoplanin-containing column were in most cases less negative than those for the aglycone-containing TAG column. The TAG CSP without sugar moieties may promote the interaction between the analyte and the CSP.

Of the five analogues, analyte $\mathbf{2}$ exhibited the smallest, and analyte $\mathbf{3}$ the largest $\Delta H^{\circ}$ and $-\Delta S^{\circ *}$ values. The positions ( 2 and 3 ) of the amino and carboxyl groups and the trans configuration in $\mathbf{2}$ probably inhibits the fitting and orientation in the cavity (the sugar units on the Chirobiotic $\mathrm{T}$ column improve the chiral recognition, while on TAG no separation was observed), and the separation was thermodynamically less favourable. The 
largest $-\Delta H^{\circ}$ and $-\Delta S^{\circ *}$ values for $\mathbf{3}$ indicated that, despite of the trans configuration, the steric arrangement of the carboxyl and amino groups may promote the steric/rigidity effect or polar interactions with the CSP and the largest $-\Delta H^{\circ}$ and $-\Delta S^{\circ *}$ values were obtained.

The difference in the changes of enthalpy, $\Delta\left(\Delta H^{\circ}\right)$ and entropy, $\Delta\left(\Delta S^{\circ}\right)$, are also presented in Table 3. The $-\Delta\left(\Delta H^{\circ}\right)$ values ranged from -1.5 to $3.3 \mathrm{~kJ} \mathrm{~mol}^{-1}$. The interactions of $\mathbf{3}$ with the TAG stationary phase were characterized by the highest negative $\Delta\left(\Delta H^{\circ}\right)$ value, while analyte 3 on the $\mathrm{T}$ column exhibited a positive $\Delta\left(\Delta H^{\circ}\right)$ value. The trends in the change of $-\Delta\left(\Delta S^{\circ}\right)$ showed that analyte 3 on TAG displayed the largest negative entropies and the $-\Delta\left(\Delta S^{\circ}\right)$ values ranged from -6.1 to $10.2 \mathrm{~J} \mathrm{~mol}^{-1} \mathrm{~K}^{-1}$ (Table 3). For all analytes, the $-\Delta\left(\Delta S^{\circ}\right)$ values are controlled by the difference in the number of degrees of freedom between the stereoisomers on the CSP, and mainly by the number of solvent molecules released from solvating both the chiral selector and the analyte when the analyte is associated with the CSP.

The thermodynamic parameter $-\Delta\left(\Delta G^{\circ}\right)$ suggests that the aglycone induces highly efficient binding to the selector, as reflected by the large negative $\Delta\left(\Delta S^{\circ}\right)$ values for $1,3,4$ and 5, while for analytes $\mathbf{2}$ and $\mathbf{3}$ the carbohydrate moieties may promote the interaction of the enantiomers (on Chirobiotic TAG, the enantiomers of analyte 2 were not separable at this eluent composition). For analyte 3 on the $\mathrm{T}$ column, the positive $\Delta\left(\Delta S^{\circ}\right)$ value compensates the positive $\Delta\left(\Delta H^{\circ}\right)$ and resulted in a relatively high $-\Delta\left(\Delta G^{\circ}\right)$ value. Native teicoplanin, containing more chiral centres ensures more interaction sites for compounds resulting in more negative $-\Delta\left(\Delta G^{\circ}\right)$ values; in this temperature range, enantioresolution is entropically driven, and the selectivity increases with increasing temperature. The complex formation proceeding via multiple intermolecular interactions was generally exothermic and the corresponding entropic contribution was also negative.

From the result, temperature $T_{i s o}$ (Table 3) was calculated at which the enantioselectivity is lost and the elution sequence changes. In most cases, $T_{i s o}$ was above $50{ }^{\circ} \mathrm{C}$, but for analyte 3 on Chirobiotic $\mathrm{T}$ it was $-26^{\circ} \mathrm{C}$. These results indicate that for most of the compounds a cold enantioseparation should be recommended for the best resolution, except for analyte $\mathbf{3}$ on the T column, where positive enthalpy and entropy changes were observed. 
Table 3. Thermodynamic parameters, $\Delta H^{\circ}, \Delta S^{0^{*}}, \Delta\left(\Delta H^{\circ}\right), \Delta\left(\Delta S^{\circ}\right), \Delta\left(\Delta G^{\circ}\right)$, correlation coefficients $\left(R^{2}\right)$ and temperatures $T_{i s o}$ of analytes $\mathbf{1 - 5}$ on Chirobiotic T and TAG columns

\begin{tabular}{|c|c|c|c|c|c|c|c|c|c|}
\hline Analyte & Column & $\begin{array}{l}\text { Stereo- } \\
\text { isomer }\end{array}$ & $\begin{array}{c}-\Delta H^{\circ} \\
\left(\mathrm{kJ} \mathrm{mol}^{-1}\right)\end{array}$ & $\begin{array}{c}-\Delta S^{\sigma^{*}} \\
\left(\mathrm{~J} \mathrm{~mol}^{-1} K^{-1}\right)\end{array}$ & $\begin{array}{c}\text { Correlation } \\
\text { coefficient } \\
\left(\boldsymbol{R}^{2}\right) \\
\end{array}$ & $\begin{array}{c}-\Delta\left(\Delta H^{9}\right) \\
\left(\mathrm{kJ} \mathrm{mol}^{-1}\right)\end{array}$ & $\begin{array}{c}-\Delta(\Delta S 9) \\
\left(\mathrm{J} \mathrm{mol}^{-1} \mathbf{K}^{-1}\right)\end{array}$ & $\begin{array}{c}-\Delta(\Delta G)_{298 K} \\
\left(\mathrm{~kJ} \mathrm{~mol}^{-1}\right)\end{array}$ & $\begin{array}{c}T_{i s o} \\
\left({ }^{\circ} \mathrm{C}\right)\end{array}$ \\
\hline \multirow{4}{*}{1} & \multirow{2}{*}{$\mathbf{T}$} & 1 & 8.1 & 16.1 & 0.9946 & \multirow{2}{*}{0.61} & \multirow{2}{*}{1.17} & \multirow{2}{*}{0.30} & \multirow{2}{*}{248} \\
\hline & & 2 & 8.7 & 17.3 & 0.9950 & & & & \\
\hline & \multirow{2}{*}{ TAG } & 1 & 9.5 & 17.7 & 0.9949 & \multirow{2}{*}{0.98} & \multirow{2}{*}{2.16} & \multirow{2}{*}{0.35} & \multirow{2}{*}{179} \\
\hline & & 2 & 10.5 & 19.8 & 0.9960 & & & & \\
\hline \multirow{4}{*}{2} & \multirow{2}{*}{$\mathbf{T}$} & 1 & 5.6 & 5.1 & 0.9966 & \multirow{2}{*}{0.61} & \multirow{2}{*}{1.86} & \multirow{2}{*}{0.06} & \multirow{2}{*}{57} \\
\hline & & 2 & 6.2 & 7.0 & 0.9977 & & & & \\
\hline & \multirow{2}{*}{ TAG } & 1 & 6.7 & 3.9 & 0.9921 & \multirow{2}{*}{0.00} & \multirow{2}{*}{0.00} & \multirow{2}{*}{0.00} & \multirow{2}{*}{-} \\
\hline & & 2 & 6.7 & 3.9 & 0.9921 & & & & \\
\hline \multirow{4}{*}{3} & \multirow{2}{*}{$\mathbf{T}$} & 1 & 14.1 & 33.5 & 0.9911 & \multirow{2}{*}{-1.50} & \multirow{2}{*}{-6.05} & \multirow{2}{*}{0.30} & \multirow{2}{*}{-26} \\
\hline & & 2 & 12.6 & 27.4 & 0.9903 & & & & \\
\hline & \multirow{2}{*}{ TAG } & 1 & 27.9 & 77.3 & 0.9901 & \multirow{2}{*}{3.31} & \multirow{2}{*}{10.22} & \multirow{2}{*}{0.25} & \multirow{2}{*}{50} \\
\hline & & 2 & 31.2 & 87.6 & 0.9910 & & & & \\
\hline \multirow{4}{*}{4} & $\mathbf{T}$ & 1 & 7.6 & 15.7 & 0.9960 & 091 & 221 & 025 & 130 \\
\hline & 1 & 2 & 8.5 & 17.9 & 0.9961 & 0.91 & 2.21 & 0.25 & 139 \\
\hline & $\mathbf{T A C}$ & 1 & 7.8 & 14.1 & 0.9906 & 079 & 130 & 040 & 338 \\
\hline & IAG & 2 & 8.6 & 15.4 & 0.9922 & 0.19 & 1.50 & 0.40 & 358 \\
\hline & $\mathbf{T}$ & 1 & 8.0 & 16.1 & 0.9985 & 054 & 147 & 010 & 03 \\
\hline 5 & 1 & 2 & 8.5 & 17.6 & 0.9985 & 0.54 & $1.4 /$ & 0.10 & 93 \\
\hline 5 & TAG & 1 & 8.8 & 15.7 & 0.9924 & 102 & 267 & 0.20 & 108 \\
\hline & & 2 & 9.8 & 18.4 & 0.9944 & & & & \\
\hline
\end{tabular}

Mobile phase, $0.1 \%$ TEAA $(\mathrm{pH}=4.1) / \mathrm{MeOH}=10 / 90(\mathrm{v} / \mathrm{v}) ; \Delta S^{\sigma^{*}}=\Delta S^{\circ}+R \ln \Phi$, where $\Phi$ is the inverse of the phase ratio; $R^{2}$, correlation coefficient of the van't Hoff plot, $\ln k-1 / T$ curves; $T_{i s o}$, temperature of $\ln k-1 / T$ curves where the enantioselectivity balances out. 


\subsection{Enantioseparation of isoxazoline-fused 2-aminocyclopentane- carboxylic acid analogues on macrocyclic antibiotic-based CSPS}

These analytes possess an isoxazoline-fused cyclopentane skeleton. Besides carboxy and primary amino groups, analogues $\mathbf{6}$ and $\mathbf{8}$ bear a methyl group on position 3, and analytes 7 and 9 an ethyl group on position 3.

\subsubsection{Effects of the nature of the mobile phase}

All data relating to the separation of the analytes, including the $k^{\prime}, \alpha, R_{S}$ and elution sequence for each analyte on the five different Chirobiotic columns, are given in Table 4. All the compounds mentioned in Table 4 were evaluated with different mobile phases, with eluent compositions varying between $0.1 \%$ TEAA $(\mathrm{pH}=4.1) / \mathrm{MeOH}=98 / 2$ and 10/90 $(v / v)$. For comparison purposes and to simplify the presentation, Table 4 lists only the chromatographic results obtained at some mobile phase compositions.

In most cases, the retention factors were lower on the Chirobiotic T2 column (except for analytes $\mathbf{6 c}, \mathbf{6 d}$ and $\mathbf{7 c}, \mathbf{7 d}$ ) than on native teicoplanin. Similar results were observed in this study for monoterpene-based analogues and $\beta$-amino acids [62,137-140].

As regards the dependence of the retention factors on the $\mathrm{MeOH}$ content, in most cases a U-shaped curve was observed for all analytes. The $k$ ' values increased with increasing water content (hydrophobic interactions) and when the $\mathrm{MeOH}$ content of the mobile phase exceeded $\sim 50 \%$ the retention factors also increased (HILIC).

The tendencies of the $\alpha$ and $R_{S}$ values were the same in most cases. For $6 \mathbf{a}-\mathbf{- 6} \mathbf{d}$ and $\mathbf{7 a - 7 d}$, the resolutions were highest on Chirobiotic TAG (except for analytes $7 \mathbf{a}, 7 \mathbf{7 b}$ ). The vancomycin-based columns were not able to separate the enantiomers of analytes $\mathbf{6 a - 6 d}$ and 7a-7d. On the other hand, these columns gave the best selectivity and resolution values for analytes 8a-8d and 9a-9d (mainly for cis analogues). In the comparison of the Chirobiotic V and VAG columns, the results were the same as in the case of the $\mathrm{T}$ and TAG selectors; the retentions were higher on the aglycone-containing CSP.

Determination of the elution sequence is often a very important task. The proportion of $\mathrm{MeOH}$ did not affect the elution sequence. For $\mathbf{6 c - 6 d}$ and $\mathbf{7 c - 7 d}$, the elution sequence was changed when the TAG column was used, but the same result was observed for all of compounds $\mathbf{8}$ and $\mathbf{9}$. Between the V and VAG columns, no change in elution 
sequence was observed. In the case of cis analytes, the elution sequence on V and VAG was the same as that on TAG.

Table 4. Retention factors of the first-eluting enantiomer $\left(k_{l}^{\prime}\right)$, separation factors $(\alpha)$, resolutions $\left(R_{S}\right)$ and elution sequences of regio- and stereoisomers of isoxazoline-fused cispentacin analogues in RP mode

\begin{tabular}{|c|c|c|c|c|c|c|}
\hline Compound & Column & $\begin{array}{c}\text { Mobile phase } \\
\text { TEAA/MeOH } \\
(v / v)\end{array}$ & $k_{1}^{\prime}$ & $\alpha$ & $\boldsymbol{R}_{S}$ & $\begin{array}{c}\text { Elution } \\
\text { sequence }\end{array}$ \\
\hline \multirow[t]{9}{*}{$6 a, 6 b$} & $\mathbf{T}$ & $90 / 10$ & 2.63 & 1.00 & 0.00 & - \\
\hline & & $60 / 40$ & 2.31 & 1.01 & 0.20 & $\mathbf{a}<\mathbf{b}$ \\
\hline & & $10 / 90$ & 4.76 & 1.07 & 0.80 & $\mathbf{a}<\mathbf{b}$ \\
\hline & T2 & $90 / 10$ & 0.93 & 1.10 & 0.70 & $\mathbf{a}<\mathbf{b}$ \\
\hline & & $60 / 40$ & 0.91 & 1.13 & 1.00 & $\mathbf{a}<\mathbf{b}$ \\
\hline & & $10 / 90$ & 2.96 & 1.16 & 1.65 & $\mathbf{a}<\mathbf{b}$ \\
\hline & TAG & $90 / 10$ & 4.31 & 1.19 & 1.80 & $\mathbf{a}<\mathbf{b}$ \\
\hline & & $60 / 40$ & 2.73 & 1.26 & 2.25 & $\mathbf{a}<\mathbf{b}$ \\
\hline & & $10 / 90$ & 4.76 & 1.33 & 3.25 & $\mathbf{a}<\mathbf{b}$ \\
\hline \multirow[t]{6}{*}{$6 c, 6 d$} & $\mathbf{T}$ & $90 / 10$ & 1.85 & 1.00 & 0.00 & - \\
\hline & & $10 / 90$ & 7.51 & 1.01 & 0.20 & $\mathbf{d}<\mathbf{c}$ \\
\hline & T2 & $90 / 10$ & 1.39 & 1.00 & 0.00 & - \\
\hline & & $10 / 90$ & 8.16 & 1.04 & 0.65 & $\mathbf{d}<\mathbf{c}$ \\
\hline & TAG & $90 / 10$ & 3.26 & 1.06 & 0.70 & $\mathbf{c}<\mathbf{d}$ \\
\hline & & $10 / 90$ & 8.20 & 1.02 & 0.20 & $\mathbf{c}<\mathbf{d}$ \\
\hline \multirow[t]{9}{*}{$7 \mathbf{a}, 7 \mathbf{b}$} & $\mathbf{T}$ & $90 / 10$ & 1.88 & 1.06 & 0.65 & $\mathbf{a}<\mathbf{b}$ \\
\hline & & $60 / 40$ & 1.77 & 1.09 & 0.85 & $\mathbf{a}<\mathbf{b}$ \\
\hline & & $10 / 90$ & 3.75 & 1.07 & 1.00 & $\mathbf{a}<\mathbf{b}$ \\
\hline & $\mathrm{T} 2$ & $90 / 10$ & 1.07 & 1.14 & 0.80 & $\mathbf{a}<\mathbf{b}$ \\
\hline & & $60 / 40$ & 0.95 & 1.18 & 1.20 & $\mathbf{a}<\mathbf{b}$ \\
\hline & & $10 / 90$ & 2.28 & 1.24 & 2.60 & $\mathbf{a}<\mathbf{b}$ \\
\hline & TAG & $90 / 10$ & 5.63 & 1.18 & 1.85 & $\mathbf{a}<\mathbf{b}$ \\
\hline & & $60 / 40$ & 2.92 & 1.30 & 2.25 & $\mathbf{a}<\mathbf{b}$ \\
\hline & & $10 / 90$ & 4.65 & 1.18 & 1.90 & $\mathbf{a}<\mathbf{b}$ \\
\hline \multirow[t]{7}{*}{$7 c, 7 d$} & $\mathbf{T}$ & $90 / 10$ & 2.55 & 1.00 & 0.00 & - \\
\hline & & $10 / 90$ & 6.52 & 1.00 & 0.00 & - \\
\hline & T2 & $90 / 10$ & 1.64 & 1.00 & 0.00 & - \\
\hline & & $10 / 90$ & 6.64 & 1.03 & 0.60 & $\mathbf{d}<\mathbf{c}$ \\
\hline & TAG & $90 / 10$ & 4.98 & 1.10 & 1.40 & $\mathbf{c}<\mathbf{d}$ \\
\hline & & $60 / 40$ & 4.52 & 1.09 & 1.55 & $\mathbf{c}<\mathbf{d}$ \\
\hline & & $10 / 90$ & 6.95 & 1.03 & 0.40 & $\mathbf{c}<\mathbf{d}$ \\
\hline \multirow[t]{10}{*}{$\mathbf{8 a}, \mathbf{8 b}$} & $T$ & $90 / 10$ & 2.09 & 1.00 & 0.00 & - \\
\hline & & $10 / 90$ & 5.01 & 1.17 & 1.45 & $\mathbf{a}<\mathbf{b}$ \\
\hline & T2 & $90 / 10$ & 1.11 & 1.00 & 0.00 & - \\
\hline & & $10 / 90$ & 3.66 & 1.00 & 0.00 & - \\
\hline & TAG & $90 / 10$ & 6.09 & 1.09 & 1.00 & $\mathbf{b}<\mathbf{a}$ \\
\hline & & $10 / 90$ & 5.66 & 1.09 & 0.85 & $\mathbf{b}<\mathbf{a}$ \\
\hline & V & $90 / 10$ & 0.30 & 1.15 & 0.55 & $\mathbf{b}<\mathbf{a}$ \\
\hline & & $10 / 90$ & 0.98 & 1.36 & 2.95 & $\mathbf{b}<\mathbf{a}$ \\
\hline & VAG & $90 / 10$ & 0.57 & 1.18 & 1.10 & $\mathbf{b}<\mathbf{a}$ \\
\hline & & $10 / 90$ & 1.18 & 1.31 & 2.70 & $\mathbf{b}<\mathbf{a}$ \\
\hline
\end{tabular}


Table 4 (continued)

\begin{tabular}{|c|c|c|c|c|c|c|}
\hline Compound & Column & $\begin{array}{c}\text { Mobile phase } \\
\text { TEAA/MeOH } \\
(v / v)\end{array}$ & $k_{1}^{\prime}$ & $\alpha$ & $\boldsymbol{R}_{S}$ & $\begin{array}{c}\text { Elution } \\
\text { sequence }\end{array}$ \\
\hline \multirow[t]{10}{*}{$\mathbf{8 c}, \mathbf{8 d}$} & \multirow[t]{2}{*}{$\mathbf{T}$} & $90 / 10$ & 1.90 & 1.13 & 1.30 & $\mathbf{d}<\mathbf{c}$ \\
\hline & & $10 / 90$ & 5.71 & 1.02 & 0.30 & $\mathbf{d}<\mathbf{c}$ \\
\hline & \multirow[t]{2}{*}{ T2 } & $90 / 10$ & 1.07 & 1.16 & 1.00 & $\mathbf{d}<\mathbf{c}$ \\
\hline & & $10 / 90$ & 3.23 & 1.14 & 1.65 & $\mathbf{d}<\mathbf{c}$ \\
\hline & \multirow[t]{2}{*}{ TAG } & $90 / 10$ & 3.18 & 1.06 & 0.60 & $c<\mathbf{d}$ \\
\hline & & $10 / 90$ & 5.75 & 1.24 & 2.15 & $c<\mathbf{d}$ \\
\hline & \multirow[t]{2}{*}{ V } & $90 / 10$ & 0.16 & 1.25 & 0.60 & $\mathbf{d}<\mathbf{c}$ \\
\hline & & $10 / 90$ & 0.78 & 1.13 & 0.80 & $\mathbf{d}<\mathbf{c}$ \\
\hline & \multirow[t]{2}{*}{ VAG } & $90 / 10$ & 0.54 & 1.00 & 0.00 & - \\
\hline & & $10 / 90$ & 1.63 & 1.06 & 0.60 & $\mathbf{d}<\mathbf{c}$ \\
\hline \multirow[t]{10}{*}{$9 a, 9 b$} & \multirow[t]{2}{*}{$\mathbf{T}$} & $90 / 10$ & 2.64 & 1.00 & 0.00 & - \\
\hline & & $10 / 90$ & 4.82 & 1.17 & 1.65 & $\mathbf{a}<\mathbf{b}$ \\
\hline & \multirow[t]{2}{*}{ T2 } & $90 / 10$ & 1.10 & 1.00 & 0.00 & - \\
\hline & & $10 / 90$ & 3.72 & 1.00 & 0.00 & - \\
\hline & \multirow[t]{2}{*}{ TAG } & $90 / 10$ & 7.86 & 1.09 & 0.90 & $\mathbf{b}<\mathbf{a}$ \\
\hline & & $10 / 90$ & 4.91 & 1.18 & 2.15 & $\mathbf{b}<\mathbf{a}$ \\
\hline & \multirow[t]{2}{*}{ V } & $90 / 10$ & 0.45 & 1.09 & 0.45 & $\mathbf{b}<\mathbf{a}$ \\
\hline & & $10 / 90$ & 0.92 & 1.35 & 2.60 & $\mathbf{b}<\mathbf{a}$ \\
\hline & \multirow[t]{2}{*}{ VAG } & $90 / 10$ & 0.81 & 1.16 & 1.35 & $\mathbf{b}<\mathbf{a}$ \\
\hline & & $10 / 90$ & 1.08 & 1.31 & 3.00 & $\mathbf{b}<\mathbf{a}$ \\
\hline \multirow[t]{5}{*}{ 9c,9d } & $\mathbf{T}$ & $10 / 90$ & 4.50 & 1.08 & 1.10 & $\mathbf{d}<\mathbf{c}$ \\
\hline & T2 & $10 / 90$ & 2.88 & 1.14 & 1.55 & $\mathbf{d}<\mathbf{c}$ \\
\hline & TAG & $10 / 90$ & 4.60 & 1.27 & 2.50 & $\mathbf{c}<\mathbf{d}$ \\
\hline & V & $10 / 90$ & 0.71 & 1.08 & 0.50 & $\mathbf{d}<\mathbf{c}$ \\
\hline & VAG & $10 / 90$ & 1.47 & 1.05 & 0.55 & $\mathbf{d}<\mathbf{c}$ \\
\hline
\end{tabular}

Chromatographic conditions: selectors and columns. T and T2, teicoplanin, Chirobiotic T and T2; TAG, teicoplanin aglycon, Chirobiotic TAG; V, vancomycin, Chirobiotic V; VAG, vancomycin aglycon, Chirobiotic VAG; mobile phase, $0.1 \%$ TEAA $(\mathrm{pH}=$ 4.1)/MeOH $(v / v)$; temperature, ambient; flow rate, $0.5 \mathrm{~mL} \mathrm{~min}^{-1}$; detection, $210 \mathrm{~nm}$

On comparison of the PI and PO modes, the retention factors were lower in the PI mode (except for analytes $\mathbf{7 a}, \mathbf{7 b}$ on $\mathrm{T} 2, \mathbf{8 a}, \mathbf{8 b}$ on $\mathrm{T}$ and $\mathrm{TAG}$, and $\mathbf{9 a}, \mathbf{9 b}$ on the TAG column). In a few cases, the lower retention factors resulted in higher selectivity and resolution values in the PI mode (Table 5). For vancomycin-based CSPs, the results were the same as in the RP mode.

The differences in the PO and PI modes can also be observed for the elution sequence. In cases of $\mathbf{6 a - 6 d}$ and $\mathbf{7 a - 7 d}$ as analytes, the elution sequence in the PI mode was the opposite of that in the PO mode on the Chirobiotic T column. In most cases, the sequence was not changed (except for analytes 9c,9d) on the T2 CSP. On the V and VAG columns, the elution sequence was the same for all analytes. 
Table 5. Retention factors of the first-eluting enantiomer $\left(k_{1}{ }^{\prime}\right)$, separation factors $(\alpha)$, resolutions $\left(R_{S}\right)$ and elution sequences of regio- and stereoisomers of isoxazoline-fused cispentacin analogues in PO and PI modes

\begin{tabular}{|c|c|c|c|c|c|c|}
\hline Compound & Column & $\begin{array}{c}\text { Mobile phase } \\
\text { MeOH }(100 \%) \\
\text { MeOH/AcOH/TEA } \\
(v / v / v)\end{array}$ & $\boldsymbol{k}_{1}^{\prime}$ & $\alpha$ & $\boldsymbol{R}_{S}$ & $\begin{array}{c}\text { Elution } \\
\text { sequence }\end{array}$ \\
\hline \multirow[t]{6}{*}{ 6a,6b } & $\mathbf{T}$ & 100 & 9.29 & 1.11 & 0.90 & $\mathbf{b}<\mathbf{a}$ \\
\hline & & $100 / 0.1 / 0.1$ & 7.78 & 1.03 & 0.35 & $\mathbf{a}<\mathbf{b}$ \\
\hline & T2 & 100 & 5.23 & 1.16 & 0.90 & $\mathbf{a}<\mathbf{b}$ \\
\hline & & $100 / 0.1 / 0.1$ & 4.91 & 1.00 & 0.00 & - \\
\hline & TAG & 100 & 11.91 & 1.05 & 0.30 & $\mathbf{b}<\mathbf{a}$ \\
\hline & & $100 / 0.1 / 0.1$ & 8.16 & 1.00 & 0.00 & - \\
\hline \multirow[t]{6}{*}{$6 c, 6 d$} & $\mathbf{T}$ & 100 & 14.70 & 1.04 & 0.40 & $\mathbf{d}<\mathbf{c}$ \\
\hline & & $100 / 0.1 / 0.1$ & 7.41 & 1.04 & 0.95 & $\mathbf{c}<\mathbf{d}$ \\
\hline & $\mathbf{T} 2$ & 100 & 16.65 & 1.04 & 0.65 & $\mathbf{d}<\mathrm{c}$ \\
\hline & & $100 / 0.1 / 0.1$ & 7.78 & 1.07 & 0.30 & $\mathbf{d}<\mathbf{c}$ \\
\hline & TAG & 100 & 7.48 & 1.00 & 0.00 & - \\
\hline & & $100 / 0.1 / 0.1$ & 7.45 & 1.00 & 0.00 & - \\
\hline \multirow[t]{6}{*}{$7 \mathbf{a}, 7 \mathbf{b}$} & $\mathbf{T}$ & 100 & 7.30 & 1.00 & 0.00 & - \\
\hline & & $100 / 0.1 / 0.1$ & 6.66 & 1.02 & 0.25 & $\mathbf{a}<\mathbf{b}$ \\
\hline & T2 & 100 & 4.19 & 1.24 & 1.40 & $\mathbf{a}<\mathbf{b}$ \\
\hline & & $100 / 0.1 / 0.1$ & 4.91 & 1.21 & 1.20 & $\mathbf{a}<\mathbf{b}$ \\
\hline & TAG & 100 & 12.91 & 1.00 & 0.00 & - \\
\hline & & $100 / 0.1 / 0.1$ & 11.01 & 1.26 & 1.20 & $\mathbf{a}<\mathbf{b}$ \\
\hline \multirow[t]{6}{*}{$7 c, 7 d$} & $\mathbf{T}$ & 100 & 16.59 & 1.00 & 0.00 & - \\
\hline & & $100 / 0.1 / 0.1$ & 6.41 & 1.00 & 0.00 & - \\
\hline & T2 & 100 & 14.49 & 1.17 & 1.00 & $\mathbf{d}<\mathbf{c}$ \\
\hline & & $100 / 0.1 / 0.1$ & 9.59 & 1.03 & 0.40 & $\mathbf{d}<\mathrm{c}$ \\
\hline & TAG & 100 & 10.14 & 1.00 & 0.00 & - \\
\hline & & $100 / 0.1 / 0.1$ & 7.38 & 1.00 & 0.00 & - \\
\hline \multirow[t]{10}{*}{$\mathbf{8 a}, \mathbf{8 b}$} & $\mathbf{T}$ & 100 & 7.27 & 1.46 & 3.75 & $\mathbf{a}<\mathbf{b}$ \\
\hline & & $100 / 0.1 / 0.1$ & 9.13 & 1.21 & 1.65 & $\mathbf{a}<\mathbf{b}$ \\
\hline & T2 & 100 & 7.16 & 1.00 & 0.00 & - \\
\hline & & $100 / 0.1 / 0.1$ & 5.92 & 1.03 & 0.25 & $\mathbf{b}<\mathbf{a}$ \\
\hline & TAG & 100 & 11.63 & 1.29 & 1.45 & $\mathbf{a}<\mathbf{b}$ \\
\hline & & $100 / 0.1 / 0.1$ & 15.49 & 1.08 & 0.50 & $\mathbf{b}<\mathbf{a}$ \\
\hline & $\mathbf{V}$ & 100 & 1.95 & 1.40 & 2.70 & $\mathbf{b}<\mathbf{a}$ \\
\hline & & $100 / 0.1 / 0.1$ & 1.60 & 1.44 & 3.05 & $\mathbf{b}<\mathbf{a}$ \\
\hline & VAG & 100 & 2.41 & 1.34 & 3.50 & $\mathbf{b}<\mathbf{a}$ \\
\hline & & $100 / 0.1 / 0.1$ & 1.73 & 1.36 & 3.10 & $\mathbf{b}<\mathbf{a}$ \\
\hline \multirow[t]{10}{*}{$8 c, 8 d$} & $T$ & 100 & 11.76 & 1.03 & 0.25 & $\mathbf{c}<\mathbf{d}$ \\
\hline & & $100 / 0.1 / 0.1$ & 785 & 1.05 & 0.45 & $c<d$ \\
\hline & T2 & 100 & 5.57 & 1.29 & 2.00 & $d<c$ \\
\hline & & $100 / 0.1 / 0.1$ & 3.19 & 1.23 & 1.35 & $\mathbf{d}<\mathrm{c}$ \\
\hline & TAG & 100 & 14.75 & 1.06 & 0.35 & $c<d$ \\
\hline & & $100 / 0.1 / 0.1$ & 6.00 & 1.09 & 1.25 & $\mathbf{c}<\mathbf{d}$ \\
\hline & $\mathbf{V}$ & 100 & 1.74 & 1.14 & 1.10 & $\mathbf{d}<\mathbf{c}$ \\
\hline & & $100 / 0.1 / 0.1$ & 1.50 & 1.00 & 0.00 & - \\
\hline & VAG & 100 & 3.45 & 1.08 & 0.75 & $\mathbf{d}<\mathbf{c}$ \\
\hline & & $100 / 0.1 / 0.1$ & 1.58 & 1.14 & 0.95 & $\mathbf{d}<\mathbf{c}$ \\
\hline
\end{tabular}


Table 5 (continued)

\begin{tabular}{|c|c|c|c|c|c|c|}
\hline Compound & Column & $\begin{array}{c}\text { Mobile phase } \\
\text { MeOH }(\mathbf{1 0 0 \%}) \\
\text { MeOH/AcOH/TEA } \\
(v / v / v)\end{array}$ & $k_{1}^{\prime}$ & $\alpha$ & $\boldsymbol{R}_{S}$ & $\begin{array}{c}\text { Elution } \\
\text { sequence }\end{array}$ \\
\hline \multirow[t]{10}{*}{ 9a,9b } & $\mathbf{T}$ & 100 & 10.06 & 1.20 & 1.70 & $\mathbf{a}<\mathbf{b}$ \\
\hline & & $100 / 0.1 / 0.1$ & 7.67 & 1.11 & 0.95 & $\mathbf{a}<\mathbf{b}$ \\
\hline & $\mathbf{T 2}$ & 100 & 7.08 & 1.00 & 0.00 & - \\
\hline & & $100 / 0.1 / 0.1$ & 6.46 & 1.00 & 0.00 & - \\
\hline & TAG & 100 & 9.25 & 1.24 & 0.90 & $\mathbf{b}<\mathbf{a}$ \\
\hline & & $100 / 0.1 / 0.1$ & 11.07 & 1.25 & 1.50 & $\mathbf{b}<\mathbf{a}$ \\
\hline & $\mathbf{V}$ & 100 & 1.81 & 1.38 & 2.20 & $\mathbf{b}<\mathbf{a}$ \\
\hline & & $100 / 0.1 / 0.1$ & 1.47 & 1.41 & 3.30 & $\mathbf{b}<\mathbf{a}$ \\
\hline & VAG & 100 & 2.18 & 1.34 & 3.15 & $\mathbf{b}<\mathbf{a}$ \\
\hline & & $100 / 0.1 / 0.1$ & 1.49 & 1.38 & 3.10 & $\mathbf{b}<\mathbf{a}$ \\
\hline \multirow[t]{10}{*}{ 9c,9d } & $\mathbf{T}$ & 100 & 8.76 & 1.09 & 0.65 & $\mathbf{d}<\mathbf{c}$ \\
\hline & & $100 / 0.1 / 0.1$ & 5.74 & 1.12 & 1.15 & $\mathbf{d}<\mathbf{c}$ \\
\hline & $\mathbf{T 2}$ & 100 & 4.90 & 1.26 & 1.75 & $\mathbf{d}<\mathbf{c}$ \\
\hline & & $100 / 0.1 / 0.1$ & 4.54 & 1.06 & 0.40 & $\mathbf{c}<\mathbf{d}$ \\
\hline & TAG & 100 & 13.94 & 1.03 & 0.30 & $\mathbf{c}<\mathbf{d}$ \\
\hline & & $100 / 0.1 / 0.1$ & 6.54 & 1.14 & 0.50 & $\mathbf{c}<\mathbf{d}$ \\
\hline & $\mathbf{V}$ & 100 & 1.51 & 1.09 & 0.45 & $d<c$ \\
\hline & & $100 / 0.1 / 0.1$ & 1.09 & 1.12 & 1.30 & $d<c$ \\
\hline & VAG & 100 & 3.24 & 1.06 & 0.50 & $\mathbf{d}<\mathbf{c}$ \\
\hline & & $100 / 0.1 / 0.1$ & 1.28 & 1.10 & 0.55 & $\mathbf{d}<\mathbf{c}$ \\
\hline
\end{tabular}

Chromatographic conditions: selectors and columns. T and T2, teicoplanin, Chirobiotic T and T2; TAG, teicoplanin aglycone, Chirobiotic TAG; V, vancomycin, Chirobiotic V; VAG, vancomycin aglycon, Chirobiotic VAG; mobile phase, $0.1 \%$ TEAA ( $\mathrm{pH}=$ 4.1) $/ \mathrm{MeOH}(v / v)$; temperature, ambient; flow rate, $0.5 \mathrm{~mL} \mathrm{~min}^{-1}$; detection. $210 \mathrm{~nm}$

\subsubsection{Effects of the structures of the molecules}

The structures of the analytes also influenced the chiral recognition. Generally, the $\alpha$ and $R_{S}$ values were better in the case of cis compounds for all five columns. However, there was no separation on the V and VAG columns for analytes $\mathbf{6 a - 6 d}$ and 7a-7d, which can be attributed to the blocking of enantioselective interactions due to the unfavourable position of the R substituent. As shown in Tables $\mathbf{4}$ and $\mathbf{5}$, the enantioseparation depended on the positions of the amino and carboxyl groups; the cis enantiomers probably fit better into the basket, resulting in stronger interactions and better separations.

The position of the methyl or ethyl group also affected the $\alpha$ and $R_{S}$ values. For both $\alpha$ and $R_{S}$, better values were obtained on the teicoplanin or teicoplanin aglyconecontaining CSPs in the case of the methyl-containing analogues: in most cases, enantiomers $\mathbf{6 a}, \mathbf{6 b}$ were better separated than $\mathbf{8 a}, \mathbf{8 b}$, while $\mathbf{8 c}, \mathbf{8 d}$ were better separated than $\mathbf{6 c}, \mathbf{6 d}$. This observation also held true for the ethyl-containing analytes. 


\subsubsection{Separation of four enantiomers of isoxazoline-fused cispentacin analogues}

Since the biological activities of isoxazoline-fused 2-aminocyclopentanecarboxylic acid analogues depend strongly on their configurations, it is a basic task to separate and identify not only the enantiomers, but also the diastereomers in one chromatographic run. The data listed in Table 4 reveal that separation of the four stereoisomers could be achieved in only a few cases. To attain separation of the four stereoisomers in one chromatographic run, the separation was optimized by variation of the CSPs and mobile phase composition. Table 6 illustrates the enantioseparation of all four stereoisomers of isoxazoline-fused 2-aminocyclopentanecarboxylic acid analogues. Unfortunately, no chromatographic condition was found for the baseline separation of $\mathbf{6 a - 6 d}$ and 9a-9d in one chromatographic run.

Table 6. Chromatographic data, retention factors and resolutions for the separation of four stereoisomers of isoxazoline-fused cispentacin derivatives on Chirobiotic TAG, VAG and V columns

\begin{tabular}{ccccccccccc}
\hline Analyte & Column & $\begin{array}{c}\text { Mobile } \\
\text { Phase }\end{array}$ & $\boldsymbol{k}_{1}^{\prime}$ & $\boldsymbol{k}_{2}{ }_{2}$ & $\boldsymbol{k}_{3}$ & $\boldsymbol{k}_{4}{ }^{\prime}$ & $\boldsymbol{R}_{\boldsymbol{S 1}}$ & $\boldsymbol{R}_{S 2}$ & $\boldsymbol{R}_{S 3}$ & $\begin{array}{c}\text { Elution } \\
\text { sequence }\end{array}$ \\
\hline $\mathbf{6}$ & $\mathbf{T A G}$ & $\mathbf{a}$ & 2.73 & 3.45 & 3.95 & 4.13 & 3.10 & 2.05 & 0.80 & $\mathbf{a}<\mathbf{b}<\mathbf{c}<\mathbf{d}$ \\
\hline $\mathbf{7}$ & $\mathbf{T A G}$ & $\mathbf{b}$ & 2.89 & 3.28 & 3.58 & 4.05 & 1.95 & 1.40 & 2.15 & $\mathbf{a}<\mathbf{b}<\mathbf{c}<\mathbf{d}$ \\
\hline $\mathbf{8}$ & $\mathbf{V A G}$ & $\mathbf{c}$ & 2.53 & 2.93 & 3.21 & 3.50 & 1.95 & 1.45 & 1.80 & $\mathbf{b}<\mathbf{d}<\mathbf{c}<\mathbf{a}$ \\
\hline $\mathbf{9}$ & $\mathbf{V}$ & $\mathbf{d}$ & 1.27 & 1.43 & 1.83 & 2.67 & 0.90 & 1.95 & 3.30 & $\mathbf{d}<\mathbf{c}<\mathbf{b}<\mathbf{a}$ \\
\hline
\end{tabular}

Chromatographic conditions: mobile phase, a, 0.1\% TEAA $(\mathrm{pH}=4.1) / \mathrm{MeOH}=60 / 40$ $(v / v), \mathbf{b}, 0.1 \%$ TEAA $(\mathrm{pH}=4.1) / \mathrm{MeOH}(v / v)=80 / 20(v / v) ; \mathbf{c}, \mathrm{MeOH}, 100 \%, \mathbf{d}$, $\mathrm{MeOH} / \mathrm{AcOH} / \mathrm{TEA}=100 / 0.1 / 0.1(\mathrm{v} / \mathrm{v} / \mathrm{v})$; temperature, $25{ }^{\circ} \mathrm{C}$ for analytes 6 and $7,10{ }^{\circ} \mathrm{C}$ for analytes 8 and 9; flow rate, $0.5 \mathrm{~mL} \mathrm{~min}^{-1}$; detection, $210 \mathrm{~nm}$

\subsubsection{Effects of temperature on chiral recognition}

A variable-temperature study was carried out on Chirobiotic T and TAG columns over the temperature range $5-45{ }^{\circ} \mathrm{C}$ (in $10{ }^{\circ} \mathrm{C}$ increments). The measurements were made with the mobile phase $0.1 \%$ TEAA $(\mathrm{pH}=4.1) / \mathrm{MeOH}=10 / 90(v / v)$ system. For the chromatographic data, all of the recorded values decreased with increasing temperature, except for $\mathbf{8 a}, \mathbf{8 b}$ on the teicoplanin aglycone-containing CSP, where $\alpha$ (and $R_{S}$ ) increased 
with increasing temperature. Increasing temperature may influence the peak symmetry and efficiency, and therefore the resolution may also improve.

Thermodynamic parameters were obtained from van't Hoff plots [Eq. (12)] in all cases. The $\Delta H^{\circ}$ and $\Delta S^{\circ *}$ values were calculated from the slopes and intercepts of these plots. In most cases, these values were more negative for the second-eluting enantiomer (Fig. 14) (the exception was analytes $\mathbf{8 a}, \mathbf{8 b}$ on Chirobiotic TAG (Fig. 15)). It is likely that the second-eluting enantiomers have fewer degrees of freedom on the CSP, i.e. they are held at more points or are less able to move or rotate. In these cases, the enthalpy change exceeded the degree of entropy change, and thus the change in Gibbs free energy was also negative.

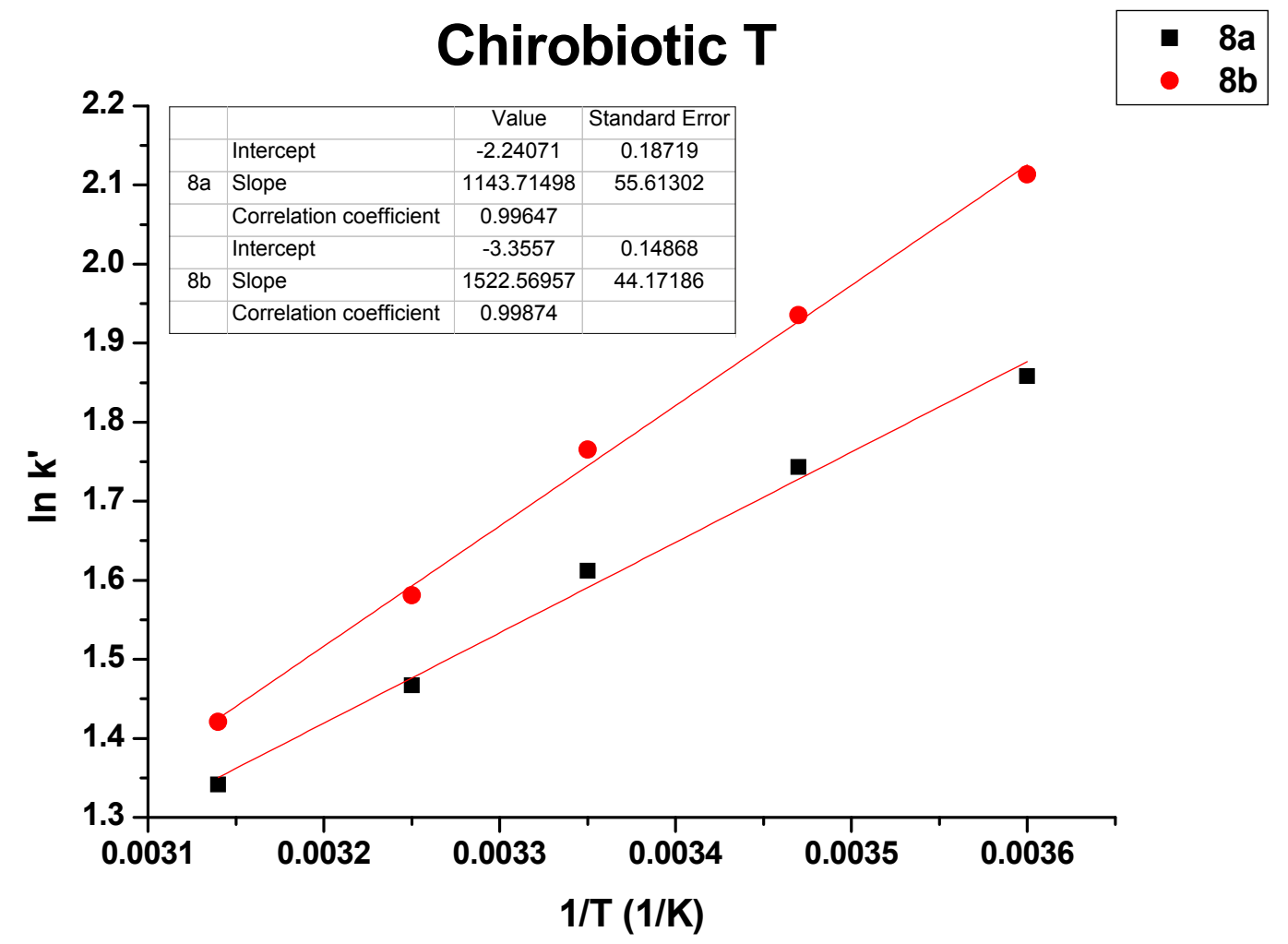

Figure 14. Temperature dependence of analytes $\mathbf{8 a}, \mathbf{8 b}$ on the Chirobiotic T column 


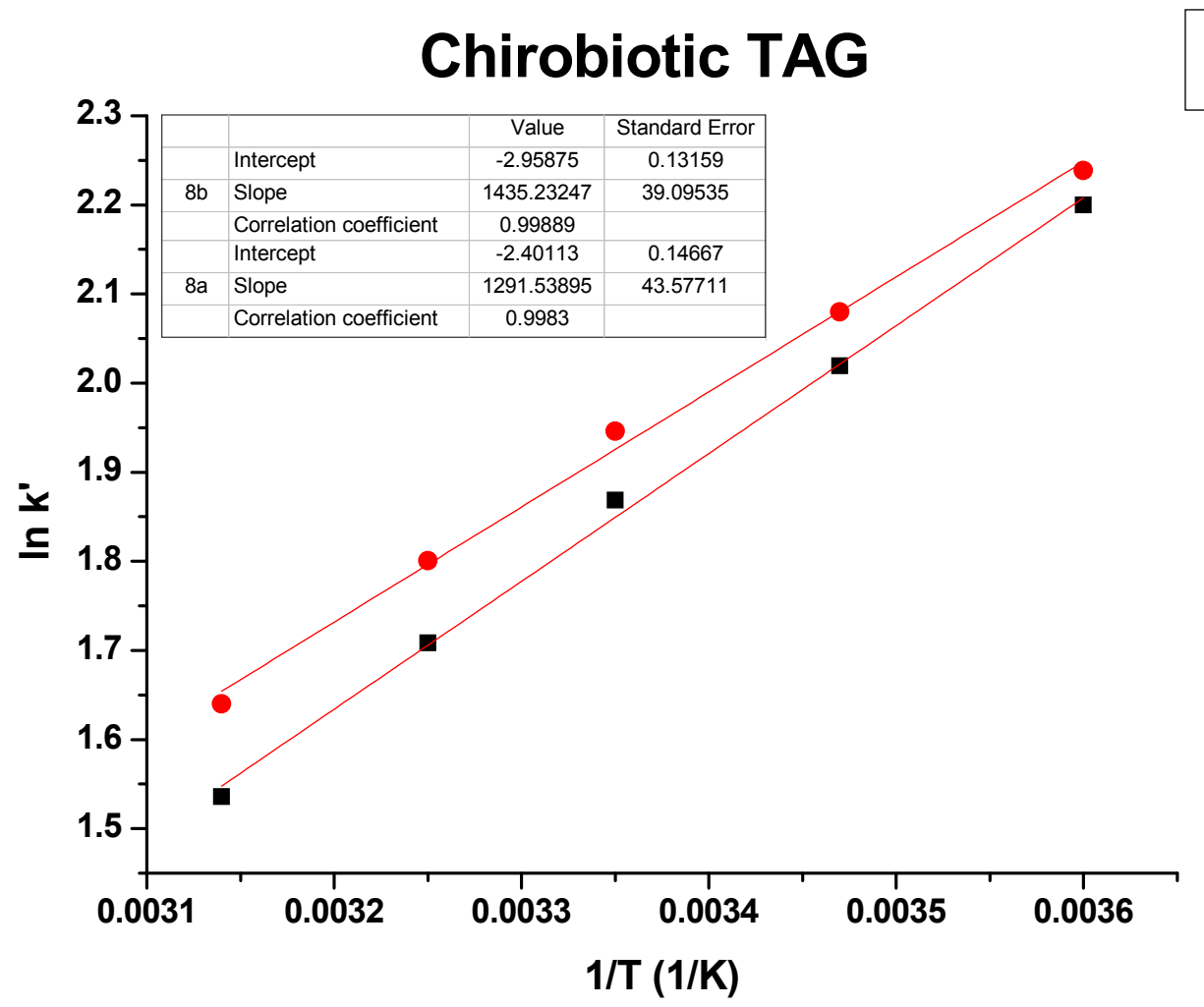

Figure 15. Temperature dependence of analytes $\mathbf{8 a , 8 b}$ on the Chirobiotic TAG column

The evolving interactions between the analytes and the CSP are therefore exothermic. For $\mathbf{8 a}, \mathbf{8 b}$ on the Chirobiotic TAG CSP, the change in entropy dominated, and the $\Delta G^{\circ}$ value was therefore positive (Fig. 16).

Smaller $\Delta H^{\circ}$ and $\Delta S^{\circ *}$ values were observed on the Chirobiotic T column than on the aglycone-containing CSP (Table 7). This may be due to the lack of sugar moeties, and this may promote the interactions between the CSP and the analyte. As shown in Table 7, the enantiomers c,d exhibited smaller, and the enantiomers a,b larger $-\Delta H^{\circ}$ and $-\Delta S^{\circ}$ values on both CSPs. The trans configuration of the amino and carboxy groups in the $\mathbf{c , d}$ enantiomer pairs may sterically inhibit their fit and orientation in the cavity, and the separation was thermodynamically less favorable. The largest $-\Delta H^{\circ}$ and $-\Delta S^{\mathrm{o}^{*}}$ values for all analytes on the TAG CSP indicate that separation on it was sterically favourable. Without sugar units, the compounds fit better into the basket, where they form stronger interactions.

The differences in the changes in enthalpy and entropy, $\Delta\left(\Delta H^{\circ}\right)$ and $\Delta\left(\Delta S^{\circ}\right)$, are also presented in Table 7. These values were calculated from $E q$. (15), indicating whether the enantioseparation was enthalpically or entropically driven. The thermodynamic parameter $-\Delta\left(\Delta G^{\circ}\right)$ suggests that TAG induces highly efficient binding to the selector, as reflected by the larger negative $\Delta\left(\Delta G^{\circ}\right)$ values for 6-9 on Chirobiotic TAG. For analytes 6- 
9 on both columns (with the exception of $\mathbf{8 a}, \mathbf{8 b}$ on Chirobiotic TAG), selector-selectand complex formation proceeded via multiple intermolecular interactions and was generally exothermic, with a corresponding negative entropic contribution.

The data were used to calculate the temperature $T_{i s o}$, at which point the enantioselectivity and the elution sequence changed (Table 7). In most cases, $T_{\text {iso }}$ was considerably higher than room temperature; enthalpically driven enantioseparation was obtained. For $\mathbf{8 a}, \mathbf{8 b}$ on Chirobiotic TAG, $T_{\text {iso }}$ was $-15{ }^{\circ} \mathrm{C}$, positive $\Delta\left(\Delta H^{\circ}\right)$ and $\Delta\left(\Delta S^{\circ}\right)$ were observed in the investigated temperature range, and the selectivity increased with increasing temperature. 
Table 7. Thermodynamic parameters, $\Delta H^{\circ}, \Delta S^{0^{*}}, \Delta\left(\Delta H^{\circ}\right), \Delta\left(\Delta S^{9}\right), \Delta\left(\Delta G^{\circ}\right)$, correlation coefficients $\left(R^{2}\right)$ and temperature $T_{i s o}$ of analytes 6-9 on Chirobiotic $\mathrm{T}$ and TAG columns

\begin{tabular}{|c|c|c|c|c|c|c|c|c|c|}
\hline Analyte & Column & $\begin{array}{l}\text { Stereo- } \\
\text { isomer }\end{array}$ & $\begin{array}{c}-\Delta \mathbf{H}^{\circ} \\
\left(\mathrm{kJ} \mathrm{mol}^{-1}\right)\end{array}$ & $\begin{array}{c}-\Delta \mathrm{S}^{\circ *} \\
\left(\mathrm{~J} \mathrm{~mol}^{-1} \mathrm{~K}^{-1}\right)\end{array}$ & $\begin{array}{c}\text { Correlation } \\
\text { coefficient } \\
\left(\mathbf{R}^{2}\right) \\
\end{array}$ & $\begin{array}{c}-\Delta\left(\Delta \mathbf{H}^{\circ}\right) \\
\left(\mathrm{KJ} \mathrm{mol}^{-1}\right)\end{array}$ & $\begin{array}{c}-\Delta\left(\Delta S^{\circ}\right) \\
\left(J \mathrm{~mol}^{-1} \mathbf{K}^{-1}\right)\end{array}$ & $\begin{array}{c}-\Delta\left(\Delta \mathrm{G}^{\circ}\right)_{288 \mathrm{~K}} \\
\left(\mathrm{~kJ} \mathrm{~mol}^{-1}\right)\end{array}$ & $\begin{array}{l}\mathbf{T}_{\text {iso }} \\
\left({ }^{\circ} \mathrm{C}\right)\end{array}$ \\
\hline \multirow{4}{*}{$6 a, 6 b$} & \multirow{2}{*}{$\mathbf{T}$} & 1 & 7.65 & 13.7 & 0.9961 & \multirow{2}{*}{1.21} & \multirow{2}{*}{3.71} & \multirow{2}{*}{0.14} & \multirow{2}{*}{54.7} \\
\hline & & 2 & 8.87 & 17.41 & 0.9974 & & & & \\
\hline & \multirow{2}{*}{ TAG } & 1 & 9.82 & 20.06 & 0.9949 & \multirow{2}{*}{3.54} & \multirow{2}{*}{9.53} & \multirow{2}{*}{0.80} & \multirow{2}{*}{98.4} \\
\hline & & 2 & 13.36 & 29.59 & 0.9977 & & & & \\
\hline \multirow{4}{*}{$6 c, 6 d$} & \multirow{2}{*}{$\mathbf{T}$} & 1 & 6.03 & 4.19 & 0.9940 & \multirow{2}{*}{0.66} & \multirow{2}{*}{2.21} & \multirow{2}{*}{0.02} & \multirow{2}{*}{36.3} \\
\hline & & 2 & 6.38 & 5.33 & 0.9930 & & & & \\
\hline & \multirow{2}{*}{ TAG } & 1 & 9.39 & 15.40 & 0.9976 & \multirow{2}{*}{0.17} & \multirow{2}{*}{0.40} & \multirow{2}{*}{0.98} & \multirow{2}{*}{146.8} \\
\hline & & 2 & 9.56 & 15.80 & 0.9977 & & & & \\
\hline \multirow{4}{*}{$7 \mathbf{a}, 7 \mathbf{b}$} & \multirow{2}{*}{$\mathbf{T}$} & 1 & 7.58 & 14.36 & 0.9953 & \multirow{2}{*}{1.56} & \multirow{2}{*}{4.71} & \multirow{2}{*}{0.20} & \multirow{2}{*}{57.9} \\
\hline & & 2 & 9.14 & 19.07 & 0.9973 & & & & \\
\hline & \multirow{2}{*}{ TAG } & 1 & 10.11 & 21.28 & 0.9942 & \multirow{2}{*}{2.14} & \multirow{2}{*}{5.80} & \multirow{2}{*}{0.47} & \multirow{2}{*}{95.7} \\
\hline & & 2 & 12.25 & 27.07 & 0.9964 & & & & \\
\hline \multirow{4}{*}{$7 c, 7 d$} & $\mathbf{T}$ & 1 & 5.88 & 4.21 & 0.9985 & 061 & & 002 & \\
\hline & 1 & 2 & 6.21 & 5.26 & 0.9995 & 0.61 & 2.04 & 0.02 & 36.4 \\
\hline & $\mathbf{T A C}$ & 1 & 9.13 & 14.61 & 0.9952 & 020 & 048 & 006 & 1517 \\
\hline & 1 AG & 2 & 9.33 & 15.09 & 0.9953 & 0.20 & 0.48 & 0.06 & 151.1 \\
\hline & $\mathbf{T}$ & 1 & 9.61 & 18.98 & 0.9952 & 218 & 027 & 048 & 662 \\
\hline $8 \mathrm{gh}$ & $\mathbf{I}$ & 2 & 12.79 & 28.35 & 0.9989 & 3.18 & 9.31 & 0.48 & 66.2 \\
\hline Oa,ON & TAG & 1 & 12.05 & 25.00 & 0.9980 & -121 & -467 & 013 & -151 \\
\hline & I AG & 2 & 10.85 & 20.32 & 0.9969 & -1.21 & $-4.0 /$ & 0.15 & -15.1 \\
\hline
\end{tabular}


Table 7 (continued)

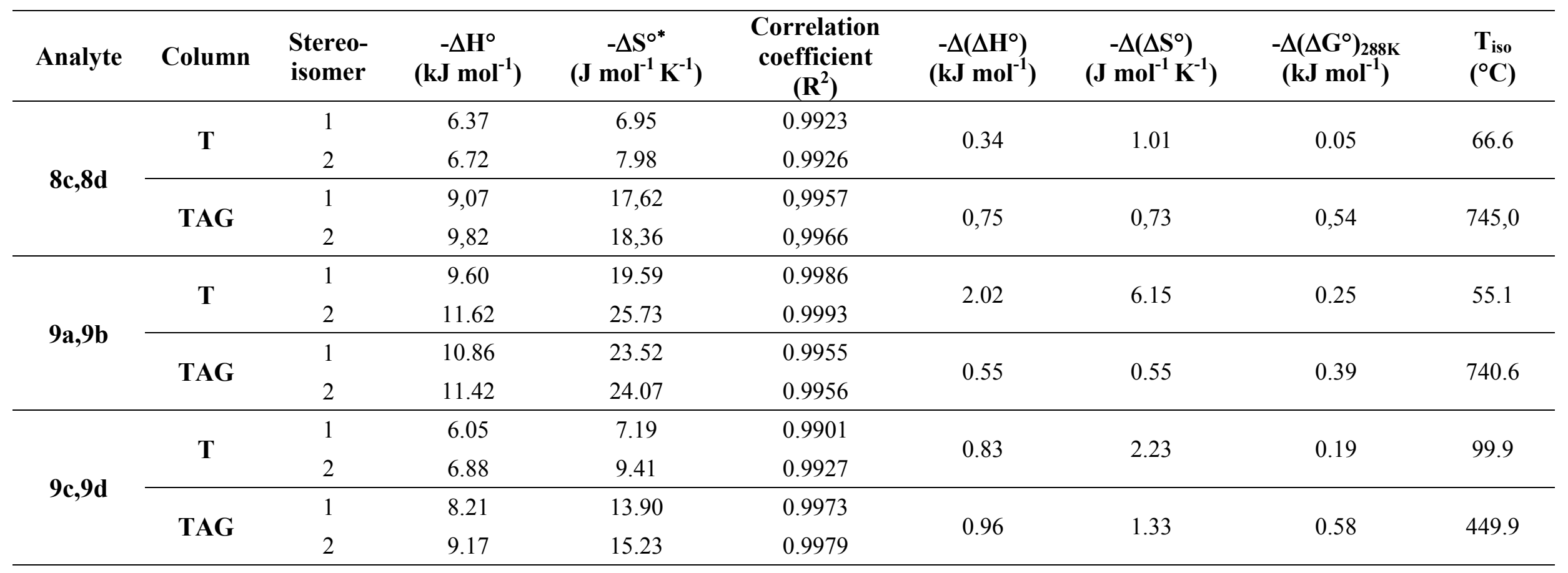

Mobile phase, $0.1 \%$ TEAA $(\mathrm{pH}=4.1) / \mathrm{MeOH}=10 / 90(v / v) ; \Delta S^{0^{*}}=\Delta S^{\circ}+\ln \Phi$, where $\Phi$ is the inverse of the phase ratio; $R^{2}$, is the correlation coefficient of the van't Hoff plot, $\ln k-1 / T$ curves; $T_{i s o}$, the temperature of $\ln k-1 / T$ curves where the enantioselectivity balances out 
For $\mathbf{6 c}, \mathbf{6 d}$ and $\mathbf{7 c , 7 d}$ on the Chirobiotic T CSP, $T_{\text {iso }}$ was $37{ }^{\circ} \mathrm{C}$. For $\mathbf{6 c}, \mathbf{6 d}$ on the Chirobiotic T column with the $0.1 \%$ TEAA $(\mathrm{pH}=4.1) / \mathrm{MeOH}=10 / 90(v / v)$ mobile phase composition, on increase of the temperature from $5{ }^{\circ} \mathrm{C}$ to $55{ }^{\circ} \mathrm{C}, \alpha$ first decreased; then, after a domain where no separation occurred, $\alpha$ slightly increased with increasing temperature and the elution sequence changed (Fig. 16). In a domain around the isoenantioselective temperature, separation of the enantiomers could not be attained.

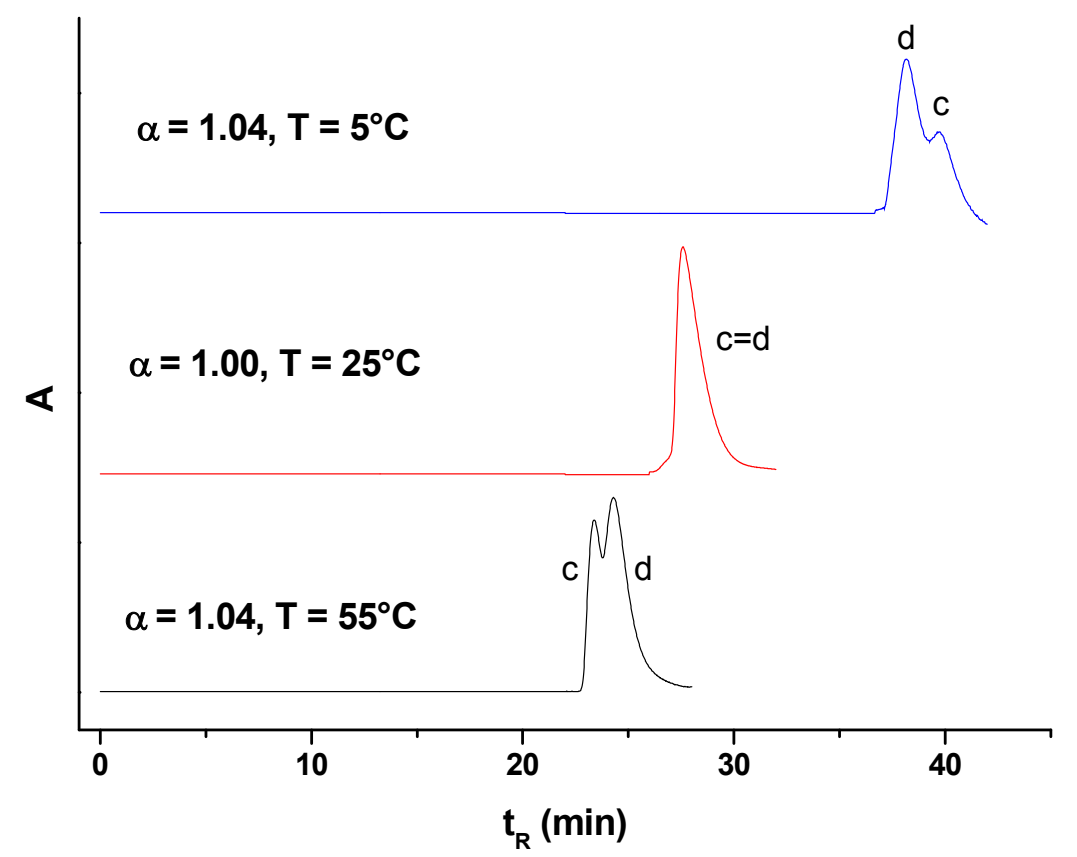

Figure 16. Change of elution sequence on the Chirobiotic T column for analytes $\mathbf{6 c}, \mathbf{6} \mathbf{d}$

This domain may be referred to as a temperature-induced blind zone in chiral recognition [138]. Outside the blind zone, enthalpically or entropically driven enantioseparation can be observed. It should be mentioned that peak inversions on temperature changes have generally been observed only for separations with marginal enantioselectivity [139-142]. 


\subsection{Separation of isoxazoline-fused cispentacin stereoisomers on chiral crown ether-containing CSPS}

The primary interaction in the course of chiral recognition is complex formation between the protonated amino group of the analyte and the CSP. For these types of columns, an acidic modifier may be added to the mobile phase to protonate the primary amino group of the analyte. Stereoselective complexation of the resulting primary ammonium ions $\left(\mathrm{R}_{-} \mathrm{NH}_{3}{ }^{+}\right)$inside the cavity of the crown ether ring of the CSP has been suggested to be essential for chiral recognition (Fig. 8) [143]. Besides these interactions, H-bonding, hydrophobic, dipole-dipole, steric, etc. interactions should likewise be taken into account.

\subsubsection{Effects of the nature and content of the alcholic modifier}

On the three crown ether-based columns, the results of the separation of enantiomers of isoxazoline-fused 2-aminocyclopentanecarboxylic acids were evaluated with different mobile phases consisting of $\mathrm{H}_{2} \mathrm{O} /$ alcohol $+10 \mathrm{mM}$ acid, where the alcohol was $\mathrm{MeOH}, \mathrm{EtOH}$ or IPA $+10 \mathrm{mM} \mathrm{AcOH}$. Data relating to the separation of compounds, including the retention factors, separation factors and resolutions for the analytes on the three CSPs, are given in Table 8. To simplify the presentation and to reduce the huge number of data, Table 8 basically lists only the columns and chromatographic results obtained when $\mathrm{H}_{2} \mathrm{O} / \mathrm{MeOH}=90 / 10$ or $5 / 95(v / v)+10 \mathrm{mM}$ AcOH mobile phases were applied, and for analytes $\mathbf{7 a , 7 b}$ and 7c,7d the dependence of the chromatographic data on the alcohol content is depicted. In Table 8, for purposes of comparison, results are also included where no separation occurred.

At a given mobile phase composition $\left[\mathrm{H}_{2} \mathrm{O} /\right.$ alcohol $=90 / 10$ or $\left.30 / 70(v / v)\right]$, applying $\mathrm{MeOH}$, EtOH or IPA as alcoholic modifier and $10.0 \mathrm{mM} \mathrm{AcOH}$ as acidic modifier, on all three columns the retention factors of the first-eluting enantiomers, $k_{l}$, were largest in the EtOH-containing mobile phase, which is illustrated for analyte 7 on Crown 2 (Fig. 17).

As concerns the separation factors, no general trends could be observed: $\alpha$ was larger for analytes 6a,6b and $\mathbf{6 c}, \mathbf{6 d}$ on Crown 1 in the $\mathrm{MeOH}$, for 7a,7b and 7c,7d on Crown 2 in the MeOH (Fig. 18) and for 8a,8b, 8c,8d, 9a,9b and 9c,9d on Crown 3 in the IPA containing eluent systems. In most cases, $R_{S}$ was larger in the $\mathrm{MeOH}$-containing mobile phase. 
Table 8. Retention factors of the first-eluting enantiomer $\left(k_{l}^{\prime}\right)$, separation factors $(\alpha)$, resolutions $\left(R_{S}\right)$ and elution sequences of isoxazoline-fused cispentacin analogues in $\mathrm{MeOH}$-containing mobile phases

\begin{tabular}{|c|c|c|c|c|c|c|}
\hline Compound & Column & $\begin{array}{c}\text { Mobile phase } \\
(v / v)\end{array}$ & $k_{1}^{\prime}$ & $\alpha$ & $\boldsymbol{R}_{S}$ & $\begin{array}{c}\text { Elution } \\
\text { sequence }\end{array}$ \\
\hline \multirow[t]{4}{*}{$6 a, 6 b$} & Crown 1 & $90 / 10$ & 0.20 & 1.20 & 0.25 & $\mathbf{b}<\mathbf{a}$ \\
\hline & & $5 / 95$ & 1.84 & 1.12 & 0.75 & $\mathbf{b}<\mathbf{a}$ \\
\hline & Crown 2 & $90 / 10$ & 0.03 & 1.00 & 0.00 & - \\
\hline & & $5 / 95$ & 1.76 & 1.11 & 0.25 & $\mathbf{b}<\mathbf{a}$ \\
\hline \multirow[t]{4}{*}{$6 c, 6 d$} & Crown 1 & $90 / 10$ & 0.92 & 1.75 & 2.70 & $\mathbf{c}<\mathbf{d}$ \\
\hline & & $5 / 95$ & 30.52 & 1.00 & 0.00 & - \\
\hline & Crown 2 & $90 / 10$ & 0.39 & 1.34 & 0.80 & $\mathbf{c}<\mathbf{d}$ \\
\hline & & $5 / 95$ & 15.56 & 1.00 & 0.00 & - \\
\hline \multirow[t]{12}{*}{$7 a, 7 b$} & Crown 1 & $90 / 10$ & 0.09 & 1.38 & 0.25 & $\mathbf{b}<\mathbf{a}$ \\
\hline & & $70 / 30$ & 0.11 & 1.00 & 0.00 & - \\
\hline & & $30 / 70$ & 0.21 & 1.00 & 0.00 & - \\
\hline & & $5 / 95$ & 1.50 & 1.18 & 1.25 & $\mathbf{b}<\mathbf{a}$ \\
\hline & Crown 2 & $90 / 10$ & 0.06 & 3.05 & 1.60 & $\mathbf{a}<\mathbf{b}$ \\
\hline & & $70 / 30$ & 0.14 & 2.49 & 1.20 & $\mathbf{a}<\mathbf{b}$ \\
\hline & & $30 / 70$ & 0.53 & 1.00 & 0.00 & - \\
\hline & & $5 / 95$ & 1.39 & 1.15 & 0.85 & $\mathbf{a}<\mathbf{b}$ \\
\hline & Crown 3 & $90 / 10$ & 0.42 & 1.00 & 0.00 & - \\
\hline & & $70 / 30$ & 0.32 & 1.00 & 0.00 & - \\
\hline & & $30 / 70$ & 0.27 & 1.00 & 0.00 & - \\
\hline & & $5 / 95$ & 0.33 & 1.02 & 0.20 & n.d. \\
\hline \multirow[t]{12}{*}{$7 c, 7 d$} & Crown 1 & $90 / 10$ & 0.54 & 1.00 & 0.00 & - \\
\hline & & $70 / 30$ & 0.85 & 1.00 & 0.00 & - \\
\hline & & $30 / 70$ & 3.72 & 1.07 & 0.25 & $\mathbf{c}<\mathbf{d}$ \\
\hline & & $5 / 95$ & 18.28 & 1.10 & 0.45 & $\mathbf{c}<\mathbf{d}$ \\
\hline & Crown 2 & $90 / 10$ & 0.42 & 1.26 & 0.55 & $\mathbf{c}<\mathbf{d}$ \\
\hline & & $70 / 30$ & 0.66 & 1.26 & 0.75 & $\mathbf{c}<\mathbf{d}$ \\
\hline & & $30 / 70$ & 1.96 & 1.06 & 0.45 & $\mathbf{c}<\mathbf{d}$ \\
\hline & & $5 / 95$ & 10.47 & 1.00 & 0.00 & - \\
\hline & Crown 3 & $90 / 10$ & 0.88 & 1.30 & 1.55 & $\mathbf{c}<\mathbf{d}$ \\
\hline & & $70 / 30$ & 0.63 & 1.35 & 1.30 & $\mathbf{c}<\mathbf{d}$ \\
\hline & & $30 / 70$ & 1.02 & 1.31 & 0.95 & $c<\mathbf{d}$ \\
\hline & & $5 / 95$ & 1.48 & 1.26 & 0.20 & $\mathbf{c}<\mathbf{d}$ \\
\hline \multirow[t]{6}{*}{$8 a, 8 b$} & Crown 1 & $90 / 10$ & 0.07 & 1.20 & 0.30 & $\mathbf{a}<\mathbf{b}$ \\
\hline & & $5 / 95$ & 3.58 & 1.24 & 1.20 & $\mathbf{a}<\mathbf{b}$ \\
\hline & Crown 2 & $90 / 10$ & 0.08 & 1.00 & 0.00 & - \\
\hline & & $5 / 95$ & 2.73 & 1.11 & 1.25 & $\mathbf{b}<\mathbf{a}$ \\
\hline & Crown 3 & $90 / 10$ & 0.23 & 1.71 & 1.50 & $\mathbf{b}<\mathbf{a}$ \\
\hline & & $5 / 95$ & 0.42 & 1.00 & 0.00 & - \\
\hline \multirow[t]{6}{*}{$8 c, 8 d$} & Crown 1 & $90 / 10$ & 0.08 & 1.00 & 0.00 & - \\
\hline & & $5 / 95$ & 1.84 & 1.37 & 0.60 & $d<c$ \\
\hline & Crown 2 & $90 / 10$ & 0.05 & 1.00 & 0.00 & - \\
\hline & & $5 / 95$ & 1.25 & 1.31 & 0.80 & $\mathbf{d}<\mathbf{c}$ \\
\hline & Crown 3 & $90 / 10$ & 0.46 & 1.00 & 0.00 & - \\
\hline & & $5 / 95$ & 0.50 & 1.00 & 0.00 & - \\
\hline \multirow[t]{4}{*}{$9 a, 9 b$} & Crown 1 & $90 / 10$ & 0.16 & 1.00 & 0.00 & - \\
\hline & & $5 / 95$ & 3.20 & 1.25 & 1.60 & $\mathbf{a}<\mathbf{b}$ \\
\hline & Crown 2 & $90 / 10$ & 0.20 & 1.00 & 0.00 & - \\
\hline & & $5 / 95$ & 2.34 & 1.23 & 1.70 & $\mathbf{b}<\mathbf{a}$ \\
\hline \multirow[t]{4}{*}{$9 c, 9 d$} & Crown 1 & $90 / 10$ & 0.08 & 1.00 & 0.00 & - \\
\hline & & $5 / 95$ & 1.31 & 1.46 & 0.80 & $\mathbf{d}<\mathbf{c}$ \\
\hline & Crown 2 & $90 / 10$ & 0.05 & 1.00 & 0.00 & - \\
\hline & & $5 / 95$ & 0.88 & 1.44 & 0.85 & $\mathbf{d}<\mathbf{c}$ \\
\hline
\end{tabular}

Chromatographic conditions: columns, Crown 1, 2 and 3; mobile phase, $\mathrm{H}_{2} \mathrm{O} / \mathrm{MeOH}(v / v)$

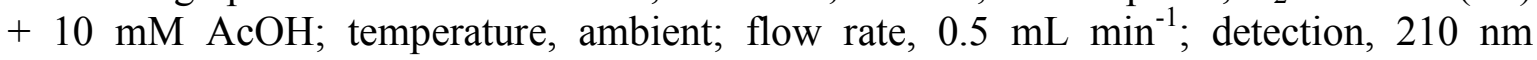




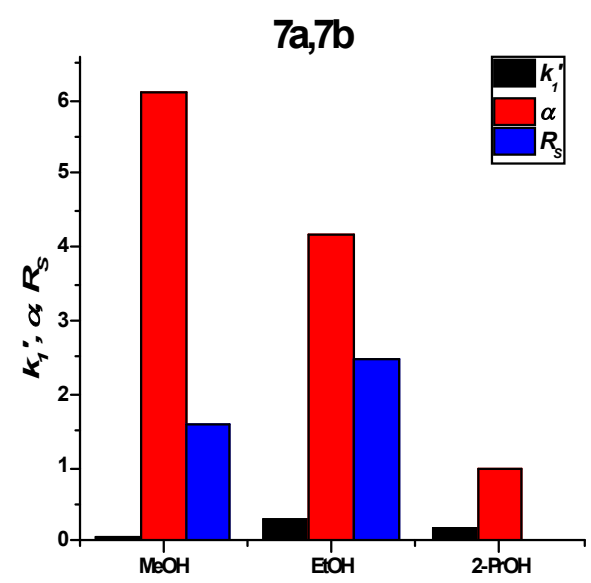

Alcoholicmodifier

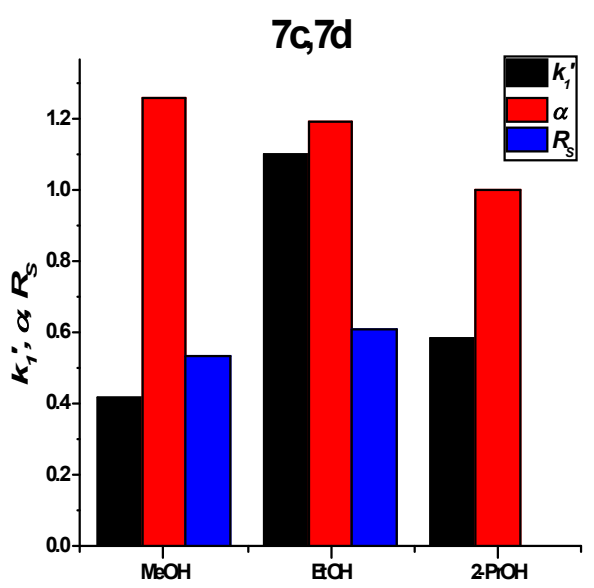

Acoholic modifier

Figure 17. Effects of the alcohol modifier on the chromatographic parameters for analyte 7. Chromatographic conditions: column, Crown 2; mobile phase, $\mathrm{H}_{2} \mathrm{O} /$ alcohol/ $\mathrm{AcOH}=$ 90/10/10 (v/v/mM); temperature, ambient; flow rate, $0.5 \mathrm{~mL} \mathrm{~min}^{-1}$; detection, $210 \mathrm{~nm}$

The effects of the alcohol (MeOH, EtOH or IPA) content of the mobile phase were investigated on all three CSPs and the examples of analytes $\mathbf{7 a}, \mathbf{7 b}$, and $\mathbf{7 c}, \mathbf{7 d}$ are depicted in Table 8. In most cases, $k^{\prime}$ increased with increasing alcohol content. This suggests that the retention behaviour may be controlled by a HILIC mechanism at high alcohol contents. Different extents of solvation of the stationary phase during HILIC and under the RP conditions may explain the observed retention behaviour. However, in some cases, in the $\mathrm{MeOH}$-containing mobile phase for analytes $\mathbf{6 a}, \mathbf{6 b}, \mathbf{6 c}, \mathbf{6 d}$ and 7a,7b on Crown 1 and for all analytes on Crown 3, a U-shaped retention curve was observed. Similarly, a U-shaped retention curve was obtained on Crown 3 in the EtOH-containing mobile phase for analytes $\mathbf{8 a}, \mathbf{8 b}, \mathbf{8 c}, \mathbf{8 d}, \mathbf{9 a}, 9 \mathbf{b}$ and $\mathbf{9 c , 9 d}$. At higher water content, the retention factor increased with increasing water content; this was probably due to enhanced hydrophobic interactions between the analyte and the CSP in the water-rich mobile phases. When the alcohol content of the mobile phase exceeded $\sim 30-40 \%$, the retention factor increased. This suggests that the retention behaviour may be controlled by a HILIC interaction mechanism, as mentioned above. The inflection points and the slopes of the U-shaped curves at higher and lower alcohol concentrations differed somewhat for each compound. As regards the variations in the separation factors $(\alpha)$ and resolutions $\left(R_{S}\right)$ with change of alcohol content, no general trends were observed.

Interesting results were observed from comparisons of the retention behaviour of the three crown ether-containing CSPs with the application of mobile phases containing large or small amounts of water (Table 8). In the $\mathrm{H}_{2} \mathrm{O} / \mathrm{MeOH}(v / v)+10 \mathrm{mM}$ AcOH eluent 
system, $k_{l}$ ' was larger on Crown 3 when the $\mathrm{H}_{2} \mathrm{O}$ content was larger, and on Crown 1 when the alcohol content was larger. In the former case, the most apolar Crown 3 in the water-rich mobile phase favours the hydrophobic interactions between Crown 3 and the analyte, resulting in larger $k_{1}$ '. In the latter case, the most polar Crown 1 in the alcoholrich eluent system favours the HILIC interactions, resulting in large $k_{l}$ ' values.

\subsubsection{Effects of the nature and content of the acidic modifier}

The effects of the nature and content of the acidic modifier on the separation were investigated by the separation of analytes $8 \mathbf{8 a}, \mathbf{8 b}, \mathbf{8 c}, \mathbf{8 d}, \mathbf{9 a}, 9 \mathbf{b}$ and $9 \mathbf{c}, 9 \mathbf{d}$ in an aqueous mobile phase at a constant concentration of the organic modifier. A comparison of the chromatographic data obtained by using $\mathrm{HCOOH}, \mathrm{AcOH}, \mathrm{TFA}, \mathrm{HClO}_{4}, \mathrm{H}_{2} \mathrm{SO}_{4}$ or $\mathrm{H}_{3} \mathrm{PO}_{4}$ as acidic modifier at a constant concentration of $10 \mathrm{mM}$ in a hydro-organic mobile phase containing $\mathrm{MeOH}$, EtOH or IPA $(70 \% v / v)$ demonstrated that in most cases larger $k$ ' values were obtained on the application of $\mathrm{AcOH}$ or $\mathrm{HCOOH}$, while the other acids resulted in lower $k^{\prime}$ (upper part of Table 9); for analytes $\mathbf{8 c , 8 d}$ and $9 \mathbf{c}, 9 \mathbf{d}$, data are not shown, but similar results were obtained).

$\mathrm{H}_{2} \mathrm{SO}_{4}, \mathrm{HClO}_{4}, \mathrm{H}_{3} \mathrm{PO}_{4}$ and TFA in the same concentration as $\mathrm{AcOH}$ resulted in much lower levels of $\mathrm{pH}$. As the $\mathrm{pH}$ was decreased, the ionic strength of the mobile phase increased. The HILIC interaction of a protonated ionic analyte with the polar mobile phase was then expected to increase, with a consequent decrease in the retention time. The ionic strength can act as a shield with respect to host-guest complex formation, reducing the retention when increased. As concerns the selectivity and resolution, in most cases larger $\alpha$ and especially $R_{S}$ values were obtained when $\mathrm{AcOH}, \mathrm{HCOOH}$ or in some cases (especially with EtOH or IPA as mobile phase additive) $\mathrm{H}_{2} \mathrm{SO}_{4}$ was applied.

Increase of the $\mathrm{AcOH}$ or $\mathrm{H}_{2} \mathrm{SO}_{4}$ content in the aqueous mobile phase decreased the retention factors, as shown in the bottom part of Table 9. As the acid content was elevated, the ionic strength of the mobile phase increased, while the $\mathrm{pH}_{\mathrm{a}}$ decreased. As mentioned above, the hydrophilic interaction of a protonated ionic analyte with the polar mobile phase was then expected to increase, resulting in a decrease in the retention time. $\alpha$ and $R_{S}$ exhibited different behaviour for analytes containing amino and carboxyl groups in cis $(\mathbf{a}, \mathbf{b})$ or trans $(\mathbf{c}, \mathbf{d})$ positions. $\alpha$, for both types of analytes increased with increasing acid content, while $R_{S}$ for analytes a,b increased and for analytes $\mathbf{c , d}$ decreased with increasing acid concentration. 
Table 9. Chromatographic data, retention factors $\left(k^{\prime}\right)$, separation factors $(\alpha)$ and resolutions $\left(R_{S}\right)$ for analytes 8a,8b,9a,9b and 9c,9d on $(+)-(18-$ crown-6)-2,3,11,12-tetracarboxylic acid CSP with variation of the type and concentration of the acidic modifier

\begin{tabular}{|c|c|c|c|c|c|c|c|c|c|c|}
\hline \multirow{3}{*}{ Compound } & \multirow{3}{*}{ Nature of acid } & \multicolumn{9}{|c|}{ Mobile phase: $\mathrm{H}_{2} \mathrm{O} /$ alcohol $=30 / 70(v / v)+10 \mathrm{mM}$ acid } \\
\hline & & \multicolumn{3}{|c|}{$\mathrm{H}_{2} \mathrm{O} / \mathrm{MeOH}$} & \multicolumn{3}{|c|}{$\mathrm{H}_{2} \mathrm{O} / \mathrm{EtOH}$} & \multicolumn{3}{|c|}{$\mathrm{H}_{2} \mathrm{O} / \mathrm{IPA}$} \\
\hline & & $k_{1}^{\prime}$ & $\alpha$ & $R_{S}$ & $k_{1}^{\prime}$ & $\alpha$ & $R_{S}$ & $k_{1}^{\prime}$ & $\alpha$ & $R_{S}$ \\
\hline \multirow{6}{*}{$\mathbf{8 a}, \mathbf{8 b}$} & $\mathrm{HCOOH}$ & 0.69 & 1.26 & 0.85 & 1.03 & 1.20 & 0.55 & 1.53 & 1.17 & 0.45 \\
\hline & $\mathrm{AcOH}$ & 0.61 & 1.23 & 0.85 & 1.84 & 1.18 & 0.40 & 0.93 & 1.10 & 0.25 \\
\hline & TFA & 0.39 & 1.15 & 0.10 & 0.24 & 1.50 & 0.25 & 0.43 & 1.10 & 0.10 \\
\hline & $\mathrm{HClO}_{4}$ & 0.31 & 1.13 & 0.10 & 0.53 & 1.10 & 0.10 & 0.71 & 1.13 & 0.10 \\
\hline & $\mathrm{H}_{2} \mathrm{SO}_{4}$ & 0.36 & 1.24 & 0.20 & 0.50 & 1.35 & 0.75 & 0.96 & 1.21 & 1.10 \\
\hline & $\mathrm{H}_{3} \mathrm{PO}_{4}$ & 0.54 & 1.26 & 0.65 & 0.59 & 1.26 & 0.65 & 0.72 & 1.20 & 0.45 \\
\hline \multirow{6}{*}{$9 a, 9 b$} & $\mathrm{HCOOH}$ & 0.65 & 1.33 & 1.00 & 1.09 & 1.20 & 0.65 & 1.35 & 1.21 & 0.80 \\
\hline & $\mathrm{AcOH}$ & 0.56 & 1.30 & 0.85 & 1.78 & 1.20 & 0.60 & 0.79 & 1.15 & 0.60 \\
\hline & TFA & 0.41 & 1.18 & 0.20 & 0.25 & 1.51 & 0.10 & 0.23 & 1.65 & 0.30 \\
\hline & $\mathrm{HClO}_{4}$ & 0.32 & 1.37 & 0.10 & 0.52 & 1.17 & 0.10 & 0.75 & 1.06 & 0.10 \\
\hline & $\mathrm{H}_{2} \mathrm{SO}_{4}$ & 0.36 & 1.39 & 0.20 & 0.50 & 1.45 & 1.40 & 0.83 & 1.30 & 1.30 \\
\hline & $\mathrm{H}_{3} \mathrm{PO}_{4}$ & 0.57 & 1.26 & 0.50 & 0.57 & 1.34 & 0.65 & 0.64 & 1.29 & 0.60 \\
\hline \multirow{2}{*}{ Compound } & Concentration & \multicolumn{6}{|c|}{ Mobile phase } & & & \\
\hline & of acid (mM) & $\mathrm{H}_{2} \mathrm{O} / \mathrm{M}$ & $=30 / 70$ & $+\mathrm{AcOH}$ & $\mathrm{H}_{2} \mathrm{O} / \mathrm{I}$ & $0 / 70($ & $\mathrm{H}_{2} \mathrm{SO}_{4}$ & & & \\
\hline \multirow{6}{*}{$9 a, 9 b$} & 0.5 & 1.64 & 1.10 & 0.20 & 1.06 & 1.21 & 0.75 & & & \\
\hline & 1.0 & 1.56 & 1.11 & 0.15 & 0.66 & 1.29 & 0.85 & & & \\
\hline & 5.0 & 1.11 & 1.23 & 0.65 & 0.51 & 1.44 & 0.90 & & & \\
\hline & 10.0 & 0.56 & 1.30 & 0.85 & 0.40 & 1.51 & 0.95 & & & \\
\hline & 20.0 & 0.58 & 1.28 & 0.90 & 0.37 & 1.55 & 1.05 & & & \\
\hline & 30.0 & 0.93 & 1.25 & 0.95 & 0.31 & 1.61 & 1.25 & & & \\
\hline \multirow{6}{*}{$9 c, 9 d$} & 0.5 & 0.46 & 1.35 & 1.00 & 0.39 & 1.57 & 1.10 & & & \\
\hline & 1.0 & 0.39 & 1.51 & 0.95 & 0.26 & 1.71 & 1.00 & & & \\
\hline & 5.0 & 0.37 & 1.53 & 0.80 & 0.09 & 2.53 & 0.95 & & & \\
\hline & 10.0 & 0.20 & 1.87 & 0.75 & 0.05 & 3.59 & 0.90 & & & \\
\hline & 20.0 & 0.08 & 2.85 & 0.65 & 0.05 & 3.55 & 0.85 & & & \\
\hline & 30.0 & 0.02 & 4.00 & 0.20 & 0.07 & 3.97 & 0.75 & & & \\
\hline
\end{tabular}

Chromatographic conditions: column, Crown 1; mobile phase, $\mathrm{H}_{2} \mathrm{O} /$ alcohol $=30 / 70(v / v)+$ acidic modifier; temperature, ambient; flow rate, $0.5 \mathrm{~mL}$ $\min ^{-1}$; detection, $205 \mathrm{~nm}$ 


\subsubsection{Effect of the structures of the analytes on chiral recognition}

The structures of the analytes influenced the chiral recognition. In the RP mode, methyl or ethyl substitution exhibited a slight effect on the retention. On Crown 1 and 2, at a given mobile phase composition, the methyl-substituted analogues interacted more strongly with the selector than did the ethyl-substituted ones, resulting in larger retentions (Table 8). However, on Crown 3, the interactions depended on the composition of the mobile phase. In water-rich media, the ethyl-substituted analytes resulted in the larger retention factors with the selector, wheres at higher $\mathrm{MeOH}$ contents, the methyl-substituted ones did so. Through the steric interactions, the position of the methyl or ethyl group influenced the $\alpha$ and $R_{S}$ values. Analytes $\mathbf{8 a}, \mathbf{8 b}$ were better separated than $\mathbf{6 a}, \mathbf{6 b}$ on all CSPs, while analytes $\mathbf{6 c}, \mathbf{6 d}$ exhibited better separation efficiency than $\mathbf{8 c , 8 d}$. In general, 9a-9d underwent better enantioseparation than 7a-7d.

For comparison of the performances of the three (+)-(18-crown-6)-2,3,11,12tetracarboxylic acid-based columns, separations were carried out with variation of the mobile phase composition. In general, Crown 3 was more suitable in a water-rich mobile phase, while Crown 1 and 2 exhibited better results in an alcohol-rich mobile phase (Table 8). In conclusion, no one column is suited for the enantioseparation of all the investigated unusual isoxazoline-fused 2-aminocyclopentanecarboxylic acids; they have a highly complementary character.

\subsubsection{Enantioseparation of four enantiomers of isoxazoline-fused cispentacin stereoisomers}

For the crown ether-based CSPs, separation of the diastereomers in one chromatographic run was also attempted. The data listed in Table $\mathbf{1 0}$ reveal that separation of the four stereoisomers could be achieved in most cases. Unfortunately, no chromatographic condition was found for the baseline separation of $\mathbf{6 a}, \mathbf{6 b}$ and $\mathbf{6 c}, \mathbf{6} \mathbf{d}$ in one chromatographic run. 
Table 10. Chromatographic data: retention factor, and resolution for the separation of four enantiomers of isoxazoline-fused cispentacin derivatives on crown ether-containing columns

\begin{tabular}{ccccccccccc}
\hline Analyte & Column & $\begin{array}{c}\text { Mobile } \\
\text { Phase }\end{array}$ & $\boldsymbol{k}_{1}^{\prime}$ & $\boldsymbol{k}_{2}{ }_{2}$ & $\boldsymbol{k}_{3}^{\prime}$ & $\boldsymbol{k}_{4}{ }_{4}$ & $\boldsymbol{R}_{S 1}$ & $\boldsymbol{R}_{S 2}$ & $\boldsymbol{R}_{S 3}$ & $\begin{array}{c}\text { Elution } \\
\text { sequence }\end{array}$ \\
\hline $\mathbf{6}$ & Crown 1 & $\mathbf{a}$ & 0.20 & 0.26 & 0.93 & 1.67 & 0.20 & 3.72 & 3.39 & $\mathbf{b}<\mathbf{a}<\mathbf{c}<\mathbf{d}$ \\
\hline $\mathbf{7}$ & Crown 2 & $\mathbf{b}$ & 0.32 & 1.14 & 2.76 & 4.17 & 1.73 & 2.66 & 1.61 & $\mathbf{a}<\mathbf{b}<\mathbf{c}<\mathbf{d}$ \\
\hline $\mathbf{8}$ & Crown 1 & $\mathbf{c}$ & 2.01 & 2.86 & 11.40 & 12.99 & 1.92 & 13.68 & 1.72 & $\mathbf{d}<\mathbf{c}<\mathbf{a}<\mathbf{b}$ \\
\hline $\mathbf{9}$ & Crown 1 & $\mathbf{c}$ & 2.34 & 3.35 & 9.99 & 11.11 & 2.16 & 12.92 & 2.11 & $\mathbf{d}<\mathbf{c}<\mathbf{a}<\mathbf{b}$ \\
\hline
\end{tabular}

Chromatographic conditions: mobile phase, a, $\mathrm{H}_{2} \mathrm{O} / \mathrm{MeOH}=90 / 10(v / v)+10 \mathrm{mM}$ AcOH; b, $\mathrm{H}_{2} \mathrm{O} / \mathrm{EtOH}=50 / 50(v / v)+10 \mathrm{mM} \mathrm{AcOH} ; \mathbf{c}, \mathrm{H}_{2} \mathrm{O} / \mathrm{MeOH}=5 / 95(v / v)+10 \mathrm{mM} \mathrm{AcOH}$; temperature, $5{ }^{\circ} \mathrm{C}$ for analytes 7,8 and $9,25{ }^{\circ} \mathrm{C}$ for analyte 6; flow rate, $0.5 \mathrm{~mL} \mathrm{~min}^{-1}$; detection, $210 \mathrm{~nm}$

\subsection{Comparison of macrocyclic antibiotic- and crown ether-based CSPS}

For the isoxazoline-fused 2-aminocyclopentanecarboxylic acid analogues, the separation abilities of the two types of selectors can be compared. It is true for both types of column that they have similar separation efficiencies for this type of analytes.

From a comparison of the retention factors, it seems that these analytes exhibited stronger interactions with macrocyclic glycopeptide selectors. The retention factors were generally higher, and in most cases were accompanied by higher resolution too.

These types of $\beta$-amino acids probably prefer apolar stationary phases. The crown ether-containing CSPs (Crown 1 and 2) are more polar (Crown 3 was an exception), than the macrocyclic antibiotics and also have fewer chiral centres and active groups for interactions. However, the strong inclusion complexation may contribute to the chiral recognition and with thorough optimization $(\mathrm{pH}$, the nature and concentration of the alcohol and the acidic modifier, and temperature) the same or similar separation efficiency can be attained on crown ether-based columns, too.

When both their advantages and disadvantages are taken into account, both types of column are capable of the separation of these types of analytes. 


\section{SUMMARY}

In the course of this work, two types of $\beta$-amino acid analogues, monoterpenebased- and isoxasoline-fused 2-aminocyclopentanecarboxylic acids, were handled. The chromatographic measurements were carried out on macrocyclic antibiotic-based and crown ether-containing CSPs. Effects of the $\mathrm{pH}$, the nature and the concentration of the alcohol and acidic modifiers, and the temperature were investigated on the chromatographic parameters.

\section{Enantioseparation of monoterpene-based 2-aminocyclopentanecarboxylic acids on macrocyclic antibiotic-based CSPS}

RP, PO and PI experimental conditions were applied in this project. The CSPs used were Chirobiotic T, T2, TAG, R, V and VAG columns.

The effects of the $\mathrm{pH}$ of the mobile phase were investigated. On the Chirobiotic $\mathrm{T}$ column, increase of the $\mathrm{pH}$ of the mobile phase decreased the retention factors, while the selectivity increased slightly and the resolution considerably.

As a result of the $\mathrm{pH}$ measurements the mobile phases contained $0.1 \%$ TEAA $(\mathrm{pH}$ $=4.1$ ) buffer and alcohol modifier. On the Chirobiotic T, T2 and TAG columns, with increasing alcohol content the retentions changed according to U-shaped curves for all the analytes (except for analyte 3 on the T and T2 columns). The explanation of this result was that in water-rich eluents the hydrophobic interactions increased the $k$ ' values, while in an alcohol-rich mobile phase the HILIC interaction increased the retention. In the case of analyte 3 , the different behaviour could be attributed to the opposite positions of the amino and carboxy groups. In general, the selectivity factors and resolutions neither described a U-shaped curve nor increased with increasing alcohol content. The other three CSPs (Chirobiotic R, V and VAG) did not give good results; the best resolution value was 1.00.

The elution sequence did not change during the measurements, except in the case of analyte 2 , where the elution sequence differed when the mobile phase was changed from RP to PI mode.

The effects of temperature were also investigated on the $\mathrm{T}$ and TAG columns between 10 and $40{ }^{\circ} \mathrm{C}$ and the thermodynamic parameters were determined in all cases. In most cases, the enantioseparations were enthalpically-driven (the only exception was analyte 3). Baseline resolution was achieved in all cases. 
Enantioseparation of isoxazoline-fused 2-aminocyclopentanecarboxylic acids on macrocyclic antibiotic CSPS

With the application of $\mathrm{MeOH}$ as mobile phase additive, in most cases the retention factors described a U-shaped curve. However, in the cases of $\mathbf{6 a}, \mathbf{6} \mathbf{b}$ on the T, T2 and TAG, and of $7 \mathbf{a}, 7 \mathbf{b}$ on the T and T2 columns, $k$ ' increased with increasing $\mathrm{MeOH}$ content. For all of the analytes, the Chirobiotic TAG column proved to be the most capables, the best resolutions were achieved on it. For $\mathbf{8 a}, \mathbf{8 b}$ and $\mathbf{9 a , 9 b}$, outstanding results were also observed on the V and VAG columns. As concerns the elution sequence, it differed only on the TAG CSP for the trans analogues.

The effects of temperature were investigated between 5 and $45{ }^{\circ} \mathrm{C}$ (in $10{ }^{\circ} \mathrm{C}$ increments) on the Chirobiotic $\mathrm{T}$ and TAG CSPs. The thermodynamic parameters were determined in all cases, and in one case the process of separation was entropically driven $\left(\mathbf{8 a}, \mathbf{8 b}\right.$ on Chirobiotic TAG). On Chirobiotic T for analogues $\mathbf{6 c}, \mathbf{6 d}$ and 7c,7d, $T_{\text {iso }}$ was 37 ${ }^{\circ} \mathrm{C}$; the change in elution sequence with change of temperature for $\mathbf{6 c}, \mathbf{6 d}$ is illustrated in Fig. 16.

As four pair of diastereomers exist for these types of analyte, the separation of four diastereomers (eight enantiomers) was achieved. In the cases of 7a-7d and 8a-8d, the eight enantiomers were separated in one chromatographic run, but the separation of $\mathbf{6 a - 6} \mathbf{d}$ and 9a-9d needed two chromatographic runs.

Enantioseparation of isoxazoline-fused 2-aminocyclopentanecarboxylic acids on crown ether-containing CSPS

The effects of the alcohol $(\mathrm{MeOH}, \mathrm{EtOH}$ or IPA) content of the mobile phase showed that in most cases $k$ ' increased with increasing alcohol content. This suggests that the retention behaviour may be controlled by a HILIC mechanism at high alcohol contents. In some cases, however, in $\mathrm{MeOH}$-containing mobile phases on Crown 1 and for all analytes on Crown 3, a U-shaped retention curve was observed. At higher water content, the retention factor increased with increasing water content; this was probably due to enhanced hydrophobic interactions between the analyte and the CSP in the water-rich mobile phases.

Comparison of the retention behaviour of the three crown ether-containing CSPs with the application of mobile phases containing large or small amounts of water revealed that $k_{1}$ ' was larger on Crown 3 when the $\mathrm{H}_{2} \mathrm{O}$ content was larger and on Crown 1 when 
the alcohol content was larger. In the former case, the most apolar Crown 3 in a water-rich mobile phase favours the hydrophobic interactions between Crown 3 and the analyte, resulting in larger $k_{1}$ '. In the latter case, the most polar Crown 1 in an alcohol-rich eluent system favours the HILIC interactions, resulting in large $k_{1}$ ' values.

A comparison of the chromatographic data obtained by using $\mathrm{HCOOH}, \mathrm{AcOH}$, TFA, $\mathrm{HClO}_{4}, \mathrm{H}_{2} \mathrm{SO}_{4}$ or $\mathrm{H}_{3} \mathrm{PO}_{4}$ as acidic modifier demonstrated that in most cases larger $k$ ' values were obtained on the application of $\mathrm{AcOH}$ or $\mathrm{HCOOH}$, while the other acids resulted in lower $k^{\prime}$. Better selectivity and resolution were obtained when $\mathrm{AcOH}$ and $\mathrm{HCOOH}$, and in some cases $\mathrm{H}_{2} \mathrm{SO}_{4}$ (with EtOH or IPA) were used. As concerns the effects of the concentration of the acid modifier, increase of the $\mathrm{AcOH}$ or $\mathrm{H}_{2} \mathrm{SO}_{4}$ content decreased the $k$ ' values. $\alpha$ increased with increasing acid concentration, whereas the $R_{S}$ values decreased with increasing concentration for the trans analogues, and increased for the cis analogues.

The structures of the analytes also influenced the chiral recognition. On all CSPs, the values of selectivity and resolution were better for analytes $\mathbf{8 a}, \mathbf{8 b}$ and $\mathbf{9 a}, \mathbf{9 b}$ than for 6a,6b and 7a,7b; the position of substituent $R$ influenced the chromatographic parameters. The trans analogues exhibited different chromatographic behaviour.

The elution sequence was determined in all cases, but no general rule could be found to describe the elution behaviour of these compounds. 


\section{REFERENCES}

[1] M.S. Tswett Tr. Protok. Varshav. Obshch. Estestvoispyt. Otd. Biol. 14 (1905).

[2] R. Willstatter, A. Stoll Utersuchungenuber Chlorophy, Springer, Berlin (1913).

[3] A.J.P. Martin, R.L.M. Synge Biochem. J. 35 (1941) 1358.

[4] B.A. Bunin, J.M. Dener, D.A. Livingston Annu. Rep. Med. Chem. 34 (1999) 267.

[5] C.D. Floyd, C. Leblanc, M. Whittaker Prog. Med. Chem. 36 (1999) 91.

[6] A.A. Tymiak, T.J. McCormick, S.E. Unger J. Org. Chem. 54 (1989) 1149.

[7] M. Eggen, S.K. Nair, G.I. Georg Org. Lett. 12 (2001) 1813.

[8] J.D. White, J. Hong, L.A. Robarge J. Org. Chem. 64 (1999) 6206.

[9]E. Juaristi, (Eds.) Enantioselective Synthesis of $\beta$-Amino Acids, Wiley-VCH, New York, (2005).

[10] S. Borman Chem. Eng. News 77 (1999) 33.

[11]R.K. Brown Modern Drug Discovery 2 (1999) 63.

[12]S. Borman Chem. Eng. News 78 (2000) 53.

[13] S. Borman Chem. Eng. News 77 (1999) 27.

[14]D. Seebach, S. Abele, K. Gademann, B. Jaun Angew. Chem. Int. Ed. 38 (1999) 1595.

[15]K. Gademann, B. Jaun, D. Seebach, R. Perozzo, L. Scapozza, G. Folkers Helv. Chim. Acta 82 (1999) 1.

[16]D.H. Appella, L.A. Christianson, I.L. Karle, D.R. Powell, S.H. Gellman J. Am. Chem. Soc. 121 (1999) 6206.

[17]D.H. Appella, L.A. Christianson, D.A. Klein, M.R. Richards, D.R. Powell, S.H. Gellman J. Am. Chem. Soc. 121 (1999) 7574.

[18]K. Gademann, M. Ernst, D. Hoyer, D. Seebach Angew. Chem. Int. Ed. 38 (1999) 1223.

[19] S. Poenaru, J.R. Lamas, G. Folkers, J.A. Lopez de Castro, D. Seebach, D. Rognan J. Med. Chem. 42 (1999) 2318.

[20] S. Reinelt, M. Marti, S. Dédier, T. Reintinger, G. Folkers, J.A. Lopez de Castro, D. Rognan J. Biol. Chem. 27 (2001) 24525.

[21]F. Fülöp Chem. Rev. 101 (2001) 2181.

[22] Y.K. Agrawal, H.G Bhatt, H.G. Raval, P.M. Oza, P.J. Gogoi Mini-Reviews in Medicinal Chemistry 7 (2007) 451.

[23] M. Simonyi, I. Fitos, J. Visy Trends Pharmacol. Sci. 7 (1986) 112.

[24] T. Walle, U.K. Walle Trends Pharmacol. Sci. 7 (1986) 155.

[25]E.J. Äriens Eur. J. Clin. Pharmacol. 26 (1984) 663.

[26]E.J. Äriens, W. Soudijn, P. Timmermans (Eds.), Stereochemistry and Biological Activity of Drugs, Blackwell, Oxford (1983).

[27]I.W. Wainer, Drug Discovery, Analytical Methods and Pharmacology $2^{\text {nd }}$ Edition, Marcel Dekker, New York (1993).

[28]E. Ariens Med. Res. Rev. 6 (1986) 451.

[29] K.M. Williams, R.O. Day Australian Prescriber 12 (1989) 22.

[30]B. Blaschke, H.P. Kraft, K. Fickentscher, F. Kohler Arzneim.-Forsch. 29 (1979) 1640 .

[31]D.J. Abraham Burger's Medicinal Chemistry and Drug Discovery 6th Edition, Vol. 1: Drug Discovery, Chapter 18, Chirality and Biological Activity (2003) 781. 
[32]M. Gross Annual Reports in Medical Chemistry 25 (1989) 323.

[33] C.E. Dalgliesh J. Chem. Soc. 137 (1952) 3940.

[34] W.H. Pirkle, T.C. Pochapsky Chem. Rev. 89 (1989) 347.

[35] K.K. Stewart, R.F. Doherty Proc. Natl. Acad. Sci. 70 (1973) 2850.

[36] J. Haginaka J. Chromatogr. A 906 (2001) 253.

[37] W.H. Pirkle, D. House J. Org. Chem. 44 (1979) 1957.

[38] W.H. Pirkle, M.H. Hyun, G.A. Bank J. Chromatogr. 316 (1984) 585.

[39] V. Vinković, M. Roje, D. Kontrec, V. Šunjić Arkivoc VIII (2008) 242.

[40] W.H. Pirkle, W. Lee Bull. Kor. Chem Soc. 31 (2010) 620.

[41] Y. Cao, X. Lang, S. Yao, Q. Cheng, H. Song J. Chem. Soc. Pak. 34 (2012) 102.

[42] M. Kotake, T. Sakan, N. Nakamura, S. Senoh J. Am. Chem. Soc. 43 (1951) 169.

[43] G. Hesse, R. Hagel Chromatographia 6 (1973) 277.

[44] Y. Okamoto, M. Kawashima, K. Hatada J. Am. Chem. Soc. 106 (1984) 5357.

[45] Y. Okamoto, K. Hatada, M. Kawashima, K. Yamamoto Chem. Lett. 5 (1984) 739.

[46] Y. Okamoto, R. Aburatani, S. Miura, K. Hatada J. Liq. Chromatogr. 10 (1987) 1613.

[47]I.W. Kim, J.K. Ryu, S.D. Ahn, J.H. Park, K.-P. Lee, J.J. Ryoo, M.H. Hyun, Y.

Okamoto, C. Yamamoto, P.W. Carr Bull. Kor. Chem. Soc. 24 (2003) 239.

[48]A. Ghanem, M.N. Aboul-Enein, A. El-Azzouny, M.F. El-Behairy J. Chromatogr. A 1217 (2010) 1063.

[49]L. Zhou, C. Welch, C. Lee, X. Gong, V. Antonucci, Z. Ge J. Pharmaceut. Biomed. 49 (2009) 964.

[50]I. Ilisz, Z. Pataj, R. Berkecz, I. Szatmari, F. Fülöp, A. Péter Chromatographia 70 (2009) 723.

[51]I. Ilisz, Z. Pataj, R. Berkecz, I. Szatmári, F. Fülöp, A. Péter J. Chromatogr. A 1217 (2010) 2980.

[52]Z. Pataj, I. Ilisz, R. Berkecz, E. Forró, F. Fülöp, A. Péter Chirality 22 (2010) 120.

[53] M. Shnayerson, M. Plotkin "The Killers Within: The Deadly Rise Of Drug-

Resistance", Back Bay Books, (2003)

[54]D.P. Levine Clin. Infect. Dis. 42 (2006) S5.

[55]F.J. Marshall J. Med. Chem. 8 (1965) 18.

[56] D.W. Armstrong, Y. Tang, S. Chen, Y. Zhou, C. Bagwill, J-R. Chen Anal. Chem. 66 (1994) 1473.

[57] Chirobiotic Handbook, Advanced Separation Technologies Inc. 4th Edition, Whyppany (2002).

[58] A. Berthod, T.L. Xiao, Y. Liu, R.D. McCulla, W.S. Jenks, D.W. Armstrong J. Chromatogr. A 955 (2002) 53.

[59] A.H. Hunt, R.M. Molloy, J.L. Occolowitz, G.G. Marconi, M. Debono J. Am. Chem. Soc. 106 (1984) 4891.

[60] G. Lancini, B. Cavalleri in H. Kleinhauf and H.V. Dohren (Eds.) Biochemistry in Peptide Antibiotics, W. De Gruyter, Berlin (1990) 159.

[61]D.W. Armstrong, Y. Liu, K.H. Ekborg-Ott Chirality 7 (1995) 474.

[62]A. Berthod, Y. Liu, C. Bagwill, D.W. Armstrong J. Chromatogr. A 731 (1996) 123.

[63] R. Berkecz, I. Ilisz, G. Benedek, F. Fülöp, D.W. Armstrong, A. Péter J. Chromatogr. A 1216 (2009) 927.

[64]A. Péter, A. Árki, E. Vékes, D. Tourwé, L. Lázár, F. Fülöp, D.W. Armstrong J. Chromatogr. A 1031 (2004) 171. 
[65]B. Zhang, R. Soukup, D.W. Armstrong J. Chromatogr. A 1053 (2004) 89.

[66]I. Ilisz, R. Berkecz, A. Péter J. Chromatogr. A 1216 (2009) 1845.

[67] K.L. Rundlett, M.P. Gasper, E.Y. Zhou, D.W. Armstrong Chirality 8 (1996) 88.

[68] T. Gondová, J. Petrovaj, P. Kutschy, Z. Čurillová, A. Salayová, M. Fabián, D.W. Armstrong Chromatographia 74 (2011) 751.

[69] K. Hroboňová, J. Lehotay, K. Bruchatá, R. Čižmárikova J. Liq. Chromatogr. Related Technol. 32 (2009) 80.

[70] M. Honetschlagerova-Vadinska, S. Srkalova, Z. Bosakova, P. Coufal, E. Tesarová J. Sep. Sci. 32 (2009) 1704.

[71] A. Berthod, X. Chen, J.P. Kullman, D.W. Armstrong, F. Gasparrini, I D’Acquarica, C. Villani Anal. Chem. 72 (2000) 1767.

[72]A. Péter, R. Török, D.W. Armstrong J. Chromatogr. A 1057 (2004) 229.

[73] J. Lokajová, E. Tesařová, D.W. Armstrong J. Chromatogr. A 1088 (2005) 57.

[74] R. Berkecz, I. Ilisz, G. Benedek, F. Fülöp, D.W. Armstrong, A. Péter J. Chromatogr. A 1216 (2009) 927.

[75]D.C Jordan in D. Gottlieb and P. Shaw (Eds.) Antibiotics, Springer, New York, Vol. 1. (1967) 84.

[76]D.L. Boger, Y. Nomoto, B.R. Teegarden J. Org. Chem. 58 (1993) 1425.

[77]D.W. Armstrong, M.P. Gasper, K.L. Rundlett J. Chromatogr. A 698 (1995) 285.

[78] K.H. Ekborg-Ott, X. Wand, D.W. Armstrong Microchem. J. 62 (1999) 26.

[79] A. Péter, G. Török, D.W. Armstrong, G. Tóth, D. Tourwé J. Chromatogr. A 904 (2000) 1.

[80]C. Wang, C. Jiang, D.W. Armstrong J. Sep. Sci. 31 (2008) 1980.

[81]B. Zhang, R. Soukup, D.W. Armstrong J. Chromatogr. A 1053 (2004) 89.

[82]D.W. Armstrong, W. DeMond J. Chromatogr. Sci. 22 (1984) 411.

[83] G. Varga, G. Tárkányi, K. Németh, R. Iványi, L. Jicsinszky, O. Toke, J. Visy, L. Szente, J. Szemán, M. Simonyi J. Pharmaceut. Biomed. 51 (2010) 84.

[84] K. Si-Ahmed, F. Tazerouti, A.Y. Badjah-Hadj-Ahmed, Z. Aturki, G. D’Orazio, A. Rocco, S. Fanali J. Pharm. Biomed. Anal. 51 (2010) 225.

[85] G. Fodor, I. Ilisz, J. Szemán, R. Iványi, L. Szente, G. Varga, E. Forró, F. Fülöp, A. Péter Chromatographia 71 (2010) S29.

[86] S.K. Thamarai Chelvi, E.L. Yong, Y. Gong J. Sep. Sci. 33 (2010) 74.

[87]I. Ilisz, R. Berkecz, E. Forró, F. Fülöp, D.W. Armstrong, A. Péter Chirality 21 (2009) 339.

[88] C.J. Pedersen J. Am. Chem. Soc. 89 (1967) 2495.

[89] G.D.Y. Sogah, D.J. Cram J. Am. Chem. Soc. 101 (1979) 3035.

[90] T. Shinbo, T. Yamaguchi, K. Nishimura, M. Sugiura J. Chromatogr. 405 (1987) 145.

[91] T. Shinbo, T. Yamaguchi, H. Yanagishita, D. Kitamoto, K. Sakaki, M. Sugiura J. Chromatogr. A 625 (1992) 101.

[92] Y. Machida, H. Nishi, K. Nakamura, H. Nakai, T. Sato J. Chromatogr. A 805 (1998) 85.

[93] M. Sawada, Y. Takai, H. Yamada, T. Kaneda, K. Kamada, T. Mizooku, K. Hirose, Y. Tobe, K. Naemura J. Chem. Soc., Chem. Commun. (1997) 2497.

[94] M.H. Hyun, J.S. Jin, W. Lee Bull. Kor. Chem Soc. 19 (1998) 819.

[95] J.P. Behr, J.M. Lehn, D. Moras, J.C. Thierry J. Amer. Chem. Soc. 103 (1981) 701.

[96] M.H. Hyun, J.S. Jin, W. Lee J. Chromatogr. A 822 (1998) 155. 
[97] W. Lee, J.Y. Jin, C.S. Baek Microchem J. 80 (2005) 213.

[98] J.S. Jin, A.M. Stalcup, M.H. Hyun J. Chromatogr. A 933 (2001) 83.

[99] M.H. Hyun, D.H. Kim Chirality 16 (2004) 294.

[100]M.H. Hyun Bull. Kor. Chem. Soc. 26 (2005) 1153.

[101]H.S. Cho, H.J. Choi, A. Lee, J.S. Jin, E.D. Jeong, M.H. Hyun Bull. Kor. Chem. Soc. 30 (2009) 1903.

[102]W. Lee, C.Y. Hong J. Chromatogr. A 879 (2000) 113.

[103]A. Péter, G. Török, F. Fülöp J. Chromatogr. Sci. 36 (1998) 311.

[104]R. Berkecz, I. Ilisz, Z. Pataj, F. Fülöp, H.J. Choi, M.H. Hyun, A. Péter Chromatographia 68 (2008) S13.

[105]H.J. Kim, H.J. Choi, Y.J. Cho, M.H. Hyun Bull. Kor. Chem. Soc. 31 (2010) 1551.

[106]U. Conrad, B. Chankwetadze, G.K.E. Scriba J. Sep. Sci. 28 (2005) 2275.

[107]M.H. Hyun, Y. Song, Y.J. Cho, D.H. Kim J. Chromatogr. A 1108 (2006) 208.

[108] M.H. Hyun, S.C. Han, J.S. Jin, W. Lee Chromatographia 52 (2000) 473.

[109]P. Sun, C.L. Wang, Z.S. Breitbach, Y. Zhang, D.W. Armstrong Anal. Chem. 81 (2009) 10215.

[110]A. Aranyi, I. Ilisz, Z. Pataj, I. Szatmári, F. Fülöp, D.W. Armstrong, A. Péter, Chirality 23 (2011) 549.

[111]P. Sun, D.W. Armstrong J. Chromatogr. A 1217 (2010) 4904.

[112]H. Qui, L. Loukotková, P. Sun, E. Tesarová, Z. Bosáková, D.W. Armstrong J. Chromatogr. A 1218 (2011) 270.

[113]V.A. Davankov, S.V. Rogozhin J. Chromatogr. 60 (1971) 280.

[114]V.A. Davankov in G. Gübitz and M.G. Schmid (Eds), Chiral Separation, Humana Press, Totowa, NJ, United States (2004) 207.

[115]B. Natalini, R. Sardella, A. Macchiarulo, R. Pellicciari J. Chromatogr. B 875 (2008) 108.

[116]M.H. Hyun, S.C. Han, S.H. Wangbo J. Chromatogr. A 992 (2003) 47.

[117]B. Natalini, R. Sardella, A. Macchiarulo, S. Natalini, R. Pellicciari J. Sep. Sci. 30 (2007) 21.

[118]M.H. Hyun, S.C. Han, C.W. Lee, Y.K. Lee J. Chromatogr. A 950 (2002) 55.

[119]B. Ekberg, K. Mosbach Trends Biotechnol. 7 (1989) 92.

[120]M. Kempe, K. Mosbach J. Chromatogr. A 664 (1994) 276.

[121]M. Kempe, K. Mosbach J. Chromatogr. A 691 (1995) 317.

[122]G. Wulff Angew. Chem.-Int. Ed. Engl. 34 (1995) 1812.

[123]J. Haginaka, H. Sanbe, H. Takehira J. Chromatogr. A 857 (1999) 117.

[124]J. Haginaka, Y. Sakai J. Pharm. Biomed. Anal. 22 (2000) 899.

[125]J.F. Wang, L.M. Zhou, X.L. Liu, Q.H. Wang, D.Q. Zhu Chinese Chem. Lett. 11 (2000) 65.

[126]J. Zhang, X. Shen, Q. Chen Curr. Org. Chem. 15 (2011) 74.

[127]M.S. da Silva, E.R. Vao, M. Temtem, L. Mafra, J. Caldeira, A. Aguiar-Ricardo, T.

Casimiro Biosens. Bioelectron. 25 (2010) 1742.

[128]Z. Szakonyi, F. Fülöp Arkivoc 14 (2003) 225.

[129]S. Gyónfalvi, Z. Szakonyi, F. Fülöp Tetrahedron: Asymmetry 14 (2003) 3965.

[130]Z. Szakonyi, T.A. Martinek, R. Sillanpää, F. Fülöp Tetrahedron: Asymmetry 18 (2007) 2442. 
[131]Z. Szakonyi, T.A. Martinek, R. Sillanpää, F. Fülöp Tetrahedron: Asymmetry 19 (2008) 2296.

[132]L. Kiss, M. Nonn, E. Forró, R. Sillanpää, F. Fülöp Tetrahedron Letters 50 (2009) 2605.

[133]M. Nonn, L. Kiss, E. Forró, Z. Mucsi, F. Fülöp Tetrahedron 67 (2011) 4079.

[134]I. D'Acquarica, F. Gasparrini, D. Misiti, G. Zappia, C. Cimarelli, G. Palmieri, A. Carotti, S. Cellamare, C. Villani Tetrahedron: Asymmetry 11 (2000) 2375.

[135]A. Berthod, X. Chen, J.P. Kullman, D.W. Armstrong, F. Gasparrini, I. D’Acquarica, C. Villani, A. Carotti Anal. Chem. 72 (2000) 1767.

[136]R. Berkecz, R. Török, I. Ilisz, E. Forró, F. Fülöp, D.W. Armstrong, A. Péter Chromatographia 63 (2006) S37.

[137]A. Sztojkov-Ivanov, L. Lázár, F. Fülöp, D.W. Armstrong, A. Péter Chromatographia 64 (2006) 89.

[138]B. Yao, F. Zhan, G. Yu, Z. Chen, W. Fan, X. Zeng, Q. Zeng, W. Weng J. Chromatogr. A 1216 (2009) 5429.

[139]K. Balmér, P.O. Lagerström, B.A. Persson J. Chromatogr. A 592 (1992) 331.

[140]W.H. Pirkle, P.G. Murray J. High Resolut. Chromatogr. 16 (1993) 285.

[141]M. Schlauch, A.W. Frahm Anal. Chem. 73 (2001) 262.

[142]R.W. Stringham, J.A. Blackwell Anal. Chem. 69 (1997) 1414.

[143]M.H. Hyun J. Sep Sci 26 (2003) 242. 


\section{ACKNOWLEDGEMENTS}

First and foremost I offer my sincerest gratitude to my supervisor, Professor Ferenc Fülöp, Head of the Institute of Pharmaceutical Chemistry, for providing me with the opportunity to carry out my research work in his institute. I would also like to express my thanks to him for his valuable guidance of my work and his helpful advice.

I would also like to thank most warmly my second supervisor, Professor Antal Péter, who has supported me throughout my work with his guidance, patience and knowledge. Without him, this thesis would cretainly not have been written or completed. I could not wish for a better or friendlier supervisor.

I also express my gratitude to Dr. István Ilisz for his great advice and help in my daily work.

I wish to express my thanks to Anita Aranyi and Dr. Zoltán Pataj, who have also helped me many times in my work and have made every day more cheerful.

I would like to thank Dr. David Durham for revising the English language of our publications and this thesis.

I offer my best regards and blessing to all members of the Institute of Pharmaceutical Chemistry, who ensured the investigated materials, helped me and created an excellent atmosphere in the laboratory practice.

Last, but definitely not least, I would like to express my heartfelt thanks to my beloved parents for their blessings, patience and encouragement during my Ph.D. years and my whole life. I am forever indebted to them... 


\section{APPENDIX}

\section{The IUPAC names of monoterpene-based $\beta$-amino acids (Fig. 11)}

$(1 R, 2 R, 3 S, 5 R)$-2-Amino-6,6-dimethylbicyclo[3.1.1]heptane-3-carboxylic acid (1a), $(1 S, 2 S, 3 R, 5 S)$ 2-amino-6,6-dimethylbicyclo[3.1.1] heptane-3-carboxylic acid (1b), $(1 R, 2 R, 3 R, 5 R)$ - 2-amino-6,6dimethylbicyclo[3.1.1]heptane-3-carboxylic acid (2a), (1S,2S,3S,5S)-2-amino-6,6dimethylbicyclo[3.1.1]heptane-3-carboxylic acid (2b), (1S,2S,3S,5R)-3-amino-6,6dimethylbicyclo[3.1.1] heptane-2-carboxylic acid (3a), $\quad(1 R, 2 R, 3 R, 5 S)$-3-amino-6,6dimethylbicyclo[3.1.1] heptane-2-carboxylic acid (3b), (1R,2R,3S,5R)-2-aminopinane-3-carboxylic acid (4a), (1S,2S,3R,5S)-2-aminopinane-3-carboxylic acid (4b), (1S,2S,3R,4S,5S)-2-amino-4,6,6trimethylbicyclo[3.1.1]heptane-3-carboxylic acid (5a), and $(1 R, 2 R, 3 S, 4 R, 5 R)$-2-amino-4,6,6trimethylbicyclo[3.1.1] heptane-3-carboxylic acid (5b).

\section{The IUPAC names of isoxazoline-fused 2-aminocyclopentanecarboxylic acid analogues (Fig. 12)}

(3a $S, 4 R, 5 S, 6 \mathrm{a} S)$-4-amino-3-methyl-4,5,6,6a-tetrahydro-3a $H$-cyclopenta[d]isoxazole-5-carboxylic acid (6a), (3a $R, 4 S, 5 R, 6 \mathrm{a} R)$-4-amino-3-methyl-4,5,6,6a-tetrahydro-3a $H$-cyclopenta[d]isoxazole-5carboxylic acid (6b), (3aS,4R,5R,6aS)-4-amino-3-methyl-4,5,6,6a-tetrahydro-3a $H$ cyclopenta[d]isoxazole-5-carboxylic acid $\quad(6 \mathbf{c}), \quad(3 \mathrm{a} R, 4 S, 5 S, 6 \mathrm{a} R)-4$-amino-3-methyl-4,5,6,6atetrahydro-3a $H$-cyclopenta[d]isoxazole-5-carboxylic acid (6d), (3a $S, 4 R, 5 S, 6 \mathrm{a} S)$-4-amino-3-ethyl4,5,6,6a-tetrahydro-3a $H$-cyclopenta[d]isoxazole-5-carboxylic acid (7a), $(3 \mathrm{a} R, 4 S, 5 R, 6 \mathrm{a} R)$-4-amino3-ethyl-4,5,6,6a-tetrahydro-3a $H$-cyclopenta[d]isoxazole-5-carboxylic acid (7b), (3a $S, 4 R, 5 R, 6 \mathrm{a} S)$-4amino-3-ethyl-4,5,6,6a-tetrahydro-3a $H$-cyclopenta[d]isoxazole-5-carboxylic acid (7c), (3a $R, 4 S, 5 S, 6 \mathrm{a} R)$-4-amino-3-ethyl-4,5,6,6a-tetrahydro-3a $H$-cyclopenta[d]isoxazole-5-carboxylic acid (7d), (3a $R, 5 S, 6 S, 6 \mathrm{a} S)$-6-amino-3-methyl-4,5,6,6a-tetrahydro-3a $H$-cyclopenta[d]isoxazole-5carboxylic acid (8a), $\quad(3 \mathrm{a} S, 5 R, 6 R, 6 \mathrm{a} R)$-6-amino-3-methyl-4,5,6,6a-tetra-hydro-3a $H$ cyclopenta[d]isoxazole-5-carboxylic acid $\quad(\mathbf{8 b}), \quad(3 \mathrm{a} R, 5 S, 6 R, 6 \mathrm{a} S)$-6-amino-3-methyl-4,5,6,6atetrahydro-3a $H$-cyclopenta[d]isoxazole-5-carboxylic acid $(\mathbf{8 c}),(3 \mathrm{a} S, 5 R, 6 S, 6 \mathrm{a} R)-6$-amino-3-methyl4,5,6,6a-tetrahydro-3a $H$-cyclopenta[d]isoxazole-5-carboxylic acid (8d), $(3 \mathrm{a} R, 5 S, 6 S, 6 \mathrm{a} S)$-6-amino3-ethyl-4,5,6,6a-tetrahydro-3a $H$-cyclopenta[d]isoxazole-5-carboxylic acid (9a), (3aS,5R,6R,6a $R)-6$ amino-3-ethyl-4,5,6,6a-tetrahydro-3a $H$-cyclopenta[d]isoxazole-5-carboxylic acid

$(9 b)$, (3a $R, 5 S, 6 R, 6 \mathrm{a} S)$-6-amino-3-ethyl-4,5,6,6a-tetrahydro-3a $H$-cyclopenta[d]isoxazole-5-carboxylic acid $(9 \mathrm{c})$, and $(3 \mathrm{a} S, 5 R, 6 S, 6 \mathrm{a} R)$-6-amino-3-ethyl-4,5,6,6a-tetrahydro-3a $H$-cyclopenta[d]isoxazole-5carboxylic acid (9d). 
Selected chromatograms of monoterpene-based $\beta$-amino acids

$1 a, b$

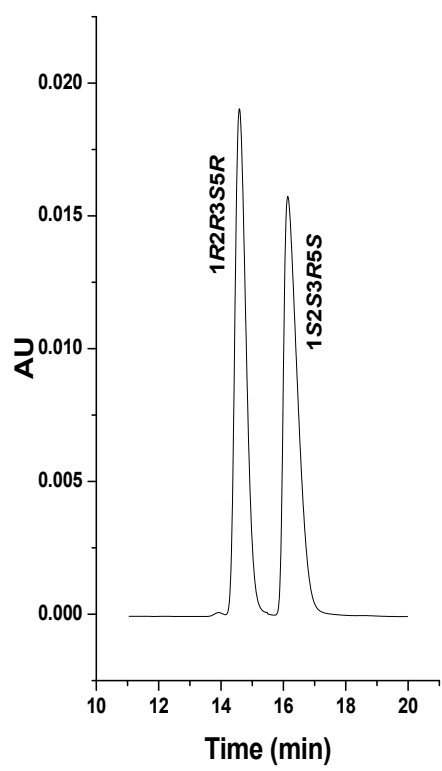

$2 a, b$

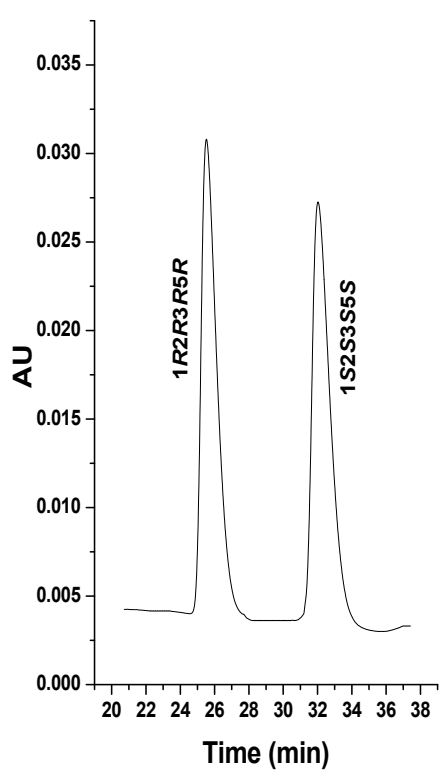

$3 a, b$

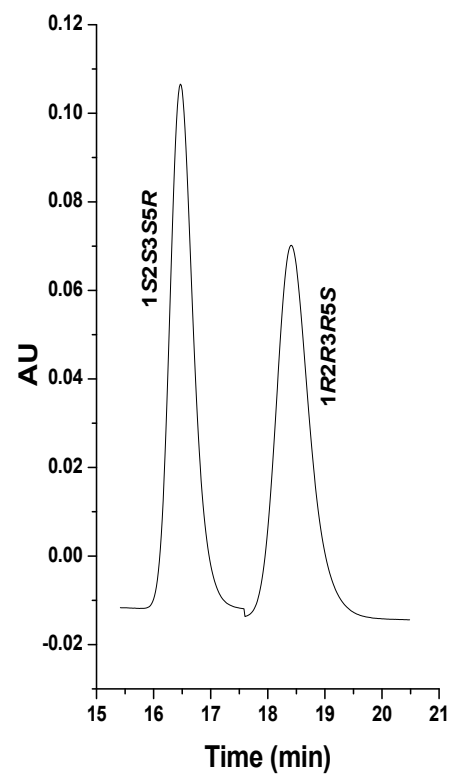

$4 a, b$

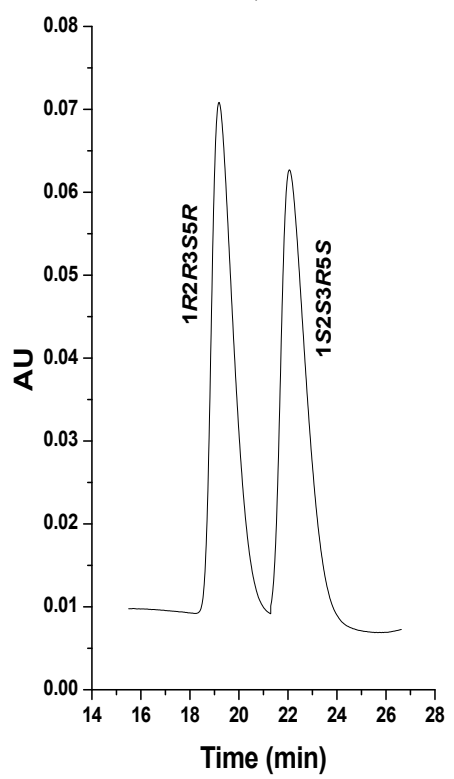

$5 a, b$

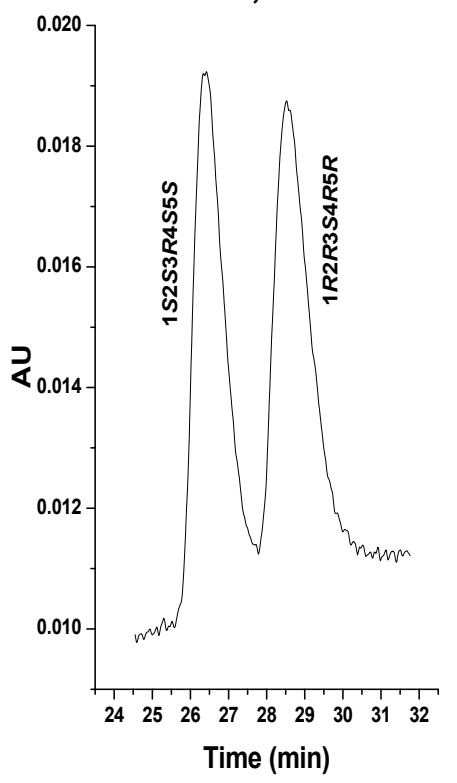

Chromatographic conditions: column, Chirobiotic $\mathrm{T}$ (analytes $\mathbf{1}$ and 3), Chirobiotic T2 (analyte 2) and Chirobiotic TAG (analytes 4 and 5); mobile phase, $0.1 \%$ TEAA $(\mathrm{pH}=4.1) / \mathrm{MeOH}=10 / 90$ $(v / v)$ (analyte 1,3 and 5), $0.1 \%$ TEAA $(\mathrm{pH}=4.1) / \mathrm{MeOH}=40 / 60(v / v)$ (analyte 4), $0.1 \%$ TEAA $(\mathrm{pH}$ $=4.1) / \mathrm{MeOH}=98 / 2(v / v)$ (analyte 2); temperature, $25{ }^{\circ} \mathrm{C}$ (analytes 1-4), $20{ }^{\circ} \mathrm{C}$ (analyte 5); flow rate, $0.5 \mathrm{~mL} \mathrm{~min}^{-1}$; detection, $210 \mathrm{~nm}$. 
Selected chromatograms of isoxazoline-fused $\beta$-amino acids on macrocyclic antibiotics

6

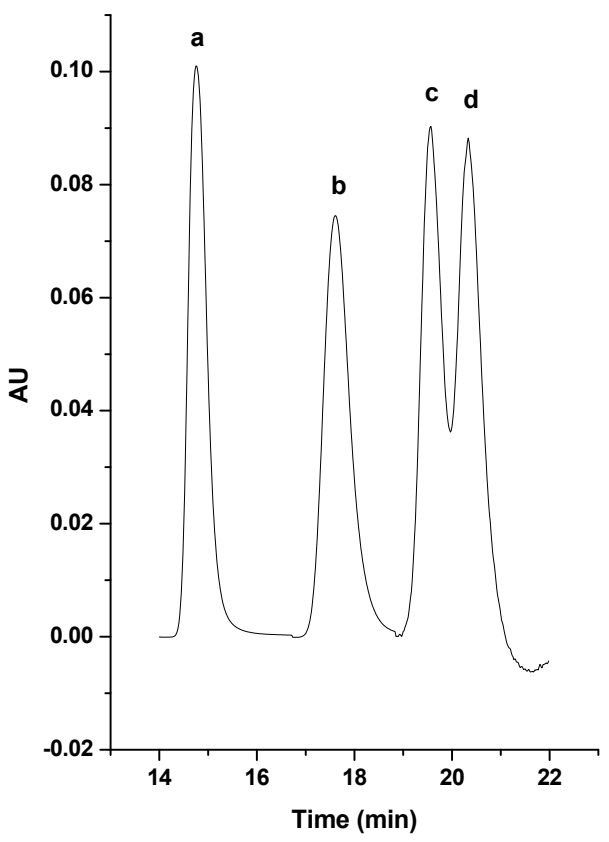

8

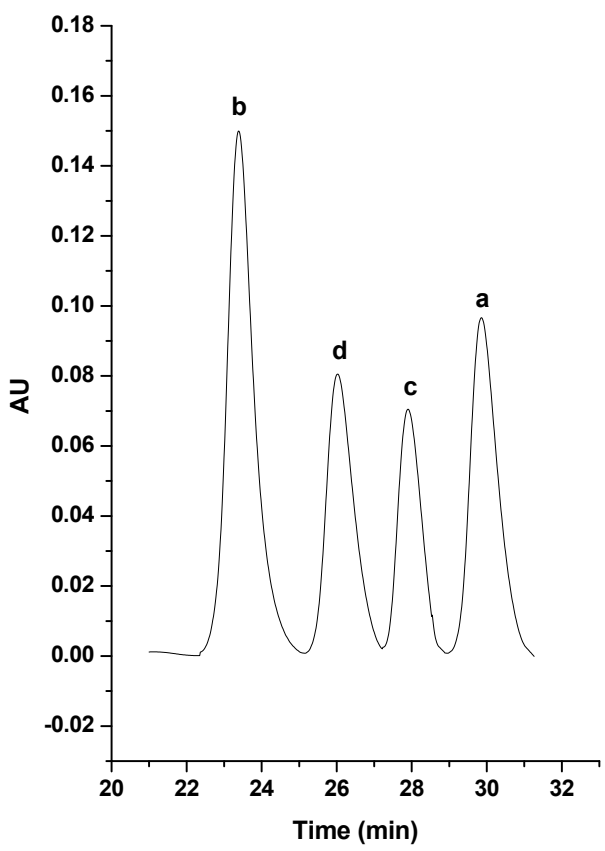

7

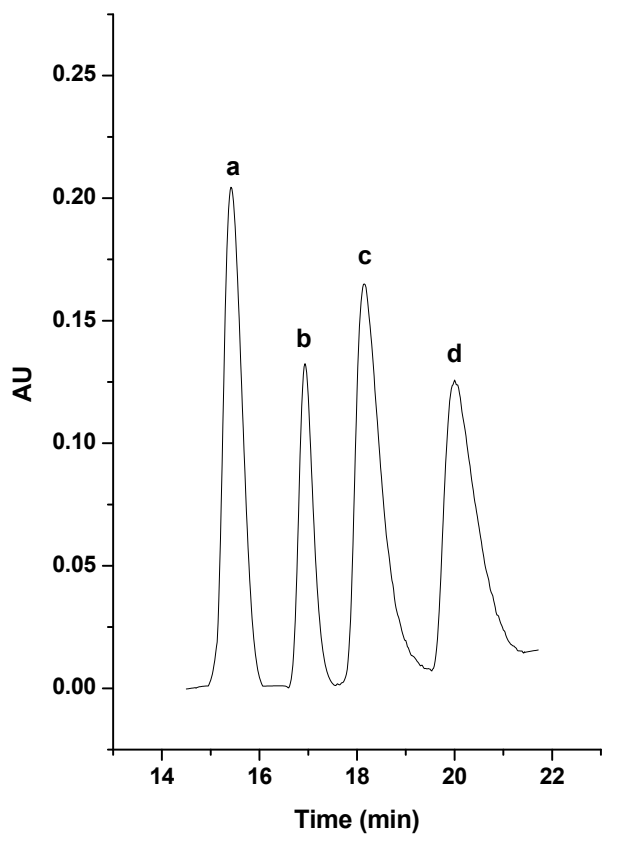

9

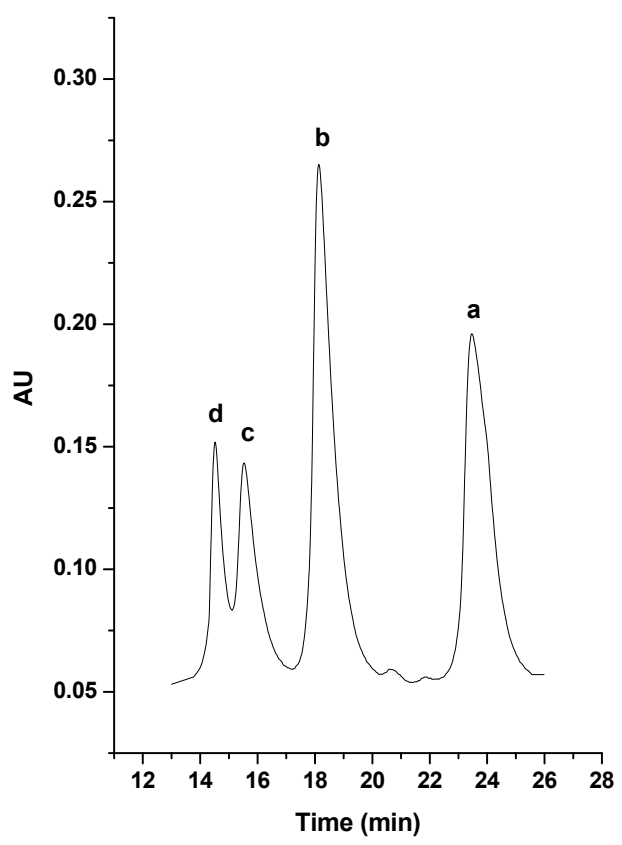

Chromatographic conditions: column, Chirobiotic TAG (analytes 6 and 7), Chirobiotic V (analyte 9) and Chirobiotic VAG (analyte 8); mobile phase, $0.1 \%$ TEAA $(\mathrm{pH}=4.1) / \mathrm{MeOH}=60 / 40(v / v)$ (analyte 6), 0.1\% TEAA $(\mathrm{pH}=4.1) / \mathrm{MeOH}=80 / 20(v / v)$ (analyte 7), $100 \% \mathrm{MeOH}$ (analyte 8), $\mathrm{MeOH} / \mathrm{AcOH} / \mathrm{TEA}=100 / 0.1 / 0.1(\mathrm{v} / \mathrm{v} / \mathrm{v})\left(\right.$ analyte 9); temperature, $25^{\circ} \mathrm{C}($ analytes 6 and 7$), 10{ }^{\circ} \mathrm{C}$ (analytes 8 and 9); flow rate, $0.5 \mathrm{~mL} \mathrm{~min}^{-1}$; detection, $210 \mathrm{~nm}$. 
Selected chromatograms of isoxazoline-fused $\beta$-amino acids on crown ether-based CSPS

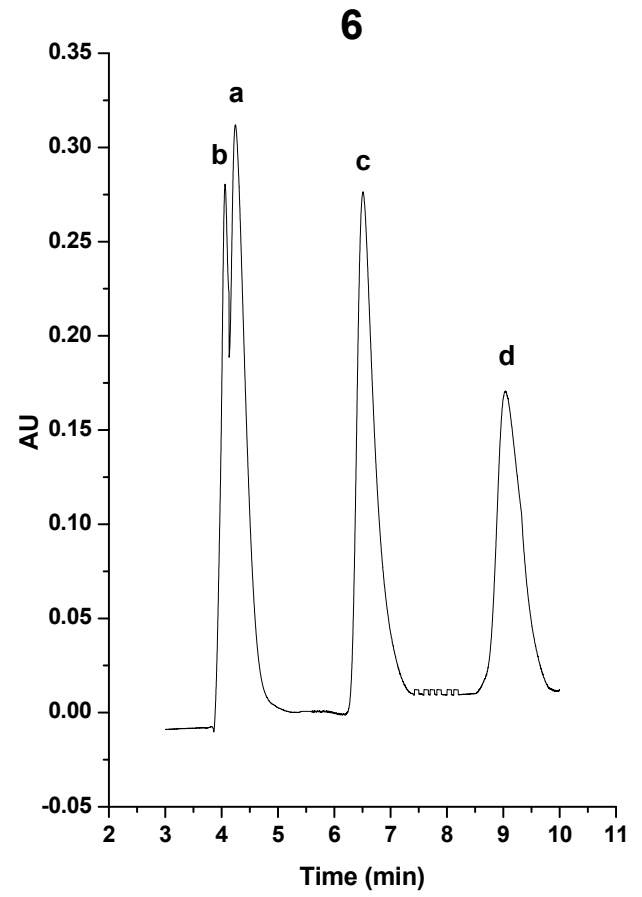

8

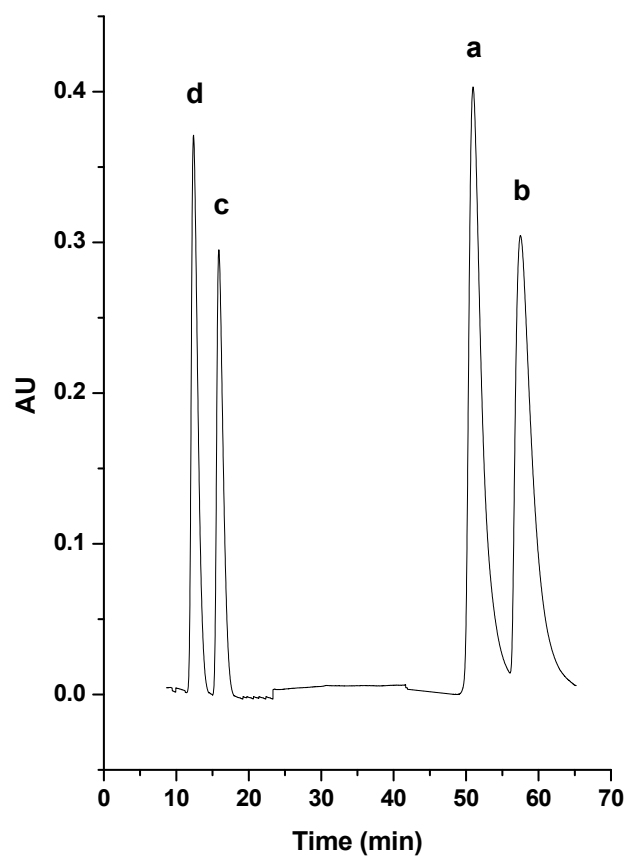

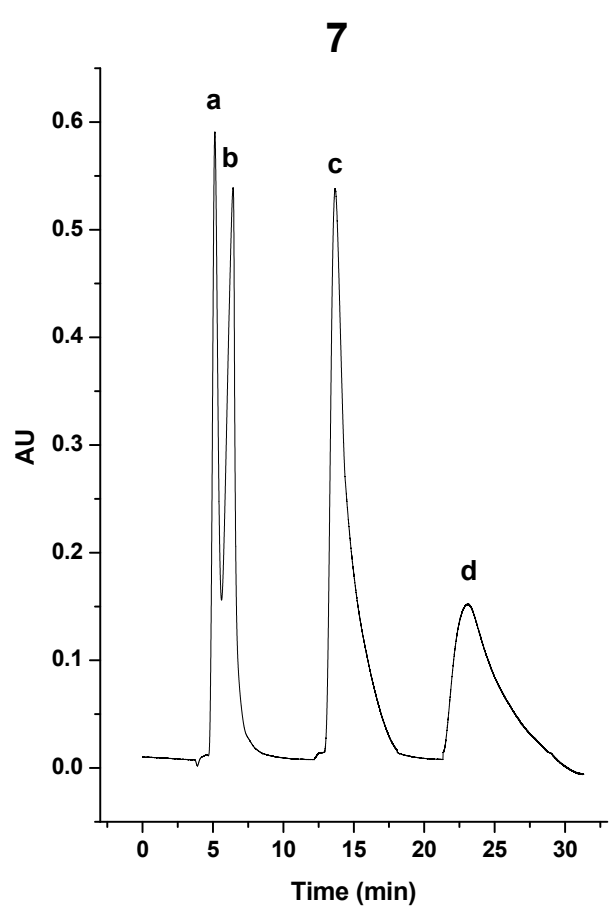

9

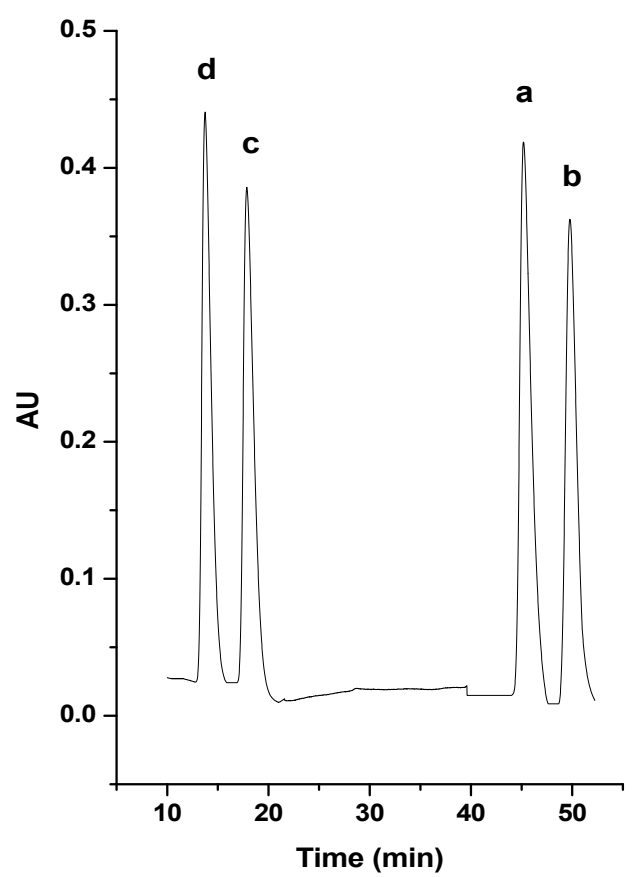

Chromatographic conditions: column, Crown 1 (for all analytes); mobile phase, $\mathrm{H}_{2} \mathrm{O} / \mathrm{MeOH} / \mathrm{AcOH}=90 / 10 / 10(v / v / m M)\left(\right.$ analyte 6), $\mathrm{H}_{2} \mathrm{O} / \mathrm{EtOH} / \mathrm{AcOH}=50 / 50 / 10(v / v / m M)$ (analyte 7), $\mathrm{H}_{2} \mathrm{O} / \mathrm{MeOH} / \mathrm{AcOH}=5 / 95 / 10(v / v / m M)$ (analytes 8 and 9); temperature, $25{ }^{\circ} \mathrm{C}$ (analyte 6), $5{ }^{\circ} \mathrm{C}$ (analytes 7 and 9); flow rate, $0.5 \mathrm{~mL} \mathrm{~min}^{-1}$; detection, $210 \mathrm{~nm}$. 


\section{PUBLICATIONS}




\title{
High-performance liquid chromatographic enantioseparation of monoterpene-based 2-amino carboxylic acids on macrocyclic glycopeptide-based phases
}

\author{
László Sipos $^{\mathrm{b}}$, István Ilisz ${ }^{\mathrm{a}}$, Zoltán Pataj ${ }^{\mathrm{a}}$, Zsolt Szakonyi ${ }^{\mathrm{b}}$, Ferenc Fülöp ${ }^{\mathrm{b}}$, \\ Daniel W. Armstrong ${ }^{\mathrm{c}}$, Antal Péter ${ }^{\mathrm{a}, *}$ \\ a Department of Inorganic and Analytical Chemistry, University of Szeged, Dóm tér 7, H-6720 Szeged, Hungary \\ ${ }^{\mathrm{b}}$ Institute of Pharmaceutical Chemistry, University of Szeged, Eötvös utca 6, H-6720 Szeged, Hungary \\ ${ }^{c}$ Department of Chemistry and Biochemistry, University of Texas at Arlington, Arlington, TX 76019-0065, USA
}

\section{A R T I C L E I N F O}

\section{Article history:}

Received 30 June 2010

Received in revised form 26 August 2010

Accepted 27 August 2010

Available online 6 September 2010

\section{Keywords:}

Column liquid chromatography

$\beta$-Amino acid

Monoterpene

Conformationally constrained

Macrocyclic glycopeptide-based chiral

stationary phases

Chirobiotic columns

\begin{abstract}
A B S T R A C T
The enantiomers of five monoterpene-based 2-amino carboxylic acids were directly separated on chiral stationary phases containing macrocyclic glycopeptide antibiotics such as teicoplanin (Astec Chirobiotic $\mathrm{T}$ and T2) and teicoplanin aglycone (Chirobiotic TAG) as chiral selectors. The effects of $\mathrm{pH}$, the mobile phase composition, the structure of the analyte and temperature on the separations were investigated. Experiments were performed at constant mobile phase compositions in the temperature range $10-40{ }^{\circ} \mathrm{C}$ to study the effects of temperature and thermodynamic parameters on separations. Apparent thermodynamic parameters and $T_{\text {iso }}$ values were calculated from plots of $\ln k$ or $\ln \alpha$ versus $1 / T$. Some mechanistic aspects of the chiral recognition process are discussed with respect to the structures of the analytes. It was found that the enantioseparations were in most cases enthalpy driven. The sequence of elution of the enantiomers was determined in all cases.
\end{abstract}

(C) 2010 Elsevier B.V. All rights reserved.

\section{Introduction}

$\beta$-Amino acids are key building blocks of numerous bioactive molecules [1-4]. Icofungipen (PLD-118; (1R,2S)-2-amino-4methylenecyclopentanecarboxylic acid), a $\beta$-amino acid, upsets the biosynthesis of protein in Candida albicans [5]. $\beta$-Amino acids and their foldameric oligomers are currently at the focus of research interest [6,7].

Enantiomerically pure $\alpha$-pinene, $\delta$-pinene and 3-carene can be transformed into $\beta$-amino acid derivatives $[8,9,10,11]$, which are excellent building blocks for the syntheses of monoterpene-fused saturated 1,3 -heterocycles $[9,12]$. Also, they were used successfully as chiral auxiliaries in the enantioselective reactions of $\mathrm{Et}_{2} \mathrm{Zn}$ with aromatic aldehydes $[10,12,8,9]$. Apopinane-based $\beta$-amino acids were used as building blocks in the construction of stable $\mathrm{H} 12$ foldameric helices and in Ugi four-centre three-component reactions $[11,13,14]$. The latter new family of monoterpene-based chiral $\beta$-lactams and $\beta$-amino acid derivatives derived from $(-)$ - and $(+)$-apopinene recently were reported to eliminate the disadvan-

\footnotetext{
* Corresponding author. Tel.: +36 62 544000/3656; fax: +36 62420505 .

E-mail address: apeter@chem.u-szeged.hu (A. Péter).
}

tageous steric effect of the methyl substituent on the pinane ring system [11]. The regioisomeric trans apopinane-based $\beta$-amino acids could be prepared by conjugate addition of lithium amides to (-)- and (+)-tert-butyl myrtenate, derived from natural (-)myrtenal and $(+)-\alpha$-pinene [3].

The wide-ranging utility of these compounds requires analytical methods to check on the stereochemistry of the final product. One of the most frequently applied techniques is chiral high-performance liquid chromatography (HPLC). HPLC enantioseparations of $\beta$-amino acids have been performed by both indirect and direct methods. In the past decade, chiral derivatizing agents (CDAs) such as Marfey' reagent (FDAA), 2,3,4,6-tetra-O-acetyl- $\beta$-D-glucopyranosyl isothiocyanate (GITC), $\mathrm{N}$-(4-nitrophenoxycarbonyl)-phenylalanine methoxyethyl ester [(S)-NIFE] [15], chiral stationary phases (CSPs) such as macrocyclic glycopeptides [16,17], quinine derived [18], crown ether based $[19,20]$, rapid double derivatization technique with gas chromatography [21] and (18-crown-6)-2,3,11,12-tetracarboxylic acid as a chiral NMR solvating agent have been used for the enantioseparation of $\beta$-amino acids [22].

In all chromatographic modes, the selectivity and retention factors are mainly controlled by the concentration and nature of the mobile phase components, together with other variables, such as 
the $\mathrm{pH}$ of the mobile phase. Enantioselective retention mechanisms are often influenced by temperature. This has been noted for some time in chiral gas chromatography $[23,24]$. It additionally known that there are both achiral and chiral contributions to retention that can vary with a wide variety of experimental parameters [24-28]. Several papers have been published that discuss the effects of temperature on enantiomers HPLC separation [29-33].

The dependence of the retention of an analyte on temperature can be expressed by the van't Hoff equation, which may be interpreted in terms certain of mechanistic aspects of chiral recognition:

$\ln k=-\frac{\Delta H^{\circ}}{R T}+\frac{\Delta S^{\circ}}{R}+\ln \phi$

in which $k$ is retention factor, $\Delta H^{\circ}$ is the enthalpy of transfer of the solute from the mobile phase to the stationary phase, $\Delta S^{\circ}$ is the entropy of transfer of the solute from the mobile phase to the stationary phase, $R$ is the gas constant, $T$ is the temperature and $\phi$ is the phase ratio of the column. This equation reveals that a plot of $\ln k$ versus $1 / T$ is linear, with slope $-\Delta H^{\circ} / R$ and intercept $\Delta S^{\circ} / R+\ln \phi$, if $\Delta H^{\circ}$ is invariant with temperature. Since the value of $\phi$ is often not known, the $\Delta S^{\circ^{*}}$ values $\left[\Delta S^{\circ *}=\Delta S^{\circ}+R \ln \phi\right]$ calculated from the intercepts of the plots via Eq. (1) are generally used. Any uncertainty in the phase ratio affects all $\Delta S^{\circ *}$ values in the same manner. In chiral chromatography, however, the van't Hoff plots often deviate from linearity, possibly as a result of the inhomogeneity of the CSP surface, leading to a mixed retention mechanism [31,32].

The corresponding $\Delta\left(\Delta H^{\circ}\right)$ and $\Delta\left(\Delta S^{\circ}\right)$ values for the separated enantiomers can be determined from a modification of Eq. (1):

$\ln \alpha=-\frac{\Delta\left(\Delta H^{\circ}\right)}{R T}+\frac{\Delta\left(\Delta S^{\circ}\right)}{R}$

where $\alpha$ is the selectivity factor $\left(\alpha=k_{2} / k_{1}\right)$.

In the present paper, direct HPLC methods are described for the enantioseparation of monoterpene-based 2-amino carboxylic acids, with the application of different macrocyclic glycopeptidebased CSPs. For comparison purposes, most of the separations were carried out at constant mobile phase compositions at different temperatures. The effects of $\mathrm{pH}$, the mobile phase composition, the specific structural features of the analytes and selectors and temperature on the retention are discussed on the basis of the experimental data. The elution sequence was determined in all cases.

\section{Experimental}

\subsection{Materials and methods}

The enantiomers of monoterpene-based cis- $\beta$-amino acids were prepared in two steps by literature methods $[10,11,8]$. Chlorosulfonyl isocyanate addition to the corresponding chiral monoterpene ((-)-apopinene for $\mathbf{1 A}$ and $\mathbf{2 A},(+)$-apopinene for $\mathbf{1 B}$ and $\mathbf{2 B},(-)$ $\alpha$-pinene for $\mathbf{4 A},(+)-\alpha$-pinene for $\mathbf{4 B},(-)-\delta$-pinene for $\mathbf{5 A}$, and $(+)-\delta$-pinene for $\mathbf{5 B}$ ) afforded $\beta$-lactams in highly regio- and stereospecific reactions, subsequent acidic hydrolysis resulted in the corresponding cis- $\beta$-amino acids. The base-catalysed isomerization of the esters of the cis-amino acids derived from apopinene (1A and 1B), followed by hydrolysis, afforded the corresponding trans enantiomers $\mathbf{2 A}$ and $\mathbf{2 B}$ in excellent yields [11]. The regioisomeric trans apopinane-based $\beta$-amino acids $\mathbf{3 A}$ and $\mathbf{3 B}$ could be prepared by conjugate addition of lithium amides to (-)- and (+)-tert-butyl myrtenate, derived respectively from natural (-)-myrtenal and $(+)-\alpha$-pinene, followed by catalytic debenzylation and hydrolysis [3].

Methanol (MeOH) of HPLC grade was purchased from Scharlau (Sentmenat, Spain). Triethylamine (TEA), glacial acetic acid (AcOH), triethylammonium-acetate (TEAA), ethanol (EtOH), n-propanol (PrOH), 2-propanol (IPA) and other reagents of analytical reagent grade were from Sigma-Aldrich (St. Louis, MO, USA). The Milli-Q water was further purified by filtration on a $0.45-\mu \mathrm{m}$ filter, type HV, Millipore (Molsheim, France).

All the compounds mentioned in Fig. 1 were evaluated with different mobile phases. Reversed-phase mobile phases consisted of $0.1 \%$ TEAA ( pH 4.1)/MeOH = 98/2, 90/10, 80/20, 60/40, 40/60, 20/80 and $10 / 90(\mathrm{v} / \mathrm{v}), 100 \% \mathrm{MeOH}$ while polar ionic mobile phase was $\mathrm{MeOH} / \mathrm{AcOH} / \mathrm{TEA}=100 / 0.1 / 0.1(\mathrm{v} / \mathrm{v} / \mathrm{v})$.

\subsection{Apparatus}

The HPLC separations were carried out on a Waters HPLC system consisting of an M-600 low-pressure gradient pump, an M-2996 photodiode-array detector and a Millenium ${ }^{32}$ Chromatography Manager data system (Waters Chromatography, Milford, MA, USA) equipped with a Rheodyne Model 7125 injector (Cotati, CA, USA) with a $20-\mu \mathrm{L}$ loop.

The macrocyclic glycopeptide-based stationary phases used for analytical separation were teicoplanin-containing Chirobiotic T and T2 and teicoplanin aglycone-containing Chirobiotic TAG columns, $250 \mathrm{~mm} \times 4.6 \mathrm{~mm}$ I.D., $5-\mu \mathrm{m}$ particle size (for each column) (Astec, Whippany, NJ, USA). Chirobiotic T and T2 are both based on silica gel with a 5- $\mu \mathrm{m}$ particle size, but the Chirobiotic T material has a $120 \AA$ pore size and the Chirobiotic T2 material a $200 \AA$ pore size. Moreover, the linkage chain in Chirobiotic T2 is approximately twice as long as that in Chirobiotic T. Hence, the coverage and spacing will be different for the two. This is manifested in the form of steric and non-enantioselective hydrophobic interaction differences between the two columns.

The columns were thermostated in a Spark Mistral column thermostat (Spark Holland, Emmen, The Netherlands). The precision of temperature adjustment was $\pm 0.1^{\circ} \mathrm{C}$.

\section{Results and discussion}

The experimental conditions, including the $\mathrm{pH}$ of the mobile phase, the buffer type, the concentration of the organic modifier and the temperature, were investigated. The analytes in this study (Fig. 1) possess a monoterpene-based skeleton. Besides carboxy and primary amino groups (in exo or endo position), analogues 4 and 5 bear one methyl group, in position 2 or 4 . These differences result in different steric effects and influence the hydrophobicity, bulkiness and rigidity of the molecules, depending on how their atoms are linked and how capable they are of different interactions with the selector.

The effects of $\mathrm{pH}$ on the separation were investigated in the acidic $\mathrm{pH}$ range. A decrease in the $\mathrm{pH}$ of the $0.1 \%$ aqueous $\mathrm{TEAA} / \mathrm{MeOH}=60 / 40(\mathrm{v} / \mathrm{v})$ eluent system from 6.50 to 4.00 considerably increased the retention factors of analyte $\mathbf{4}$ on both the Chirobiotic T and TAG columns; the selectivity decreased slightly, while the resolution did so considerably. Similar results were obtained by Armstrong et al. [34] on a teicoplanin CSP for analytes with free carboxylic acid groups. The $\mathrm{pH} \mathrm{6-7}$ that produced the highest $\alpha$ also yielded the best resolution. According to the Armstrong's work [34] the protonation of teicoplanin either directly affects the coulombic or dipolar interactions between the analyte and the CSP, or indirectly influences the separation by changing the conformation of the selector.

All data relating to the separation of the compounds, including the retention factors, separation factors and resolutions for each analyte on the three different Chirobiotic columns, are given in Table 1 . For purposes of comparison and to simplify the presentation, Table 1 lists only the chromatographic results obtained when the enantiomeric separation was achieved with mobile phase com- 
<smiles>[X]C1(C)CC(N)C(C(=O)O)C1</smiles>

$1 a$

$1 R 2 R 3 S 5 R$<smiles>CC1(C)CC2CC(C(=O)O)C(N)C1C2</smiles><smiles>[X]CC1(C)CCC(N)C1C(=O)O</smiles><smiles>[X]C1(C)CCC(C(=O)O)C(C)(N)C1</smiles><smiles>CC(C)[Ge](C(=O)O)[C@H](N)CC(C)(C)C</smiles>

2a

$1 R 2 R 3 R 5 R$

$3 \mathbf{a}$

$1 S 2 S 3 S 5 R$

$4 a$

$1 R 2 R 3 S 5 R$

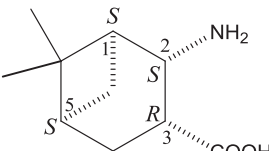

$1 b$

$1 S 2 S 3 R 5 S$<smiles>CC1(C)C[C@H](N)[C@@H](C(=O)O)C1</smiles>

2b

$1 S 2 S 3 S 5 S$<smiles>CC1(C)CCC(C(=O)O)C(N)C1</smiles>

3b

$1 R 2 R 3 R 5 S$<smiles>CC1(C)[C@@H]2C[C@@H]1C[C@H](C(=O)O)[C@]2(C)N</smiles>

4b

$1 S 2 S 3 R 5 S$

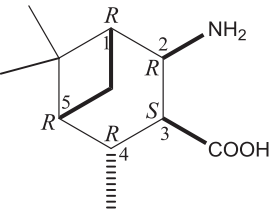

$5 b$

$1 R 2 R 3 S 4 R 5 R$

Fig. 1. Chemical structures of analytes. 1a $(1 R, 2 R, 3 S, 5 R)-2$-amino-6,6-dimethylbicyclo[3.1.1]heptane-3-carboxylic acid; 1b (1S,2S,3R,5S)-2-amino-6, 6dimethylbicyclo[3.1.1] heptane-3-carboxylic acid; 2a (1R,2R,3R,5R)-2-amino-6,6-dimethylbicyclo[3.1.1] heptane-3-carboxylic acid; 2b (1S,2S,3S,5S)-2-amino-6,6-dimethylbicyclo[3.1.1]heptane-3-carboxylic acid; $\quad 3 a \quad(1 S, 2 S, 3 S, 5 R)-3$-amino-6,6-dimethylbicyclo[3.1.1] heptane-2-carboxylic acid; $3 \mathbf{b} \quad(1 R, 2 R, 3 R, 5 S)-3$-amino-6,6dimethylbicyclo[3.1.1]heptane-2-carboxylic acid; $\quad 4 a \quad(1 R, 2 R, 3 S, 5 R)$-2-aminopinane-3-carboxylic acid; $\quad \mathbf{4 b} \quad(1 S, 2 S, 3 R, 5 S)$-2-aminopinane-3-carboxylic acid; $\mathbf{5 a}$ $(1 S, 2 S, 3 R, 4 S, 5 S)$-2-amino-4,6,6-trimethylbicyclo[3.1.1] heptane-3-carboxylic acid; $5 \mathbf{b}(1 R, 2 R, 3 S, 4 R, 5 R)$-2-amino-4,6,6-trimethylbicyclo[3.1.1] heptane-3-carboxylic acid.

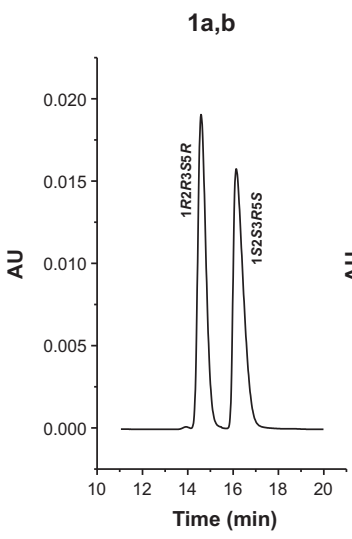

$1 \mathrm{~b}$

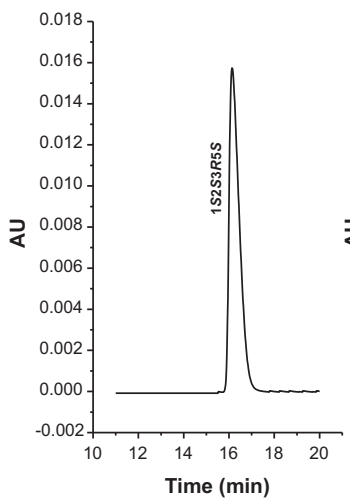

2a,b

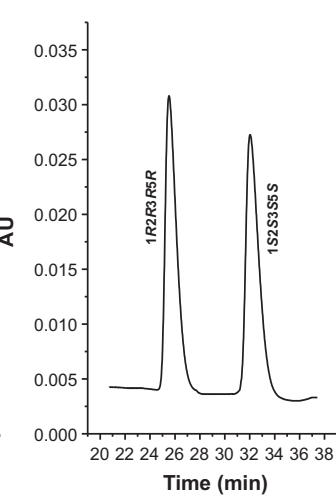

2a

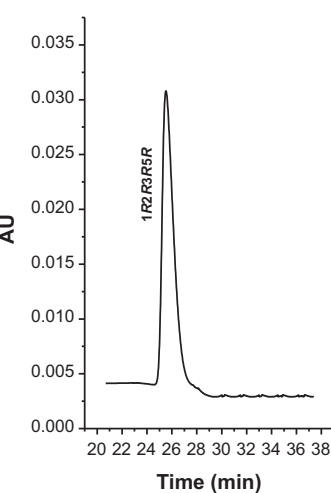

3a,b

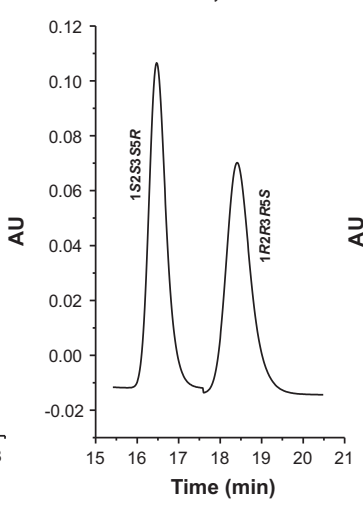

$3 a$

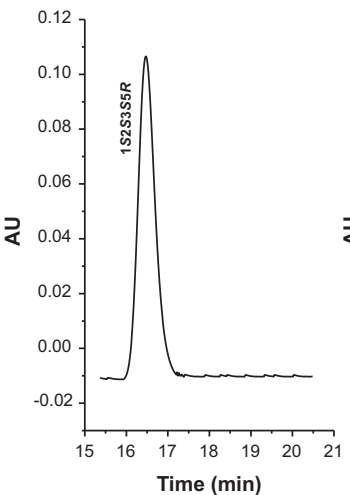

4a,b

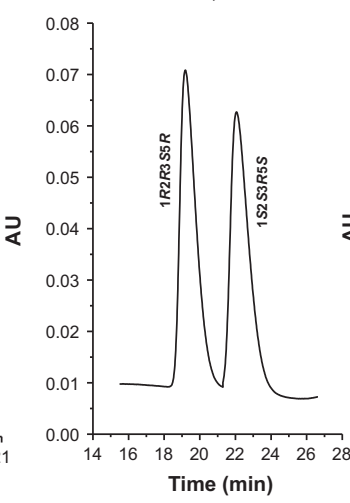

$4 a$

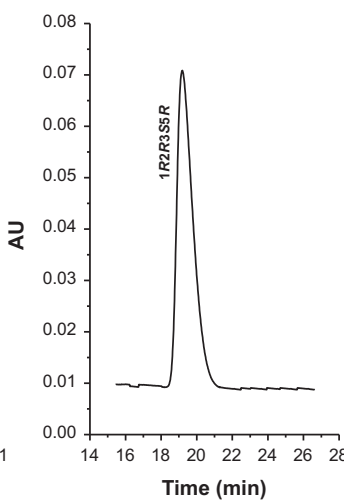

5a,b

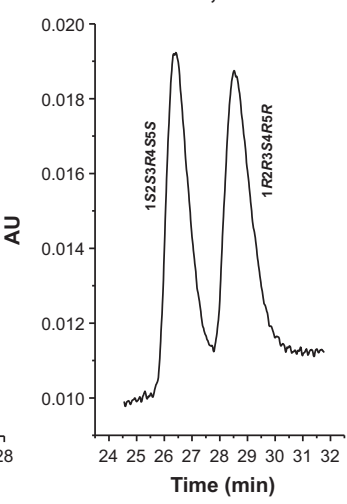

$5 b$

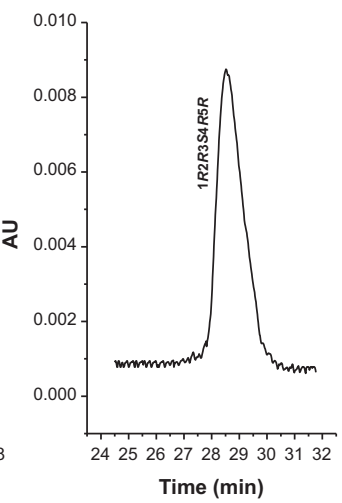

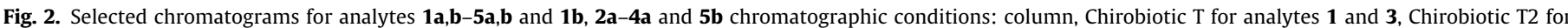

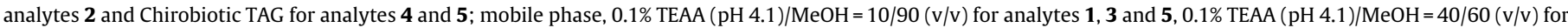
4 and $0.1 \%$ TEAA $(\mathrm{pH} 4.1) / \mathrm{MeOH}=98 / 2(\mathrm{v} / \mathrm{v})$ for $\mathbf{2}$; temperature, ambient for analytes $\mathbf{1 - 4}, 20^{\circ} \mathrm{C}$ for $\mathbf{5}$; flow rate, $0.5 \mathrm{~mL} \mathrm{~min}^{-1}$; detection, $210 \mathrm{~nm}$. 
Table 1

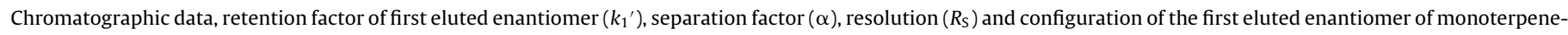
based 2-amino acids on different monocyclic glycopeptide-based columns.

\begin{tabular}{|c|c|c|c|c|c|c|}
\hline Analyte & Column & $\begin{array}{l}\text { Mobile phase TEAA/MeOH (v/v), } \\
\text { a } \mathrm{MeOH} / \mathrm{AcOH} / \mathrm{TEA}(\mathrm{v} / \mathrm{v} / \mathrm{v}), \mathbf{b}\end{array}$ & $k_{1}^{\prime}$ & $\alpha$ & $R_{\mathrm{S}}$ & $\begin{array}{l}\text { Configuration of the } \\
\text { first eluted enantiomer }\end{array}$ \\
\hline \multirow{15}{*}{1} & $\mathbf{T}$ & $90 / 10, \mathbf{a}$ & 3.48 & 1.14 & 1.27 & $1 R 2 R 3 S 5 R$ \\
\hline & & $40 / 60, \mathbf{a}$ & 1.98 & 1.08 & 0.72 & \\
\hline & & $10 / 90, \mathbf{a}$ & 2.65 & 1.15 & 1.74 & \\
\hline & & $0 / 100, \mathbf{a}$ & 4.18 & 1.19 & 1.85 & \\
\hline & & $100 / 0.1 / 0.1, \mathbf{b}$ & 3.05 & 1.24 & 1.57 & \\
\hline & T2 & $90 / 10, \mathbf{a}$ & 3.21 & 1.00 & 0.00 & \\
\hline & & $40 / 60, \mathbf{a}$ & 1.59 & 1.12 & 1.24 & \\
\hline & & $10 / 90, \mathbf{a}$ & 2.00 & 1.16 & 1.40 & \\
\hline & & $0 / 100, \mathbf{a}$ & 2.67 & 1.19 & 1.17 & \\
\hline & & $100 / 0.1 / 0.1, \mathbf{b}$ & 2.01 & 1.00 & 0.00 & \\
\hline & TAG & $90 / 10, \mathbf{a}$ & 6.92 & 1.00 & 0.00 & \\
\hline & & $40 / 60, \mathbf{a}$ & 3.74 & 1.15 & 1.79 & \\
\hline & & $10 / 90, \mathbf{a}$ & 4.89 & 1.22 & 1.63 & \\
\hline & & $0 / 100, \mathbf{a}$ & 6.61 & 1.23 & 1.13 & \\
\hline & & $100 / 0.1 / 0.1, \mathbf{b}$ & 3.88 & 1.00 & 0.00 & \\
\hline \multirow{15}{*}{2} & $\mathbf{T}$ & $90 / 10, \mathbf{a}$ & 3.28 & 1.00 & 0.00 & $1 R 2 R 3 R 5 R$ \\
\hline & & $40 / 60, \mathbf{a}$ & 2.30 & 1.04 & 0.39 & \\
\hline & & $10 / 90, \mathbf{a}$ & 3.65 & 1.06 & 0.80 & \\
\hline & & $0 / 100, \mathbf{a}$ & 4.73 & 1.08 & 0.90 & \\
\hline & & $100 / 0.1 / 0.1, \mathbf{b}$ & 3.39 & 1.08 & 0.56 & $1 S 2 S 3 S 5 S$ \\
\hline & T2 & $90 / 10, \mathbf{a}$ & 3.13 & 1.18 & 1.35 & $1 R 2 R 3 R 5 R$ \\
\hline & & $40 / 60, \mathbf{a}$ & 2.23 & 1.03 & 0.27 & \\
\hline & & $10 / 90, \mathbf{a}$ & 3.35 & 1.05 & 0.51 & \\
\hline & & $0 / 100, \mathbf{a}$ & 5.98 & 1.06 & 0.60 & \\
\hline & & $100 / 0.1 / 0.1, \mathbf{b}$ & 2.32 & 1.09 & 0.42 & $1 S 2 S 3 S 5 S$ \\
\hline & TAG & $90 / 10, \mathbf{a}$ & 7.63 & 1.19 & 1.06 & $1 R 2 R 3 R 5 R$ \\
\hline & & $40 / 60, \mathbf{a}$ & 4.88 & 1.00 & 0.00 & \\
\hline & & $10 / 90, \mathbf{a}$ & 7.05 & 1.00 & 0.00 & \\
\hline & & $0 / 100, \mathbf{a}$ & 8.96 & 1.02 & 1.53 & \\
\hline & & $100 / 0.1 / 0.1, \mathbf{b}$ & 4.09 & 1.00 & 0.00 & $1 S 2 S 3 S 5 S$ \\
\hline \multirow{15}{*}{3} & $\mathbf{T}$ & $90 / 10, \mathbf{a}$ & 11.95 & 1.00 & 0.00 & $1 R 2 R 3 R 5 S$ \\
\hline & & $40 / 60, \mathbf{a}$ & 7.49 & 1.00 & 0.00 & \\
\hline & & $10 / 90, \mathbf{a}$ & 3.68 & 1.15 & 1.34 & \\
\hline & & $0 / 100, \mathbf{a}$ & 1.30 & 1.48 & 3.49 & \\
\hline & & $100 / 0.1 / 0.1, \mathbf{b}$ & 3.17 & 1.32 & 2.67 & \\
\hline & T2 & $90 / 10, \mathbf{a}$ & 10.11 & 1.00 & 0.00 & \\
\hline & & $40 / 60, \mathbf{a}$ & 2.43 & 1.12 & 0.62 & \\
\hline & & $10 / 90, \mathbf{a}$ & 2.00 & 1.22 & 1.22 & \\
\hline & & $0 / 100, \mathbf{a}$ & 1.80 & 1.29 & 1.97 & \\
\hline & & $100 / 0.1 / 0.1, \mathbf{b}$ & 2.84 & 1.09 & 0.95 & \\
\hline & TAG & $90 / 10, \mathrm{a}$ & 11.90 & 1.07 & 0.81 & \\
\hline & & $40 / 60, \mathbf{a}$ & 5.96 & 1.08 & 0.35 & \\
\hline & & $10 / 90, \mathbf{a}$ & 4.75 & 1.29 & 1.83 & \\
\hline & & $0 / 100, \mathbf{a}$ & 4.84 & 1.32 & 2.76 & \\
\hline & & $100 / 0.1 / 0.1, \mathbf{b}$ & 3.13 & 1.35 & 1.97 & \\
\hline \multirow{15}{*}{4} & $\mathbf{T}$ & $90 / 10, \mathbf{a}$ & 3.28 & 1.34 & 2.95 & $1 S 2 S 3 R 5 S$ \\
\hline & & $40 / 60, \mathbf{a}$ & 1.79 & 1.08 & 0.66 & \\
\hline & & $10 / 90, \mathbf{a}$ & 2.17 & 1.15 & 1.32 & \\
\hline & & $0 / 100, \mathbf{a}$ & 3.29 & 1.22 & 1.38 & \\
\hline & & $100 / 0.1 / 0.1, \mathbf{b}$ & 2.07 & 1.30 & 2.31 & \\
\hline & T2 & $90 / 10, \mathbf{a}$ & 3.22 & 1.20 & 1.78 & \\
\hline & & $40 / 60, \mathbf{a}$ & 1.40 & 1.12 & 1.07 & \\
\hline & & $10 / 90, \mathbf{a}$ & 1.52 & 1.27 & 1.78 & \\
\hline & & $0 / 100, \mathbf{a}$ & 1.90 & 1.45 & 1.92 & \\
\hline & & $100 / 0.1 / 0.1, \mathbf{b}$ & 1.25 & 1.65 & 2.11 & \\
\hline & TAG & $90 / 10, \mathbf{a}$ & 9.68 & 1.06 & 0.48 & \\
\hline & & $40 / 60, \mathbf{a}$ & 3.86 & 1.17 & 1.68 & \\
\hline & & $10 / 90, \mathbf{a}$ & 3.25 & 1.25 & 1.80 & \\
\hline & & $0 / 100, \mathbf{a}$ & 4.63 & 1.30 & 1.83 & \\
\hline & & $100 / 0.1 / 0.1, \mathbf{b}$ & 2.69 & 1.49 & 3.27 & \\
\hline
\end{tabular}


Table 1 (Continued)

\begin{tabular}{|c|c|c|c|c|c|c|}
\hline Analyte & Column & $\begin{array}{l}\text { Mobile phase TEAA/MeOH (v/v), } \\
\text { a } \mathrm{MeOH} / \mathrm{AcOH} / \mathrm{TEA}(\mathrm{v} / \mathrm{v} / \mathrm{v}), \mathbf{b}\end{array}$ & $k_{1}^{\prime}$ & $\alpha$ & $R_{\mathrm{S}}$ & $\begin{array}{l}\text { Configuration of the } \\
\text { first eluted enantiomer }\end{array}$ \\
\hline \multirow{15}{*}{5} & \multirow[t]{5}{*}{$\mathbf{T}$} & $90 / 10, \mathbf{a}$ & 4.40 & 1.00 & 0.00 & \multirow[t]{15}{*}{$1 R 2 R 3 S 4 R 5 R$} \\
\hline & & $40 / 60, \mathbf{a}$ & 1.91 & 1.00 & 0.00 & \\
\hline & & $10 / 90, \mathbf{a}$ & 2.44 & 1.05 & 0.67 & \\
\hline & & $0 / 100, \mathbf{a}$ & 3.69 & 1.09 & 0.81 & \\
\hline & & $100 / 0.1 / 0.1, \mathbf{b}$ & 2.51 & 1.12 & 1.78 & \\
\hline & \multirow[t]{5}{*}{ T2 } & $90 / 10, \mathbf{a}$ & 4.38 & 1.12 & 0.89 & \\
\hline & & $40 / 60, \mathbf{a}$ & 1.59 & 1.08 & 0.74 & \\
\hline & & $10 / 90, \mathbf{a}$ & 1.90 & 1.10 & 0.86 & \\
\hline & & $0 / 100, \mathbf{a}$ & 2.24 & 1.14 & 0.90 & \\
\hline & & $100 / 0.1 / 0.1, \mathbf{b}$ & 1.54 & 1.17 & 0.75 & \\
\hline & \multirow[t]{5}{*}{ TAG } & $90 / 10, \mathbf{a}$ & 10.93 & 1.07 & 0.66 & \\
\hline & & $40 / 60, \mathbf{a}$ & 4.49 & 1.09 & 0.81 & \\
\hline & & $10 / 90, \mathbf{a}$ & 3.86 & 1.11 & 1.09 & \\
\hline & & $0 / 100, \mathbf{a}$ & 5.34 & 1.16 & 1.11 & \\
\hline & & $100 / 0.1 / 0.1, \mathbf{b}$ & 2.88 & 1.25 & 1.36 & \\
\hline
\end{tabular}

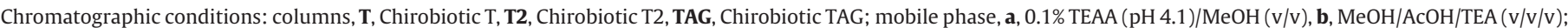

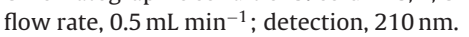

positions of $0.1 \%$ TEAA ( $\mathrm{pH} 4.1) / \mathrm{MeOH}=90 / 10,40 / 60$ and 10/90 $(\mathrm{v} / \mathrm{v}), 100 \% \mathrm{MeOH}$ and $\mathrm{MeOH} / \mathrm{AcOH} / \mathrm{TEA}=100 / 0.1 / 0.1(\mathrm{v} / \mathrm{v} / \mathrm{v})$. At a given mobile phase composition, the retention factors were lower on the teicoplanin CSPs (T and T2) than on the aglycone CSP (TAG) (except for analyte $\mathbf{3}$ in some cases). The native teicoplanin phase (Chirobiotic T) exhibited intermediate $k^{\prime}$ values. Similar trends, with higher $k^{\prime}$ values on Chirobiotic TAG than on a Chirobiotic T column, were observed by Berthod et al. [35], D'Acquarica et al. [16] and Péter et al. [36-38] for unusual $\alpha$-amino acids and cyclic $\beta$-amino acids. Comparison of the data for the Chirobiotic T and $\mathrm{T} 2$ columns revealed that the retention factors on Chirobiotic $\mathrm{T}$ were somewhat larger (except for analytes $\mathbf{2}$ and $\mathbf{3}$ at 100\% $\mathrm{MeOH}$ ) (Table 1). Slightly higher $k^{\prime}$ values on Chirobiotic T2 than on Chirobiotic T were observed by Péter et al. [38] for $\beta^{3}$-homoamino acids.

The effects of the $\mathrm{MeOH}$ content of the mobile phase were investigated on all three CSPs. In most cases, a U-shaped retention curve was observed for all analogues (the only exception was analyte 3). At higher water contents, the retention factor increased with increasing water content; this was probably due to enhanced hydrophobic interactions between the analyte and the CSP in the water-rich mobile phases (Table 1 ). In the reversed-phase mode, one of the most important interactions between the analyte and the CSP is the hydrophobic interaction inside the "basket" of the glycopeptide. Here, an increase in $k^{\prime}$ at high water content was observed for all analytes (Table 1). When the $\mathrm{MeOH}$ content of the mobile phase exceeded $\sim 50 \%$, the retention factor increased (an exception was analyte $\mathbf{3}$ ). This suggests that the separation may rather be controlled by the hydrophilic interaction chromatography (HILIC) than by the reversed-phase mechanism at high $\mathrm{MeOH}$ contents. In this study, as earlier [34], the inflection point and the slope of the U-shaped curve at higher and lower MeOH concentrations differed somewhat for each compound. Different extents of solvation of the stationary phase during HILIC and under the reversed-phase conditions may explain the observed retention behaviour. For analyte 3 , an increase in $k^{\prime}$ was observed with increasing water content. The different behaviour of analyte 3 may be due to the different positions of the carboxy and amino groups, resulting in differences in the steric interaction with the selector. In regard to the variations in the separation factors $(\alpha)$ and resolutions $\left(R_{\mathrm{S}}\right)$ with change of the $\mathrm{MeOH}$ content, no general trends were observed.

Use of the $\mathrm{MeOH} / \mathrm{AcOH} / \mathrm{TEA}=100 / 0.1 / 0.1(\mathrm{v} / \mathrm{v} / \mathrm{v})$ mobile phase system generally resulted in lower retention than with $100 \% \mathrm{MeOH}$ (except for analyte $\mathbf{3}$ ). However, for analytes $\mathbf{4}$ and $\mathbf{5}$, in most cases despite the lower $k^{\prime}$ values, higher $\alpha$ and $R_{\mathrm{S}}$ values were obtained, indicating that the level of chiral discrimination improved in the polar ionic mode probably due to the steric effect of methyl group (Table 1).

The structures of the analytes influenced the chiral recognition. In the reversed-phase mode in water-rich mobile phases, analyte 3 exhibited large $k_{1}{ }^{\prime}$ values, not accompanied by high resolution. At high water contents, the non-specific hydrophobic interaction resulted in high retention without chiral recognition. The value of $\alpha$ reached its maximum when using mobile phases of high $\mathrm{MeOH}$ content. Analytes $\mathbf{4}$ and $\mathbf{5}$, which have an additional methyl group, are sterically constrained. In most cases this led to higher $\alpha$ (and $R_{\mathrm{S}}$ ) values relative to those for analytes $\mathbf{1}$ and $\mathbf{2}$. Interestingly, the position of the methyl group on the cycloalkane skeleton (position 2 or 4 ) influenced the values of $\alpha$ and $R_{S}$ considerably; in that the more constrained analyte $\mathbf{4}$ displayed higher $\alpha$ and $R_{\mathrm{S}}$ values than those of analyte $\mathbf{5}$.

Elution sequences were determined in all cases. For analytes 1-5 on the Chirobiotic T, T2 and TAG columns, no consistent elution sequence was observed. Neither the configuration of the carbon atom attached to the carboxyl group nor that of the carbon atom attached to the amino group determined the elution sequence, and in the case of analyte $\mathbf{2}$ the elution sequence differed when the mobile phase was changed from reversed-phase to polar ionic mode. Selected chromatograms for analytes 1-5 are depicted in Fig. 2.

\subsection{Effects of temperature and thermodynamic parameters}

In order to investigate the effects of temperature on the chromatographic parameters, a variable-temperature study was carried out on Chirobiotic T and TAG columns over the temperature range $10-40{ }^{\circ} \mathrm{C}$ (in 5 or $10^{\circ} \mathrm{C}$ increments). Experimental data for the mobile phase $0.1 \%$ TEAA $(\mathrm{pH} 4.1) / \mathrm{MeOH}=10 / 90(\mathrm{v} / \mathrm{v})$ are listed in Table 2. A comparison of the retention factors in Table 2 and Fig. 3 reveals that all of the recorded values decreased with increasing temperature (similar tendencies were measured at other mobile phase compositions). It is evident that an increase in the separation temperature lowers the separation factor, $\alpha$. However, for analyte 3 on the Chirobiotic T column, $\alpha$ (and $R_{\mathrm{S}}$ ) increased with increasing temperature (Fig. 3 ). Increasing temperature may improve the peak symmetry and efficiency, and therefore the resolution may also improve.

Since the effect of temperature on the separation was complex, an extensive study relating to the thermodynamics of this system was carried out. The initial step of this process is to accumulate accurate chromatographic data from which van't Hoff plots were constructed [Eq. (1)]. The $\Delta H^{\circ}$ and $\Delta S^{\circ *}$ values calculated from the slopes and intercepts of these plots for the enantiomers on all three 
Table 2

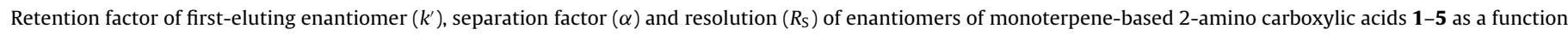
of temperature.

\begin{tabular}{|c|c|c|c|c|c|c|c|}
\hline \multirow[t]{2}{*}{ Analyte } & \multirow[t]{2}{*}{ Columns } & \multirow[t]{2}{*}{$k_{1}{ }^{\prime}, \alpha, R_{\mathrm{S}}$} & \multicolumn{5}{|c|}{ Temperature $\left({ }^{\circ} \mathrm{C}\right)$} \\
\hline & & & 10 & 15 & 20 & 30 & 40 \\
\hline \multirow[t]{6}{*}{1} & \multirow[t]{3}{*}{$\mathbf{T}$} & $k_{1}^{\prime}$ & 4.49 & 4.18 & 4.05 & 3.58 & 3.21 \\
\hline & & $\alpha$ & 1.13 & 1.12 & 1.12 & 1.11 & 1.10 \\
\hline & & $R_{\mathrm{S}}$ & 1.66 & 1.64 & 1.51 & 1.59 & 1.62 \\
\hline & \multirow[t]{3}{*}{ TAG } & $k_{1}^{\prime}$ & 6.79 & 6.29 & 5.81 & 5.09 & 4.63 \\
\hline & & $\alpha$ & 1.17 & 1.16 & 1.15 & 1.14 & 1.12 \\
\hline & & $R_{\mathrm{S}}$ & 1.46 & 1.48 & 1.66 & 1.71 & 1.88 \\
\hline \multirow[t]{6}{*}{2} & \multirow[t]{3}{*}{$\mathbf{T}$} & $k_{1}^{\prime}$ & 5.84 & 5.54 & 5.31 & 4.97 & 4.63 \\
\hline & & $\alpha$ & 1.04 & 1.03 & 1.03 & 1.02 & 1.01 \\
\hline & & $R_{\mathrm{S}}$ & 0.53 & 0.50 & 0.39 & 0.38 & 0.46 \\
\hline & \multirow[t]{3}{*}{ TAG } & $k_{1}^{\prime}$ & 10.66 & 9.96 & 9.65 & 8.68 & 8.12 \\
\hline & & $\alpha$ & 1.00 & 1.00 & 1.00 & 1.00 & 1.00 \\
\hline & & $R_{\mathrm{S}}$ & 0.00 & 0.00 & 0.00 & 0.00 & 0.00 \\
\hline \multirow[t]{6}{*}{3} & \multirow[t]{3}{*}{$\mathbf{T}$} & $k_{1}^{\prime}$ & 7.30 & 6.26 & 5.66 & 4.76 & 4.05 \\
\hline & & $\alpha$ & 1.09 & 1.11 & 1.12 & 1.14 & 1.17 \\
\hline & & $R_{\mathrm{S}}$ & 0.70 & 0.81 & 0.85 & 1.07 & 1.09 \\
\hline & \multirow[t]{3}{*}{ TAG } & $k_{1}^{\prime}$ & 13.37 & 10.21 & 8.09 & 6.18 & 4.08 \\
\hline & & $\alpha$ & 1.20 & 1.17 & 1.13 & 1.09 & 1.04 \\
\hline & & $R_{\mathrm{S}}$ & 1.97 & 1.33 & 1.04 & 0.75 & 0.33 \\
\hline \multirow[t]{6}{*}{4} & \multirow[t]{3}{*}{$\mathbf{T}$} & $k_{1}^{\prime}$ & 3.74 & 3.51 & 3.35 & 3.06 & 2.73 \\
\hline & & $\alpha$ & 1.13 & 1.12 & 1.11 & 1.10 & 1.09 \\
\hline & & $R_{\mathrm{S}}$ & 1.27 & 1.28 & 1.30 & 1.32 & 1.35 \\
\hline & \multirow[t]{3}{*}{ TAG } & $k_{1}^{\prime}$ & 5.18 & 4.86 & 4.48 & 4.13 & 3.75 \\
\hline & & $\alpha$ & 1.20 & 1.19 & 1.18 & 1.17 & 1.16 \\
\hline & & $R_{\mathrm{S}}$ & 1.47 & 1.74 & 1.84 & 1.95 & 2.09 \\
\hline \multirow[t]{6}{*}{5} & \multirow[t]{3}{*}{$\mathbf{T}$} & $k_{1}^{\prime}$ & 4.29 & 4.02 & 3.77 & 3.43 & 3.08 \\
\hline & & $\alpha$ & 1.05 & 1.05 & 1.04 & 1.04 & 1.03 \\
\hline & & $R_{\mathrm{S}}$ & 0.72 & 0.67 & 0.61 & 0.48 & 0.38 \\
\hline & \multirow[t]{3}{*}{ TAG } & $k_{1}^{\prime}$ & 6.23 & 5.82 & 5.64 & 4.89 & 4.37 \\
\hline & & $\alpha$ & 1.12 & 1.11 & 1.10 & 1.09 & 1.07 \\
\hline & & $R_{\mathrm{S}}$ & 1.24 & 1.25 & 1.30 & 1.29 & 1.22 \\
\hline
\end{tabular}

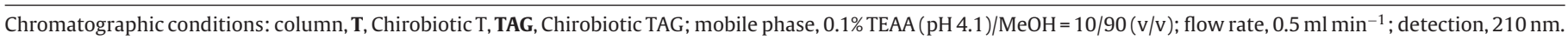
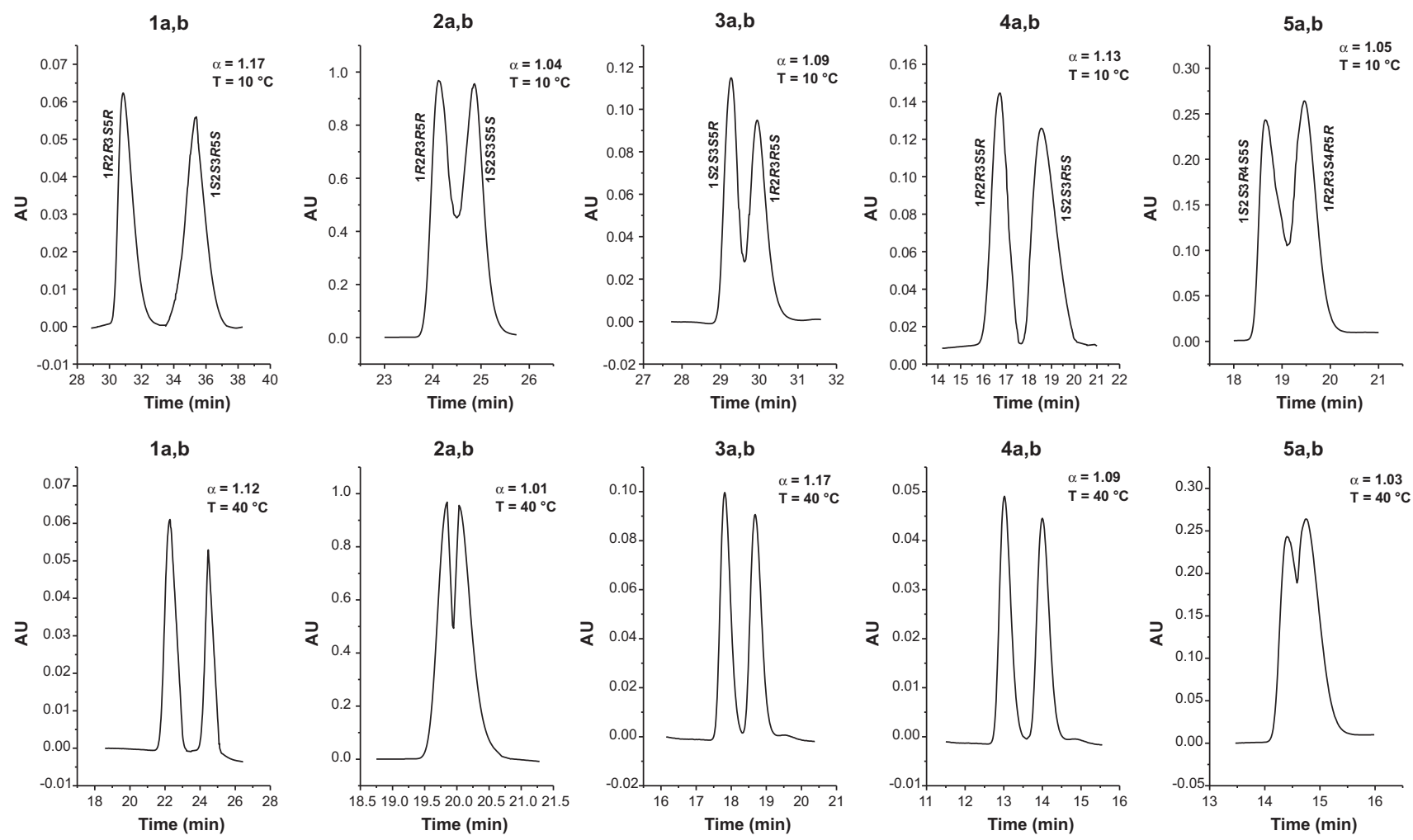

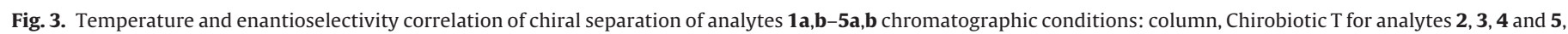

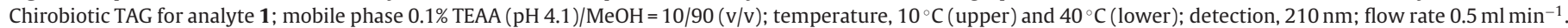




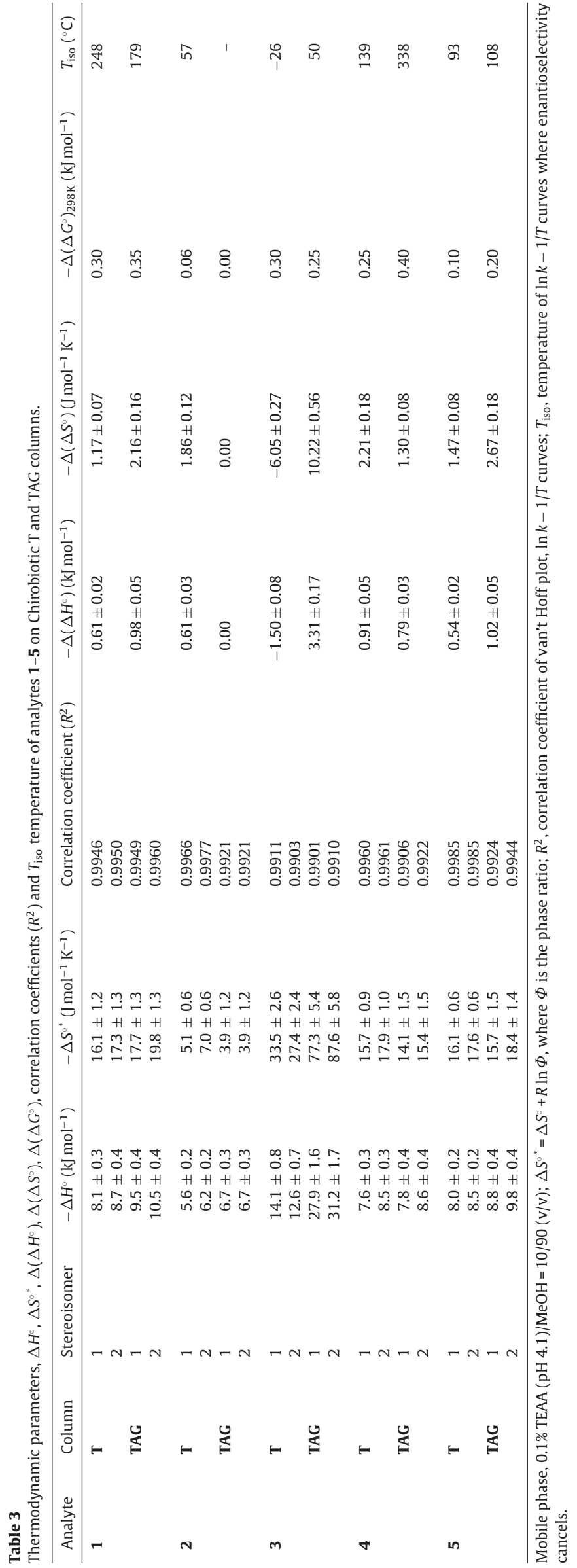

columns were negative (Table 3 ). The second-eluting enantiomers have more negative $\Delta S^{0^{*}}$ values, it is likely that they have fewer degrees of freedom on the CSP, i.e., they are held at more points or are less able to move or rotate. It is widely accepted that both enantiomers undergo the same non-specific interactions, whereas the more strongly retained one is subject to additional stereospecific interactions. Moreover, it was observed that $\Delta H^{\circ}{ }_{1}$ and $\Delta H^{\circ}{ }_{2}$, and in parallel $\Delta S_{1}^{\circ *}$ and $\Delta S_{2}^{\circ}$, for the Chirobiotic T column were in most cases less negative than those for the Chirobiotic TAG column. This may be due to the fact that the teicoplanin aglycone (TAG) has been the sugar units removed and this may promote the interaction between the analyte and the CSP.

Of the five analytes, analyte $\mathbf{2}$ exhibited the smallest, and analyte 3 the largest $-\Delta H^{\circ}$ and $-\Delta S^{\circ *}$ values. The positions ( 2 and 3 ) of the amino and carboxy groups and their trans configuration in 2 probably inhibit fitting and orientation in the cavity (the sugar moieties on Chirobiotic T improved the chiral recognition, while on teicoplanin aglycone no separation was observed), and the separation was thermodynamically less favorable. The largest $-\Delta H^{\circ}$ and $-\Delta S^{0^{*}}$ values for 3 indicate that, despite the trans configuration, the separation sterically was favorable.

The differences in the changes in enthalpy and entropy, $\Delta\left(\Delta H^{\circ}\right)$ and $\Delta\left(\Delta S^{\circ}\right)$, are also presented in Table 3. The $-\Delta\left(\Delta H^{\circ}\right)$ values ranged from -1.5 to $3.3 \mathrm{~kJ} \mathrm{~mol}^{-1}$. The interactions of 3 with the Chirobiotic TAG stationary phase were characterized by the highest negative $\Delta\left(\Delta H^{\circ}\right)$ value, while analyte 3 on Chirobiotic T exhibited a positive $\Delta\left(\Delta H^{\circ}\right)$. The trends in the change in $-\Delta\left(\Delta S^{\circ}\right)$ showed that analyte $\mathbf{3}$ on Chirobiotic TAG displayed the largest negative entropies, $-\Delta\left(\Delta S^{\circ}\right)$ ranging from -6.1 to $10.2 \mathrm{~J} \mathrm{~mol}^{-1} \mathrm{~K}^{-1}$ (Table 3). For analyte 3 , similarly to $\Delta\left(\Delta H^{\circ}\right)$ on Chirobiotic T column $\Delta\left(\Delta S^{\circ}\right)$ was also positive. The $\Delta\left(\Delta S^{\circ}\right)$ values are controlled by the difference in the degrees of freedom between the stereoisomers on the CSP, and mainly by the number of solvent molecules released from both the chiral selector and the analyte when the analyte is associated with the CSP.

The thermodynamic parameter $-\Delta\left(\Delta G^{\circ}\right)$ suggests that teicoplanin without sugar units induces highly efficient binding to the selector, as reflected by the large negative $\Delta\left(\Delta G^{\circ}\right)$ values for $\mathbf{1}$, 3, 4 and 5. For analyte 2 on Chirobiotic $\mathrm{T} \Delta\left(\Delta G^{\circ}\right)$ exhibits a small negative value while on Chirobiotic TAG, the enantiomers of analyte $\mathbf{2}$ were not separable at this eluent composition. For analytes 1-5 on both columns (with exception of analyte 3 on Chirobiotic T) the selector-selectand complex formation proceeds via multiple intermolecular interactions and was generally exothermic, with a corresponding negative entropic contribution.

For analyte 3, on Chirobiotic T, the positive $\Delta\left(\Delta S^{\circ}\right)$ compensated for the positive $\Delta\left(\Delta H^{\circ}\right)$ and resulted in a relatively high $-\Delta\left(\Delta G^{\circ}\right)$ value. The teicoplanin, which contains several sugar moieties having more chiral centres, ensures more interaction sites for the analytes, leading to more negative $-\Delta\left(\Delta G^{\circ}\right)$ values. In this temperature range, enantioresolution is entropically driven, and the selectivity increases with increasing temperature (Fig. 3).

From the data, the temperature, $T_{\text {iso }}$, was calculated at which the enantioselectivity balances out and the elution sequence changes (Table 3 ). In most cases, $T_{\text {iso }}$ was above $50^{\circ} \mathrm{C}$, but for analyte 3 on Chirobiotic $\mathrm{T}$ it was $-26^{\circ} \mathrm{C}$. These temperatures indicate that lower temperatures are preferable for the best separation of most of the analytes, with the exception of analyte 3 on the Chirobiotic T, where positive $\Delta\left(\Delta H^{\circ}\right)$ and $\Delta\left(\Delta S^{\circ}\right)$ were observed.

\section{Conclusions}

HPLC methods were developed for the separation of the enantiomers of monoterpene-based 2-amino carboxylic acids, using macrocyclic glycopeptide-based CSPs: (i.e., Chirobiotic T, $\mathrm{T} 2$ and TAG). Baseline resolution was achieved in all cases. 
The values of thermodynamic parameters such as the changes in enthalpy, $\Delta\left(\Delta H^{\circ}\right)$, entropy, $\Delta\left(\Delta S^{\circ}\right)$, and Gibbs free energy, $\Delta\left(\Delta G^{\circ}\right)$, depended on the structures of the analytes and on the chiral selectors used. The elution sequence was determined in all cases, but no general predictive rule could be found to describe the elution behaviour of these compounds.

\section{Acknowledgements}

The authors gratefully acknowledge support for this work by Hungarian National Science Foundation grant OTKA K 67563 and National Institutes of Health grant NIH R01 GM53825-13.

\section{References}

[1] A. Kuhl, M.G. Hahn, M. Dumic, J. Mittendorf, Amino Acids 29 (2005) 89.

[2] E. Juaristi, V.A. Soloshonok (Eds.), Enantioselective Synthesis of $\beta$-Amino Acids, Wiley-Interscience, New York, 2005.

[3] S.G. Davies, A.D. Smith, P.D. Price, Tetrahedron: Asymmetry 16 (2005) 2833.

[4] F. Fülöp, T.A. Martinek, G.K. Tóth, Chem. Soc. Rev. 35 (2006) 323.

[5] A. Hasenoehrl, T. Galic, G. Ergovic, N. Marsic, M. Skerlev, J. Mittendorf, U. Geschke, A. Schmidt, W. Schoenfeld, Antimicrob. Agents Chemother. 50 (2006) 3011.

[6] W.S. Horne, J.L. Price, J.L. Keck, S.H. Gellman, J. Am. Chem. Soc. 129 (2007) 4178

[7] T.A. Martinek, A. Hetényi, L. Fülöp, I.M. Mándity, G.K. Tóth, I. Dékány, F. Fülöp, Angew. Chem. Int. Ed. 45 (2006) 2396.

[8] Z. Szakonyi, F. Fülöp, Arkivoc 14 (2003) 225.

[9] S. Gyónfalvi, Z. Szakonyi, F. Fülöp, Tetrahedron: Asymmetry 14 (2003) 3965.

[10] Z. Szakonyi, T.A. Martinek, R. Sillanpää, F. Fülöp, Tetrahedron: Asymmetry 18 (2007) 2442.

[11] Z. Szakonyi, T.A. Martinek, R. Sillanpää, F. Fülöp, Tetrahedron: Asymmetry 19 (2008) 2296.
[12] Z. Szakonyi, Á. Balázs, T.A. Martinek, F. Fülöp, Tetrahedron: Asymmetry 17 (2006) 199

[13] A. Hetényi, Z. Szakonyi, I.M. Mándity, É. Szolnoki, G.K. Tóth, T.A. Martinek, F. Fülöp, Chem. Commun. 177 (2009).

[14] Z. Szakonyi, R. Sillanpää, F. Fülöp, Mol. Divers. 14 (2010) 59.

[15] I. Ilisz, R. Berkecz, A. Péter, J. Pharm. Biomed. Anal. 47 (2008) 1

[16] I. D’Acquarica, F. Gasparrini, D. Misiti, G. Zappia, C. Cimarelli, G. Palmieri, A Carotti, S. Cellamare, C. Villani, Tetrahedron: Asymmetry 11 (2000) 2375.

[17] I. Ilisz, R. Berkecz, A. Péter, J. Sep. Sci. 29 (2006) 1305.

[18] A. Péter, J. Chromatogr. A 955 (2002) 141.

[19] M.H. Hyun, H.J. Choi, B.S. Kang, G. Tan, Y.J. Choi, Bull. Korean Chem. Soc. 27 (2006) 1775.

[20] M.H. Hyun, Y. Song, Y.J. Cho, H.J. Choi, J. Sep. Sci. 30 (2007) 2539.

[21] E. Forró, J. Chromatogr. A 1216 (2009) 1025.

[22] T.J. Wenzel, C.E. Bourne, R.L. Clark, Tetrahedron: Asymmetry 20 (2009) 2052.

[23] B. Koppenhoefer, E. Bayer, Chromatographia 19 (1984) 123.

[24] V. Schurig, J. Ossig, R. Link, Angew. Chem. 101 (1989) 197.

[25] S. Allenmark, V. Schurig, J. Mater. Sci. 7 (1977) 1955

[26] I. Spanik, J. Krupcik, V. Schurig, J. Chromatogr. A 843 (1999) 123.

[27] G. Gotmar, T. Fornstedt, G. Guiochon, Anal. Chem. 72 (2000) 3908.

[28] A. Cavazzini, G. Nadalini, F. Dondi, F. Gasparrini, A. Ciogli, C. Villani, J. Chromatogr. A 1031 (2004) 143

[29] J. Oxelbark, S. Allenmark, J. Chem. Soc., Perkin Trans. 2 (1999) 1587.

[30] L. Thurnberg, S. Allenmark, A. Friberg, F. Ek, T. Frejd, Chirality 16 (2004) 614.

[31] T. Fornstedt, P. Sajonz, G. Guichon, J. Am. Chem. Soc. 119 (1997) 1254.

[32] T. Fornstedt, P. Sajonz, G. Guichon, Chirality 10 (1998) 375.

[33] E. Peyrin, Y.C. Guillaume, C. Guinchard, Anal. Chem. 69 (1997) 4979.

[34] D.W. Armstrong, Y. Liu, K.H. Ekborg-Ott, Chirality 7 (1995) 474.

[35] A. Berthod, X. Chen, J.P. Kullman, D.W. Armstrong, F. Gasparrini, I. D’Acquarica, C. Villani, A. Carotti, Anal. Chem. 72 (2000) 1767.

[36] A. Péter, A. Árki, D. Tourwé, E. Forró, F. Fülöp, D.W. Armstrong, J. Chromatogr. A 1031 (2004) 159.

[37] R. Berkecz, R. Török, I. Ilisz, E. Forró, F. Fülöp, D.W. Armstrong, A. Péter, Chromatographia 63 (2006) S37.

[38] A. Sztojkov-Ivanov, L. Lázár, F. Fülöp, D.W. Armstrong, A. Péter, Chromatographia 64 (2006) 89. 


\title{
High-performance liquid chromatographic enantioseparation of unusual isoxazoline-fused 2-aminocyclopentanecarboxylic acids on macrocyclic glycopeptide-based chiral stationary phases
}

\author{
László Sipos $^{\mathrm{a}}$, István Ilisz ${ }^{\mathrm{b}}$, Melinda Nonn ${ }^{\mathrm{a}}$, Ferenc Fülöp ${ }^{\mathrm{a}}$, Zoltán Pataj ${ }^{\mathrm{b}}$, Daniel W. Armstrong ${ }^{\mathrm{c}}$, \\ Antal Péter ${ }^{\mathrm{b}, *}$
}

a Institute of Pharmaceutical Chemistry, University of Szeged, Eötvös utca 6, H-6720 Szeged, Hungary

${ }^{\mathrm{b}}$ Department of Inorganic and Analytical Chemistry, University of Szeged, Dóm tér 7, H-6720 Szeged, Hungary

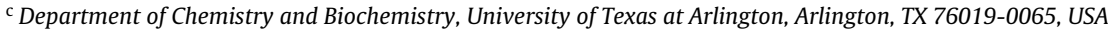

\section{A R T I C L E I N F O}

\section{Article history:}

Available online 25 November 2011

\section{Keywords:}

Column liquid chromatography

Isoxazoline-fused

2-aminocyclopentanecarboxylic acids

Macrocyclic glycopeptide-based chiral

stationary phases

Chirobiotic columns

\begin{abstract}
A B S T R A C T
The enantiomers of four unusual isoxazoline-fused 2-aminocyclopentanecarboxylic acids were directly separated on chiral stationary phases containing macrocyclic glycopeptide antibiotics teicoplanin (Astec Chirobiotic T and T2), teicoplanin aglycone (Chirobiotic TAG), vancomycin (Chirobiotic V) and vancomycin aglycone (Chirobiotic VAG) as chiral selectors. The effects of the mobile phase composition, the structure of the analytes and temperature on the separations were investigated. Experiments were performed at constant mobile phase compositions in the temperature range $5-45^{\circ} \mathrm{C}$ to study the effects of temperature, and thermodynamic parameters were calculated from plots of $\ln k$ or $\ln \alpha$ versus $1 / T$. Some mechanistic aspects of the chiral recognition process are discussed with respect to the structures of the analytes. It was found that the enantiomeric separations were in most cases enthalpy-driven. The sequence of elution of the enantiomers was determined in all cases.
\end{abstract}

(C) 2011 Elsevier B.V. All rights reserved.

\section{Introduction}

By virtue of their pharmacological potential, alicyclic $\beta$-amino acids are of great interest among synthetic and medicinal chemists. The naturally occurring $\beta$-amino acid cispentacin (1R,2S-2-aminocyclopentanecarboxylic acid), icofungipen (1R,2S-2-amino-4-methylenecyclopentanecarboxylic acid) and oryzoxymycin (2S,5R,6R-2,6-amino-5-hydroxy-1,3cyclohexadiene-1-carbonyloxypropionic acid) are bioactive compounds with antibacterial and antifungal activities. A number of cyclic, conformationally restricted $\beta$-amino acids have been used as building blocks for the synthesis of new peptides, which might be of importance in the synthesis of peptide-based drugs [1-3].

Amino acids containing an isoxazoline moiety have revealed anti-influenza activities and antifungal properties. Several isoxazole carboxylic acids, such as conformationally constrained aspartate and glutamate analogs, have been reported as enzyme inhibitors or agents possessing neuroprotective activities [4-7]. Isoxazoline-fused amino acids have served as important precursors

\footnotetext{
* Corresponding author. Tel.: +36 62 544000/3656; fax: +36 62420505.

E-mail address: apeter@chem.u-szeged.hu (A. Péter).
}

for the synthesis of novel multisubstituted cyclopentene derivatives with antiviral activities [8-10].

The wide-ranging utility of these compounds requires analytical methods to check on the stereochemistry of the final product. One of the most frequently applied techniques is chiral highperformance liquid chromatography (HPLC). HPLC enantioseparations of $\beta$-amino acids have been performed by both indirect and direct methods. In the past decade, chiral derivatizing agents such as Marfey's reagent, 2,3,4,6-tetra- $O$-acetyl- $\beta$-D-glucopyranosyl isothiocyanate and $N$-(4-nitrophenoxycarbonyl) phenylalanine methoxyethyl ester [11], chiral stationary phases (CSPs) such as macrocyclic glycopeptides [12,13], quinine derivatives [14] and (+)(18-crown-6)-2,3,11,12-tetracarboxylic acid-derivatives [15-19], a rapid double derivatization technique with gas chromatography [20] and (18-crown-6)-2,3,11,12-tetracarboxylic acid as a chiral NMR solvating agent have been used for the analysis of $\beta$-amino acids enantiomeric composition [21].

Enantioselective retention and separation are influenced by temperature [22-29]. In order to investigate the thermodynamic functions of enantioselective adsorption, van't Hoff plots were constructed, which may be interpreted in terms of the mechanistic aspects of chiral recognition:

$\ln k=-\frac{\Delta H^{\circ}}{R T}+\frac{\Delta S^{\circ}}{R}+\ln \phi$ 

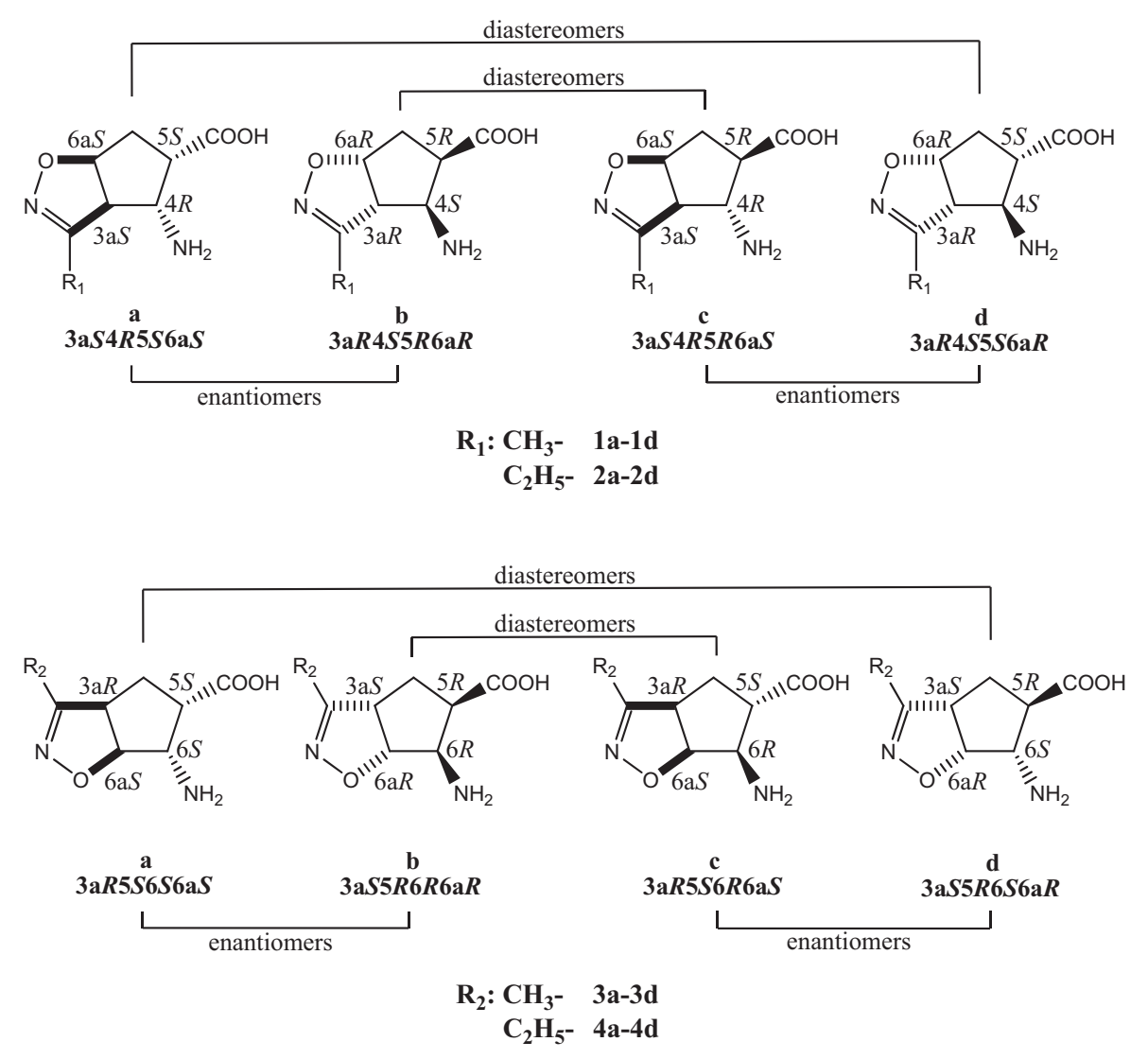

Fig. 1. Structures of isoxazoline-fused 2-aminocyclopentanecarboxylic acids.

in which $k$ is the retention factor, $\Delta H^{\circ}$ is the enthalpy of transfer of the solute from the mobile phase to the stationary phase, $\Delta S^{\circ}$ is the entropy of transfer of the solute from the mobile phase to the stationary phase, $R$ is the gas constant, $T$ is temperature and $\phi$ is the ratio of volume of stationary phase $\left(V_{S}\right)$ and mobile phase $\left(V_{M}\right)$. The corresponding $\Delta\left(\Delta H^{\circ}\right)$ and $\Delta\left(\Delta S^{\circ}\right)$ values for the separated enantiomers can be determined from a modification of Eq. (1):

$\ln \alpha=-\frac{\Delta\left(\Delta H^{\circ}\right)}{R T}+\frac{\Delta\left(\Delta S^{\circ}\right)}{R}$

where $\alpha$ is the selectivity factor $\left(\alpha=k_{2} / k_{1}\right)$. If $\Delta\left(\Delta H^{\circ}\right)$ is invariant with temperature (i.e. a linear van't Hoff plot is obtained), this expression shows that a plot of $R \ln \alpha$ versus $1 / T$ has a slope of $-\Delta\left(\Delta H^{\circ}\right)$ and an intercept of $\Delta\left(\Delta S^{\circ}\right)$.

In the present paper, direct HPLC methods are described for the separation of enantiomers new cyclic $\beta^{3}$-amino acids (Fig. 1 ), with the application of macrocyclic glycopeptide-based CSPs. For comparison purposes, most of the separations were carried out at constant mobile phase composition. The effects of the mobile phase composition, the specific structural features of the analytes and selectors and temperature on the retention are discussed on the basis of the experimental data. The elution sequence was determined in all cases.

\section{Experimental}

\subsection{Chemicals and reagents}

Racemic isoxazoline-fused cispentacin stereoisomers were prepared by 1,3-dipolar cycloaddition of nitrile oxides to
$\mathrm{N}$-Boc-protected ethyl 2-amino-3-cyclopentenecarboxylate as dipolarophile. The nitrile oxides were generated from nitroethane or 1-nitropropane in the presence of $\mathrm{Boc}_{2} \mathrm{O}$ and 4-dimethylaminopyridine (DMAP). When the dipolarophile underwent cycloaddition in THF at $20^{\circ} \mathrm{C}$ for $15 \mathrm{~h}$, two regioisomers and one diastereomer were formed [30]. The isoxazoline-fused cispentacin enantiomers were prepared from enantiomerically pure Boc-protected ethyl 2-amino-3-cyclopentenecarboxylate $[31,32]$. The cycloadditions were performed similarly as for the racemic compounds. Under the same experimental conditions (nitroethane/1-nitropropane, $\mathrm{Boc}_{2} \mathrm{O}$ and DMAP), the racemic trans counterparts furnished selectively only one cycloadduct, which also could be prepared by epimerization at C-5 of the very minor product. The two racemic major regioisomers were epimerized at C-5 with $\mathrm{NaOEt}$ in EtOH to give isoxazoline-fused trans amino esters [33]. These reactions were extended to their preparation in enantiomerically pure form $[31,32]$. In the next step, the earlier-prepared racemic and enantiomerically pure isoxazoline-fused ethyl 2-amino-cyclopentanecarboxylates were hydrolysed in the presence of $\mathrm{HCl} / \mathrm{H}_{2} \mathrm{O}(2: 1)$ in dioxane to give the corresponding amino acid derivatives (1a, 1d; 2a, 2d; 3a, 3c; 4a, 4c).

Methanol (MeOH) of HPLC grade was purchased from Scharlau (Sentmenat, Spain). Triethylamine (TEA), glacial acetic acid $(\mathrm{AcOH})$ and other reagents of analytical reagent grade were from Sigma-Aldrich (St. Louis, MO, USA). The Milli-Q water was further purified by filtration on a $0.45-\mu \mathrm{m}$ filter, type HV, Millipore (Molsheim, France).

All compounds mentioned in Fig. 1 were evaluated with different mobile phases. Reversed-phase mobile phases consisted of $0.1 \%$ triethylammonium acetate (TEAA) $(\mathrm{pH} 4.1) / \mathrm{MeOH}=98 / 2,90 / 10$, 
$80 / 20,60 / 40,40 / 60,20 / 80$ and $10 / 90(\mathrm{v} / \mathrm{v})$, the polar organic phase (POM) was $100 \% \mathrm{MeOH}$, and the polar ionic mobile phase (PIM) was $\mathrm{MeOH} / \mathrm{AcOH} / \mathrm{TEA}=100 / 0.1 / 0.1(\mathrm{v} / \mathrm{v} / \mathrm{v})$.

\subsection{Apparatus and chromatography}

The HPLC measurements were carried out on a Waters HPLC system consisting of an M-600 low-pressure gradient pump, an M-996 photodiode-array detector and a Millenium ${ }^{32}$ Chromatography Manager data system; the alternative Waters Breeze system consisted of a 1525 binary pump, a 487 dual-channel absorbance detector, a 717 plus autosampler and Breeze data manager software (both systems from Waters Chromatography, Milford, MA, USA). Both chromatographic systems were equipped with Rheodyne Model 7125 injectors (Cotati, CA, USA) with 20- $\mu$ l loops.

The macrocyclic glycopeptide-based stationary phases used for analytical separation were teicoplanin-containing Chirobiotic T and T2, teicoplanin aglycone-containing Chirobiotic TAG, vancomycincontaining Chirobiotic $\mathrm{V}$ and vancomycin aglycone-containing Chirobiotic VAG columns, $250 \mathrm{~mm} \times 4.6 \mathrm{~mm}$ I.D., 5 - $\mu \mathrm{m}$ particle size (for each column) (Astec, Whippany, NJ, USA). The differences between the Chirobiotic T and T2 columns are that they are both on 5 - $\mu$ m particle size silica gel, but the Chirobiotic T uses a $120 \AA$ pore size material and Chirobiotic T2 uses a $200 \AA$ pore material. Also, the linkage chain on Chirobiotic T2 is approximately twice as long as that on Chirobiotic T. Hence, the coverage and spacing are different for the two stationary phases. This manifests itself mainly in the form of steric interaction differences between the two columns.

\subsection{HPLC operating conditions applied for validation process}

To determine validation characteristics of the analytical procedure separations were carried out repeatedly for analytes $\mathbf{2 a}, \mathbf{2 b}$ on the Chirobiotic TAG CSP with a mobile phase $0.1 \%$ TEAA $(\mathrm{pH}$ 4.1 $) / \mathrm{MeOH}=60 / 40(\mathrm{v} / \mathrm{v})$ at $25^{\circ} \mathrm{C}$ and for analytes $3 \mathbf{a}, \mathbf{3 b}$ on Chirobiotic VAG CSP with a mobile phase $100 \% \mathrm{MeOH}$ at $10^{\circ} \mathrm{C}$, at a flow rate of $0.5 \mathrm{ml} \mathrm{min}^{-1}$. Analytes $\mathbf{2 a}, \mathbf{2 b}$ possess an ethyl group side-chain while analyte $\mathbf{3 a}$, $\mathbf{3 b}$ a methyl side-chain. The injection volume was $20 \mu \mathrm{l}$, while the detector was set at $210 \mathrm{~nm}$.

\section{Results and discussion}

The analytes in this study (Fig. 1) possess an isoxazoline-fused cyclopentane skeleton. Besides carboxy and primary amino groups, analogs 1 and $\mathbf{3}$ bear a methyl group on position 3, and analogs $\mathbf{2}$ and $\mathbf{4}$ an ethyl group on position 3. These differences result in different steric effects and influence the hydrophobicity, bulkiness and rigidity of the molecules, depending on how their atoms are linked and how capable they are of different interactions with the selector.

All data relating to the separation of the compounds, including the retention factors, separation factors and resolutions for each analyte on the five different Chirobiotic columns, are given in Tables 1 and 2. All the compounds mentioned in Tables 1 and 2 were evaluated with different mobile phases, with eluent compositions varied between $0.1 \%$ TEAA ( $\mathrm{pH} 4.1) / \mathrm{MeOH}=98 / 2$ and $10 / 90(\mathrm{v} / \mathrm{v})$, $100 \% \mathrm{MeOH}$ and $\mathrm{MeOH} / \mathrm{AcOH} / \mathrm{TEA}=100 / 0.1 / 0.1(\mathrm{v} / \mathrm{v} / \mathrm{v})$. To simplify the presentation, Tables 1 and 2 basically list only the columns and chromatographic results obtained when the enantiomeric separation was achieved, but for purposes of comparison some results are presented when no separation occurred. At a given mobile phase composition, the retention factors were lower on the teicoplanin CSPs ( $\mathrm{T}$ and T2) than on the aglycone CSP (TAG) (except for analytes 1c, 1d; 2c, 2d and $\mathbf{4 a}, \mathbf{4 b}$ on Chirobiotic $T$ in POM, 1c, 1d; 2c, 2d on Chirobiotic T2 in PIM and POM and 3c, 3d on Chirobiotic T in PIM; Table 2). Similar trends, with higher $k^{\prime}$ values on Chirobiotic TAG than on a Chirobiotic T column, were observed by Berthod et al. [34], D’Acquarica et al. [12] and Péter et al. [35-37] for unusual $\alpha$-amino acids and cyclic $\beta$-amino acids. Comparison of the data for the Chirobiotic T and T2 columns revealed that the retention factors on Chirobiotic $\mathrm{T}$ were in most cases somewhat larger (Tables 1 and 2). Slightly higher $k^{\prime}$ values on Chirobiotic T2 than on Chirobiotic T were observed by Péter et al. [37] for $\beta^{3}$-homoamino acids.

The effects of the $\mathrm{MeOH}$ content of the mobile phase in reversedphase mode were investigated on all five CSPs. In most cases, a U-shaped retention curve was observed for all analogs. At higher water content, the retention factor increased with increasing water content; this was probably due to enhanced hydrophobic interactions between the analyte and the CSP in the water-rich mobile phases. In the reversed-phase mode, one of the most important interactions between the analyte and the CSP is the hydrophobic interaction inside the "basket" of the glycopeptide. Here, an increase in $k^{\prime}$ at high water content was observed for all analytes. When the $\mathrm{MeOH}$ content of the mobile phase exceeded $\sim 50 \%$, the retention factor increased. This suggests that the retention behavior may be controlled by a mechanism of hydrophilic interaction chromatography (HILIC) at high $\mathrm{MeOH}$ contents. In this study, as earlier [38], the inflection points and the slopes of the U-shaped curves at higher and lower $\mathrm{MeOH}$ concentrations differed somewhat for each compound. Different extents of solvation of the stationary phase during HILIC and under the reversedphase conditions may explain the observed retention behavior. As regards the variations in the separation factors $(\alpha)$ and resolutions $\left(R_{S}\right)$ with change of $\mathrm{MeOH}$ content, no general trends were observed.

Use of the $\mathrm{MeOH} / \mathrm{AcOH} / \mathrm{TEA}=100 / 0.1 / 0.1(\mathrm{v} / \mathrm{v} / \mathrm{v})$ mobile phase system generally resulted in lower retention than with $100 \% \mathrm{MeOH}$ (except for analytes 2a, 2b on Chirobiotic T2, 3a, 3b on Chirobiotic $\mathrm{T}$ and TAG, and $\mathbf{4 a}, \mathbf{4 b}$ on Chirobiotic TAG). However, in a few cases (especially for analytes $\mathbf{3}$ and $\mathbf{4}$ ), despite the lower $k^{\prime}$ values, higher $\alpha$ and $R_{S}$ values were obtained, indicating that the level of chiral discrimination was better in the polar ionic mode (Table 2).

The structures of the analytes influenced the chiral recognition. In the reversed-phase mode methyl or ethyl substitution exhibited a slight effect on retention and in most cases retention factors of methyl or the ethyl substituted analogs did not differ considerably. The position of the methyl or ethyl group influenced the $\alpha$ and $R_{S}$ values. On the teicoplanin-containing CSPs for methyl-substituted analogs better $\alpha$ and $R_{S}$ values were obtained in most cases for enantiomers $\mathbf{1 a}, \mathbf{1 b}$ than for $\mathbf{3 a} \mathbf{a} \mathbf{3 b}$, while $\mathbf{3 c}$, 3d were better separated than 1c, 1d. Similarly, for ethyl-substituted analogs, 2a, 2b and 4c, 4d exhibited better separation than $\mathbf{4 a}, \mathbf{4 b}$ and $\mathbf{2 c}, \mathbf{2 d}$, respectively, on Chirobiotic T, T2 and TAG CSPs.

For comparison of the performances of the macrocyclic glycopeptide-based columns, separations were carried out with the same mobile phases (Table 1). Of the three teicoplanin-based columns Chirobiotic TAG seemed to be more effective in the separation of all enantiomers with exception pair of $\mathbf{2 a}, \mathbf{2 b}$ for which Chirobiotic T2 and 3a, 3b for which Chirobiotic T was better. Comparison of the teicoplanin and vancomycin-based selectors demonstrated that the vancomycin-based CSPs were effective only in the separation of the enantiomers of $\mathbf{3 a}, \mathbf{3 b}$ and $\mathbf{4 a}, \mathbf{4 b}$ (the enantiomers of $\mathbf{1}$ and $\mathbf{2}$ were not separable on Chirobiotic $\mathrm{V}$ and VAG).

In summary, the macrocyclic glycopeptide-based CSPs display a complementary character. Elution sequences were determined in all cases. For analytes 1-4 on the Chirobiotic T, T2, TAG, V and VAG columns, no consistent elution sequence was observed. Neither the configuration of the carbon atom attached to the carboxyl group nor 
Table 1

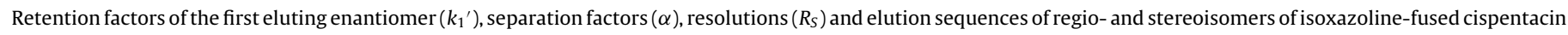
analogs in reversed-phase mode.

\begin{tabular}{|c|c|c|c|c|c|c|}
\hline Compound & Column & $\begin{array}{l}\text { Mobile phase } \\
\text { TEAA/MeOH (v/v) }\end{array}$ & $k_{1}^{\prime}$ & $\alpha$ & $R_{S}$ & Elution sequence \\
\hline \multirow[t]{9}{*}{$1 a, 1 b$} & $\mathrm{~T}$ & $90 / 10$ & 2.63 & 1.00 & 0.00 & - \\
\hline & & $60 / 40$ & 2.31 & 1.01 & 0.20 & $a<b$ \\
\hline & & $10 / 90$ & 4.76 & 1.07 & 0.80 & $a<b$ \\
\hline & $\mathrm{T} 2$ & $90 / 10$ & 0.93 & 1.10 & 0.70 & $a<b$ \\
\hline & & $60 / 40$ & 0.91 & 1.13 & 1.00 & $a<b$ \\
\hline & & $10 / 90$ & 2.96 & 1.16 & 1.65 & $a<b$ \\
\hline & TAG & $90 / 10$ & 4.31 & 1.19 & 1.80 & $a<b$ \\
\hline & & $60 / 40$ & 2.73 & 1.26 & 2.25 & $a<b$ \\
\hline & & $10 / 90$ & 4.76 & 1.33 & 3.25 & $a<b$ \\
\hline \multirow[t]{6}{*}{ 1c, 1d } & $\mathrm{T}$ & $90 / 10$ & 1.85 & 1.00 & 0.00 & - \\
\hline & & $10 / 90$ & 7.51 & 1.01 & 0.20 & $d<c$ \\
\hline & $\mathrm{T} 2$ & $90 / 10$ & 1.39 & 1.00 & 0.00 & - \\
\hline & & $10 / 90$ & 8.16 & 1.04 & 0.65 & $d<c$ \\
\hline & TAG & $90 / 10$ & 3.26 & 1.06 & 0.70 & $c<d$ \\
\hline & & $10 / 90$ & 8.20 & 1.02 & 0.20 & $c<d$ \\
\hline \multirow[t]{9}{*}{$2 a, 2 b$} & $\mathrm{~T}$ & $90 / 10$ & 1.88 & 1.06 & 0.65 & $a<b$ \\
\hline & & $60 / 40$ & 1.77 & 1.09 & 0.85 & $a<b$ \\
\hline & & $10 / 90$ & 3.75 & 1.07 & 1.00 & $a<b$ \\
\hline & $\mathrm{T} 2$ & $90 / 10$ & 1.07 & 1.14 & 0.80 & $a<b$ \\
\hline & & $60 / 40$ & 0.95 & 1.18 & 1.20 & $a<b$ \\
\hline & & $10 / 90$ & 2.28 & 1.24 & 2.60 & $a<b$ \\
\hline & TAG & $90 / 10$ & 5.63 & 1.18 & 1.85 & $a<b$ \\
\hline & & $60 / 40$ & 2.92 & 1.30 & 2.25 & $a<b$ \\
\hline & & $10 / 90$ & 4.65 & 1.18 & 1.90 & $a<b$ \\
\hline \multirow[t]{7}{*}{$2 c, 2 d$} & $\mathrm{~T}$ & $90 / 10$ & 2.55 & 1.00 & 0.00 & - \\
\hline & & $10 / 90$ & 6.52 & 1.00 & 0.00 & - \\
\hline & $\mathrm{T} 2$ & $90 / 10$ & 1.64 & 1.00 & 0.00 & - \\
\hline & & $10 / 90$ & 6.64 & 1.03 & 0.60 & $d<c$ \\
\hline & TAG & $90 / 10$ & 4.98 & 1.10 & 1.40 & $c<d$ \\
\hline & & $60 / 40$ & 4.52 & 1.09 & 1.55 & $c<d$ \\
\hline & & $10 / 90$ & 6.95 & 1.03 & 0.40 & $c<d$ \\
\hline \multirow[t]{10}{*}{$3 a, 3 b$} & $\mathrm{~T}$ & $90 / 10$ & 2.09 & 1.00 & 0.00 & - \\
\hline & & $10 / 90$ & 5.01 & 1.17 & 1.45 & $a<b$ \\
\hline & $\mathrm{T} 2$ & $90 / 10$ & 1.11 & 1.00 & 0.00 & - \\
\hline & & $10 / 90$ & 3.66 & 1.00 & 0.00 & - \\
\hline & TAG & $90 / 10$ & 6.09 & 1.09 & 1.00 & $b<a$ \\
\hline & & $10 / 90$ & 5.66 & 1.09 & 0.85 & $b<a$ \\
\hline & $\mathrm{V}$ & $90 / 10$ & 0.30 & 1.15 & 0.55 & $b<a$ \\
\hline & & $10 / 90$ & 0.98 & 1.36 & 2.95 & $b<a$ \\
\hline & VAG & $90 / 10$ & 0.57 & 1.18 & 1.10 & $b<a$ \\
\hline & & $10 / 90$ & 1.18 & 1.31 & 2.70 & $b<a$ \\
\hline \multirow[t]{10}{*}{ 3c, 3d } & $\mathrm{T}$ & $90 / 10$ & 1.90 & 1.13 & 1.30 & $d<c$ \\
\hline & & $10 / 90$ & 5.71 & 1.02 & 0.30 & $d<c$ \\
\hline & $\mathrm{T} 2$ & $90 / 10$ & 1.07 & 1.16 & 1.00 & $d<c$ \\
\hline & & $10 / 90$ & 3.23 & 1.14 & 1.65 & $d<c$ \\
\hline & TAG & $90 / 10$ & 3.18 & 1.06 & 0.60 & $c<d$ \\
\hline & & $10 / 90$ & 5.75 & 1.24 & 2.15 & $c<d$ \\
\hline & $\mathrm{V}$ & $90 / 10$ & 0.16 & 1.25 & 0.60 & $d<c$ \\
\hline & & $10 / 90$ & 0.78 & 1.13 & 0.80 & $d<c$ \\
\hline & VAG & $90 / 10$ & 0.54 & 1.00 & 0.00 & - \\
\hline & & $10 / 90$ & 1.63 & 1.06 & 0.60 & $d<c$ \\
\hline \multirow[t]{10}{*}{$4 a, 4 b$} & $\mathrm{~T}$ & $90 / 10$ & 2.64 & 1.00 & 0.00 & - \\
\hline & & $10 / 90$ & 4.82 & 1.17 & 1.65 & $a<b$ \\
\hline & $\mathrm{T} 2$ & $90 / 10$ & 1.10 & 1.00 & 0.00 & - \\
\hline & & $10 / 90$ & 3.72 & 1.00 & 0.00 & - \\
\hline & TAG & $90 / 10$ & 7.86 & 1.09 & 0.90 & $b<a$ \\
\hline & & $10 / 90$ & 4.91 & 1.18 & 2.15 & $b<a$ \\
\hline & V & $90 / 10$ & 0.45 & 1.09 & 0.45 & $b<a$ \\
\hline & & $10 / 90$ & 0.92 & 1.35 & 2.60 & $b<a$ \\
\hline & VAG & $90 / 10$ & 0.81 & 1.16 & 1.35 & $b<a$ \\
\hline & & $10 / 90$ & 1.08 & 1.31 & 3.00 & $b<a$ \\
\hline \multirow[t]{5}{*}{$4 c, 4 d$} & $\mathrm{~T}$ & $10 / 90$ & 4.50 & 1.08 & 1.10 & $d<c$ \\
\hline & $\mathrm{T} 2$ & $10 / 90$ & 2.88 & 1.14 & 1.55 & $d<c$ \\
\hline & TAG & $10 / 90$ & 4.60 & 1.27 & 2.50 & $c<d$ \\
\hline & $\mathrm{V}$ & $10 / 90$ & 0.71 & 1.08 & 0.50 & $d<c$ \\
\hline & VAG & $10 / 90$ & 1.47 & 1.05 & 0.55 & $d<c$ \\
\hline
\end{tabular}

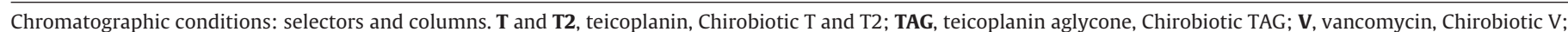
VAG, vancomycin aglycone, Chirobiotic VAG; mobile phase, $0.1 \%$ triethylammonium acetate (pH 4.1$) / \mathrm{MeOH}(\mathrm{v} / \mathrm{v})$; flow rate, $0.5 \mathrm{ml} \mathrm{min}{ }^{-1}$; detection, $210 \mathrm{~nm}$. 
Table 2

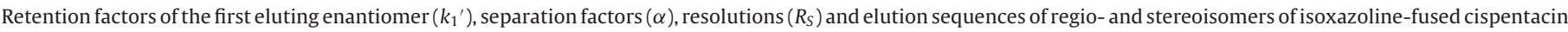
analogs in polar organic and polar ionic modes.

\begin{tabular}{|c|c|c|c|c|c|c|}
\hline Compound & Column & $\begin{array}{l}\text { Mobile phase MeOH (100\%) } \\
\text { MeOH/AcOH/TEA (v/v/v) }\end{array}$ & $k_{1}^{\prime}$ & $\alpha$ & $R_{S}$ & Elution sequence \\
\hline $1 a, 1 b$ & $\begin{array}{l}\mathrm{T} \\
\mathrm{T} 2 \\
\mathrm{TAG}\end{array}$ & $\begin{array}{l}100 \\
100 / 0.1 / 0.1 \\
100 \\
100 / 0.1 / 0.1 \\
100 \\
100 / 0.1 / 0.1\end{array}$ & $\begin{array}{r}9.29 \\
7.78 \\
5.23 \\
4.91 \\
11.91 \\
8.16\end{array}$ & $\begin{array}{l}1.11 \\
1.03 \\
1.16 \\
1.00 \\
1.05 \\
1.00\end{array}$ & $\begin{array}{l}0.90 \\
0.35 \\
0.90 \\
0.00 \\
0.30 \\
0.00\end{array}$ & $\begin{array}{l}b<a \\
a<b \\
a<b \\
- \\
b<a \\
-\end{array}$ \\
\hline 1c, 1d & $\begin{array}{l}\mathrm{T} \\
\mathrm{T} 2 \\
\mathrm{TAG}\end{array}$ & $\begin{array}{l}100 \\
100 / 0.1 / 0.1 \\
100 \\
100 / 0.1 / 0.1 \\
100 \\
100 / 0.1 / 0.1\end{array}$ & $\begin{array}{r}14.70 \\
7.41 \\
16.65 \\
7.78 \\
7.48 \\
7.45\end{array}$ & $\begin{array}{l}1.04 \\
1.04 \\
1.04 \\
1.07 \\
1.00 \\
1.00\end{array}$ & $\begin{array}{l}0.40 \\
0.95 \\
0.65 \\
0.30 \\
0.00 \\
0.00\end{array}$ & $\begin{array}{l}d<c \\
c<d \\
d<c \\
d<c \\
- \\
-\end{array}$ \\
\hline $2 a, 2 b$ & $\begin{array}{l}\mathrm{T} \\
\mathrm{T} 2 \\
\mathrm{TAG}\end{array}$ & $\begin{array}{l}100 \\
100 / 0.1 / 0.1 \\
100 \\
100 / 0.1 / 0.1 \\
100 \\
100 / 0.1 / 0.1\end{array}$ & $\begin{array}{r}7.30 \\
6.66 \\
4.19 \\
4.91 \\
12.91 \\
11.01\end{array}$ & $\begin{array}{l}1.00 \\
1.02 \\
1.24 \\
1.21 \\
1.00 \\
1.26\end{array}$ & $\begin{array}{l}0.00 \\
0.25 \\
1.40 \\
1.20 \\
0.00 \\
1.20\end{array}$ & $\begin{array}{l}- \\
a<b \\
a<b \\
a<b \\
- \\
a<b\end{array}$ \\
\hline $2 c, 2 d$ & $\begin{array}{l}\mathrm{T} \\
\mathrm{T} 2 \\
\mathrm{TAG}\end{array}$ & $\begin{array}{l}100 \\
100 / 0.1 / 0.1 \\
100 \\
100 / 0.1 / 0.1 \\
100 \\
100 / 0.1 / 0.1\end{array}$ & $\begin{array}{r}16.59 \\
6.41 \\
14.49 \\
9.59 \\
10.14 \\
7.38\end{array}$ & $\begin{array}{l}1.00 \\
1.00 \\
1.17 \\
1.03 \\
1.00 \\
1.00\end{array}$ & $\begin{array}{l}0.00 \\
0.00 \\
1.00 \\
0.40 \\
0.00 \\
0.00\end{array}$ & $\begin{array}{l}- \\
- \\
d<c \\
d<c \\
- \\
-\end{array}$ \\
\hline $3 a, 3 b$ & $\begin{array}{l}\mathrm{T} \\
\mathrm{T} 2 \\
\mathrm{TAG} \\
\mathrm{V} \\
\mathrm{VAG}\end{array}$ & $\begin{array}{l}100 \\
100 / 0.1 / 0.1 \\
100 \\
100 / 0.1 / 0.1 \\
100 \\
100 / 0.1 / 0.1 \\
100 \\
100 / 0.1 / 0.1 \\
100 \\
100 / 0.1 / 0.1\end{array}$ & $\begin{array}{r}7.27 \\
9.13 \\
7.16 \\
5.92 \\
11.63 \\
15.49 \\
1.95 \\
1.60 \\
2.41 \\
1.73\end{array}$ & $\begin{array}{l}1.46 \\
1.21 \\
1.00 \\
1.03 \\
1.29 \\
1.08 \\
1.40 \\
1.44 \\
1.34 \\
1.36\end{array}$ & $\begin{array}{l}3.75 \\
1.65 \\
0.00 \\
0.25 \\
1.45 \\
0.50 \\
2.70 \\
3.05 \\
3.50 \\
3.10\end{array}$ & $\begin{array}{l}a<b \\
a<b \\
- \\
b<a \\
a<b \\
b<a \\
b<a \\
b<a \\
b<a \\
b<a\end{array}$ \\
\hline $3 c, 3 d$ & $\begin{array}{l}\mathrm{T} \\
\mathrm{T} 2 \\
\text { TAG } \\
\mathrm{V} \\
\text { VAG }\end{array}$ & $\begin{array}{l}100 \\
100 / 0.1 / 0.1 \\
100 \\
100 / 0.1 / 0.1 \\
100 \\
100 / 0.1 / 0.1 \\
100 \\
100 / 0.1 / 0.1 \\
100 \\
100 / 0.1 / 0.1\end{array}$ & $\begin{array}{r}11.76 \\
7.85 \\
5.57 \\
3.19 \\
14.75 \\
6.00 \\
1.74 \\
1.50 \\
3.45 \\
1.58\end{array}$ & $\begin{array}{l}1.03 \\
1.05 \\
1.29 \\
1.23 \\
1.06 \\
1.09 \\
1.14 \\
1.00 \\
1.08 \\
1.14\end{array}$ & $\begin{array}{l}0.25 \\
0.45 \\
2.00 \\
1.35 \\
0.35 \\
1.25 \\
1.10 \\
0.00 \\
0.75 \\
0.95\end{array}$ & $\begin{array}{l}c<d \\
c<d \\
d<c \\
d<c \\
c<d \\
c<d \\
d<c \\
- \\
d<c \\
d<c\end{array}$ \\
\hline $4 a, 4 b$ & $\begin{array}{l}\mathrm{T} \\
\mathrm{T} 2 \\
\mathrm{TAG} \\
\mathrm{V} \\
\mathrm{VAG}\end{array}$ & $\begin{array}{l}100 \\
100 / 0.1 / 0.1 \\
100 \\
100 / 0.1 / 0.1 \\
100 \\
100 / 0.1 / 0.1 \\
100 \\
100 / 0.1 / 0.1 \\
100 \\
100 / 0.1 / 0.1\end{array}$ & $\begin{array}{r}10.06 \\
7.67 \\
7.08 \\
6.46 \\
9.25 \\
11.07 \\
1.81 \\
1.47 \\
2.18 \\
1.49\end{array}$ & $\begin{array}{l}1.20 \\
1.11 \\
1.00 \\
1.00 \\
1.24 \\
1.25 \\
1.38 \\
1.41 \\
1.34 \\
1.38\end{array}$ & $\begin{array}{l}1.70 \\
0.95 \\
0.00 \\
0.00 \\
0.90 \\
1.50 \\
2.20 \\
3.30 \\
3.15 \\
3.10\end{array}$ & $\begin{array}{l}a<b \\
a<b \\
- \\
- \\
b<a \\
b<a \\
b<a \\
b<a \\
b<a \\
b<a\end{array}$ \\
\hline $4 c, 4 d$ & $\begin{array}{l}\text { T } \\
\text { T2 } \\
\text { TAG } \\
\text { V } \\
\text { VAG }\end{array}$ & $\begin{array}{l}100 \\
100 / 0.1 / 0.1 \\
100 \\
100 / 0.1 / 0.1 \\
100 \\
100 / 0.1 / 0.1 \\
100 \\
100 / 0.1 / 0.1 \\
100 \\
100 / 0.1 / 0.1\end{array}$ & $\begin{array}{r}8.76 \\
5.74 \\
4.90 \\
4.54 \\
13.94 \\
6.54 \\
1.51 \\
1.09 \\
3.24 \\
1.28\end{array}$ & $\begin{array}{l}1.09 \\
1.12 \\
1.26 \\
1.06 \\
1.03 \\
1.14 \\
1.09 \\
1.12 \\
1.06 \\
1.10\end{array}$ & $\begin{array}{l}0.65 \\
1.15 \\
1.75 \\
0.40 \\
0.30 \\
0.50 \\
0.45 \\
1.30 \\
0.50 \\
0.55\end{array}$ & $\begin{array}{l}d<c \\
d<c \\
d<c \\
c<d \\
c<d \\
c<d \\
d<c \\
d<c \\
d<c \\
d<c\end{array}$ \\
\hline
\end{tabular}

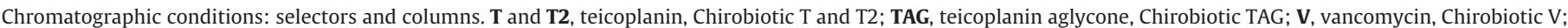
VAG, vancomycin aglycone, Chirobiotic VAG; mobile phase, $0.1 \%$ triethylammonium acetate ( $\mathrm{pH} 4.1$ )/MeOH (v/v); flow rate, $0.5 \mathrm{ml} \mathrm{min}{ }^{-1}$; detection. $210 \mathrm{~nm}$. 

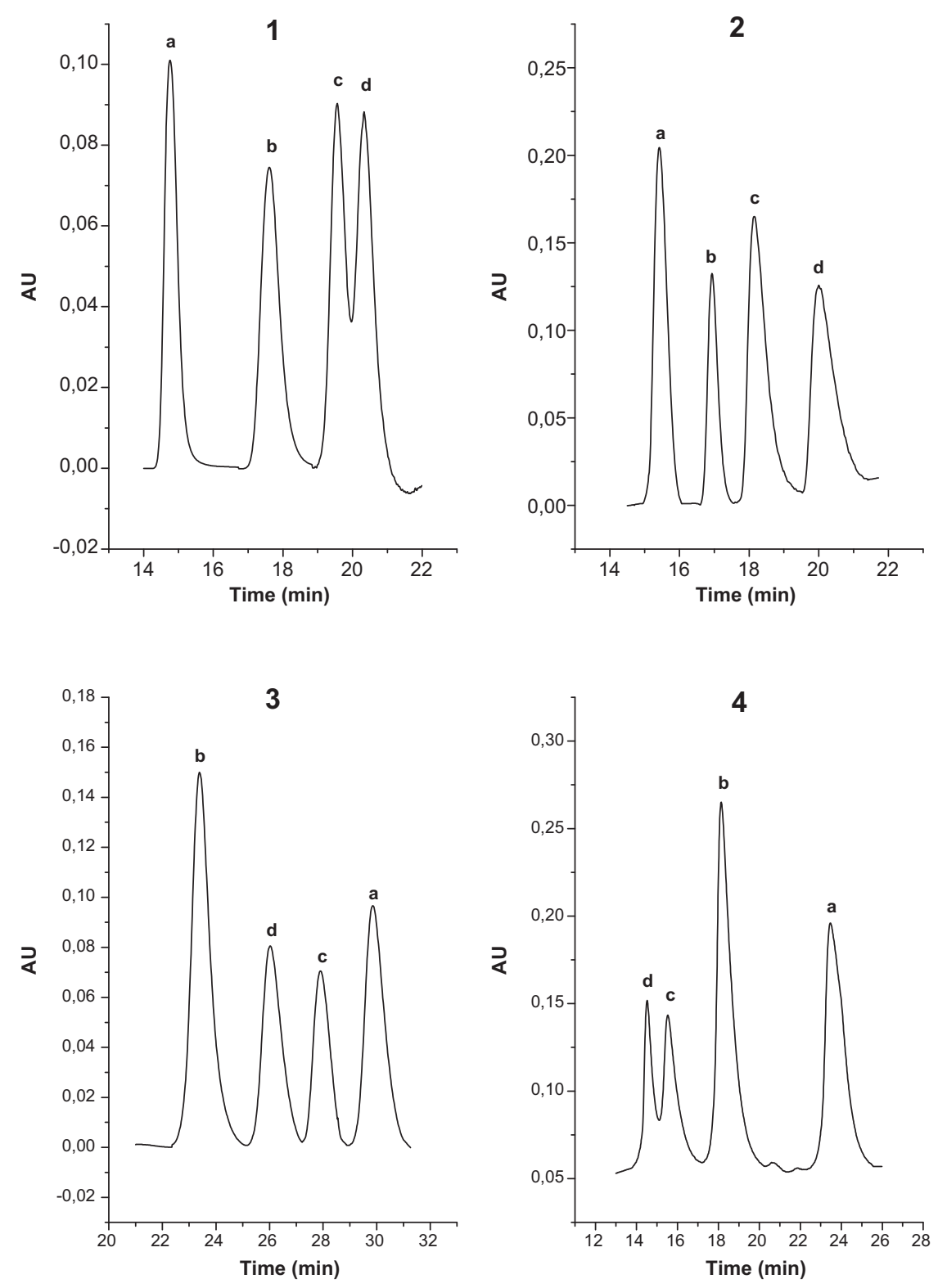

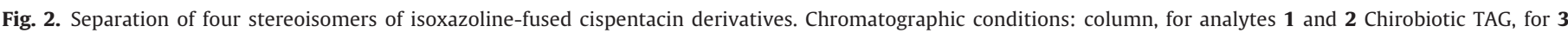

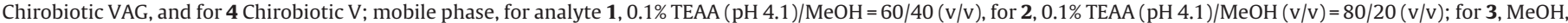
$100 \%$, and for $\mathbf{4}, \mathrm{MeOH} / \mathrm{AcOH} / \mathrm{TEA}=100 / 0.1 / 0.1(\mathrm{v} / \mathrm{v} / \mathrm{v})$; temperature, $25^{\circ} \mathrm{C}$ for analytes $\mathbf{1}$ and $\mathbf{2}$, and $10^{\circ} \mathrm{C}$ for analytes $\mathbf{3}$ and $\mathbf{4}$; flow rate, $0.5 \mathrm{ml} \mathrm{min}{ }^{-1}$; detection, $210 \mathrm{~nm}$.

that of the carbon atom attached to the amino group determined the elution sequence, and in some cases the elution sequence also differed when the mobile phase was changed from reversed-phase to polar organic or polar ionic mode.

\subsection{Separation of four enantiomers of isoxazoline-fused 2-aminocyclopentanecarboxylic acids}

Since the biological activities of isoxazoline-fused 2aminocyclopentanecarboxylic acid analogs depend strongly on their configurations, it is a basic task to separate and identify not only the enantiomers, but also the diastereomers in one chromatographic run. The data listed in Table 1 reveal that separation of the four stereoisomers could be achieved in only a few cases. To attain separation of the four stereoisomers in one chromatographic run, the separation was optimized by variation of the CSPs and mobile phase composition. Fig. 2 and Table 3 illustrate the enantioseparation of all four stereoisomers of isoxazoline-fused 2-aminocyclopentanecarboxylic acid analogs.

\subsection{Effects of temperature and thermodynamic parameters}

In order to investigate the effects of temperature on the chromatographic parameters, a variable-temperature study was carried out on Chirobiotic T and TAG columns over the temperature range $5-45^{\circ} \mathrm{C}$ (in $10^{\circ} \mathrm{C}$ increments). Experimental data for the mobile phase $0.1 \%$ TEAA (pH 4.1)/MeOH $=10 / 90(\mathrm{v} / \mathrm{v})$ are listed in Table 4. A comparison of the retention factors in Table 4 reveals that all of the recorded values decreased with increasing temperature. It is evident that an increase in the separation temperature lowers the separation factor, $\alpha$. However, for analytes $\mathbf{3 a}$, 3b on the Chirobiotic TAG column, $\alpha$ (and $R_{S}$ ) increased with increasing temperature. Increasing temperature may improve the peak symmetry and efficiency, and therefore the resolution may also improve. 
Table 3

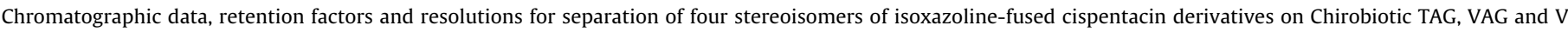
columns.

\begin{tabular}{|c|c|c|c|c|c|c|c|c|c|c|}
\hline Analyte & Column & Mobile phase & $k_{1}^{\prime}$ & $k_{2}^{\prime}$ & $k_{3}^{\prime}$ & $k_{4}^{\prime}$ & $R_{S 1}$ & $R_{S 2}$ & $R_{S 3}$ & Elution sequence \\
\hline 1 & TAG & $\mathbf{a}$ & 2.73 & 3.45 & 3.95 & 4.13 & 3.10 & 2.05 & 0.80 & $a<b<c<d$ \\
\hline 2 & TAG & b & 2.89 & 3.28 & 3.58 & 4.05 & 1.95 & 1.40 & 2.15 & $a<b<c<d$ \\
\hline 3 & VAG & c & 2.53 & 2.93 & 3.21 & 3.50 & 1.95 & 1.45 & 1.80 & $b<d<c<a$ \\
\hline 4 & $\mathrm{~V}$ & d & 1.27 & 1.43 & 1.83 & 2.67 & 0.90 & 1.95 & 3.30 & $d<c<b<a$ \\
\hline
\end{tabular}

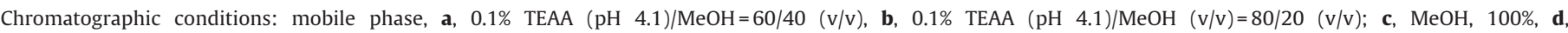
$\mathrm{MeOH} / \mathrm{AcOH} / \mathrm{TEA}=100 / 0.1 / 0.1(\mathrm{v} / \mathrm{v} / \mathrm{v})$; temperature, $25^{\circ} \mathrm{C}$ for analytes $\mathbf{1}$ and $\mathbf{2}, 10^{\circ} \mathrm{C}$ for analytes 3 and $\mathbf{4}$; flow rate, $0.5 \mathrm{ml} \mathrm{min}{ }^{-1}$; detection, 210 nm.

Table 4

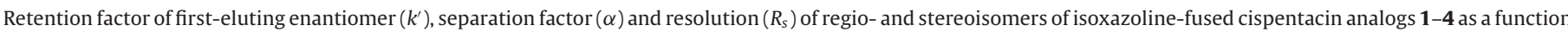
of temperature.

\begin{tabular}{|c|c|c|c|c|c|c|c|}
\hline \multirow[t]{2}{*}{ Analyte } & \multirow[t]{2}{*}{ Column } & \multirow[t]{2}{*}{$k_{1}^{\prime}, \alpha, R_{S}$} & \multicolumn{5}{|c|}{ Temperature $\left({ }^{\circ} \mathrm{C}\right)$} \\
\hline & & & 5 & 15 & 25 & 35 & 45 \\
\hline \multirow[t]{6}{*}{$1 a, 1 b$} & \multirow[t]{3}{*}{$\mathrm{T}$} & $k_{1}^{\prime}$ & 5.20 & 4.77 & 4.23 & 3.80 & 3.47 \\
\hline & & $\alpha$ & 1.08 & 1.06 & 1.04 & 1.03 & 1.01 \\
\hline & & $R_{S}$ & 0.80 & 0.70 & 0.40 & 0.30 & 0.20 \\
\hline & \multirow[t]{3}{*}{ TAG } & $k_{1}^{\prime}$ & 6.18 & 5.39 & 4.76 & 4.19 & 3.59 \\
\hline & & $\alpha$ & 1.47 & 1.40 & 1.33 & 1.26 & 1.21 \\
\hline & & $R_{S}$ & 3.40 & 3.35 & 3.30 & 3.15 & 2.65 \\
\hline \multirow[t]{6}{*}{$1 c, 1 d^{\mathrm{a}}$} & \multirow[t]{3}{*}{$\mathrm{T}$} & $k_{1}^{\prime}$ & 8.22 & 7.42 & 6.82 & 6.45 & 5.86 \\
\hline & & $\alpha$ & 1.02 & 1.01 & 1.00 & 1.00 & 1.00 \\
\hline & & $R_{S}$ & 0.20 & 0.10 & 0.00 & 0.00 & 0.00 \\
\hline & \multirow[t]{3}{*}{ TAG } & $k_{1}^{\prime}$ & 9.02 & 7.96 & 7.02 & 6.07 & 5.46 \\
\hline & & $\alpha$ & 1.02 & 1.02 & 1.02 & 1.02 & 1.01 \\
\hline & & $R_{S}$ & 0.30 & 0.25 & 0.20 & 0.20 & 0.15 \\
\hline \multirow[t]{6}{*}{$2 a, 2 b$} & \multirow[t]{3}{*}{$\mathrm{T}$} & $k_{1}^{\prime}$ & 4.66 & 4.26 & 3.82 & 3.39 & 3.12 \\
\hline & & $\alpha$ & 1.12 & 1.09 & 1.06 & 1.04 & 1.02 \\
\hline & & $R_{S}$ & 1.05 & 0.85 & 0.75 & 0.55 & 0.35 \\
\hline & \multirow[t]{3}{*}{ TAG } & $k_{1}^{\prime}$ & 6.05 & 5.26 & 4.65 & 4.06 & 3.46 \\
\hline & & $\alpha$ & 1.25 & 1.22 & 1.18 & 1.14 & 1.12 \\
\hline & & $R_{S}$ & 2.05 & 2.00 & 1.90 & 1.80 & 1.45 \\
\hline \multirow[t]{6}{*}{$2 c, 2 d$} & \multirow[t]{3}{*}{$\mathrm{T}$} & $k_{1}^{\prime}$ & 7.65 & 7.01 & 6.52 & 5.97 & 5.56 \\
\hline & & $\alpha$ & 1.02 & 1.01 & 1.00 & 1.00 & 1.00 \\
\hline & & $R_{S}$ & 0.15 & 0.10 & 0.00 & 0.00 & 0.00 \\
\hline & \multirow[t]{3}{*}{ TAG } & $k_{1}^{\prime}$ & 8.86 & 7.87 & 6.95 & 5.96 & 5.47 \\
\hline & & $\alpha$ & 1.03 & 1.03 & 1.03 & 1.03 & 1.02 \\
\hline & & $R_{S}$ & 0.40 & 0.35 & 0.30 & 0.25 & 0.20 \\
\hline \multirow[t]{6}{*}{ 3a, 3b } & \multirow[t]{3}{*}{$\mathrm{T}$} & $k_{1}^{\prime}$ & 6.41 & 5.72 & 5.01 & 4.34 & 3.83 \\
\hline & & $\alpha$ & 1.29 & 1.21 & 1.17 & 1.12 & 1.08 \\
\hline & & $R_{S}$ & 1.90 & 1.60 & 1.45 & 1.20 & 0.70 \\
\hline & \multirow[t]{3}{*}{ TAG } & $k_{1}^{\prime}$ & 9.03 & 7.53 & 6.48 & 5.52 & 4.65 \\
\hline & & $\alpha$ & 1.04 & 1.06 & 1.08 & 1.10 & 1.11 \\
\hline & & $R_{S}$ & 0.15 & 0.45 & 0.85 & 0.95 & 1.00 \\
\hline \multirow[t]{6}{*}{ 3c, 3d } & $\mathrm{T}$ & $k_{1}^{\prime}$ & 6.73 & 6.31 & 5.71 & 5.17 & 4.82 \\
\hline & & $\alpha$ & 1.03 & 1.02 & 1.02 & 1.01 & 1.01 \\
\hline & & $R_{S}$ & 0.40 & 0.30 & 0.25 & 0.20 & 0.10 \\
\hline & TAG & $k_{1}{ }^{\prime}$ & 6.02 & 5.40 & 4.62 & 4.10 & 3.73 \\
\hline & & $\alpha$ & 1.25 & 1.25 & 1.24 & 1.23 & 1.21 \\
\hline & & $R_{S}$ & 2.40 & 2.30 & 2.15 & 1.95 & 1.90 \\
\hline $4 a, 4 b$ & $\mathrm{~T}$ & $k_{1}^{\prime}$ & 5.99 & 5.28 & 4.54 & 3.99 & 3.59 \\
\hline & & $\alpha$ & 1.15 & 1.10 & 1.08 & 1.05 & 1.03 \\
\hline & & $R_{S}$ & 1.55 & 1.05 & 1.00 & 0.70 & 0.30 \\
\hline & TAG & $k_{1}^{\prime}$ & 6.38 & 5.54 & 4.82 & 4.12 & 3.50 \\
\hline & & $\alpha$ & 1.19 & 1.18 & 1.17 & 1.17 & 1.16 \\
\hline & & $R_{S}$ & 1.40 & 1.75 & 1.80 & 2.00 & 2.05 \\
\hline $4 c, 4 d$ & $\mathrm{~T}$ & $k_{1}^{\prime}$ & 5.67 & 5.33 & 4.89 & 4.42 & 4.12 \\
\hline & & $\alpha$ & 1.10 & 1.08 & 1.07 & 1.06 & 1.05 \\
\hline & & $R_{S}$ & 0.85 & 0.75 & 0.65 & 0.60 & 0.50 \\
\hline & TAG & $k_{1}^{\prime}$ & 6.52 & 5.79 & 5.18 & 4.55 & 4.21 \\
\hline & & $\alpha$ & 1.29 & 1.27 & 1.26 & 1.24 & 1.22 \\
\hline & & $R_{S}$ & 2.70 & 2.55 & 2.50 & 2.45 & 2.30 \\
\hline
\end{tabular}

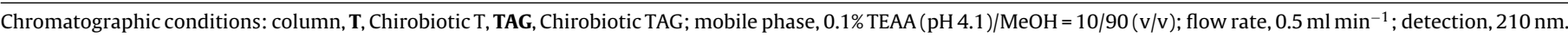

a For analyte $1 \mathrm{c}, 1 \mathrm{~d}$ at $55^{\circ} \mathrm{C}: k_{1(\mathbf{c})}{ }^{\prime}, 5.63 ; k_{2(d)}{ }^{\prime}, 5.88 ; \alpha, 1.05 ; R_{S}, 0.35$. 
Table 5

Thermodynamic parameters, $\Delta H^{\circ}, \Delta S^{\circ}, \Delta\left(\Delta H^{\circ}\right), \Delta\left(\Delta S^{\circ}\right), \Delta\left(\Delta G^{\circ}\right)$, correlation coefficients $\left(R^{2}\right)$ and $T_{\text {iso }}$ temperature of analytes 1-4 on Chirobiotic T and TAG columns.

\begin{tabular}{|c|c|c|c|c|c|c|c|c|c|}
\hline Analyte & Column & $\begin{array}{l}\text { Stereo- } \\
\text { isomer }\end{array}$ & $\begin{array}{l}-\Delta H^{\circ} \\
\left(\mathrm{kJ} \mathrm{mol}^{-1}\right)\end{array}$ & $\begin{array}{l}-\Delta S^{\circ} \\
\left(\mathrm{J} \mathrm{mol}^{-1} \mathrm{~K}^{-1}\right)\end{array}$ & $\begin{array}{l}\text { Correlation } \\
\text { coefficient } \\
\left(R^{2}\right)\end{array}$ & $\begin{array}{l}-\Delta\left(\Delta H^{\circ}\right) \\
\left(\mathrm{kJ} \mathrm{mol}^{-1}\right)\end{array}$ & $\begin{array}{l}-\Delta\left(\Delta S^{\circ}\right) \\
\left(\mathrm{J} \mathrm{mol}^{-1} \mathrm{~K}^{-1}\right)\end{array}$ & $\begin{array}{l}-\Delta\left(\Delta G^{\circ}\right) \\
(288 \mathrm{~K}) \\
\left(\mathrm{kJ} \mathrm{mol}^{-1}\right)\end{array}$ & $T_{\text {iso }}\left({ }^{\circ} \mathrm{C}\right)$ \\
\hline \multirow[t]{4}{*}{$1 a, 1 b$} & $\mathrm{~T}$ & 1 & 7.7 & 13.7 & 0.9961 & 1.2 & 3.7 & 0.2 & 55 \\
\hline & & 2 & 8.9 & 17.4 & 0.9974 & & & & \\
\hline & TAG & 1 & 9.8 & 20.1 & 0.9949 & 3.5 & 9.5 & 0.8 & 98 \\
\hline & & 2 & 13.4 & 29.6 & 0.9977 & & & & \\
\hline \multirow[t]{4}{*}{ 1c, 1d } & $\mathrm{T}$ & 1 & 6.0 & 4.2 & 0.9940 & 0.7 & 2.2 & $\ll 0.1$ & 36 \\
\hline & & 2 & 6.4 & 5.3 & 0.9930 & & & & \\
\hline & TAG & 1 & 9.4 & 15.4 & 0.9976 & 0.2 & 0.4 & 1.0 & 147 \\
\hline & & 2 & 9.6 & 15.8 & 0.9977 & & & & \\
\hline \multirow[t]{4}{*}{$2 a, 2 b$} & $\mathrm{~T}$ & 1 & 7.6 & 14.4 & 0.9953 & 1.6 & 4.7 & 0.2 & 58 \\
\hline & & 2 & 9.1 & 19.1 & 0.9973 & & & & \\
\hline & TAG & 1 & 10.1 & 21.3 & 0.9942 & 2.1 & 5.8 & 0.5 & 96 \\
\hline & & 2 & 12.3 & 27.1 & 0.9964 & & & & \\
\hline \multirow[t]{4}{*}{$2 c, 2 d$} & $\mathrm{~T}$ & 1 & 5.9 & 4.2 & 0.9985 & 0.6 & 2.0 & $\ll 0.1$ & 37 \\
\hline & & 2 & 6.2 & 5.3 & 0.9995 & & & & \\
\hline & TAG & 1 & 9.1 & 14.6 & 0.9952 & 0.2 & 0.5 & 0.1 & 152 \\
\hline & & 2 & 9.3 & 15.1 & 0.9953 & & & & \\
\hline \multirow[t]{4}{*}{$3 a, 3 b$} & $\mathrm{~T}$ & 1 & 9.6 & 19.0 & 0.9952 & 3.2 & 9.4 & 0.5 & 66 \\
\hline & & 2 & 12.8 & 28.4 & 0.9989 & & & & \\
\hline & TAG & 1 & 12.1 & 25.0 & 0.9980 & -1.2 & -4.7 & 0.2 & -15 \\
\hline & & 2 & 10.9 & 20.3 & 0.9969 & & & & \\
\hline \multirow[t]{4}{*}{ 3c, 3d } & $\mathrm{T}$ & 1 & 6.4 & 7.0 & 0.9923 & 0.3 & 1.0 & 0.1 & 67 \\
\hline & & 2 & 6.7 & 8.0 & 0.9926 & & & & \\
\hline & TAG & 1 & 9.1 & 17.6 & 0.9957 & 0.8 & 0.7 & 0.5 & 745 \\
\hline & & 2 & 9.8 & 18.4 & 0.9966 & & & & \\
\hline \multirow[t]{4}{*}{$4 a, 4 b$} & $\mathrm{~T}$ & 1 & 9.6 & 19.6 & 0.9986 & 2.0 & 6.2 & 0.3 & 55 \\
\hline & & 2 & 11.6 & 25.7 & 0.9993 & & & & \\
\hline & TAG & 1 & 10.9 & 23.5 & 0.9955 & 0.6 & 0.6 & 0.4 & 740 \\
\hline & & 2 & 11.4 & 24.1 & 0.9956 & & & & \\
\hline \multirow[t]{4}{*}{$4 c, 4 d$} & $\mathrm{~T}$ & 1 & 6.1 & 7.2 & 0.9901 & 0.8 & 2.2 & 0.2 & 100 \\
\hline & & 2 & 6.9 & 9.4 & 0.9927 & & & & \\
\hline & TAG & 1 & 8.2 & 13.9 & 0.9973 & 1.0 & 1.3 & 0.6 & 450 \\
\hline & & 2 & 9.2 & 15.2 & 0.9979 & & & & \\
\hline
\end{tabular}

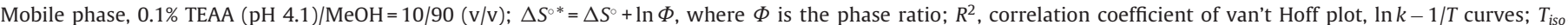
temperature of $\ln k-1 / T$ curves where enantioselectivity cancels.

Thermodynamic parameters were obtained from van't Hoff plots [Eq. (1)]. The $\Delta H^{\circ}$ and $\Delta S^{\circ *}$ values calculated from the slopes and intercepts of these plots for the enantiomers on Chirobiotic $\mathrm{T}$ and TAG columns were negative (Table 5). The second-eluting enantiomers with (the exception of $\mathbf{3 a} \mathbf{3} \mathbf{3 b}$ on Chirobiotic TAG) exhibited more negative $\Delta H^{\circ}$ and $\Delta S^{\circ *}$ values; it is likely that they have fewer degrees of freedom on the CSP, i.e. they are held at more points or are less able to move or rotate. It is widely accepted that both enantiomers undergo the same non-specific interactions, whereas the more strongly retained one is subject to additional stereospecific interactions. Moreover, it was observed that $\Delta H^{\circ}{ }_{1}$ and $\Delta H^{\circ}{ }_{2}$, and in parallel $\Delta S^{\circ *}{ }_{1}$ and $\Delta S^{\circ}{ }_{2}$, for the Chirobiotic T column were in most cases less negative than those for the Chirobiotic TAG column. This may be due to the fact that the latter does not contain sugar units, and this may promote the interaction between the analyte and the CSP.

For the four analytes, the $\mathbf{c}$, d enantiomers exhibited smaller, and the $\mathbf{a}$, $\mathbf{b}$ enantiomers larger $-\Delta H^{\circ}$ and $-\Delta S^{\circ *}$ values on both CSPs. The trans configuration of the amino and carboxy groups in the $\mathbf{c}, \mathbf{d}$ enantiomer pairs may sterically inhibit their fit and orientation in the cavity, and the separation was thermodynamically less favorable. The largest $-\Delta H^{\circ}$ and $-\Delta S^{\circ *}$ values for all analytes on the TAG CSP indicate that separation on it were sterically favorable.

The differences in the changes in enthalpy and entropy, $\Delta\left(\Delta H^{\circ}\right)$ and $\Delta\left(\Delta S^{\circ}\right)$, are also presented in Table 5 . The $-\Delta\left(\Delta H^{\circ}\right)$ values on the Chirobiotic T CSP ranged from -0.3 to $-3.2 \mathrm{~kJ} \mathrm{~mol}^{-1}$ and on the Chirobiotic TAG CSP from 1.2 to $-3.5 \mathrm{~kJ} \mathrm{~mol}^{-1}$. The interactions of $\mathbf{1 a}, \mathbf{1 b}$ with the Chirobiotic TAG CSP were characterized by the highest negative $\Delta\left(\Delta H^{\circ}\right)$ value, while 3a, 3b on Chirobiotic TAG exhibited a positive $\Delta\left(\Delta H^{\circ}\right)$. The trends in the change in $-\Delta\left(\Delta S^{\circ}\right)$ showed that 1a, 1b on Chirobiotic TAG displayed the largest negative entropies, and on the Chirobiotic T CSP $-\Delta\left(\Delta S^{\circ}\right)$ ranged from -1.0 to $-9.4 \mathrm{~J} \mathrm{~mol}^{-1} \mathrm{~K}^{-1}$ and on the Chirobiotic TAG CSP from 4.7 to $-9.5 \mathrm{~J} \mathrm{~mol}^{-1} \mathrm{~K}^{-1}$ (Table 5 ). For $\mathbf{3 a}, \mathbf{3 b}$, similarly to $\Delta\left(\Delta H^{\circ}\right)$ on the Chirobiotic TAG column, $\Delta\left(\Delta S^{\circ}\right)$ was positive.

The thermodynamic parameter $-\Delta\left(\Delta G^{\circ}\right)$ suggests that TAG induces highly efficient binding to the selector, as reflected by the larger negative $\Delta\left(\Delta G^{\circ}\right)$ values for $\mathbf{1 - 4}$ on Chirobiotic TAG. For analytes 1-4 on both columns (with the exception of $\mathbf{3 a}, \mathbf{3 b}$ on Chirobiotic TAG), selector-selectand complex formation proceeds via multiple intermolecular interactions and was generally exothermic, with a corresponding negative entropic contribution.

For 3a, 3b on Chirobiotic TAG, the positive $\Delta\left(\Delta S^{\circ}\right)$ compensated the positive $\Delta\left(\Delta H^{\circ}\right)$ and resulted in a negative $\Delta\left(\Delta G^{\circ}\right)$. In this temperature range, enantioresolution is entropically driven, and the selectivity increases with increasing temperature (Table 5).

The data were used to calculate the temperature, $T_{i s o}$, at which point the enantioselectivity and the elution sequence changed (Table 5 ). In most cases, $T_{\text {iso }}$ was considerably higher than room temperature; enthalpically driven enantioseparation was obtained. For $\mathbf{3 a}, \mathbf{3 b}$ on Chirobiotic TAG, $T_{\text {iso }}$ was $-15^{\circ} \mathrm{C}$, positive $\Delta\left(\Delta H^{\circ}\right)$ and $\Delta\left(\Delta S^{\circ}\right)$ were observed in the investigated temperature range and the selectivity increased with increasing temperature. 

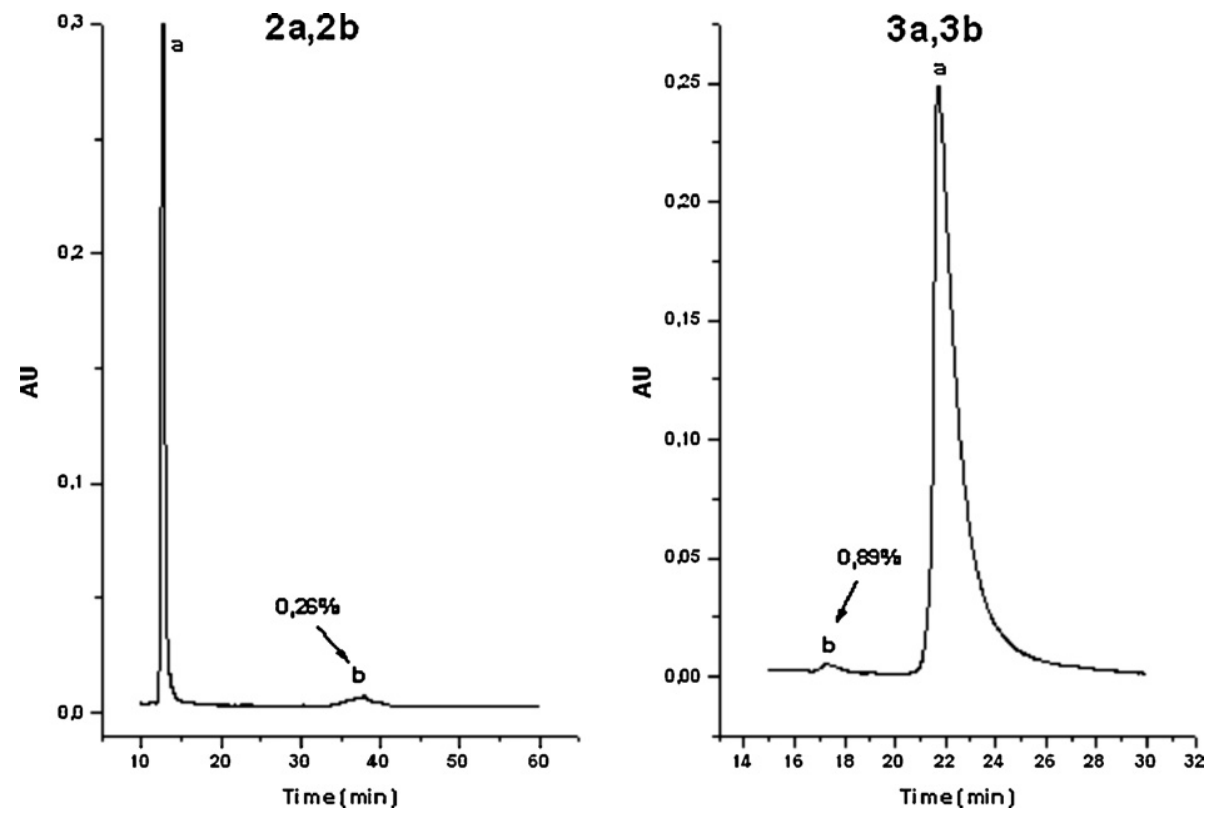

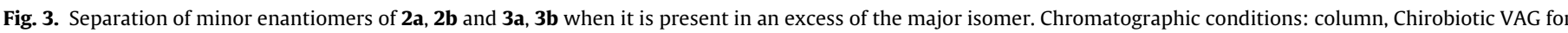

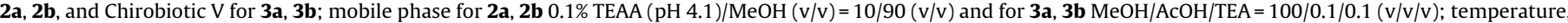
$25^{\circ} \mathrm{C}$; flow rate, $0.5 \mathrm{ml} \mathrm{min}^{-1}$; detection, $210 \mathrm{~nm}$.

For 1c, 1d and 2c, 2d, on the Chirobiotic T CSP, $T_{\text {iso }}$ was $37^{\circ} \mathrm{C}$. For 1c, 1d on the Chirobiotic T column with the $0.1 \%$ TEAA $(\mathrm{pH}$ $4.1) / \mathrm{MeOH}=10 / 90(v / v)$ mobile phase composition, on increase of the temperature from $5{ }^{\circ} \mathrm{C}$ to $55^{\circ} \mathrm{C}, \alpha$ first decreased; then, after a domain where no separation occurred, $\alpha$ slightly increased with increasing temperature at $55^{\circ} \mathrm{C}$ and the elution sequence changed (Table 4). In a domain around the isoenantioselective temperature, the separation of enantiomers could not be obtained. This domain may be referred to as a "temperature-induced blind zone" in chiral recognition [39]. Outside the blind zone, enthalpically or entropically driven enantioseparation can be observed. It should be mentioned that peak inversions on temperature changes were generally observed only for separations with marginal enantioselectivity [40-43].

\section{Method validation}

\subsection{Linearity}

Solution of the racemates were prepared at six different concentration levels, from 1 to $100 \mu \mathrm{g} \mathrm{ml}^{-1}$ for analytes $\mathbf{2 a}, \mathbf{2 b}$ and $\mathbf{3 a}, \mathbf{3 b}$, respectively. Three parallel injections of each solution were made under the chromatographic conditions described above. The peak area response of the first and the second eluting enantiomers was plotted against the corresponding concentration and the linear regression was computed by the least square method using Microsoft Excel program. Very good linearity was observed in the investigated concentration range with the following regression equations: for $\mathbf{2 a}, y=1.93 \times 10^{6} x+3385\left(R^{2}=0.9989\right)$, for $\mathbf{2 b}$, $y=1.85 \times 10^{6} x+3263\left(R^{2}=0.9997\right)$, for 3a, $y=9.56 \times 10^{6} x+2574$ $\left(R^{2}=0.9990\right)$ and for $\mathbf{3 b}, y=1.00 \times 10^{7} x+2656\left(R^{2}=0.9987\right)$. (The difference of the regression parameters of the enantiomers were within the standard error.)

\subsection{Limit of detection (LOD) and limit of quantitation (LOQ)}

LOD and LOQ were determined based on the calibration curve according to the $\mathrm{ICH}$ guidelines using the $S / N$ ratio equal to 3 and 10 , respectively [44]. LOD was $5 \mu \mathrm{g} \mathrm{ml}^{-1}$ and $2.5 \mu \mathrm{g} \mathrm{ml}^{-1}$, while
LOQ $16 \mu \mathrm{g} \mathrm{ml}^{-1}$ and $8.0 \mu \mathrm{g} \mathrm{ml}^{-1}$ for $\mathbf{2 a}, \mathbf{2 b}$ and $\mathbf{3 a}, \mathbf{3 b}$, respectively. Further, the determination limit for the minor isomer is less than $0.1 \%$ when it is present in an excess of the major isomer (Fig. 3 ).

\subsection{Precision}

Replicate HPLC analysis showed that the relative standard deviation were no more than $5 \%$ for the peak area response and less than $1.8 \%$ for the retention time.

\section{Conclusions}

The enantiomeric separations of isoxazoline-fused 2aminocyclopentanecarboxylic acid analogs were investigated using macrocyclic glycopeptide-based CSPs, i.e. Chirobiotic T, T2, TAG, V and VAG columns. The separations could be accomplished in reversed-phase mode using $0.1 \%$ TEAA ( $\mathrm{pH} 4.1) / \mathrm{MeOH}$ mobile phases with different compositions. Of the five Chirobiotic columns, Chirobiotic T and TAG appeared most suitable for the enantioseparation of isoxazoline-fused 2-aminocyclopentanecarboxylic acids. The values of thermodynamic parameters such as the changes in enthalpy, $\Delta\left(\Delta H^{\circ}\right)$, entropy, $\Delta\left(\Delta S^{\circ}\right)$, and Gibbs free energy, $\Delta\left(\Delta G^{\circ}\right)$, depended on the structures of the analytes and on the chiral selectors used. The elution sequence was determined in all cases, but no general predictive rule could be found to describe the elution behavior of these compounds.

\section{Acknowledgment}

This work was supported by Hungarian National Science Foundation grant OTKA K 67563.

\section{References}

[1] A. Hetényi, I.M. Mándity, T.A. Martinek, G.K. Tóth, F. Fülöp, J. Am. Chem. Soc. $127(2005) 553$

[2] F. Fülöp, T.A. Martinek, G.K. Tóth, Chem. Soc. Rev. 35 (2006) 323.

[3] L. Kiss, E. Forró, F. Fülöp, Synthesis of carbocyclic $\beta$-amino acids, in: A.B. Hughes (Ed.), Amino Acids, Peptides and Proteins in Organic Chemistry, vol. 1, WileyVCH, Weinheim, 2009, p. 367. 
[4] H. Kai, H. Matsumoto, N. Hattori, A. Takase, T. Fujiwara, H. Sugimoto, Bioorg. Med. Chem. Lett. 11 (2001) 1997.

[5] M. Basappa, P. Sadashiva, K. Mantelingu, N.S. Swamy, K.S. Rangappa, Bioorg. Med. Chem. 11 (2003) 4539.

[6] P. Conti, A. Caligiuri, A. Pinto, G. Roda, L. Tamborini, B. Nielsen, U. Madsen, K. Frydenvang, A. Colombo, C. De Micheli, Eur. J. Med. Chem. 42 (2007) 1059.

[7] A. Pinto, P. Conti, M. De Amici, L. Tamborini, G. Grazioso, S. Colleoni, T. Mennini, M. Gobbi, C. De Micheli, Tetrahedron: Asymmetry 19 (2008) 867.

[8] P. Chand, S. Bantia, P.L. Kotian, Y. El-Kattan, T.-H. Lin, Y.S. Babu, Bioorg. Med. Chem. 13 (2005) 4071.

[9] P. Chand, P.L. Kotian, A. Dehghani, Y. El-Kattan, T.-H. Lin, T.L. Hutchison, Y.S. Babu, S. Bantia, A.J. Elliot, J.A. Montgomery, J. Med. Chem. 44 (2001) 4379.

[10] T. Mineno, M.J. Miller, J. Org. Chem. 68 (2003) 6591.

[11] I. Ilisz, R. Berkecz, A. Péter, J. Pharm. Biomed. Anal. 47 (2008) 1.

[12] I. D’Acquarica, F. Gasparrini, D. Misiti, G. Zappia, C. Cimarelli, G. Palmieri, A. Carotti, S. Cellamare, C. Villani, Tetrahedron: Asymmetry 11 (2000) 2375.

[13] I. Ilisz, R. Berkecz, A. Péter, J. Sep. Sci. 29 (2006) 1305.

[14] A. Péter, J. Chromatogr. A 955 (2002) 141.

[15] M.H. Hyun, H.J. Choi, B.S. Kang, G. Tan, Y.J. Choi, Bull. Korean Chem. Soc. 27 (2006) 1775.

[16] M.H. Hyun, Y. Song, Y.J. Cho, H.J. Choi, J. Sep. Sci. 30 (2007) 2539.

[17] R. Berkecz, A. Sztojkov-Ivanov, I. Ilisz, E. Forró, F. Fülöp, M.H. Hyun, A. Péter, J. Chromatogr. A 1125 (2006) 138.

[18] R. Berkecz, I. Ilisz, F. Fülöp, Z. Pataj, M.H. Hyun, A. Péter, J. Chromatogr. A 1189 (2008) 285

[19] R. Berkecz, I. Ilisz, A. Misicka, D. Tymecka, F. Fülöp, H.J. Choi, M.H. Hyun, A. Peter, J. Sep. Sci. 32 (2009) 981.

[20] E. Forró, J. Chromatogr. A 1216 (2009) 1025.

[21] T.J. Wenzel, C.E. Bourne, R.L. Clark, Tetrahedron: Asymmetry 20 (2009) 2052.

[22] S. Allenmark, V. Schurig, J. Mater. Sci. 7 (1977) 1955.
[23] V. Schurig, J. Ossig, R. Link, Angew. Chem. 101 (1989) 197.

[24] I.I. Spanik, J. Krupcik, V. Schurig, J. Chromatogr. A 843 (1999) 123.

[25] T. Fornstedt, P. Sajonz, G. Guichon, J. Am. Chem. Soc. 119 (1997) 1254.

[26] T. Fornstedt, P. Sajonz, G. Guichon, Chirality 10 (1998) 375

[27] G. Gotmar, T. Fornstedt, G. Guiochon, Anal. Chem. 72 (2000) 3908.

[28] A. Cavazzini, G. Nadalini, F. Dondi, F. Gasparrini, A. Ciogli, C. Villani, J. Chromatogr. A 1031 (2004) 143.

[29] E. Peyrin, Y.C. Guillaume, C. Guinchard, Anal. Chem. 69 (1997) 4979

[30] L. Kiss, M. Nonn, E. Forró, R. Sillanpää, F. Fülöp, Tetrahedron Lett. 50 (2009) 2605.

[31] E. Forró, F. Fülöp, Tetrahedron: Asymmetry 15 (2004) 2875

[32] L. Kiss, E. Forró, R. Sillanpää, F. Fülöp, J. Org. Chem. 72 (2007) 8786.

[33] M. Nonn, L. Kiss, E. Forró, Z. Mucsi, F. Fülöp, Tetrahedron 67 (2011) 4079

[34] A. Berthod, X. Chen, J.P. Kullman, D.W. Armstrong, F. Gasparrini, I. D'Acquarica, C. Villani, A. Carotti, Anal. Chem. 72 (2000) 1767.

[35] A. Árki, D. Tourwé, M. Solymár, F. Fülöp, D.W. Armstrong, A. Péter, Chromatographia 60 (2004) S43.

[36] A. Péter, A. Árki, E. Vékes, D. Tourwé, L. Lázár, F. Fülöp, D.W. Armstrong, J. Chromatogr. A 1031 (2004) 171.

[37] A. Sztojkov-Ivanov, L. Lázár, F. Fülöp, D.W. Armstrong, A. Péter, Chromatographia 64 (2006) 89.

[38] D.W. Armstrong, Y. Liu, K.H. Ekborg-Ott, Chirality 7 (1995) 474.

[39] B. Yao, F. Zhan, G. Yu, Z. Chen, W. Fan, X. Zeng, Q. Zeng, W. Weng, J. Chromatogr. A 1216 (2009) 5429.

[40] K. Balmér, P.O. Lagerström, B.A. Persson, J. Chromatogr. 592 (1992) 331.

[41] W.H. Pirkle, P.G. Murray, J. High Resolut. Chromatogr. 16 (1993) 285.

[42] M. Schlauch, A.W. Frahm, Anal. Chem. 73 (2001) 262.

[43] R.W. Stringham, J.A. Blackwell, Anal. Chem. 69 (1997) 1414

[44] Q2(R1) Document: Validation of Analytical Procedures: Text and Methodology, International Conference on Harmonization (ICH), Geneva, 2005. 


\title{
High-Performance Liquid Chromatographic Enantioseparation of Unusual Isoxazoline-Fused 2-Aminocyclopentanecarboxylic Acids on (+)-(18-Crown-6)-2,3,11,12-Tetracarboxylic Acid-Based Chiral Stationary Phases
}

\author{
LÁSZLÓ SIPOS, ${ }^{1}$ ISTVÁN ILISZ, ${ }^{2}$ ANITA ARANYI, ${ }^{2}$ ZSANETT GECSE, ${ }^{2}$ MELINDA NONN,,${ }^{1}$ FERENC FÜLÖP, ${ }^{1}$ MYUNG HO HYUN, ${ }^{3}$ AND \\ ANTAL PÉTER ${ }^{2 *}$ \\ ${ }^{1}$ Institute of Pharmaceutical Chemistry, University of Szeged, Szeged, Hungary \\ ${ }^{2}$ Department of Inorganic and Analytical Chemistry, University of Szeged, Szeged, Hungary \\ ${ }^{3}$ Department of Chemistry and Chemistry Institute for Functional Materials, Pusan National University, Busan, South Korea
}

\begin{abstract}
The enantiomers of four unusual isoxazoline-fused 2-aminocyclopentanecarboxylic acids were directly separated on chiral stationary phases containing (+)-(18-crown-6)2,3,11,12-tetracarboxylic acid as chiral selector. The nature of the alcoholic modifier $(\mathrm{MeOH}$, EtOH, IPA) exerted a great effect on the retention, whereas the selectivity and resolution did not change substantially. Two types of dependence of retention on alcohol content were detected: $k_{1}$ increased continuously with increasing alcohol content or a U-shaped retention curve was observed. A comparison of the chromatographic data obtained with $\mathrm{HCOOH}, \mathrm{AcOH}$, TFA, $\mathrm{HClO}_{4}, \mathrm{H}_{2} \mathrm{SO}_{4}$, or $\mathrm{H}_{3} \mathrm{PO}_{4}$ as acidic modifier at a constant concentration demonstrated that in most cases, larger $k$ values were obtained on the application of $\mathrm{AcOH}$ or $\mathrm{HCOOH}$, and an increase of the acid content resulted in a decrease of retention. Some mechanistic aspects of the chiral recognition process are discussed with respect to the structures of the analytes and selector. The sequence of elution of the enantiomers was determined in all cases. Chirality 24:817-824, 2012. (c) 2012 Wiley Periodicals, Inc.
\end{abstract}

KEY WORDS: column liquid chromatography; enantiomer separation; isoxazoline-fused 2-aminocyclopentanecarboxylic acids(+)-(18-crown-6)-2,3,11,12-tetracarboxylic acid-based chiral stationary phases

\section{INTRODUCTION}

As a consequence of their pharmacological potential, alicyclic $\beta$-amino acids are currently a hot topic in medicinal chemistry. The natural $\beta$-amino acid cispentacin $([1 R, 2 S]-2-$ aminocyclopentanecarboxylic acid), icofungipen ([1R,2S]-2-amino4-methylenecyclopentanecarboxylic acid) and oryzoxymycin ([S]-2-[[5R,6R]-6-amino-5-hydroxycyclohexa-1,3-dienecarbonyloxy] propanoic acid) are pharmacologically important compounds with strong antibacterial and antifungal activities. In the synthesis of peptide-based drugs, many cyclic, conformationally constrained $\beta$-amino acids may serve as building blocks. ${ }^{1-3}$

Amino acids with an isoxazoline moiety are important antiviral and antifungal agents. Some isoxazole ring-containing carboxylic acids, as conformationally restricted aspartate and glutamate analogs, are known as enzyme inhibitors with neuroprotective properties. ${ }^{4-7}$ Moreover, isoxazoline-fused amino acids may function as important precursors for the synthesis of novel highly substituted cycloalkane derivatives with antiviral properties. ${ }^{8-10}$

Because the biological and physicochemical properties of amino acids are strongly related to the stereochemistry, it is very important to have at hand effective analytical methods that are suitable for the separation and identification of the enantiomers. Among the possible methods, enantioselective high-performance liquid chromatography (HPLC) is routinely used for the discrimination of enantiomers. HPLC enantioseparations of $\beta$-amino acids have been performed by both indirect and direct methods. In the last decade, chiral derivatizing (c) 2012 Wiley Periodicals, Inc. agents ${ }^{11}$ and chiral stationary phases (CSPs) such as macrocyclic glycopeptides, ${ }^{12,13}$ quinine derivatives, ${ }^{14}$ and $(+)-(18-$ crown-6)-2,3,11,12-tetracarboxylic acid derivatives ${ }^{15-19}$ as CSPs and as a chiral NMR solvating agent have been used for analysis of the enantiomeric composition of $\beta$-amino acids. ${ }^{20}$ Very recently, macrocyclic glycopeptides have been applied for the enantioseparation of isoxazoline-fused 2-aminocyclopentanecarboxylic acids. ${ }^{21}$

In the present paper, direct HPLC methods are described for the separation of enantiomers of new cyclic $\beta^{3}$-amino acids (Fig. 1), with the application of two different (+)-(18-crown-6)2,3,11,12-tetracarboxylic acid-based CSPs (Fig. 2). All analytes were separated with different mobile phase compositions involving $\mathrm{H}_{2} \mathrm{O} / \mathrm{alcohol} / \mathrm{acid}$ systems. The effects of the nature and concentration of the mobile phase additives (alcoholic and acidic modifiers) and the specific structural features of the analytes and selectors on the separation are discussed on the basis of the experimental data. The elution sequence was determined in all cases.

\footnotetext{
$\overline{\text { Contract grant }}$ sponsor: Hungarian National Science Foundation; Contract grant number: K 67563.

${ }^{*}$ Correspondence to: Antal Péter, Department of Inorganic and Analytical Chemistry, University of Szeged, H-6720 Szeged, Dóm tér 7, Hungary. E-mail: apeter@chem.u-szeged.hu

Received for publication 27 February 2012; Accepted 25 April 2012

DOI: $10.1002 /$ chir.22077

Published online 28 July 2012 in Wiley Online Library

(wileyonlinelibrary.com).
} 


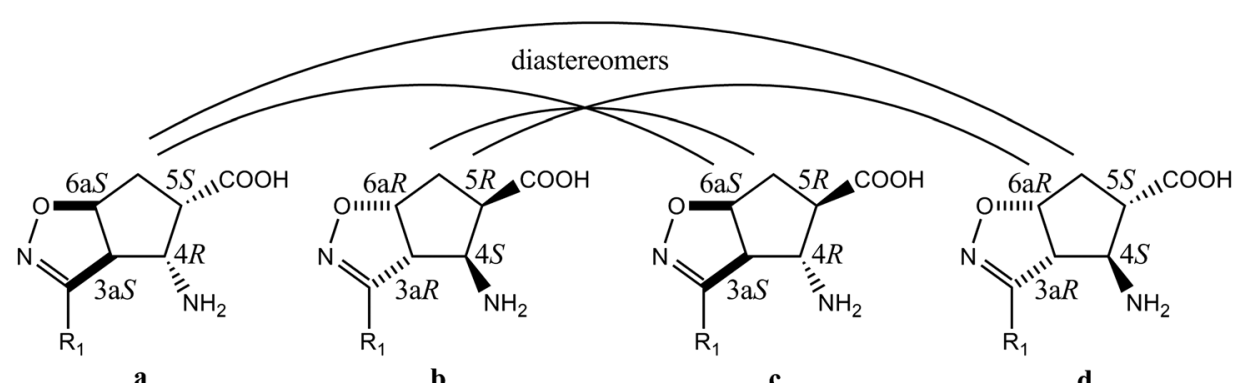

3aS4R5S6aS

3aR4S5R6aR

$\underset{3 a S 4 R 5 R 6 a S}{c}$

d

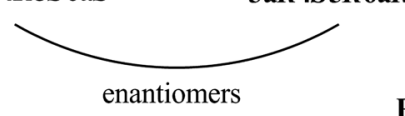

$\mathrm{R}_{1}: \mathrm{CH}_{3}-\mathbf{1 a - 1 d}$

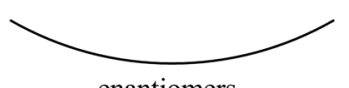

$\mathrm{C}_{2} \mathbf{H}_{5}-2 \mathrm{a}-2 \mathrm{~d}$

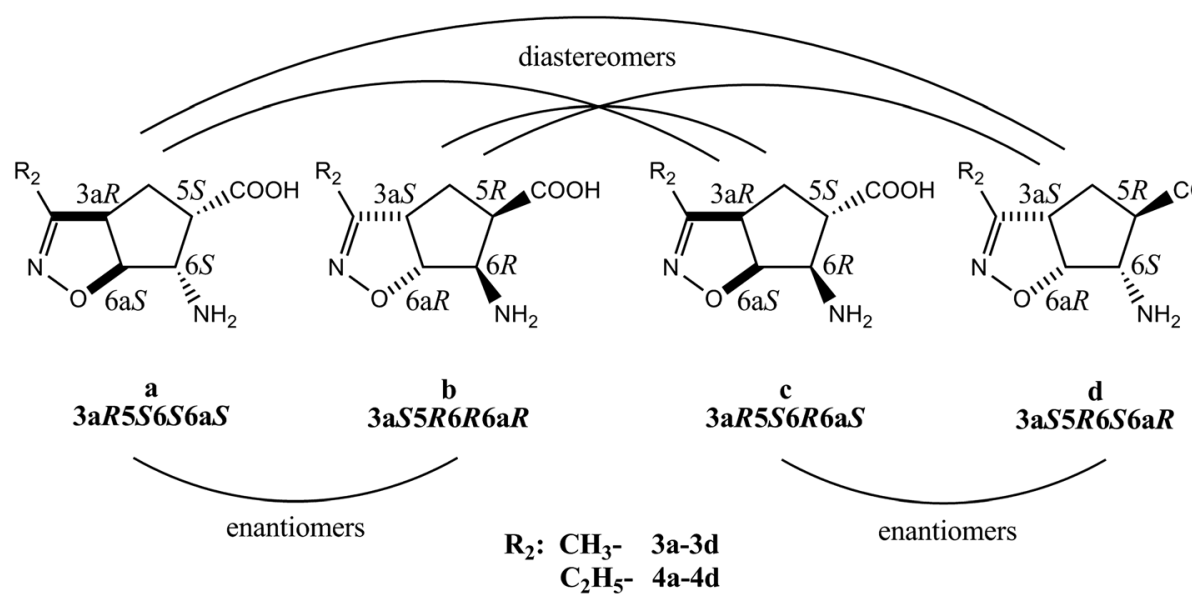

Fig. 1. Structures of isoxazoline-fused 2-aminocyclopentanecarboxylic acids.

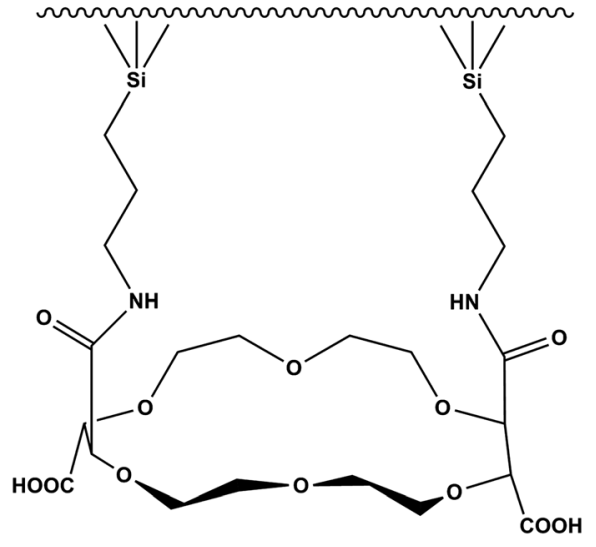

CSP1

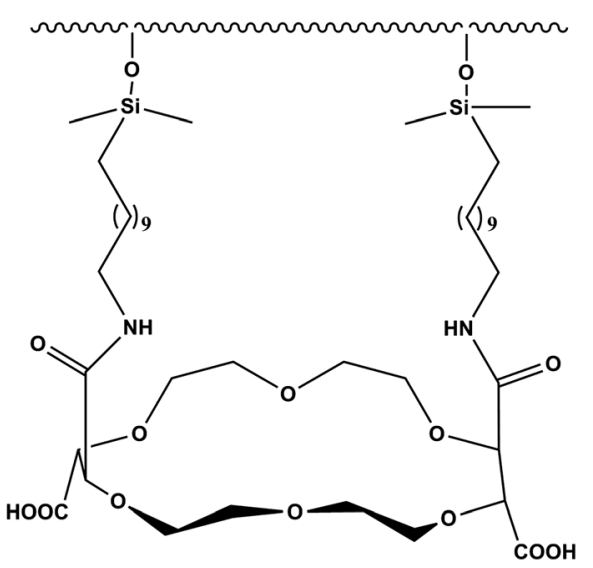

CSP2

Fig. 2. Structures of chiral stationary phase 1 (CSP1) and chiral stationary phase 2 (CSP2).

\section{EXPERIMENTAL \\ Synthesis of Isoxazoline-Fused 2-Aminocyclopentanecarboxylic Acids}

Racemic isoxazoline-fused cispentacin regioisomers and stereoisomers were synthetized from $N$-Boc-protected ethyl 2-amino-3-cyclopentenecarboxylate in reactions with nitrile oxides, through 1,3-dipolar cycloaddition. The nitrile oxides were generated from nitroethane or 1-nitropropane in the presence of di-t-butyl dicarbonate $\left(\mathrm{Boc}_{2} \mathrm{O}\right)$ and 4-dimethylaminopyridine (DMAP). When the cycloaddition was performed in THF at $20^{\circ} \mathrm{C}$ for $15 \mathrm{~h}$, the reaction resulted in two regioisomers and one diastereoisomer. ${ }^{22}$ The isoxazoline-fused cispentacin enantiomers were prepared from the Chirality DOI 10.1002/chir
$N$-Boc-protected ethyl 2-amino-3-cyclopentenecarboxylate enantiomer. ${ }^{5,23,24}$ The cycloadditions were achieved similarly as for the racemic compounds. Under the same experimental conditions (nitroethane/1-nitropropane, $\mathrm{Boc}_{2} \mathrm{O}$ and DMAP), the racemic trans counterparts afforded selectively only one cycloadduct, which was also prepared by epimerization at C-5 of the very minor product. The two racemic major regioisomers were epimerized at $\mathrm{C}-5$ in the presence of sodium ethoxide in ethanol (EtOH), giving the corresponding isoxazoline-fused trans amino esters. ${ }^{25}$ The aforementioned reactions were also extended to the synthesis of these derivatives in enantiomerically enriched form. ${ }^{23,24}$ In the final step, the earlier-prepared racemic and enantiomerically pure isoxazoline-fused ethyl 2-aminocyclopentanecarboxylates were submitted to hydrolysis in the presence 
of $\mathrm{HCl} / \mathrm{H}_{2} \mathrm{O}$ (2:1) in dioxane to afford the corresponding amino acid derivatives (1a, 1d; 2a, 2d; 3a, 3c; 4a, 4c).

\section{Chemicals and Reagents}

Methanol (MeOH), EtOH, and 2-propanol (IPA) of HPLC grade were purchased from Scharlau (Sentmenat, Spain). Formic acid $(\mathrm{HCOOH})$, glacial acetic acid $(\mathrm{AcOH})$, trifluoroacetic acid (TFA), sulfuric acid $\left(\mathrm{H}_{2} \mathrm{SO}_{4}\right)$, perchloric acid $\left(\mathrm{HClO}_{4}\right)$, phosphoric acid $\left(\mathrm{H}_{3} \mathrm{PO}_{4}\right)$, and other reagents of analytical reagent grade were from Sigma-Aldrich (St. Louis, MO, USA). Milli-Q water was further purified by filtration on a $0.45-\mu \mathrm{m}$ filter, type HV, Millipore (Molsheim, France).

Chiral resolution of all the compounds shown in Figure 1 was investigated using mobile phases of $\mathrm{H}_{2} \mathrm{O} / \mathrm{MeOH} / \mathrm{acid}, \mathrm{H}_{2} \mathrm{O} / \mathrm{EtOH} / \mathrm{acid}$, and $\mathrm{H}_{2} \mathrm{O} / \mathrm{IPA} /$ acid in different ratios, where acid in most cases was $\mathrm{AcOH}$.

\section{Apparatus and Chromatography}

The HPLC measurements were carried out on a Waters Breeze system consisting of a 1525 binary pump, a 487 dual-channel absorbance detector, a 717 plus autosampler, and Breeze data manager software (Waters Chromatography, Milford, MA, USA). The chromatographic systems were equipped with a Rheodyne Model 7125 injector (Cotati, CA, USA) with $20-\mu 1$ loops.

Two different (+)-(18-crown-6)-2,3,11,12-tetracarboxylic acid-based CSPs were used for analytical separations (Fig. 2). CSP1 was prepared via a method described earlier, ${ }^{26}$ except for the use of Kromasil aminopropylsilica gel (Kromasil ${ }^{\circledR} \mathrm{NH}_{2}, 5 \mu \mathrm{m}$ ) instead of Rainan AMINO silica gel, whereas for CSP2, a long 11-methylene-unit spacer ${ }^{27}$ was applied. All silica gels had a particle size of $5 \mu \mathrm{m}$ and were packed in a $150 \times 4.0 \mathrm{~mm}$ I.D. column. The differences in the two CSPs arise from the different chain length of spacers (3-methylene or 11-methylene units) and the end capping procedure (Fig. 2).

\section{RESULTS AND DISCUSSION}

The analytes in this study (Fig. 1) possess an isoxazolinefused cyclopentane skeleton. Besides carboxy and primary amino groups, analogs $\mathbf{1}$ and $\mathbf{3}$ bear a methyl group on C-3, in contrast with an ethyl group on C-3 in analogs 2 and 4. This results in different steric effects, influencing the hydrophobicity, bulkiness, and rigidity of the molecules, and hence their interactions with the selector.

For such columns, an acidic modifier may be added to the mobile phase to protonate the primary amino group of the analyte. Stereoselective complexation of the resulting primary ammonium ions $\left(\mathrm{R}-\mathrm{NH}_{3}^{+}\right)$inside the cavity of the crown ether ring of the CSP has been suggested to be essential for chiral recognition. ${ }^{28}$ Besides these interactions, H-bonding, hydrophobic, dipole-dipole, steric, among others, interactions should likewise be taken into account. Lee et al. ${ }^{29}$ reported that the high enantioselectivity of this type of CSP for $\alpha$-amino acids was due to the H-bonding between one carboxylic acid in the CSP and a carbonyl group oxygen in the amino acid.

\section{Effects of the Nature and Content of the Alcoholic Modifier in the Mobile Phase}

On the two crown ether-based columns, the results of the separation of the enantiomers of isoxazoline-fused 2-aminocyclopentanecarboxylic acids were evaluated with different mobile phases consisting of $\mathrm{H}_{2} \mathrm{O} / \mathrm{alcohol} / \mathrm{acid}$ mixtures, where the alcohol was $\mathrm{MeOH}$, EtOH, or IPA, whereas acid in most cases was $\mathrm{AcOH}$. To simplify the presentation and to reduce the huge number of data, Table 1 lists chromatographic data $\left(k_{1}, \alpha\right.$, and $\left.R_{S}\right)$ obtained on CSP1 and $k_{1}$ on CSP2 when $\mathrm{H}_{2} \mathrm{O} / \mathrm{MeOH} / \mathrm{AcOH}(90 / 10 / 10,70 / 30 / 10,50 / 50 / 10,30 / 70 / 10$, $10 / 90 / 10$, and $5 / 95 / 10(v / v / \mathrm{mM}))$ mobile phases were applied and the final concentration of $\mathrm{AcOH}$ was $10.0 \mathrm{mM}$.
Investigation of the effects of the alcohol content $(\mathrm{MeOH}$, EtOH or IPA) of the mobile phase revealed two types of dependence. In MeOH-containing mobile phases for analytes 2c,2d, 3, and 4, $k_{1}$ increased continuously with increasing $\mathrm{MeOH}$ content, whereas for analytes $\mathbf{1 a}, \mathbf{1 b}, \mathbf{1 c}, \mathbf{1 d}$, and $\mathbf{2 a}, \mathbf{2 b}$ on CSP1 and for all analytes on CSP2, a U-shaped retention curve was observed (Table 1). In the EtOH-containing and IPA-containing mobile phases, $k_{1}$ increased continuously with increasing alcohol content (data not shown). An increase in $k_{1}$ with increasing alcohol content suggests that the retention behavior may be controlled by a mechanism of hydrophilic interaction chromatography (HILIC) at higher alcohol contents. Different extents of solvation of the CSP during HILIC (and under the reversed phase) conditions may explain the observed retention behavior. As concerns the U-shaped retention curve, the increase in the retention factor with increasing water content was probably due to enhanced hydrophobic interactions between the analyte and the CSP in the water-rich mobile phase. When the alcohol content of the mobile phase exceeded $\sim 30-50 \%$, the retention factor increased. The inflection points and the slopes of the U-shaped curves at higher and lower alcohol concentrations differed somewhat for each compound. As regards the variations in the separation factors $(\alpha)$ and resolutions $\left(R_{S}\right)$ with change of alcohol content, no general trends were observed.

In the $\mathrm{H}_{2} \mathrm{O} / \mathrm{MeOH} / \mathrm{AcOH}$ eluent system, $k_{1}$ was generally larger on CSP1 when the alcohol content was larger and on CSP2 when the $\mathrm{H}_{2} \mathrm{O}$ content was larger (1c, $1 \mathbf{d}$ was exception) (Table 1). In the former case, the more polar CSP1 favors the HILIC interactions resulting larger $k_{1}$ in alcohol rich mobile phase, whereas in the latter case, the more apolar CSP2 favors the hydrophobic interactions in water rich mobile phase. Similar trends were observed in EtOH-containing and IPAcontaining mobile phases (Table 2) with exception of analytes 1 and 2 . For these analytes, $k_{1}$ was larger on CSP2 at higher EtOH or IPA (70 vol\%) content.

The nature of the alcoholic modifier (MeOH, EtOH, IPA) exerted a great effect on the retention, whereas the selectivity and resolution did not change substantially. The effect of the $\mathrm{EtOH}$ or IPA content was measured in the aqueous mobile phases containing $10,30,50$, and $70 \mathrm{vol} \%$ of alcohol and $10 \mathrm{mM}$ of $\mathrm{AcOH}$. For all analytes at constant organic modifier and acid content of $\mathrm{H}_{2} \mathrm{O} /$ alcoholic modifier (90/10 and 30/ $70 v / v$ ) and $10.0 \mathrm{mM} \mathrm{AcOH}$, the retention factors of first eluting enantiomers on both columns in most cases were largest in EtOH-containing mobile phases (exceptions were 1c,1d and $\mathbf{2 c}, \mathbf{2 d}$ on CSP1 and $\mathbf{4 c}, \mathbf{4 d}$ on CSP2 at $\mathrm{H}_{2} \mathrm{O} / \mathrm{alcohol} /$ acid $[30 / 70 / 10 v / v / \mathrm{mM}]$ ) (Table 2). It was generally observed on both columns that $k_{1}$ in $\mathrm{H}_{2} \mathrm{O}$ /alcoholic modifier/AcOH (90/ $10 / 10 v / v / \mathrm{mM}$ ) was smallest in IPA-containing eluent system (exception was 2c,2d), whereas in the mobile phase with higher alcohol content, $\mathrm{H}_{2} \mathrm{O} /$ alcoholic modifier/AcOH $(30 / 70 / 10 v / v / \mathrm{mM}) k_{1}$ was smallest in MeOH-containing mobile phase (exceptions were $\mathbf{1 c}, \mathbf{1 d}$ and $\mathbf{4 a}, \mathbf{4 b}$ ). In the former case, the hydrophobic interactions between analytes and CSP in the presence of IPA decrease to a larger extent than in the presence of $\mathrm{MeOH}$, whereas in the latter case, the more apolar IPA promotes the HILIC interactions; the higher carbon number of the alcohols was disadvantageous for polar interactions between the mobile phase and amino acids.

However, the nature of the alcoholic modifier exhibited a small effect on the enantioselectivity and resolution; that is, the nonchiral interactions between the CSP and the analytes are more 
TABLE 1. Retention factors of the first eluting enantiomer $\left(k_{1}\right)$, separation factors $(\alpha)$, resolutions $\left(R_{S}\right)$, and elution sequences for the resolution of stereoisomers of isoxazoline-fused cispentacin analogs on chiral stationary phase 1 (CSP1) and retention factors of the first eluting enantiomer $\left(k_{1}\right)$ on chiral stationary phases 2 (CSP2) in MeOH-containing mobile phase

\begin{tabular}{|c|c|c|c|c|c|c|}
\hline \multirow[b]{2}{*}{ Compound } & \multirow[b]{2}{*}{ Mobile phase $(v / v / \mathrm{mM})$} & \multicolumn{4}{|c|}{ CSP1 } & \multirow{2}{*}{$\frac{\mathrm{CSP} 2}{k_{1}}$} \\
\hline & & $k_{1}$ & $\alpha$ & $R_{S}$ & Elution sequence & \\
\hline \multirow[t]{6}{*}{$1 a, 1 b$} & $90 / 10 / 10$ & 0.20 & 1.20 & 0.25 & $b<a$ & 0.51 \\
\hline & $70 / 30 / 10$ & 0.07 & 1.00 & 0.00 & - & 0.25 \\
\hline & $50 / 50 / 10$ & 0.06 & 1.00 & 0.00 & - & 0.18 \\
\hline & $30 / 70 / 10$ & 0.23 & 1.00 & 0.00 & - & 0.26 \\
\hline & $10 / 90 / 10$ & 1.20 & 1.11 & 0.65 & $b<a$ & 0.33 \\
\hline & $5 / 95 / 10$ & 1.84 & 1.12 & 0.75 & $b<a$ & 0.41 \\
\hline \multirow[t]{6}{*}{$1 \mathrm{c}, 1 \mathrm{~d}$} & $90 / 10 / 10$ & 0.92 & 1.75 & 2.70 & $c<d$ & 0.62 \\
\hline & $70 / 30 / 10$ & 0.51 & 1.67 & 1.85 & $c<d$ & 0.47 \\
\hline & $50 / 50 / 10$ & 0.80 & 1.00 & 0.00 & - & 0.28 \\
\hline & $30 / 70 / 10$ & 5.92 & 1.00 & 0.00 & - & 0.50 \\
\hline & $10 / 90 / 10$ & 22.70 & 1.00 & 0.00 & - & 1.13 \\
\hline & $5 / 95 / 10$ & 30.52 & 1.00 & 0.00 & - & 1.70 \\
\hline \multirow[t]{6}{*}{$2 a, 2 b$} & $90 / 10 / 10$ & 0.15 & 1.08 & 0.25 & $b<a$ & 0.42 \\
\hline & $70 / 30 / 10$ & 0.06 & 1.00 & 0.00 & - & 0.32 \\
\hline & $50 / 50 / 10$ & 0.06 & 1.00 & 0.00 & - & 0.20 \\
\hline & $30 / 70 / 10$ & 0.21 & 1.00 & 0.00 & - & 0.27 \\
\hline & $10 / 90 / 10$ & 0.99 & 1.17 & 0.70 & $b<a$ & 0.29 \\
\hline & $5 / 95 / 10$ & 1.50 & 1.18 & 1.25 & $b<a$ & 0.33 \\
\hline \multirow[t]{6}{*}{$2 \mathrm{c}, 2 \mathrm{~d}$} & $90 / 10 / 10$ & 0.54 & 1.00 & 0.00 & - & 0.88 \\
\hline & $70 / 30 / 10$ & 0.84 & 1.00 & 0.00 & - & 0.63 \\
\hline & $50 / 50 / 10$ & 1.49 & 1.06 & 0.20 & n.d. & 0.65 \\
\hline & $30 / 70 / 10$ & 3.72 & 1.07 & 0.20 & n.d. & 1.02 \\
\hline & $10 / 90 / 10$ & 14.04 & 1.10 & 0.30 & $n . d$. & 1.05 \\
\hline & $5 / 95 / 10$ & 18.28 & 1.10 & 0.45 & $c<d$ & 1.48 \\
\hline \multirow[t]{6}{*}{$3 a, 3 b$} & $90 / 10 / 10$ & 0.07 & 1.20 & 0.30 & $n . d$. & 0.53 \\
\hline & $70 / 30 / 10$ & 0.19 & 1.00 & 0.00 & - & 0.18 \\
\hline & $50 / 50 / 10$ & 0.25 & 1.21 & 0.45 & $a<b$ & 0.20 \\
\hline & $30 / 70 / 10$ & 0.61 & 1.23 & 0.85 & $a<b$ & 0.27 \\
\hline & $10 / 90 / 10$ & 2.48 & 1.23 & 1.10 & $a<b$ & 0.33 \\
\hline & $5 / 95 / 10$ & 3.58 & 1.24 & 1.20 & $a<b$ & 0.42 \\
\hline \multirow[t]{6}{*}{$3 c, 3 d$} & $90 / 10 / 10$ & 0.08 & 1.00 & 0.00 & - & 0.56 \\
\hline & $70 / 30 / 10$ & 0.12 & 1.00 & 0.00 & - & 0.27 \\
\hline & $50 / 50 / 10$ & 0.13 & 1.61 & 0.55 & $d<c$ & 0.18 \\
\hline & $30 / 70 / 10$ & 0.33 & 1.56 & 0.85 & $d<c$ & 0.27 \\
\hline & $10 / 90 / 10$ & 1.37 & 1.38 & 0.75 & $d<c$ & 0.38 \\
\hline & $5 / 95 / 10$ & 1.84 & 1.37 & 0.60 & $d<c$ & 0.50 \\
\hline \multirow[t]{6}{*}{$4 a, 4 b$} & $90 / 10 / 10$ & 0.16 & 1.00 & 0.00 & - & 0.65 \\
\hline & $70 / 30 / 10$ & 0.18 & 1.00 & 0.00 & - & 0.42 \\
\hline & $50 / 50 / 10$ & 0.23 & 1.30 & 0.60 & $a<b$ & 0.30 \\
\hline & $30 / 70 / 10$ & 0.56 & 1.30 & 0.85 & $a<b$ & 0.26 \\
\hline & $10 / 90 / 10$ & 2.40 & 1.26 & 1.65 & $a<b$ & 0.24 \\
\hline & $5 / 95 / 10$ & 3.20 & 1.25 & 1.60 & $a<b$ & 0.24 \\
\hline \multirow[t]{6}{*}{$4 c, 4 d$} & $90 / 10 / 10$ & 0.08 & 1.00 & 0.00 & - & 0.66 \\
\hline & $70 / 30 / 10$ & 0.09 & 1.65 & 0.35 & n.d. & 0.35 \\
\hline & $50 / 50 / 10$ & 0.15 & 2.03 & 0.65 & $d<c$ & 0.18 \\
\hline & $30 / 70 / 10$ & 0.28 & 1.60 & 0.85 & $d<c$ & 0.24 \\
\hline & $10 / 90 / 10$ & 1.01 & 1.47 & 1.60 & $d<c$ & 0.30 \\
\hline & $5 / 95 / 10$ & 1.31 & 1.46 & 0.80 & $d<c$ & 0.32 \\
\hline
\end{tabular}

Chromatographic conditions: mobile phase, $\mathrm{H}_{2} \mathrm{O} / \mathrm{MeOH} / \mathrm{AcOH}(v / v / \mathrm{mM})$; final concentration of AcOH, $10.0 \mathrm{mM}$; flow rate, $0.5 \mathrm{ml} \mathrm{min}^{-1}$; detection, $210 \mathrm{~nm}$.

favored than the chiral ones. Table 3 presents selected data of the optimized separations $\left(R_{S}>1\right)$ on CSP1 and CSP2 in $\mathrm{H}_{2} \mathrm{O}$ / $\mathrm{MeOH} / \mathrm{AcOH}, \mathrm{H}_{2} \mathrm{O} / \mathrm{EtOH} / \mathrm{AcOH}$, and $\mathrm{H}_{2} \mathrm{O} / \mathrm{IPA} / \mathrm{AcOH}$ mobile phases where the final concentration of $\mathrm{AcOH}$ was $10.0 \mathrm{mM}$.

\section{Effects of the Nature and Content of the Acidic Modifier in the Mobile Phase}

The effects of the nature and content of the acidic modifier on the separation were investigated by the separation of analytes Chirality DOI 10.1002/chir 3a,3b, 3c,3d, $\mathbf{4 a}, \mathbf{4 b}$, and $\mathbf{4 c , 4 d}$ in an aqueous mobile phase at a constant concentration of the organic modifier. A comparison of the chromatographic data obtained with $\mathrm{HCOOH}, \mathrm{AcOH}$, TFA, $\mathrm{HClO}_{4}, \mathrm{H}_{2} \mathrm{SO}_{4}$, or $\mathrm{H}_{3} \mathrm{PO}_{4}$ as acidic modifier at a constant concentration of $10 \mathrm{mM}$ in a hydro-organic mobile phase containing $\mathrm{MeOH}, \mathrm{EtOH}$, or IPA $(70 \% v / v)$ demonstrated that in most cases, larger $k$ values were obtained on the application of $\mathrm{AcOH}$ or $\mathrm{HCOOH}$ (Table 4; for analytes 3c,3d and 4c,4d, similar results were obtained). 
HPLC ENANTIOSEPARATION OF UNUSUAL AMINO ACIDS

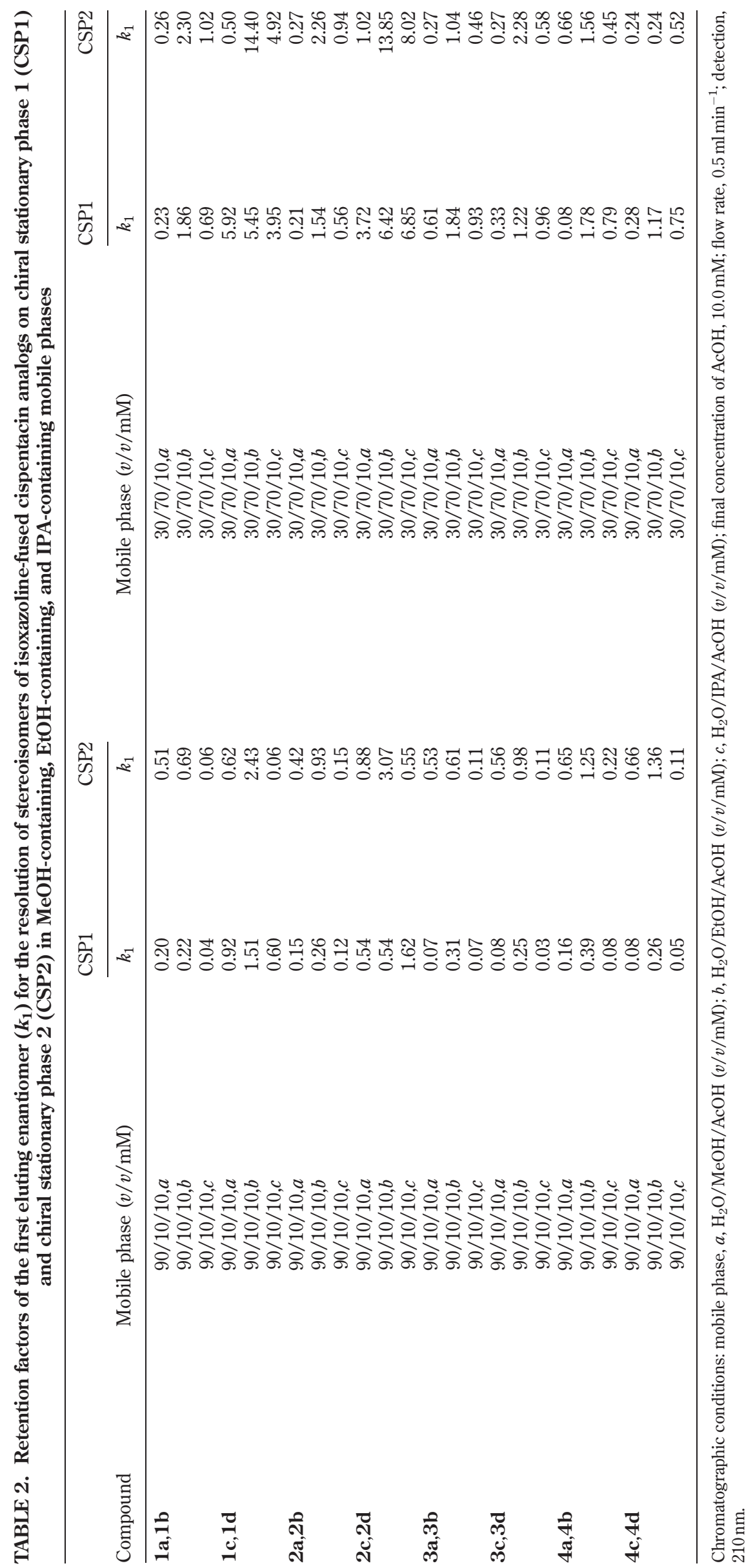


TABLE 3. Selected data of retention factors of the first eluting enantiomer $\left(k_{1}\right)$, separation factors $(\alpha)$, resolutions $\left(R_{S}\right)$, and elution sequences for the resolution of stereoisomers of isoxazoline-fused cispentacin analogs on chiral stationary phase 1 (CSP1) and chiral stationary phase 2 (CSP2) in MeOH-containing, EtOH-containing, and IPA-containing mobile phases

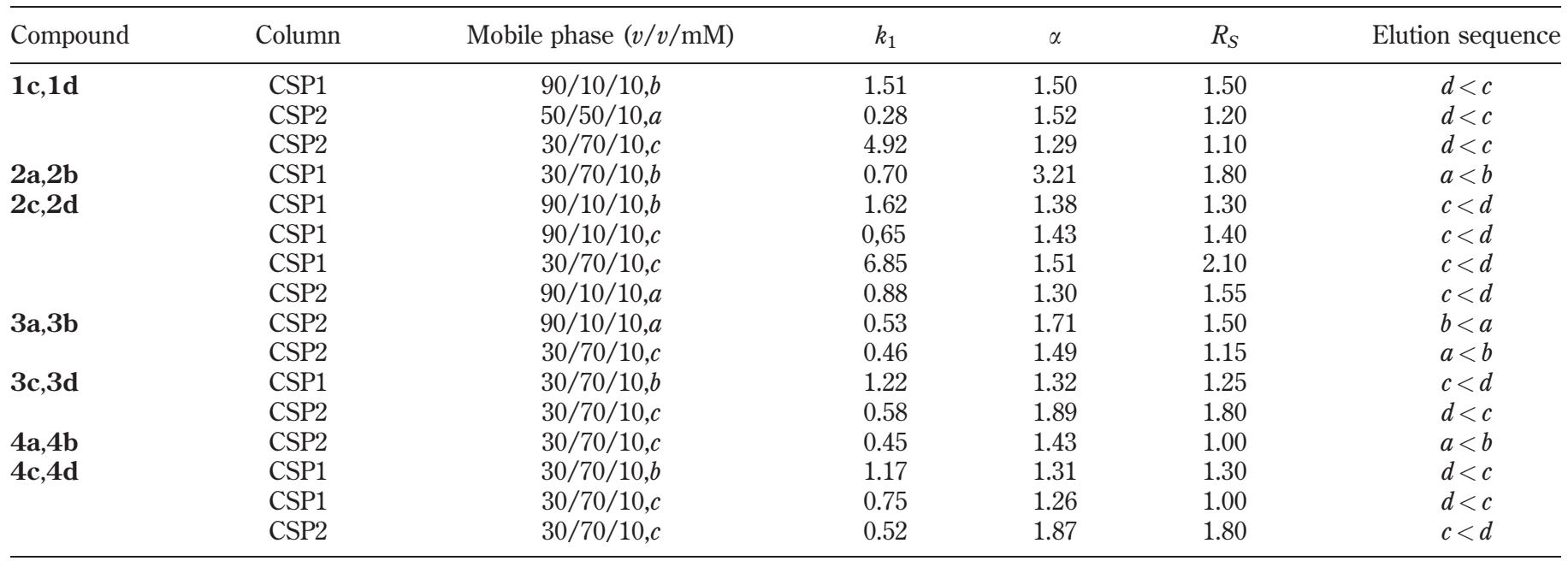

Chromatographic conditions: mobile phase, $a$, $\mathrm{H}_{2} \mathrm{O} / \mathrm{MeOH} / \mathrm{AcOH}(v / v / \mathrm{mM}) ; b, \mathrm{H}_{2} \mathrm{O} / \mathrm{EtOH} / \mathrm{AcOH}(v / v / \mathrm{mM}) ; c, \mathrm{H}_{2} \mathrm{O} / \mathrm{IPA} / \mathrm{AcOH}(v / v / \mathrm{mM})$; final concentration of $\mathrm{AcOH}, 10.0 \mathrm{mM}$; flow rate, $0.5 \mathrm{ml} \mathrm{min}^{-1}$; detection, $210 \mathrm{~nm}$.

$\mathrm{H}_{2} \mathrm{SO}_{4}, \mathrm{HClO}_{4}, \mathrm{H}_{3} \mathrm{PO}_{4}$, and TFA in the same concentration as $\mathrm{AcOH}$ demonstrated much lower levels of $\mathrm{pH}$. At lower $\mathrm{pH}$, the ionic strength of the mobile phase is higher. The HILIC interaction of a protonated ionic analyte with the polar mobile phase is then expected to increase, with a consequent decrease in the retention time. The ionic strength can act as a "shield" with respect to the host-guest complex formation, a higher ionic strength reducing the retention. Larger $\alpha$ and especially $R_{S}$ values were obtained in most cases when $\mathrm{AcOH}, \mathrm{HCOOH}$, and in some cases when $\mathrm{H}_{2} \mathrm{SO}_{4}$ (especially with $\mathrm{EtOH}$ or IPA in the mobile phase) were applied.

The increase of the $\mathrm{AcOH}$ or $\mathrm{H}_{2} \mathrm{SO}_{4}$ content of the aqueous mobile phase decreased the retention factors (Table 5). As the acid content was elevated, the ionic strength of the mobile phase increased, whereas $\mathrm{pH}$ decreased, resulting in a decrease in the retention time. $\alpha$ and $R_{S}$ exhibited different behavior for analytes containing amino and carboxyl groups in cis $(\mathbf{a}, \mathbf{b})$ or trans $(\mathbf{c}, \mathbf{d})$ positions. $\alpha$ for both types of analytes increased with increasing acid content, whereas $R_{S}$ increased for analytes a,b and decreased for analytes $\mathbf{c}, \mathbf{d}$ with increasing acid concentration.

\section{Effects of the Structures of the Analytes}

The structures of the analytes influenced the chiral recognition. In the reversed-phase mode, methyl or ethyl substitution exerted a slight effect on the retention. On CSP1 at a given mobile phase composition, the methyl-substituted analogs in most cases interacted more strongly with the selector than did the ethyl-substituted ones, resulting in larger retentions. On CSP2, the interactions depended on the composition of the mobile phase (Table 1). At higher water content, the ethyl-substituted analogs exhibited stronger interactions with CSP2, whereas at higher $\mathrm{MeOH}$ content, the methyl-substituted

TABLE 4. Chromatographic data, retention factors $\left(k_{1}\right)$, separation factors $(\alpha)$, and resolutions $\left(R_{S}\right)$ for analytes $3 a, 3 b$ and $4 a, 4 b$ on chiral stationary phase 1 at mobile phase composition of $\mathrm{H}_{2} \mathrm{O} / \mathrm{MeOH} / \mathrm{acid}, \mathrm{H}_{2} \mathrm{O} / \mathrm{EtOH} / \mathrm{acid}$ and $\mathrm{H}_{2} \mathrm{O} / \mathrm{IPA} / \mathrm{acid}(30 / 70 / 10 \mathrm{v} / \mathrm{v} /$ $\mathrm{mM}$ ) with variation of the type of acidic modifier

\begin{tabular}{|c|c|c|c|c|c|c|c|c|c|c|}
\hline Compound & Nature of acid & \multicolumn{9}{|c|}{ Mobile phase: $\mathrm{H}_{2} \mathrm{O} /$ alcohol/acid $(30 / 70 / 10(v / v / \mathrm{mM})$} \\
\hline \multirow[t]{4}{*}{$3 a, 3 b$} & $\mathrm{HCOOH}$ & 0.69 & 1.26 & 0.85 & 1.03 & 1.20 & 0.55 & 1.53 & 1.17 & 0.45 \\
\hline & $\mathrm{AcOH}$ & 0.61 & 1.23 & 0.85 & 1.84 & 1.18 & 0.40 & 0.93 & 1.10 & 0.25 \\
\hline & TFA & 0.39 & 1.15 & 0.10 & 0.24 & 1.15 & 0.25 & 0.43 & 1.10 & 0.10 \\
\hline & $\mathrm{H}_{3} \mathrm{PO}_{4}$ & 0.54 & 1.16 & 0.65 & 0.59 & 1.18 & 0.65 & 0.72 & 1.10 & 0.45 \\
\hline \multirow[t]{5}{*}{$4 a, 4 b$} & $\mathrm{HCOOH}$ & 0.65 & 1.33 & 1.00 & 1.09 & 1.20 & 0.65 & 1.35 & 1.21 & 0.80 \\
\hline & $\mathrm{AcOH}$ & 0.56 & 1.30 & 0.85 & 1.78 & 1.20 & 0.60 & 0.79 & 1.15 & 0.60 \\
\hline & TFA & 0.41 & 1.18 & 0.20 & 0.25 & 1.31 & 0.10 & 0.23 & 1.35 & 0.30 \\
\hline & $\mathrm{HClO}_{4}$ & 0.32 & 1.17 & 0.10 & 0.52 & 1.17 & 0.10 & 0.75 & 1.06 & 0.10 \\
\hline & $\mathrm{H}_{2} \mathrm{SO}_{4}$ & 0.36 & 1.19 & 0.20 & 0.50 & 1.45 & 1.40 & 0.40 & 1.51 & 1.10 \\
\hline
\end{tabular}

Chromatographic conditions: flow rate, $0.5 \mathrm{ml} \mathrm{min}^{-1}$; detection, $205 \mathrm{~nm}$.

Chirality DOI 10.1002/chir 
TABLE 5. Chromatographic data, retention factors $\left(k^{\prime}\right)$, separation factors $(\alpha)$, and resolutions $\left(\boldsymbol{R}_{S}\right)$ for analytes $\mathbf{4 a}, \mathbf{4 b}$ and $\mathbf{4 c}, \mathbf{4 d}$ on chiral stationary phase 1 at mobile phase compositions of $\mathrm{H}_{2} \mathrm{O} / \mathrm{alcohol} / \mathrm{acid}(30 / 70 / 0.5-30 \mathrm{v} / \mathrm{v} / \mathrm{mM})$ with variation of the type (AcOH or $\mathrm{H}_{2} \mathrm{SO}_{4}$ ) and concentration of the acidic modifiers

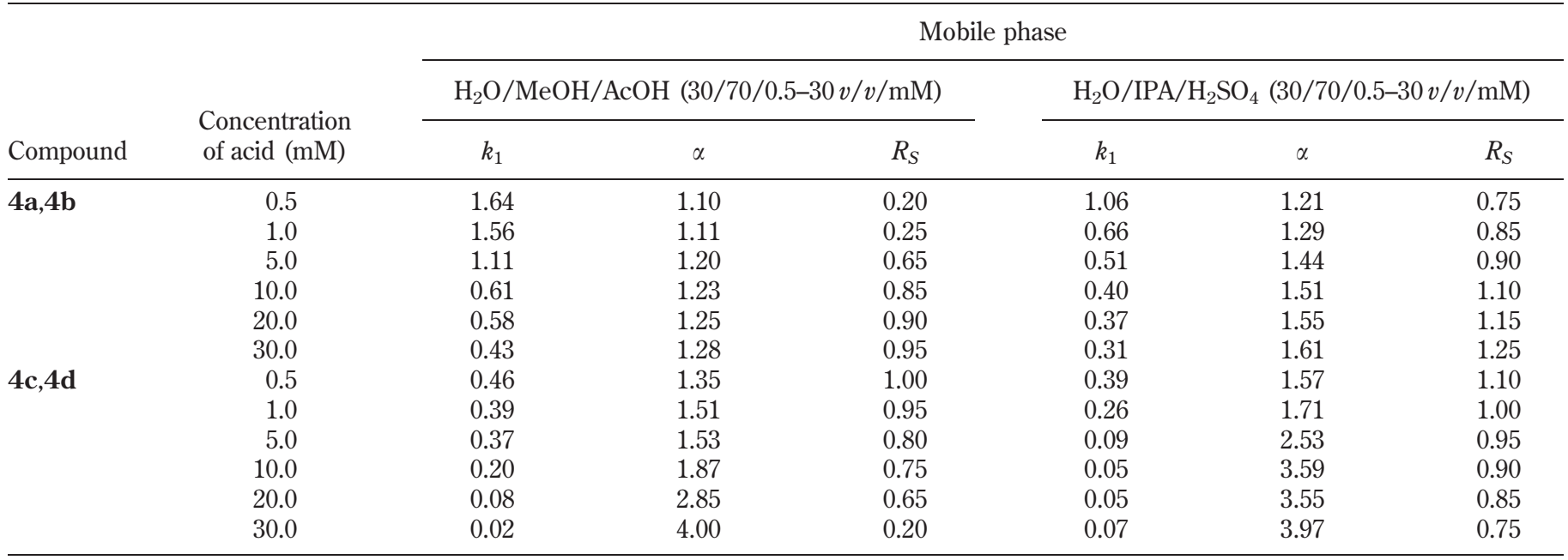

Chromatographic conditions: flow rate, $0.5 \mathrm{ml} \mathrm{min}^{-1}$; detection, $205 \mathrm{~nm}$.
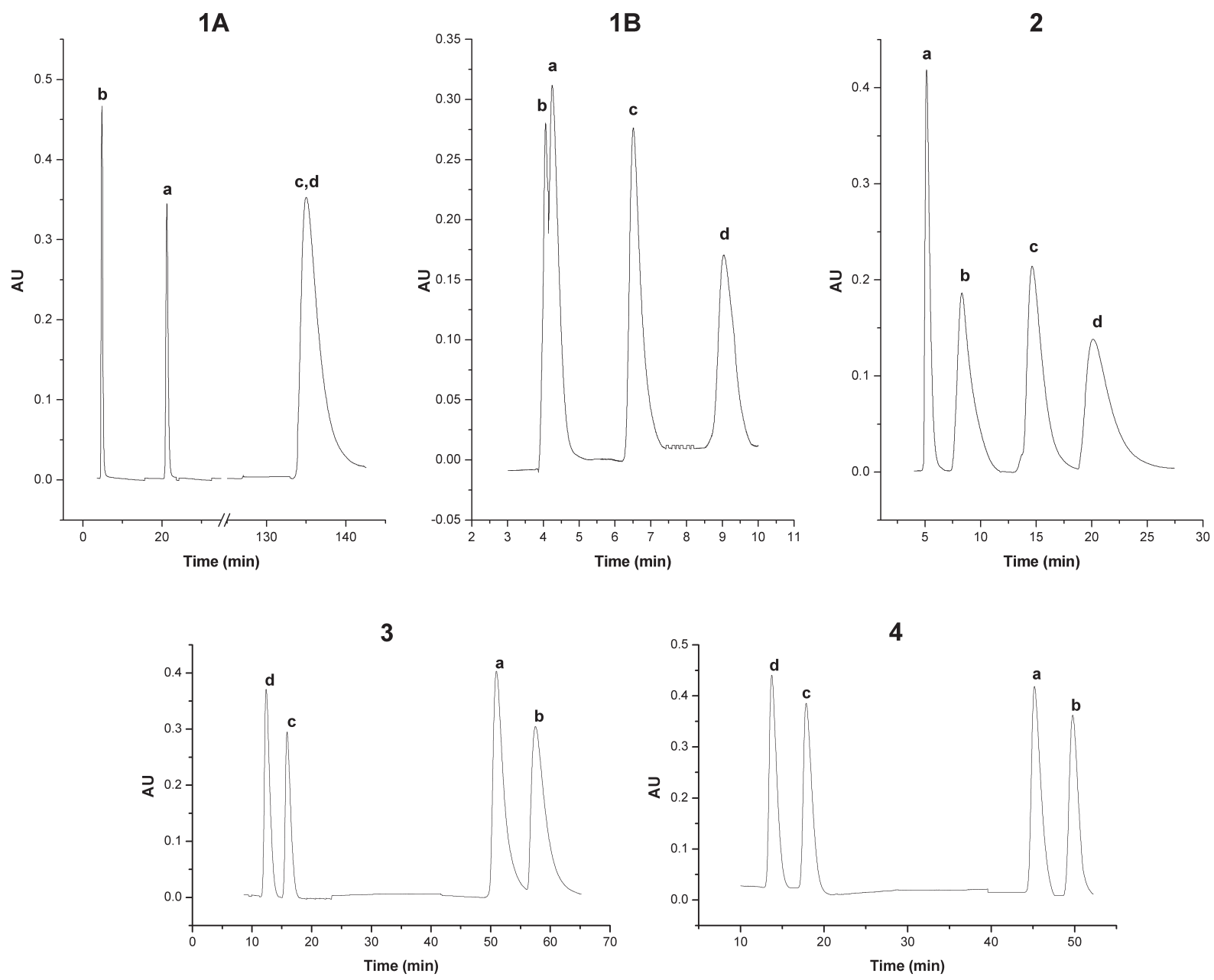

Fig. 3. Separation of the four stereoisomers of isoxazoline-fused cispentacin derivatives. Chromatographic conditions: column, for all analytes CSP1; mobile phase, for analyte $\mathbf{1}(\mathbf{1 A}), \mathrm{H}_{2} \mathrm{O} / \mathrm{MeOH} / \mathrm{AcOH}(5 / 95 / 30 v / v / \mathrm{mM})$, for (1B), $\mathrm{H}_{2} \mathrm{O} / \mathrm{MeOH} / \mathrm{AcOH}(90 / 10 / 10 v / v / \mathrm{mM})$, for analyte 2, $\mathrm{H}_{2} \mathrm{O} / \mathrm{EtOH} / \mathrm{AcOH}(50 / 50 /$ $10 v / v / \mathrm{mM})$, and for analytes 3 and $\mathbf{4}, \mathrm{H}_{2} \mathrm{O} / \mathrm{MeOH} / \mathrm{AcOH}(5 / 95 / 10 v / v / \mathrm{mM})$; temperature, $25^{\circ} \mathrm{C}$ for analyte $\mathbf{1}(\mathbf{1 B})$ and $5{ }^{\circ} \mathrm{C}$ for analytes $\mathbf{1}(\mathbf{1 A}), \mathbf{2}, \mathbf{3}$, and $\mathbf{4}$; flow rate, $0.5 \mathrm{ml} \mathrm{min}^{-1}$; detection, $210 \mathrm{~nm}$.

ones did so. However, the stronger interactions resulted in larger $\alpha$ and $R_{S}$ values in only a few cases, indicating almost the same interactions of the two enantiomers with the CSP.
Through the steric interactions, the position of the methyl or ethyl group influenced the $\alpha$ and $R_{S}$ values. $\mathbf{3 a}, \mathbf{3 b}$ were better separated than $\mathbf{1 a}, \mathbf{1 b}$ on both CSP1 and CSP2, whereas $\mathbf{1 c}, \mathbf{1 d}$ 
exhibited better separation efficiency than $\mathbf{3 c , 3 d . ~} \mathbf{4 a}-\mathbf{4 d}$ in general underwent better enantioseparation than $\mathbf{2 a - 2 d}$.

Elution sequences were determined in all cases, but no consistent elution sequence was observed. The primary interaction in the course of chiral recognition is the complex formation between the protonated amino group of the analyte and CSP, but neither the configuration of the carbon atom attached to the amino group nor that of the carbon atom attached to the carboxyl group determined the elution sequence.

\section{Separation of the Four Enantiomers of Isoxazoline-fused 2-Aminocyclopentanecarboxylic Acids}

Because the biological activities of isoxazoline-fused 2-aminocyclopentanecarboxylic acid analogs depend strongly on their configurations, it is essential to separate and identify not only the enantiomers but also the diastereomers in one chromatographic run. The data listed in Tables 1 and 2 reveal that separation of the four stereoisomers was achieved in only a few cases. In attempts to attain separation of the four stereoisomers in one chromatographic run, the separation was optimized by variation of the CSPs, the mobile phase composition, and temperature. Figure 3 illustrates data relating to the optimal enantioseparation of the four stereoisomers of the isoxazolinefused 2-aminocyclopentanecarboxylic acid analogs. Analytes $\mathbf{1 a}, \mathbf{1 b}$ and $\mathbf{1 c}, \mathbf{1 d}$ could be separated on CSP1 in two different eluent systems.

\section{CONCLUSIONS}

The enantiomeric separations of isoxazoline-fused 2-aminocyclopentanecarboxylic acid analogs were investigated on (+)-(18-crown-6)-2,3,11,12-tetracarboxylic acid-based CSPs. The chromatographic retention behavior and resolution proved to depend on the natures and concentrations of the alcoholic and acidic modifiers, the temperature, and the nature and positions of the substituents. The elution sequence was determined in all cases, but no general rule could be found to describe the elution behavior of these compounds.

\section{LITERATURE CITED}

1. Hetényi A, Mándity IM, Martinek TA, Tóth GK, Fülöp F. Chain lengthdependent helical motifs and self-association of $\beta$-peptides with constrained side-chains. J Am Chem Soc 2005;127:547-553.

2. Fülöp F, Martinek TA, Tóth GK. Application of alicyclic beta-amino acids in peptide chemistry. Chem Soc Rev 2006;35:323-334.

3. Kiss L, Forró E, Fülöp F. Synthesis of carbocyclic $\beta$-amino acids. In: Hughes $\mathrm{AB}$, editor. Amino acids, peptides and proteins in organic chemistry. Weinheim: Wiley-VCH; 2009. Vol. 1. p 367-409.

4. Kai H, Matsumoto H, Hattori N, Takase A, Fujiwara T, Sugimoto $\mathrm{H}$. Anti-influenza virus activities of 2-alkoxyimino- $N$-(2-isoxazoline-3ylmethyl) acetamides. Bioorg Med Chem Lett 2001;11:1997-2000.

5. Basappa M, Sadashiva P, Mantelingu K, Swamy NS, Rangappa KS. Solution phase synthesis of novel d2-isoxazoline libraries via 1,3-dipolar cycloaddition and their antifungal properties. Bioorg Med Chem 2003;11:4539-4544.

6. Conti P, Caligiuri A, Pinto A, Roda G, Tamborini L, Nielsen B, Madsen U, Frydenvang K, Colombo A, De Micheli C. Synthesis and pharmacological evaluation of novel conformationally constrained homologues of glutamic acid. Eur J Med Chem 2007;42:1059-1068.

7. Pinto A, Conti P, De Amici M, Tamborini L, Grazioso G, Colleoni S, Mennini T, Gobbi M, De Micheli C. Synthesis of enantiomerically pure HIP-A and HIP-B and investigation of their activity as inhibitors of excitatory amino acid transporters. Tetrahedron: Asymmetry 2008;19: 867-875.

8. Chand P, Bantia S, Kotian PL, El-Kattan Y, Lin TH, Babu YS. Comparison of the anti-influenza virus activity of cyclopentane derivatives with oseltamivir and zanamivir in vivo. Bioorg Med Chem 2005;13: 4071-4077.

9. Chand P, Kotian PL, Dehghani A, El-Kattan Y, Lin TH, Hutchison TL, Babu YS, Bantia S, Elliott AJ, Montgomery JA. Systematic structure-based design and stereoselective synthesis of novel multisubstituted cyclopentane derivatives with potent antiinfluenza activity. J Med Chem 2001;44:4379-4392.

10. Mineno T, Miller MJ. Stereoselective total synthesis of racemic BCX-1812 (RWJ-270201) for the development of neuraminidase inhibitors as antiinfluenza agents. J Org Chem 2003;68:6591-6596.

11. Ilisz I, Berkecz R, Péter A. Application of chiral derivatizing agents in the high-performance liquid chromatographic separation of amino acid enantiomers: a review. J Pharm Biomed Anal 2008;47:1-15.

12. D'Acquarica I, Gasparrini F, Misiti D, Zappia G, Cimarelli C, Palmieri G, Carotti A, Cellamare S, Villani C. Application of a new chiral stationary phase containing the glycopeptide antibiotic A-40,926 in the direct chromatographic resolution of beta-amino acids. Tetrahedron: Asymmetry 2000;11:2375-2385.

13. Ilisz I, Berkecz R, Péter A. HPLC separation of amino acid enantiomers and small peptides on macrocyclic antibiotic-based chiral stationary phases: a review. J Sep Sci 2006;29:1305-1321.

14. Péter A. Direct high-performance liquid chromatographic enantioseparation of apolar $\beta$-amino acids on a quinine-derived chiral anion-exchanger stationary phase. J Chromatogr A 2002;955:141-150.

15. Hyun MH, Choi HJ, Kang BS, Tan G, Choi YJ. Resolution of $\beta$-amino acids on a chiral stationary phase based on (+)-(18-crown-6)-2,3,11,12-tetracarboxylic acid without extra free aminopropyl groups on silica surface: the effect of ammonium ion mobile phase modifier on the resolution behaviors. Bull Korean Chem Soc 2006;27:1775-1779.

16. Hyun MH, Song Y, Cho YJ, Choi HJ. Resolution of $\beta$-amino acids on a high performance liquid chromatographic doubly tethered chiral stationary phase containing $\mathrm{N}_{-} \mathrm{CH}_{3}$ amide linkage based on (+)-(18-crown-6)2,3,11,12-tetracarboxylic acid. J Sep Sci 2007;30:2539-2543.

17. Berkecz R, Sztojkov-Ivanov A, Ilisz I, Forró E, Fülöp F, Hyun MH, Péter A. High-performance liquid chromatographic enantioseparation of $\beta$-amino acid stereoisomers on a (+)-(18-crown-6)-2,3,11,12-tetracarboxylic acidbased chiral stationary phase. J Chromatogr A 2006;1125:138-143.

18. Berkecz R, Ilisz I, Fülöp F, Pataj Z, Hyun MH, Péter A. High-performance liquid chromatographic enantioseparation of $\beta$-3-homo-amino acid stereoisomers on a (+)-(18-crown-6)-2,3,11,12-tetracarboxylic acid-based chiral stationary phase. J Chromatogr A 2008;1189:285-291.

19. Berkecz R, Ilisz I, Misicka A, Tymecka D, Fülöp F, Choi HJ, Hyun MH, Peter A. HPLC enantioseparation of $\beta^{2}$-amino acids using crown etherbased stationary phase. J Sep Sci 2009;32:981-987.

20. Wenzel TJ, Bourne CE, Clark RL. (18-Crown-6)-2,3,11,12-tetracarboxylic acid as a chiral NMR solvating agent for determining the enantiomeric purity and absolute configuration of $\beta$-amino acids. Tetrahedron: Asymmetry 2009;20:2052-2060.

21. Sipos L, Ilisz I, Nonn M, Fülöp F, Pataj Z, Armstrong DW, Péter A. High-performance liquid chromatographic enantioseparation of unusual isoxazoline-fused 2-aminocyclopentanecarboxylic acids on macrocyclic glycopeptide-based chiral stationary phases. J Chromatogr A 2012;1232:142-151.

22. Kiss L, Nonn M, Forró E, Sillanpää R, Fülöp F. Synthesis of novel isoxazolinefused cispentacin stereoisomers. Tetrahedron Lett 2009;50:2605-2608.

23. Forró E, Fülöp F. Advanced procedure for the enzymatic ring opening of unsaturated alicyclic $\beta$-lactams. Tetrahedron: Asymmetry 2004;15:2875-2880.

24. Kiss L, Forró E, Sillanpää R, Fülöp F. Diastereo- and enantioselective synthesis of orthogonally protected 2,4-diaminocyclopentanecarboxylates: a flip from $\beta$-amino- to $\beta, \gamma$-diaminocarboxylates. J Org Chem 2007;72:8786-8790.

25. Nonn M, Kiss L, Forró E, Mucsi Z, Fülöp F. Synthesis of novel isoxazoline-fused cyclic beta-amino esters by regio- and stereo-selective 1,3-dipolar cycloaddition. Tetrahedron 2011;67:4079-4085.

26. Hyun MH, Jin JS, Lee W. Liquid chromatographic resolution of racemic amino acids and their derivatives on a new chiral stationary phase based on crown ether. J Chromatogr A 1998;822:155-161.

27. Hyun MH, Kim DH. Spacer length effect of a chiral stationary phase based on (+)-(18-crown-6)-2,3,11,12-tetracarboxylic acid. Chirality 2004;16:294-301.

28. Hyun MH. Characterization of liquid chromatographic chiral separation on chiral crown ether stationary phase. J Sep Sci 2003;26:242-250.

29. Lee W, Jin JY, Baek CS. Comparison of enantiomer separation on two chiral stationary phases derived from (+)-18-crown-6-2,3,11,12-tetracarboxylic acid of the same chiral selector. Microchem J 2005;80:213-217. 